\title{
Ultrasonographical aspects of follicle growth
}

Citation for published version (APA):

Wetzels, L. C. G. (1983). Ultrasonographical aspects of follicle growth. [Doctoral Thesis, Maastricht University]. Rijksuniversiteit Limburg. https://doi.org/10.26481/dis.19830520lw

Document status and date:

Published: 01/01/1983

DOI:

10.26481/dis.19830520lw

Document Version:

Publisher's PDF, also known as Version of record

\section{Please check the document version of this publication:}

- A submitted manuscript is the version of the article upon submission and before peer-review. There can be important differences between the submitted version and the official published version of record.

People interested in the research are advised to contact the author for the final version of the publication, or visit the DOI to the publisher's website.

- The final author version and the galley proof are versions of the publication after peer review.

- The final published version features the final layout of the paper including the volume, issue and page numbers.

Link to publication

\footnotetext{
General rights rights.

- You may freely distribute the URL identifying the publication in the public portal. please follow below link for the End User Agreement:

www.umlib.nl/taverne-license

Take down policy

If you believe that this document breaches copyright please contact us at:

repository@maastrichtuniversity.nl

providing details and we will investigate your claim.
}

Copyright and moral rights for the publications made accessible in the public portal are retained by the authors and/or other copyright owners and it is a condition of accessing publications that users recognise and abide by the legal requirements associated with these

- Users may download and print one copy of any publication from the public portal for the purpose of private study or research.

- You may not further distribute the material or use it for any profit-making activity or commercial gain

If the publication is distributed under the terms of Article $25 \mathrm{fa}$ of the Dutch Copyright Act, indicated by the "Taverne" license above, 


\section{Ultrasonographical aspects of follicle growth}

Proefschrift

ter verkrijging van de graad wan doctor in de geneeskunde aan de Rijksuniversiteit Limburg te Maastricht, op gezag van de Rector Magnificus Prof. Dr. H.C. Hemker, volgens besluut van het College van Dekanen in het openbaar te verdedigen in de aula van de universiteit op vrijdag 20 mei 1983, des middags om vier uur

door

Leonardus Catharina Gerardus Wetzels

geboren te Limbricht 



\section{Contents}

\section{Voorwoord}

\section{Chapter I}

Introduction and outline of the investigation

1.1. General review of the use of ultrasound for observation of follicle growth and ovulation

1.1.1. Description of the application fields for ultrasound observation of follicle growth and ovulation

1.1.2. Technical aspects of visualization and measurement of preovulatory follicles by ultrasound

1.1.3. Possible biological effects of diagnostic ultrasound at the level of the Graafian follicle

1.1.4. Results of ultrasound investigations

1.2. Outline of the present investigation

\section{Chapter II}

Subjects, materials and methods

$\begin{array}{lll}\text { 2.1. Selection of subjects } & 15\end{array}$

$\begin{array}{lll}\text { 2.2. } & \text { Schedule of observations } & 17\end{array}$

$\begin{array}{lll}2.3 . & 18\end{array}$

2.4. The measurement procedure 18

2.5. Potential sources of error, standardization procedures 19

2.6. Calibration experiments 23

\section{Chapter III}

Observations, related to the ultrasonographical evidence of follicle rupture: definitions and incidence

3.1. Review of the literature 29

3.2. Ultrasonographical signs of follicle rupture 31

3.3. The "cumulus oophorus" 32

3.4. Definitions of Ultrasonographical Ovulation Time (UOT) and Ultrasonographical Ovulation Period (UOP)

3.5. The location of follicle rupture 35 


\section{Follicular growth}

4.1. Review of the literature 39

4.1.1. Detection of ovaries and follicles 39

4.1.2. The development and recognition of dominance 40

4.1.3. The pattern of follicular growth during the spontaneouscycle 41

4.1.4. The pattern of follicle growth after Clomiphene citrate 42

4.2. Folliculargrowth pattern in the present series 43

$\begin{array}{ll}\text { 4.2.1. Methods } & 43\end{array}$

4.2.2. Results 45

4.2.2.1. Follicular growth pattern 45

4.2.2.2. The onset of the preovulatory phase in follicular growth 49

4.2.2.3. The ultimate preovulatory diameters 50

4.2.2.4. Within subject variation in follicular growth 51

4.2.2.5. Predictability of the day of follicle rupture 53

\section{Chapter V}

Time relationships between ulltrasonographical ovulation time (UOT) and other events of the menstrual cycle

5.1. Review of the literature

5.1.1. The LH surge and peak for the detection and prediction of ovulation $\quad 57$

5.1.1.1. Difficulties in defining the L.H surge and LH peak 57

5.1.1.2. The LH peak as a method for detection of the ovulation 58

5.1.1.3. The L.H surge as a method for prediction of the ovulation 60

5.1.1.4. Reports on the temporal relationship between ultrasound evidence of ovulation and L.H surge and -peak 60

5.1.2. The oestradiol-17-beta peak 61

5.1.2.1. Relationships between oestradiol-17-beta and other parameters of the cycle 61

5.1.2.2. Preowulatory ocstradiol-17-beta production and the configuration of the peak 62

5.1.2.3. Definitions of the oestradiol-17-beta peak and surge 62

5.1.2.4. The interval between oestradiol-17-beta peak and-surge and ovulation $\quad 63$

5.1.3. Progesterone 63

5.1.3.1. The initial progesterone rise 63

5.1.3.2. Progesterone during the luteal phase and its use for the diagnosis of luteal phase defect 64

5.1.4. The duration of the luteal phase and its relation with other parameters $\quad 66$

5.1.5. The relation between midpain and ovulation 66 
5.1.6. Basal Body Temperature (BBT) as a method of ovulation detection

5.2. The relationships between ultrasound evidence of follicle rupture and other events of the menstrual cycle

5.2.1. Definitions 67

5.2.2. Results $\quad 72$

5.2.2.1. The LH surge and peak: temporal relationship with UOT 72

5.2.2.2. The oestradiol-17-beta peak: temporal relationship with UOT $\quad 76$

$\begin{array}{ll}\text { 5.2.2.3. Progesterone } & 77\end{array}$

5.2.2.4. Rellationships between preovulatory and postovulatory parameters of the menstrual cycle 80

5.2.2.5. Temporal relationship between midpain and UOT $\quad 82$

5.2.2.6. Relationship between the temperature shift in the BBT and the day of UOT

\section{Chapter VI}

Aberrant cycles, diagnosed by the combination of ultrasound observations and hormonal parameters

6.1. Review of the literature

6.2. Apparently "aberrant" cycles in the present study, definitions and incidence

6.3. Features of "aber rant" cycle type I

("delayed ovulation")

6.4. Features of "aberrant" cycle type II

("failute of follicle rupture")

\section{Chapter VII}

The possible role of ultrasound in monitoring ovulation induction by Human Chorionic Gonadotropin ( $\mathrm{HCG}$ )

7.1. Review of the literature 99

7.1.1. Pharmacokinetic aspects of HCG 99

7.1.2. Potential adverse effects of preovulatory HCG administration

7.1.3. The practice of HCG application in $\begin{array}{ll}\text { ovulation induction } & 100\end{array}$

7.1.4. The interval between HCGinjection and ovulation 101

7.1.5. Contributions of the ultrasound observation $\begin{array}{ll}\text { to the timing of } \mathrm{HCG} \text { administration } & 102\end{array}$

7.2. Present investigation 
Summary

$\begin{array}{ll}\text { Samenvatting } & 113\end{array}$

List of abbreviations $\quad 116$

$\begin{array}{ll}\text { References } & 117\end{array}$

$\begin{array}{ll}\text { Curriculum vitae } & 135\end{array}$ 


\section{Voorwoord}

Het in dit proefschrift beschreven onderzoek werd uitgevoerd onder supervisie en bezielende begeleiding van Prof. dr. J. de Haan en Dr. H.J. Hoogland. De referenten Prof. dr. R. Rolland en Dr. Ir. A.P.G. Hoeks ben ik dank verschaldigd voor hun kritische beschouwing van het manuscript en hun vele essentiële opmerkingen.

Uitvoering van het onderzoek en de totstandkoming van dit proefschrift zou onmogelijk geweest zijn zonder:

- Yenny Kurniawan die twee jaar lang op onnavolgbare wijze orde wist te handhaven in de gegevens en zorg droeg voor de grafische uitwerking;

- Wilma Coenegrachts, die de vele generaties van het manuscript geduldig uittypte;

- Chris J. Lawrence F.F.A.R.C.S. die de taalkundige kwaliteit bewaakte:

- de waardewolle adviezen van Ir. A. Volovics en Ir. L. Strijbosch (Dienst Informatieverwerking, Rijksuniversitteit Limburg). In het bijzonder was de inzet van Piet Zinken van onschatbare waarde;

- F.A.M. Smeets (afdeling Biofysica, hoofd dr. J. Somer) die de bundel geometric analyseerde;

- het vele werk verricht door Dr. C. Mink, C.P. Degenaar en J. Habets (afdeling klin ische chemie, ziekenhuis St. Anmadal) en de medewerkers van het isotopenlaboratorium;

- de afdeling Medische Fotografie van het Ziekenhuis St. Annadal (C. Evers, J. Houben en C. Schliessner-Jamin);

- mijn collega's Jeroen Degen, Jan Duyzers, Carl Hamilton en Dieke Smit die op uiteenlopende wijze hun bijdrage leverden in het onderzoek;

- collega mw. J.P. Schermers die in de opbouwfase van onze kliniek de voltooing van dit proefschrift mede mogelijk maakte;

- de verpleegkundigen van de verloskamers van het ziekenhuis. St. Annadal(hoofd mw. F. Hoekwater), onvermoeibaar in het axndragen van water en andere benodigdheden;

- de acht, niet met name te noemen, vrijwilligsters die de ontberingen wan het onderzock met enthousiasme hebben doorstatan;

- de vele patienten die vertrouwden dat dit onderzoek een nieuw perspectief zou kunnen bieden voor de verbetering van hun fertiliteitskans. Hun vertrouwen, de successen en de mislukkingen waren de belangrijkste bron woor mijn motivatie;

- mijn ouders, die de eerste en belangrijkste aanzet gaven;

- Marjan, Leonard en Charlotte 



\section{Introduction and outline of the investigation}

1.1. General review of the use of ultrasound for
of follicle growth and ovulation
1.1.1. Description of the application fields for ultrasound
observation of follicle growth and ovulation

After the description of the full bladder technique by Donald (1963) the female genital organs were exposed to ultrasound investigation. Further development of the equipment was required to allow detailed study of the non pregnant state of these organs. After this requirement was fulfilled, uterine size during the menstrual cycle was described (Kratochwil, 1968; Piironen, 1975), the ultrasound structure of the ovary was studied (Kratochwil et al. 1972), the Graafian follicle and the formation and decline of the corpus luteum were visualized (Scheer and Goldstein, 1973), and the lack of ovulation in polycystic ovaries was ascertained (Kun and Bosze, 1973). Technical improvement of the ultrasound equipment allowed Hackeloër et al (1977) and Hackeloër and Robinson (1978) to describe the growth of follicles in stimulated and spontaneous cycles respectively.

In the years thereafter numerous investigations were initiated on the use of ultrasound in areas which had been a subject of scientific or practical interest for a long time. Schematically the application of ultrasound can be subdivided in 4 topics:

\section{- Detection of ovulation}

Direct observation of the ovaries around ovulation by means of laparoscopy or laparotomy had been applied in studies concerning the time of the ovulation (Buxton and Engle, 1950; Edwards, 1973; Nigi, 1977; Pauerstein et al 1978). Their application was however limited ewen for scientific purposes on account of their invasive character.

The most widely used indirect method for ovulation detection was the interpretation of changes in the Basal Body Temperature (BBT). First described by Ogino (1930), it was up to now considered as very useful and accurate by many authors (Benjamin., 1960; Döring et al, 1967; Billings et al, 1972; Swyer el al, 1975; Marshall, 1976; Moghissi, 1976; Magyar et al, 1979; Hilgers and Bailey, 1980) but doubted and challenged by many others (WHO scientific report, 1967; Johansson et al, 1972; Morris et al, 1976; Lenton et al, 1977; Baman, 1981: Wetzels et al, 1982).

Apart from being a widely used method for ovulation detection, the BBT has served as a reference method for two other indirect methods of ovulation detection: dating of endometrial biopsy (Noyes et al, 1950), and dating of the corpus luteum (Corner, 1956). Hence, these methods could have a similar inaccuracy. 
- Searching for correlations between structural changes in the ovary and hormone patterns during the menstrual cycle

The peripheral patterns of gonadal steroids during the menstrual cycle and the interactions between thypothalamus, pituitary and the owarian steroid production have been extensively studied during the past fifteen years. Alimited number of efforts was made to explore the hormone patterns within the follicle (Bertrand et al, 1972; Delforge et al, 1972; Baird and Fraser, 1974; McNatty et al, 1974, 1976; McNatty and Sawers, 1975; Dorrington, 1975; Bomsel-Helmreich et al, 1979). There were only a few reports, which tried to correlate the functional state of a follicle to its morphology, particularly its size (Fowler et al, 1977; McNatty et al, 1979; Bomsel-Helmreich et al, 1979). A serious handicap of these investigations was that normal follicle development was disturbed at the moment of tissue sampling, so that the development could only be studied in a cross-sectionall mode.

In recent years a discussion was going on about the existence, the etiology and the possible meaning of the so-called luteinization of unruptured follicle (LUF) syndrome (Marik and Hulka, 1978; Koninckx et al, 1978, 1980a, 1980b; Dmowskiet al, 1980). A method for the continuous monitoring of follicle development could possibly reveal important aspects of the pathophysiology of this LUF syndrome and other conditions of ovarian dysfunction.

\section{- Monitoring of ovulation induction}

For the induction of ovulation in anovulatory states and for the achievement of well timed ovulations, therapeutic regimens like the Human Menopausal Gonadotropin - Human chorionic Gonadotropin (HMG-HCG) combination, the clomiphene-HCG combination or clomiphene alone were applied. Monitoring of the ovarian reaction to these regimens was supposed to be valuable. Especially the time of the HCG admunistration appeared to be crucial both for the prevention of multiple pregnancy and overstimulation and the achievement of a well timed ovulation.

The benefits of the different methods of monitoring are difficult to evaluate because of at least one reason: the great variety in indications for treatment. HMG-HCG treatment was used for low gonadotropin - low steroid anowulation, excluding the premature menopause (Jewelewicz, 1975; Schwartz and Jewelewicz, 1981; Hull, 1981), the polycystic ovary syndrome (Crooke et al, 1963; Wang and Gemzell, 1980, Kemman et al, 1981), the galactorrhocawamenorrhoeas sydrome (Schwartz et al, 1980), the so-called "resistant ovary syndrome" (Starup et al, 1971; Van Campenhout et al, 1972), and finally for the premature menopause (Taubert et al, 1977). The clomiphene-HCG combination or clomiphene alone were applied for the states of normogonadotropic, normo-oestrogenic anovulation or in those patients in whom there was a need for a predictable, well timed ovulation (Kistner, 1966; Pollak et al, 1973; Swyer et al, 1975; Garcia et al, 1977; Radwanska et al, 1980a). Furthermore, the results of the ovulation induction are difficult to evaluate. Instead of the ovulation rate, which would theoretically be the only accurate criterium, frequently other parameters like pregnancy rate, a temperature shift in the BBT or succesful lertilization in vitro were used, in part these events are essentially multifactorial. Only hyperstimulation can be ewaluated by more or less unequivocal criteria: the multiple pregnancy rate and the symptoms of the hyperstimulation syndrome. 
Two basic trends can be distinguished in the management of ovulation induction:

a. the use of empirical schedules, mostly applied in the clomiphene-HCG treatment, but also in the HMG-HCG regimen (Edwards, 1973; Steptoe and Edwards, 1970).

In these schedules, HCG was injected on a fixed day after the last clomphene or HMG administration without control of the effect of the previous medication. Usually the day at which clomiphene responders showed indirect signs of ovulation, was chosen as the day for HCG injection. The results in terms of pregnancy rates or in vitro fertilization rates were mostly disappointing (Kistner, 1976; Radwanska et al, 1980a; Edwards et al, $1980 \mathrm{a})$.

b. Oestrogen monitoring was the most widely used method for the timing of the HCG administration and the control of hyperstimulation in HMG-HCG regimens. Recently it was also applied for the governing of clomiphene-HCG treatment (Lopata et all, 1978; Thebault et al, 1980; Persson et al, 1980).

Oestrogen monitoring for the control of hyperstimulation was based on the observations of Johansson and Gemzell (1969), Taymor et al (1970) and Robertson and Steele (1972) that there was a positive correlation between high preovulatory oestrogen levels, luteal progesterone levels and the occurrence of hyperstimulation. Brown et al (1969) and Shaaban and Klopper (1973) considered a preovulatory urinary oestrogen excretion of $50-100$ microgram 24 hours or plasma oestrogen levels between $300-500 \mathrm{pg} / \mathrm{ml}$ as the limit for the administration of $\mathrm{HCG}$.

Oestrogen monitoring for the successful achievement of ovulation or the recovery of fertilizable oocytes was based on the knowledge that HCG administration on a moment of the cycle before the oestrogen peak or gonadotropin peaks can suppress or postpone the ovulation (Tamada and Matsumoto, 1969; Friedrich et al, 1975; Williams and Hodgen, 1980).

The oestrogen monitoring for the prevention of multiple pregnancy and hyperstimulation meant an improvement compared to the monitoring of indirect signs of aestrogen production like cervical score and ovarian size, (Taubert et al 1977). Especially hyperstimulation could to a great extent be prevented by this method (1-1ull, 1981 ; Sch wartz and Jewelewicz, 1981).

However, the value of oestrogen monitoring with respect to effective induction of an ovulation is less certain. Theoretically HCG has to be administered on the moment of optimal follicular maturity, which is supposed to be indicated by a certain oestrogen level. Klopper et al (1974) and Brown et al (1969) described that in induced cycles, higher oestrogen levels were necessary for the successful induction of ovulation by $\mathrm{HCG}$, possibly because of the higher resistance to exogenous gonadotropins (Kliopper et al, 1974; Talbot et al, 1976) or because of the higher oestrogen production by other follicles than the dominant one (Brown et al, 1969). The disappointing results in many series, with respect to pregnancy rates, $(40 \%$, Hull, 1981) could eventually be based upon failures to induce ovulation. For the purpose of in vitro fertilization, ovulation induction has been abandoned by Edwards et al (1980a), Testart et al (1980) and Taymor et al (1980) because of unpredictable results. They proceeded to time laparoscopy in spontaneous cycles by means of LH surge detection. 


\section{Prediction of ovulation}

The oldest methods by which owulation prediction was attempted, BBT and cerwical mucus qualities have not convincingly proven to be adequate. Cervical mucus qualities, expressed as ferning or cervical index (Moghissi et al, 1972; Insler et al 1972 ) have a semiquantitative value. The exact prediction of the ovulation by this method is questionable (Prins et al, 1979). This is even more true for the BBT as even its value for detection of the ovulation was doubted by many authors.

Since the availability of accurate radioimmunoassays and immunochemical assays of luteirizing hormone and the discovery of the rather constant temporal relationship between the LH peak and the ovulation (Yussman et al, 1970; Thomas et al, 1970; Landgren et al, 1977) the LH peak has become the leading method for ovulation prediction at least in case of artificial insemination and in vitro fertilization (Hosseinian and Kim, 1976; Younger et al, 1978; Edwards et al, 1980a; Roger et al, 1980). The avallability of rapid radioimmunoassays initiated the use of the Surge Initiating Rise (SIR) of LH which would have a more constant time rellationship to the ovulation than the LH peak (WHO Task Force, 1980; Djahanbackch et al, 1981; Testart et al, 1980).

Major disadvantages of the LH peak or surge for prediction of the ovulation are the costs and the time consuming character of the procedure. The value of the oestradiol peak for ovulation prediction is questionable (Warren, comment to Pauerstein et al, 1978; Adlercreutz et al, 1980; WHO-Task Force „1980).

\subsubsection{Technical aspects of visualization and measurement of preovulatory follicles by ultrasound}

At the time of the first descriptions of Graafian follicles by Kratochwill et al (1972) and Kun and Bosze (1973) the observations were limited to the last one or two days before ovulation. The grayscale display and the improvement of the piezo-electric crystals enabled to measure also smaller structures so that observation of the entire preovulatory phase became possible. Nevertheless, the measurement of these small structures practised in almost all reports since 1977 deserves some theoretical reservation especially with respect to its accuracy. First, the size of small, preovulatory follicles is at the margin of the lateral resolution of the ultrasound equipment. Secondly, a two dimensional technique is applied to measure a three dimensional structure. Hence, the ultrasound measurement of follicle size appears to be very susceptible to errors, both from the equipment and from a methodological point of vicw.

Evaluation of results and comparison between investigations should necessarily include a careful consideration of the equipment and the methods used.

\section{The Equipment}

Virtually all the investigators in this field since 1977 used a B-mode compound or sector scanner. Hackeloèr et al (1977) compared the results, obtained by various transducer frequencies and preferred the $3,5 \mathrm{MHz}$ transducer with medium or long focus. This frequency was widely applied (Terinde et al, 1979; Robertson et al, 1979; Smith et al, 1980; Kerin et al, 1981; Cabau and Bessis, 1981; Freundl et al, 1981). Lower frequencies were only employed when occasional circumstances like obesity made it necessary (Cabau and Bessis, 1981). Only Ylöstalo et al, (1979), Renaud et al (1980) and Seibel et al (1981) applied different frequencies ( 2 or $5 \mathrm{mHz}$ ) without mentioning a special reason for this. 
The most common method in the literature was the B-niode compound scanning, apparently for only one reason: its optimal resolution. The B-mode real time sector scanner was used by some authors instead of the compound method (Queenan et al, 1980) or in combination with it (Ylöstalo et al, 1979).

Others applied a linear array real time equipment in combination with $B$-mode compound scan or alone (O'Herlihy et al, 1980 a,b; Ylöstalo et al, 1981). Finally, Seibel et all (1981) and Garcia et al (1981), who used the ultrasound as an adjuvant to other methods in the prediction of ovulation, combined real time sector and real time hinear array techniques without making clear for which respective indications both methods were applied. The main reason for the use of real time methods and their main advantage over the compound method seems to be that they were more convenient (O'Herlihy et al, $1980 \mathrm{~b}$; Queenan et al, 1980). A possible advantage, a diminishing of the influence of breathing movements on the measurements was not memtioned. Up to now, only Ylöstalo et al (1981) made an effort to compare the accuracy of the compound and sector scanner method. They found a linear correlation between the results of the two methods $(r=0.72, p$ $0.001 \mathrm{y}$ in the measurement of the largest follicles in HMG stimulated cycles. These figures seem not to allow their conclusion that the real time method is reliable, because of methodological reasons: the limitation to very large follicles, the measurement of the follicle size in only one cross-section and the fact that a linear correlation coefficient of 0.72 appears not to be favourable for pairs of measurements on identical objects.

\section{Potential sources of error}

A basic review of the potential errors, influencing the accurary in uitrasound measuring of small objects was given by Robinson (1973) and Robinson and Fleming (1975). They considered the measurement of distances from 1 to 10 centimeters, especially with respect to fetal crown-rump length determination. Their theories appear to be also applicable to follicle measurements, although two aspects are different. Follicle size, whether expressed as a mean diameter, as largest diameter or as calculated volume refers to a volume i.e. a three dimensional entity. Secondly, instead of fetal movements which can disturb the measurements of the fetal crown-rump length, in the area of follicle obserwation the passive movements of the follicle caused by breathing of the subject are a source of error.

Robinson and Fleming (1975) subdivided the potential errors in random and systematic errors. Modified and completed for the follicle measurement the following sources of error are applicable:

random errors:

- skill of the operator

- setting of the ultrasound equipment

- movements of the follicle, caused by respiration

- location of the folliclle

- refraction, caused by the curvature of the abdominal wall

systematic errors: - distortion or deviation in the oscilloscope scale

- distortion or deviation in the photo camerat

- velocity calibration errors

- limutation of resolution by the beam width

- variation of resolution according to distance. 
methodologic errors: - scanning directions, referred to body axis, instead of follicle axis (see chapter II)

- the selection of the sections which have to be measured

- choice of correct follicle axes along which the measurements should be performed

For the crown-rump length measurements, Robinson and Fleming (1975) calculated that the standard deviation caused by random sources of error was $1.2 \mathrm{~mm}$, irrespective of the actual length. In their set up, the inaccuracy by beam width accounted for a mean overestimation of $1 \mathrm{~mm}$ and the aberrations in scale factor and velocity calibration for a mean error of $3.7 \%$. Although these figures cannot easily be applied to other investigations with different equipment and objects, they indicate that the extent of the errors is important, especially when small objects are concerned.

The accuracy of volume calculations by two-dimensional ultrasound measurements was evaluated for the fetal bladder by Campbell et al (1973). They demonstrated that a standardized measurement of the three largest diameters in two cross-sections at right angles and calcullations according to the formula $4 / 3$ pi. $r_{1} \cdot r_{2} \cdot r_{3}$ provided a reliable estimation of the volume. The mean error was $0.7 \mathrm{ml}$, and was equal for all the volumes ranging from $41039 \mathrm{ml}$. The relative error thus increased towards the lower volumes. Although this approach can be applied to follicles, there are differences: follicle volumes vary from II to $10 \mathrm{ml}$ during the cycle (Queenan et all, 1980), which means that the relative errors are potentially larger than in bladder measurements. Furthermore follicles can be flattened in different degrees on account of bladder filling (O'Herlihy et al, 1980a), or stage of the cycle (Hackelöer and Robinson, 1978) and the axes of an asymmetrical follicle can take any position to the body axis, while the fetal bladder has to some extent a fixed shape and position. These differences might cause a higher methodological error in follicle measurements.

The control of error-sources in the literature on ultrasound follicle measurements.

Some of the potential sources of error, mentioned betore, are not easy to control. This is ospecially true for the random sources of error. They originate from adaptations of the observer to subject-dependent variations: the thickness and shape of the abdominal wall, the location of the follicle with respect to uterus and bladder, the extent of respiratory movements. The limitation of the influence of these error sources on the accuracy of the measurement depends on the skill and the experience of the observer and cannot be controlled.

On the contrary, all systematic and methodological sources of error can be minimized and quantified by careful control of the equipment and phantom measurements respectively.

Reviewing the reports on follicle growth observation, the attention paid to the aspect of control of methodological errors by standardization of the procedure is variable.

The full bladder technique (Donald, 1963) was uniformly applied.

Among the authors who used the compound B-scan, Kerin et al (1981) described their method in detail: cross sections were performed in two directions, parallel and at right angles to the body axis. Scans were made at intervals of $2 \mathrm{~mm}$. The pictures were stored on 
photograph: for each follicle measurement an average number of ten photographs was taken. Afterwards the largest diameters in three directions were chosen from the photographs, and the mean diameter was calculated as the parameter of follicle size. In other investigations the methods were different. The procedure of measurements was not mentioned by Hackeloër et al $(1977,1979)$ and Hackeloèr and Robinson (1978). A scanning interval of $5 \mathrm{~mm}$ was used by Robertson et al (1979). Ylöstalo of al (1979, 1981) and Smith et al (1980). The beam width of the applied transducers was not mentioned, so that it is not discernible whether this wide scanning distance was adequate to find the largest cross sections.

Photographs were used for storage of the cross sections, in order to select the largest section by comparison (Robertson et al, 1979; Queenan et al, 1980; Kerin et al, 1981; $Y \|$ ostalo et al, 1981). Apparently Hackelöer and Robinson (1978) measured the crosssections by caliper from the grayscale display screen. Probably the selection of the largest cross-section was less accurate in this procedure.

Also the mean of the three largest diameters was not generally used as a characterization of follicle size: Hackelöer and Robinson (1978) and Hackelöer et al (1979) averaged only the two largest diameters in the transverse and longitudinal cross sections. It is evident that the results of these investigations carnot be compared to those who refer to the method. described by Campbell et al (1973). Other approaches were even more aberrant.Close reading of the reports by Robertson et al (1979), Smith et al (1980), Smit-Koppert and Coelingh Bennink (1982) gives the impression that these investigations only referred to transverse sections. Persson et al (1980) measured only the anteroposterior diameter. Renaud et al (1980) chose one diameter as representation of follicle size when the follicle appeared to be symmetrical and only the largest of all, when the follicle was asymmetrical. A number of authors only referred to the reports of Hackelöer al al $(1977,1979)$ and did not further evaluate the procedure (Terinde et al, 1979; Freundl et al, 1981; Beck et al, 1981). Others did not mention a procedure at all (Hall et al, 1979; Cabau and Bessis, 1981).

As indicated earlier, the most important advantage of real time methods compared to $B$ mode compound scanning was the faster and more convenient application. Also there was a possible advantage in the elimination of the effects of respiratory movements because these movements are better controlled with real time scanning. Up to now, there were no reports on the precise extent of these advantages. The potential disadvantages need to bo mentioned in brief. Selection of the correct cross sections and of the correct angle between the transverse and longitudinal section were fully dependent on the observers judgement (Queenan et al, 1.980; O'Herlihy et al, 1980a, 1981; Garcia et al, 1981). Also the resolution of real time devices appeared to be less than compound $\mathrm{B}$ scan as indicated by O'Herlihy et al (1980b) and de Crespigny et al (1981a). These potential handicaps regarding reproducibility and accuracy were the reason for the choice of the compound $B$ mode scan in the present study. It has to be investigated to what extent pros and cons are balanced and to what extent real time scanning gives reliable measurements.

The systematic sources of error were managed differently throughout earlier reports. The differences in transducer frequency were mentioned before. Beam width was not considered by any of the authors. Neither was the possibility of a distortion in the photographs mentioned. Calibration velocity, i.e. the sound velocity at which the caliper system is 
callibrated, should be standardized, for instance to the mean sound velocity in the soft lissues of the human body $(1540 \mathrm{~m} / \mathrm{s} ;$ Bots, 1982). As far as some authors mentioned this calibration of the caliper system, the sound velocity varied between $1500 \mathrm{~m} / \mathrm{s}$ and $1600 \mathrm{~m} / \mathrm{s}$ (Hackelöer and Robinson, 1978; Ylöstalo et al, 1979; Queenan et al, 1980; Renaud et al, 1980).

The aceuracy of the results of measurements, the ultrasonographically estimated volumes of follicles, was subject of a few small comparative studies. O'Herlihy et al (1980a) compared the calculated volumes, using real time and compound B-mode scanning as well, with the aspirated volumes at laparoscopy. The mean of the aspirated volumes was $0.4 \mathrm{ml}$ below that of the calculated volumes. Nothing was mentioned about the correlation between the two sets of measurements, or about the relative extent of the crror.Kerin ef al (1981) found a mean aspirated volume, considerably lower than the mean of the calculated volumes by compound B-scan: $5.8 \mathrm{ml}$ ws $6.9 \mathrm{ml}$. The authors supposed that this difference was caused by spill during the aspiration and by residual volumes of the follicles after the aspiration. Beside the means and the standard error of the mean, no data are available. Both reports concerned only large, preovulatory follicles and the accuracy might not be representative for the measurement of smaller follicles. The low correlation between $B$ mode compound and real time sector scanning, reported by Ylöstalo et al (1981) was mentioned before.

\subsubsection{Possible biological effects of diagnostic ultrasound at the level of the Graafian follicle}

Th"s issue, which was not specifically subject of the present investigation, deserves a short review. There are two possible biological effects of which one is specific to the field of follicle observation: the danger of injury to the genetic material within the oocyte and the possibility of alterations in the natural process of ovulation.

Injury to tissues and cell-cultures by ultrasound has been demonstrated in animal and human substrates ats well (Macintosh and Davey, 1970; Buckton and Barker, 1972; Kremkau and Witcofski, 1974; Liebeskind et al, 1979; Child et al, 1980). In some of these reports the doses and exposure times were however outside the normal range applied in the diagnostic use of ultrasound. In another part standardization and reproducibility were defective (Macintosh et al, 1975). Other reports could not prove a negative trend in chromosome quatities by expostre to ultrasound (Macintosh et al, 1975; Abdulla, 1978). There were two efforts to summarize the relevance of these and other investigations for the practical, diagnostic use of ultrasound. Wells (1974) searched for the relationship between noxious effects and the time and dose of ultrasound exposure. Based on the literature up to 1974 , this report concluded that irrespective of the exposure time, the usual energy emission in diagnostic, pulsed ultrasound $\left(1-50 \mathrm{~mW} / \mathrm{cm}^{2}\right)$ could not be suspected to be potentially hazandous.

The American Institute for U/trasound in Medicine (AIUM) Committee on Bioffects (1979) stated that up to that time, in the lower Megaherz frequency range no independently confirmed significant bulogical effects had been found in intensities below $100 \mathrm{~mW} / \mathrm{cm}^{2}$ SPTA (Spatial Peak Temporal Average).

Although the latter two reports are reassuring, the fact that diagnostic ultrasound of the: 
Graafian follicle is aimed directly on the genetic material of the oocyte performing its second meiotic division, should keep one alert to the possibility of noxious effects. This is one argument for the use of the lowest energy emitting method i.e. the pulsed compound $B$ scan in the serial observation of Graafian follicles. In the application of real time mothods. the freeze-frame should be used routinely.

The second potential biologic effect, modifications of the normal preovulatory development, was recently suggested by Testart et al (1982). They observed that the interval between the ovulatory stimulus (Surge Initiating Rise of LH or HCG administration) and ovulation was shorter after previous ultrasound observation (25-36 hours in one third of the cycles) than without ultrasound (not before 37 hours). Supposed mechanisms causing this "premature ovulation" could be increased abdominal pressure by the full bladder or by the ultrasound transducer, transient electrolyte imbalance by the high water intake, accompanying ultrasound investigations, or a biological effect of ultrasound on the follicie wall. Although these effects cannot be excluded, the findings of Testart et al (1982) appear to be insufficient to prove the existence of a "premature ovulation". First, they supposed that there is at "normal" L.H peak-ovulation interval, and they did not consider the possibility of interindividual variations. The minimum time interval between the LH surge and ovulation in their series was $37 \mathrm{~h}$, when there was no ultrasound influence. This result is much different from the 26-54 hour interval, found by the WHO Task Force Study (1980), applying a similar definition for the LH surge in 107 cycles, not influenced by ultrasound observation. Secondly, the supposed effect of ultrasound observation on the ovulation was absent in clomiphene and HCG stimulated cycles. The support which the authors derived from the investigation of Kerin et al (1981), who also found short LH surge ovulation intervals, cannot be taken seriously because of large methodologic differences between the wo investigations, especially in the LH surge detection.

In the present study, a series of spontaneous and Clomiphene induced cycles in which HCG was applied as an ovulatory stimulus can act as a contribution to the discussion (chapter VII).

\subsubsection{Results of ultrasound investigations}

In this part, only those issues will be extensively discussed, which had no specific place in the present investigation. The remainder will be considered in reviews preceding each chapter and will only be mentioned shortly here.

Detection of the ovulation was one of the first aims of ultrasound investigation (Hackelöer et al, 1977). The description of ultrasound features of the postovulatory statc was not uniform (Hackelöer and Robinson, 1978; Terinde et al "1979; Hackelöer et al ,1979; O'Herlihy et al, 1980,b; Queenan et al, 1980; Renaud et al, 1980; Garcia et al, 1981; Beck et al, 1981). A detailed description of the actual event of follicle rupture is found in the continuous ultrasound observations of De Crespigny et al (1981b).

Ultrasound detection of ovulation has served as a reference point for midpain (O'Herlihy et al, 1980c) and BBT ovulation detection (Wetzels et al, 1982). Furthermore it has been a basic element in the investigations of follicle growth pattern, correlation to hormonal events and evaluation of ovulation induction. 
Correlations between structural changes in the ovary and hormone patterns during the mensitual cycle.

The pattern of follicular growth, the ultrasound evidence of follicle rupture and the time relationships ${ }^{\circ}$ LH peak and oestradiol peak will be extensively discussed in the following chapters. Here, the relationship between follicle dewelopment and oestradiol production deserves attention.

Baird and Firazer (1974) found that the dominant follicle was responsible for $90 \%$ of the preovulatory oestradioll-17-beta production. In many reports on the ultrasound observation of follicles, the relationship between the oestradiol levels and follicle size was investigated. In spontaneous cycles there was a high correlation between mean oestradiol-17-beta levels and mean follicle size ( $\mathrm{r}=0.968$; Hackelöer et al, 1979 ) whereas it was considerably less ( $\mathrm{r}$ $=0.52$ and 0.56 ) between each indiwidual follicle and its accompanying oestradiol level (Ylöstallo et al, 1979; Beck et al, 1981). Freund et al (1981) found an improvement of the correlation when groups of measurements within one individual were considered. The occurrence of bifolliculat development, i.e. the co-existence of two follicles of large size, was expressed significantly in higher oestradiol levels (Freundl et al, 1981).

In clomiphene induced cycles significantly higher oestradiol levels were found than in not induced cycles. At comparable moments of the cycle the oestradioll levels were higher while the sizes of dominant follicles were not significantly larger (Ylöstalo et al, 1979; Smith et al, 1980). The authors supposed that this was a sign of additional oestradiol production by other structures than the dominant follicle.

In cycles induced with Human Menopausal Gonadotropin (HMG) the relationship between follicle growth and oestradiol levels were studied by Nitschke-Dabelstein et al (1980). There was a good limear correlation between oestradiol-17-beta levels in peripheral plasma and follicle size in the unifollicular development. The plasma levels were not significantly higher than in spontaneous unifollicular cycles. In the multifollicular development, ocstradiol-17-beta was generally three times higher than un the unifollicular situation. These figures were in agreement with those of Ylöstallo et al (1981).

Acoording to Ylöstalo et al (1981), there was al significant correlation between oestradiol levels and the total volume of the ovary, which in their view supported the theory that there were oestradiol sources outside the domimant follicle. It is however questionable if and to what extent an ultrasound measurement of the ovarian volume is reliable.

In general it can be concluded from the former reports that a plain, linear relationship between oestradiol production and follicle size is absent. At least it appears to be impossible to estimate the oestradiol level from the follicle size with sufficiont accuracy to replace ocstradiol determinations in ovulation induction schedules by follicle measurements. On the other hand, the estimation of the stage of follicle development by means of oestradiol levels seems to be inadequate in cycles with multiple follicles.

Cervical mucus quality in relation to the day of follicle rupture was briefly investigated by Renaud et al (1980). In four out of nine cycles the highest cervical score coincided with follicle rupture: in the remaining five it was up to 3 days earlier. Freundl et al (1981) found a correlation between cervical score and follicle size up to a mean diameter of $19 \mathrm{~mm}$. From this point until rupture (in their series at a size of up to $26 \mathrm{~mm}$ ) the scores at best remained constant, but decreased in most cases. It appeared that cervical score was a poor indicator of the impending ovulation. 


\section{Prediction of the ovulation}

Prediction of the ovulation was one of the most important early purposes of the ultrasound observation of the growing follicle. It was also the first issue that was abandoned by most authors because there proved to be a wide range in preovulatory diameters which precluded the use of this parameter for ovulation prediction (Robertson et al, 1979; Queenan et al, 1980; O'Herlihy et all, $1980 \mathrm{a}, \mathrm{b}$; Garcia et al, 1981). Recently Bryce et al (1982) retrospectively calculated that when the follicle had reached $20 \mathrm{~mm}$ mean diameter, prediction of ovulation could be made within $1.4 \pm 1.2$ days (SD). Their sample was however small ( 14 cycles in 14 subjects), and the maximum diameter instead of the mean diameter was applied to characterize follicle size. The possibility that there could be an individual pattern of follicular growth, which could provide some degree of predictability (Garcia et al, 1981) was not investigated up to now probably because this would require a very laborious serial study.

O'Herlihy et al (1980b) concluded from the comparison of follicular growth patterns and the LII peak, that the latter remains the most useful method for prediction of the ovulation.

As will be further discussed in cllapter III, the suggestion that a phenomenon, interpreted as "cumulus oophorus" by Hackelöer and Robinson (1978), had a great future as a marker of the impending ovulation was doubted by other investigators.

\section{Monitoring of ovulation induction}

Observation of follicular development by ultrasound was intensively used during ovulation induction with two objectives:

- the prevention of hyperstimulation, especially in $\mathrm{HMG}-\mathrm{HCG}$ induction

- the timing of HCG application after HMG or anti-oestrogen pretreatment.

The earliest report on the growth of the preovulatory follicle by Hackeloer et al (1977) concerned the effect of ovulation induction in one case. Rönnberg et al (1978) reported a sucessfull induction of ovulation in a spontancous cycle by means of HCG administration. The timing of the HCG injection was performed by ultrasound measurement of follicle size.

Ever since, two trends could be distinguished in the research on the use of ultrasound in ovulation induction: the evaluation of uitrasound observation as an adjuvant to the more conventional oestrogen assays and as a single method for monitoring.

The use of ultrasound monitoring for surveillance of ovulation induction, additional to oestrogen assays, was reported by Ylöstalo et al (1979, 1981), Smith et al (1980), Cabau and Bessis (1981), Schmidt et al (1981) and Seibel et al (1981). Unfortumately, some of the authors did not carefully define their criteria and describe their methods in follicle measurement (Cabau and Bessis, 1981; Smith et al, 1980; Seibel et al, 1981), or they used methods, aberrant from those which appeared to be generally accepted (Ylöstalo ct al, 1979,1981 ).

To what extent the ultrasound observation was incorporated in the policy, differed from one investigation to another: Schmidt et al (1981) controlled the induction by means of oestradiol measurements, cervical index and gynaccologic examination, and applicd 
ultrasound only to werify the existence of a developing follicle and to count the apparently dominant follicles. Ylostalo et al $(1979,1981)$ reported efforts to rely only upon ultrasound criteriat for timing the medication. Others did not provide information to what extent the ultrasound observations contributed to their induction policy (Cabau and Bessis, 1981). The results of these investigations are best summarized on the basis of the conclusions by Seibel et al (1981). The ultrasound observation of the follicle was considered to be useful for:

- determination whether or not there is a response of the ovary to a certain level of induction (Schmidt et al, 1981; Seibel et al, 1981).

- elimination of useless oestrogen determinations, especially before the follicles reached a certain diameter, for instance $10 \mathrm{~mm}$ (Seibel et al, 1981). The first follicles became ultrasonographically visible after a varying period, 2 to 7 days, of HMG-treatment (Ylöstalo et al, 1981).

- prevention of multiple pregnancies and hyperstimulation. Many authors agreed that the supposed rellationship between oestradiol levels and follicle development was only valid to some degree in the unifollicular situation (Ylöstalo et al, 1979; Smith et al, 1980; Cabau and Bessis, 1981). In the case of multiple follicles of dominant size, HCG administration was omitted.

The clinical results of this policy were divergent.Cabau and Bessis (1981) reported twins in two out of six pregnancies and mild or moderate symptoms of hyperstimulation could not be avoided in tour out of six cases. The value of ultrasound as additional surveillance appeared to be minimal in this series.

In contrary, Schmidt et al (1981) reported the elimination of serious side effects, a high ovulation rate $(94 \%)$ and pregnancy rate $(44 \%)$ in 103 cycles in 47 subjects. Probably the selection of indications for ovulation induction or differences in application of ultrasound criteria may have contributed to this divergence, but the cause can not be elucidated from the reports.

The use of ultrasound as a solitary method for monitoring ovulation induction was to some extent prepared in the investigations mentioned before: Rönnberg et al (1978) and Ylöstalo et al (1979) reported 15-16 mm to be the optimal size of the follicle after HMG pretreatment to react adequately to HCG administration. Monitoring ovulation induction by hormonal parameters, a large range was found in ultimate preovulatory diameters: 17 to $28 \mathrm{~mm}$ (Schmidt et al, 1981), 15-22 $\mathrm{mm}$ (Ylöstalo et al, 1981) and 15-23 mm (Seibel et al, 1981). Pregnancies occurred in the whole range of preovulatory follicle sizes (Seibel et al, 1981). The diameters of follicles at the moment of the HCG injection ranged from $13-24 \mathrm{~mm}$ in the group of Seibel et al (1981). Signs of luteal deficiency appeared only if follicle size was 13 and $14 \mathrm{~mm}$ at the moment of the HCG injection, which led to the preliminary conclusion that a follicle size of $15 \mathrm{~mm}$ should be regarded as a minimum for the administration of HCG. Up to now there have been four prospective studies in which the injection of HCG after HMG or Clomid pretreatment was merely timed on the basis of follicle size. Nitschke-Dabelstein et al (1980) started with a low dose of HMG and increased the dose until follicular reaction was seen by ultrasound. A very unpredictable sensitivity to HMG was noticed. HCG administration was planned at a mean follicular diameter of 20 to 22 $\mathrm{mm}$, which was the mean size before ovulation in spontaneous and Clomiphene induced cycles. In 22 cycles, ovulation was observed within 24 hours $(n=11)$ or within 48 hours ( 
$=11$ ) from the HCG injection. No hyperstimulation was seen and the pregnancy rate was 6 in 13 patients.

Sallam et al. (1982) reported a group of 61 cycles in 22 patients, monitored with reall time ultrasound. HCG was administered after HMG at 20-25 mm (mean 21.3) mean follicle diameter. In 3 cycles, HCG was witheld because of imminent hyperstimulation or multiple pregnancy. The remaining 58 cycles were all ovulatory and resulted in 12 single pregnancies. O'Herlihy et al (1982) administered HCG following Clomiphene at the diameter of $18 \mathrm{~mm}$. because this was the mean diameter 36 hours before the ovulation in control cycles. The events in the ovary following this injection were not monitored ultrasonographically, but the pregnancy rate of $67 \%$ within 6 treatment cycles indicated a high ovulation rate.

Trounson et al (1981) reported a relatively high rate (30\%) of fertilizability of ova, when laparoscopy was performed 36 hours after HCG administration, given at a follicle size of $17 \mathrm{~mm}$.

Reviewing these reports, a common feature was that the choice of follicle size for HCG administration was empirically and arbitrarily based upon the experience with spontaneous cycles. The question whether follicle development after HMG exhibited the same variation as in the spontaneous cycle or was more uniform remains unanswered. Hence it remains possible that in a part of the cases the $\mathbb{H C G}$ administration was falsely timed for methodological reasons. Nevertheless, the favourable pregnancy rates indicate that the ultrasound method of surveillance is promising.

\subsection{Outline of the present investigation}

This study was started three years after the first report in this field by Hackelöer et al (1977). At that moment, only studies on limited numbers of cycles were published.

Moreover, these studies had a cross-sectional character and conclusions were mostly preliminary. The reports about the follicular growth pattern during spontaneous cycles were far from unequivocal. The methods and criteria were far from uniform.

The present investigation was designed as a prospective serial study of the spontaneous cycle. It was controlled in a sense that the schedules of ultrasound observations and hormone determinations were uniform and fixed and that the errors, originating from the ultrasound measurements were diminished as far as possible by standardization of the methods used.A serial study, implicating that sequences of cycles were observed in the same subject, had not been described up to then.

In addition to spontaneous cycles, two smaller groups of cycles were observed cycles with ovulation induction by means of anti-oestrogens and cycles in which ovulation was triggered by Human Chorionic Gonadotropin (HCG).

In general terms the aims of the study were:

- detection of the ultrasonographical signs of follicle rupture

- description of follicle growth pattern

- prediction of ovulation in spontaneous cycles and after HCG induction

- the relationship between follicle development and endocrinc parameters. 


\section{Chapter II.}

\section{Subjects, materials and methods}

\subsection{Selection of subjects}

The entire group of subjects comprised 43 persons. They were subdivided in three groups: healthy volunteers (8), patients with primary infertility (26) and patients with secondary infertility (9). Table II.1. gives further details about these groups.

A number of 8 female hospital workers and students were willing to participate in the investigation as a volunteer. Their age ranged from 27 to 38 years. None of them used hormonal medication of any kind. They had a history of regular menstrual cycles, ranging from 25 to 31 days. Four volunteers had one or more children, two of them used an IUCD for contraception, two had undergone tubal ligation. The remaining 4 volunteers were nulligravida. In this group a total of 43 cycles was investigated, 5 cycles in 6 subjects and 6 and 7 in two other subjects. In 7 subjects all the cycles were consecutive, in one subject there was an interruption of 1 month.

Besides the 8 volunteers, a number of 35 patients were involved. All had undergone a fully completed infertility investigation at the outpatient clinic. No patients with anatomical causes of infertility, detectable with hysterosalpingography, entered the study. Most of the patients had been treated by means of Artificial Insemination Homologous (AIH) or various methods of ovulation induction for variable times. With respect to the cause of the infertility, this group can be subdivided as is shown in table II.2.

- Male infertility ( 20 couples). This diagnosis included various degrees and combinations of oligospermia (less than $20 \mathrm{million} / \mathrm{ml}$ sperm count), asthenospermia (less than $50 \%$ motile sperm or a repeatedly subnormal performance in the sperm migration test) and teratospermia (over $40 \%$ abnormals). Other factors, including the cycle features were normal in these couples. Some of the female partners received drugs for induction of ovulation, in order to regulate a more or less irregular cycle. Usually, during the period of ultrasound examination, artificial insemination (AIH) was performed in these patients.

- Male infertility accompanied by ovulation disorders ( 7 conples). All the ovulation disorders in this group concerned oligomenorthoea without evident disorders in gonadotropins, steroid hormone levels, androgens, prolactin and thyroid hormones. Most of the patients had drugs for induction of ovulation before the start of ultrasound investigations.

In some cases the medication was changed in the course of the ultrasound investigation.

- A group with female causes for infertility, comprising 7 women with unexplained failure to ovulate on treatment by clomiphene, clomiphene-HCG or HMG-HCG. 


\begin{tabular}{|c|c|c|c|c|c|c|}
\hline & \multirow{2}{*}{$\begin{array}{l}\text { number of } \\
\text { subjects }\end{array}$} & \multirow{2}{*}{$\begin{array}{c}\text { nuwber of } \\
\text { cycles }\end{array}$} & \multirow{2}{*}{$\begin{array}{c}\text { number of } \\
\text { sponianeous } \\
\text { cycles }\end{array}$} & \multirow{2}{*}{$\begin{array}{c}\text { number of } \\
\text { cyclest } \\
\text { subject } \\
\text { (range) }\end{array}$} & \multicolumn{2}{|c|}{ age (years) } \\
\hline & & & & & median & range \\
\hline $\begin{array}{l}\text { healthy volunteers } \\
\text { (mulligravida) }\end{array}$ & 4 & 23 & 23 & $5-7$ & 30 & $28-36$ \\
\hline $\begin{array}{l}\text { Healthy volunteds } \\
\text { (proven fertility) }\end{array}$ & 4 & 20 & 20 & 5 & 29 & $27-38$ \\
\hline $\begin{array}{l}\text { patients (primary } \\
\text { infertility) }\end{array}$ & 26 & 110 & 56 & $1-11$ & 28 & $23-32$ \\
\hline $\begin{array}{l}\text { patients (secondary } \\
\text { infertility) }\end{array}$ & 9 & 25 & 12 & $1-8$ & 30 & $25-37$ \\
\hline total & 43 & 178 & 111 & & & \\
\hline
\end{tabular}

Table II. 2 .

Distribution of patients according to diagnosis

\begin{tabular}{|c|c|c|c|c|c|}
\hline & $\begin{array}{c}\text { number of } \\
\text { patients }\end{array}$ & $\begin{array}{c}\text { nurnber of } \\
\text { cycles }\end{array}$ & $\begin{array}{l}\text { number of } \\
\text { spont.cycles }\end{array}$ & $\begin{array}{c}\text { induced cycles } \\
\text { (ani- } \\
\text { oestrogens) }\end{array}$ & $\begin{array}{c}\text { induced cycles } \\
\text { () }\end{array}$ \\
\hline male infertility & 20 & 88 & 49 & 17 & 21 \\
\hline cycle disturbance & 7 & 21 & 8 & 11 & 2 \\
\hline $\begin{array}{l}\text { combination male } \\
\text { female factors }\end{array}$ & 7 & 23 & $\| 1$ & 9 & 3 \\
\hline unrecognized & 1 & 3 & 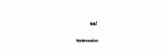 & 3 & 1 \\
\hline totall & 35 & 13 & 68 & 40 & 27 \\
\hline
\end{tabular}

7) comprising: HMG (2); Bromergocriptin (2); HCG 10.000 IE (8); HMG-HCG (1); Clomiphene-HCG (12); Clomiphene-oestrogens (1); Tamoxiphene-HCG (1)

- One patient with an unrecognized cause of infertility in whom thorough examination had failed to reveal the reason for longstanding infertility. The ultrasound examination was planned to exclude derangements in the ovulation pattern.

An additional remark is necessary with respect to the composition of the groups. The number of cycles, observed in one subject, shows a wide range, especially in the patientgroups (table II I.). Although this imbalance is intrinsic to the acquisition of patients for 
the investigation, it leads to the possibility that individual characteristics hawe a disproportionate influence on the results of the group. The overall distribution of the number of cycles per subject is shown in fig. II.1A. There were only three subjects who had more than 7 cycles investigated. Furthermore the character of the cycles in these large series per subject was not uniform so that they were divided ower different groups. Considering the group of spontaneous cycles $(n=111)$, it was composed out of shorter series of cycles per subject: median: 5 cycles/subject, range 1 to 7 (fig. II IB). The antioestrogen induced cycles $(n=40)$ consisted of short sequences per subject: median 2 cycles/subject, range 1-5 (fig. II. 1C).
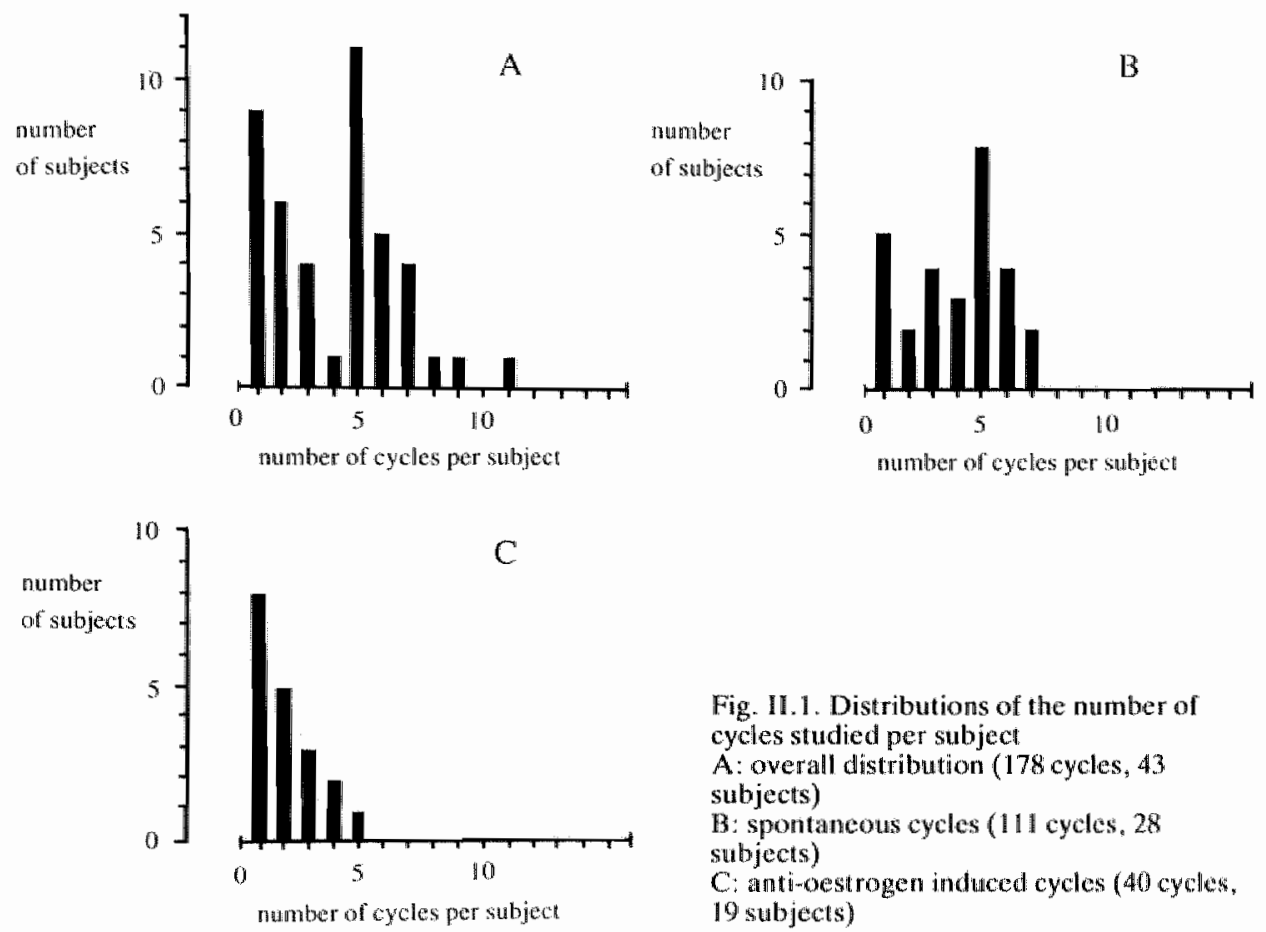

Fig. II.1. Distributions of the number of cycles studied per subject

A: overall distribution ( 178 cycles, 43 subjects)

B: spontancous cycles (111 cycles, 28 subjects)

C: anti-oestrogen induced cycles ( 40 cycles, 19 stibjects)

\subsection{Schedule of observations}

The aim of the study was to observe follicles during the last 5 days before follicle rupture. Depending on the duration of the previous cycle, the first ultrasound examination took place between the 7 th and the 10th day of the cycle. As soon as follicles we re seen with a mean diameter of $10 \mathrm{~mm}$ or more, ultrasound was performed with a 20 to 28 hour interval, mostly during the daytime $(8 \mathrm{a} . \mathrm{m}$. to $6 \mathrm{p} . \mathrm{m}$.$) . As soon as a follicle reached the preovulatory$ size, it was tried to increase the frequency of observations to two times daily, mostly in the early morning and the late afternoon.

Vemous blood samples were taken daily at the end of each ultrasound session, thus during the daytime between $8 \mathrm{a} . \mathrm{m}$. and $6 \mathrm{p} . \mathrm{m}$. After clotting and centrifugation, serum was frozen at $-20^{\circ}$ Celsius until assays were performed. For economical reasons the selection of samples for the various assays was made after ulltrasonographical signs of follicle rupture had 
occurred. Onday 5 to 7 after this event, one blood sample was taken for progesterone determination.

All homone levels were determined in triplicate by means of commercial radioimmunoassay procedures. Luteinizing Hormone (LH) by a double antibody solid phase kit (IRE, Fleurus; Belgium), progesterone following extraction, by a Nordic lab procedure (Oulensalo; Finland) and oestradiol-17-beta using a kit of Wörenhingen, Radio isotopen service, EIR. The coefficients of variation and the level at which they were calculated are summarized in table II. 3 .

Table 11.3.

Coefficients of variation in the hormone assays

\begin{tabular}{lccc} 
& \multicolumn{2}{c}{$\begin{array}{c}\text { coefficieniof of vation }(\%) \\
\text { wirhin-assay }\end{array}$} & value \\
\hline Luteinizing Hormone & 5.0 & 8.7 & $11.7 \mathrm{ng} / \mathrm{ml}$ \\
Oestradiol-17-beta & 8.0 & 9.8 & $1.10 \mathrm{n} \mathrm{mol} / 1$ \\
Progesterone & 8.5 & 12.2 & $8.7 \mathrm{n} \mathrm{mol} / 1$ \\
\hline
\end{tabular}

\subsection{The equipment}

For the ultrasound observations a compound B-mode scanner Emisonic NE 4201 was used, callibrated at $1540 \mathrm{~m} / \mathrm{s}$. The best results were achieved with a $3.5 \mathrm{MHz}$ NE 4388 transducer. Only in a few instances, especially when the transducer-object distance was enlarged by obesity the use of a $2.5 \mathrm{MHz} 4323$ transducer was necessary. The decision of changing the transducer was based upon the observers judgement about the acuity of the depiction. The beam-geometrics of the $3.5 \mathrm{MHz}$ transducer were determined by means of a beamscanner described by Hoeks et al (1979). Fig. II.2. shows the transverse sections of the beam at various distances, the amplitude plot of the cross sections and a characteristic of the whole beam, composed out of four of these cross-sections.

The beam appears to be focused from $7.51013 \mathrm{~cm}$ of depth, the beam width ( $\pm 6 \mathrm{~dB}$ ) over this distance being 2.7 to $4.5 \mathrm{~mm}$.

Before each measurement the pelvic area was surveyed by means of the $3.5 \mathrm{MHz}$ Emisonic $\mathrm{NE} 4264 \mathrm{~B}$-mode sector scanner. The resolution and the display quality of this real time equipment appeared to be less than those of the compound mode. However it proved to be profitable to survey the observation field before starting the measurements because it facilitated and shortened the search for follicles with the much less manageable compound B-mode transducer.

Photograplis were taken using a Vidicam 200 camera.

\subsection{The measurement procedure}

The examinations were performed only with an optimal filling of the bladder, so that the ovaries were outside of the zone of reverberations originating from the abdominal wall, 


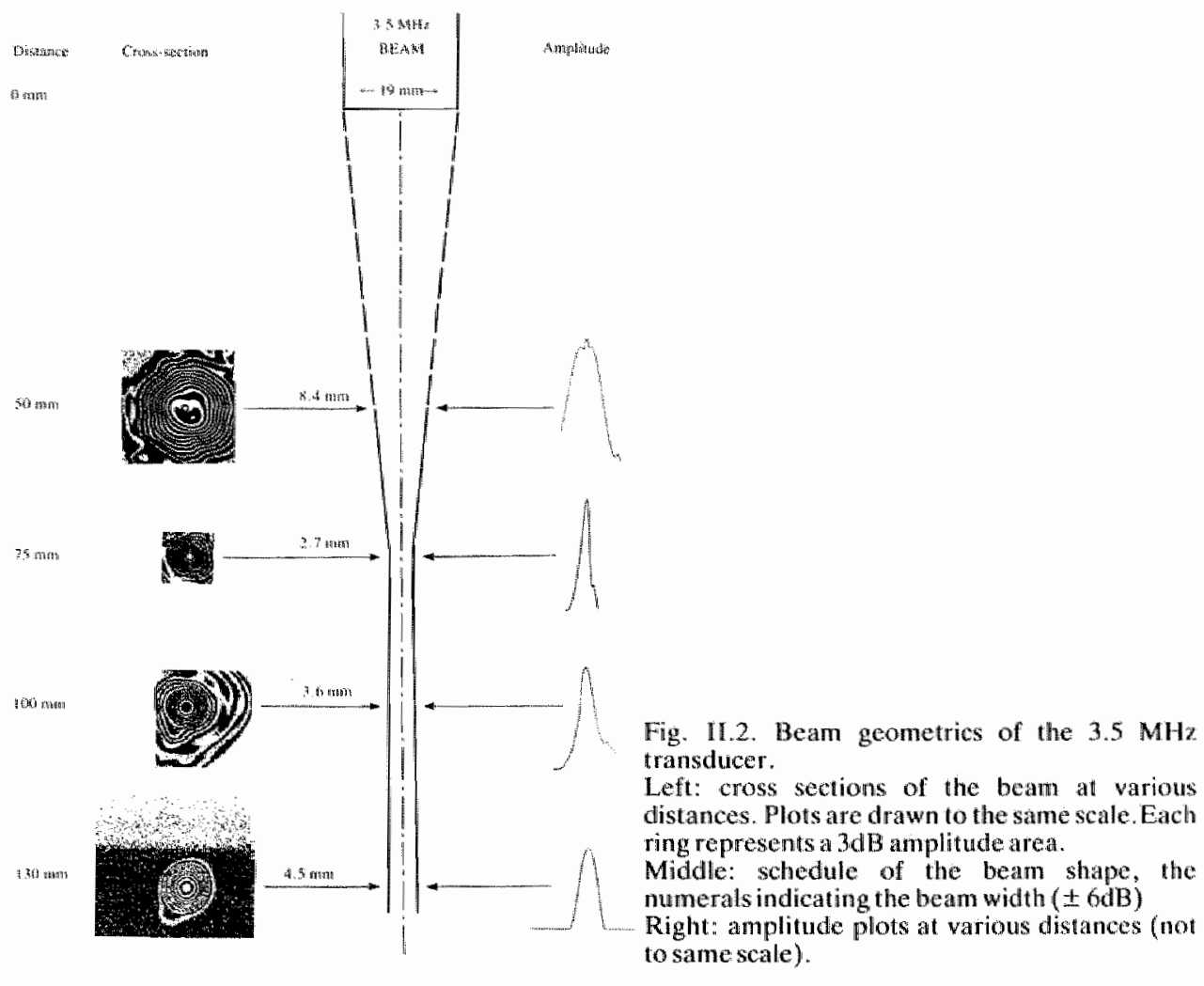

and inside the focus range of the transducer. After localizing the ovaries with the real time sector scanner, the measurements were performed with compound B scan. Follicles were scanned in two directions at right angles: paramedian and transwerse, referring to the body axis. In both directions tomograms were made at an interval of $2 \mathrm{~mm}$ and 3 to 5 of the transsections which appeared to be near the largest were photographed. The settings of the equipment and the handling of the transducer were such, that the best description of the margins of the follicle was achieved.

Afterwards, the largest diameters in both directions were seiceted and measured from the photographs. The antero-posterior diameter was measured perpendicular to one of both largest diameters (fig. II.3.).

In order to characterize the size of the follicle, the mean diameter was calculated out of these three diameters.

\subsection{Potential sources of error, standardization procedures}

Referring to the reports of Robinson (1973), Campbell et al (1973) and Robinson and Fleming (1976) concerning the accuracy of fetal crown-rump length measurements and the volume estimation of the fetal bladder, we distinguished three groups of sources of ermor: systematic, random and methodological (chapter I). These categories will be revicwed here, with a short mention of the efforts to control them. 

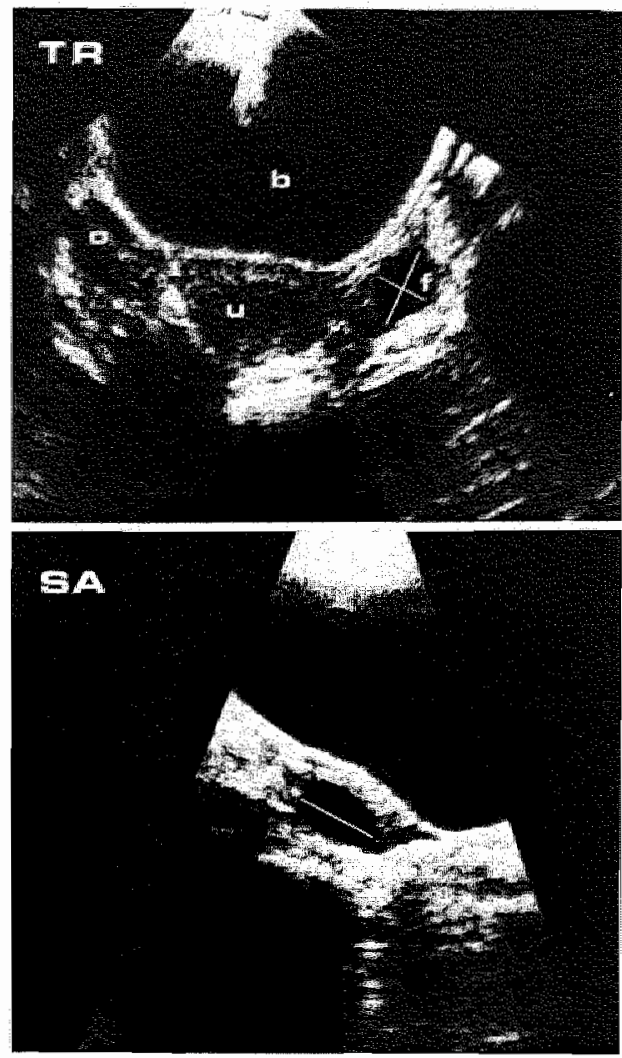

Fig. II.3. Transverse (TR) and sagittal (SA) section of a follicle $(B=$ bladder, $U=$ uterus, $F$ $=$ follicle, $\mathrm{O}=$ contralateral ovary). White lines indicate the direction of the three standard measurements for the calculation of the mean follicle diameter.

A. Systematic errors can be divided as follows:

1) Velocity calibration.

The calipers were set at $1540 \mathrm{~m} / \mathrm{s}$. According to the manufacturers specification the accuracy of the caliper system was $0.1 \mathrm{~mm}$. Calibration was checked monthly by measuring plastic containers in a water bath of $60^{\circ}$ Celsius. Special attention was paid to the equallity of the caliper settings for the compound and the sector scan systems. When adjusted according to the manufacturers manual, the deviation in the mensurement of the two systems was about $10 \%$. The adjustment was corrected.

2) Adjustment of camera and monitor distortion.

A Vidicam 200 camera was used for the photographs. In this device, ultrasound pictures were displayed on a separate monitor. They were photographed on paperfilm. The mean scale factor of the pictures was 1.78. At the start of the investigation the possibility of distortion, caused by incorrect monitor settings was checked. By displaying identical caliper settings at different sites on the monitor and in continuously changing directions, a direction-dependent distortion of up to $10 \%$ was revealed.

This distortion was reduced to a mean of $2.3 \%$ after readjustment of the height and width settings of the image lines. 
3) The resolution of the ultrasonic beam.

The axial resolution of the pulsed beam is not likely to impair seriously the accuracy of the measurements. Hoeks et al (1979) calculated for a $3 \mathrm{MHz}$ beam that the axial resolution would theoretically be $0.125 \mathrm{~mm}$. The major problem is the limitation of the transverse resolution, depending on the geometric qualities of the beam. As reported in chapter II. 1 the focused area of the $3.5 \mathrm{MHz}$ transducer in this study extended from 7.5 to $13 \mathrm{~cm}$ depth and the beam width in this range was 2.7 to 4.5 $\mathrm{mm}$. Theoretically the transverse resolution cannot be better than the beam width. In practice, the error of this kind is diminished by the skill of the obserwer. Employing the single beam technique the observer was able to handle the transducer in such a way that the beam axis was always nearly at right angles to the surface of the structures of special interest. Ideally, the transducer described a curve, identical to the curvature of the follicle wall, thus exploiting the more favorable axial resolution. By doing so the skill of the observer, one of the random sources of error, was supposed to have a correcting influence on the effect of this systematic error. Only when the optimal tilting of the transducer was impossible, for instance in case of a flat abdominal wall or a hidden location of the follicle, this correction failed. The variation of resolution according to distance was encountered by pursuing an optimal bladder filling resulting in a transducer-follicle distance of 7 to $10 \mathrm{~cm}$.

\section{B. Random sources of error}

The random sources of error are in part the same as those, distinguished by Robinson and Fleming (1974) for the measurement of crown-rump length. In part they are specific to the volume estimation of follicles.

1) The settings of the ultrasound equipment for the achievement of an optimal picture are a source of error of which the impact on the results depends on the observers experience. The effect was difficult to estimate. The only standardization in the present investigation was the fact that all the examinations were performed by the same observer. A similar problem was the choice of the margins and the direction of axes for measuring the diameters from the photograph. In many instances, margins and optimal directions were not unequivocal. In these instances, the decision of the observer was a random source of error. Again the influence on the results was hard to quantify.

2) The effect of movements of the object. This factor was of utmost importance in the measurements of the fetal crown-rump length. The ovary can passively move, be it to a limited extent. Movements under the influence of breathing or bowel activity could occasionally be observed with real time techniques.

Theoretically these movenents limit the accuracy when the purpose of scanning is to find the largest transsection, especially with the use of static compound-B-scan technique. The potential impact of this factor was supposed to be limited by two circumstances: abdominal breathing was probably impaired by the full bladder and scans were performed with the small interval of $2 \mathrm{~mm}$. In this investigation 3 to 5 pictures were taken of the supposed largest cross-section, which means that a maximum span of $6-10 \mathrm{~mm}$ was covered. In the exceptional case that movements 
were experienced during the real time survey or by continuously changing size of the B-mode cross-section, a double set of scans was performed, and the subject was periodically asked to hold her breath.

3) Specific to the subject of follicle measurement are the problems, caused by hidden positions of the follicle. The ovary could take any possible position in the lower abdomen. Usually it was found just berteath the posterior wall of the full bladder, in the vicinity of the uterus, optimally exposed to the ultrasound investigation. The following positions could be problematic, either by impeding efforts to hit the follicular wall at right angles, or by covering the follicle with angular loss (Bots, 1982) originating from the edges of the uterus or the endometrium:
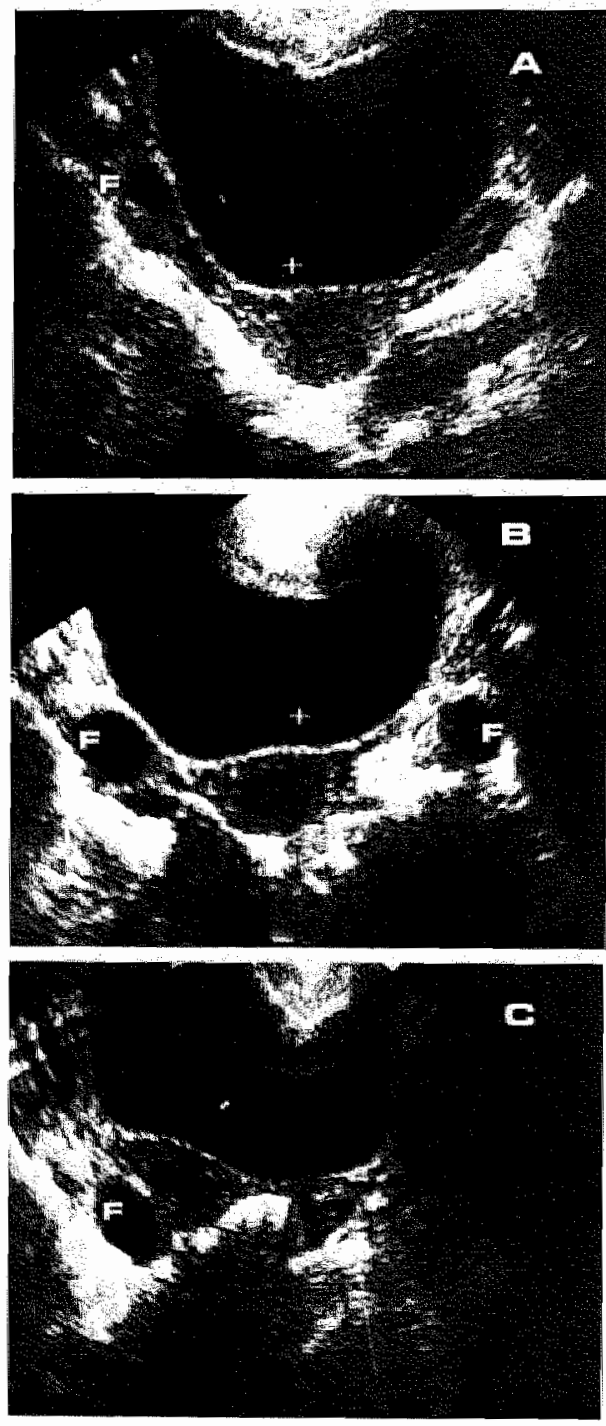
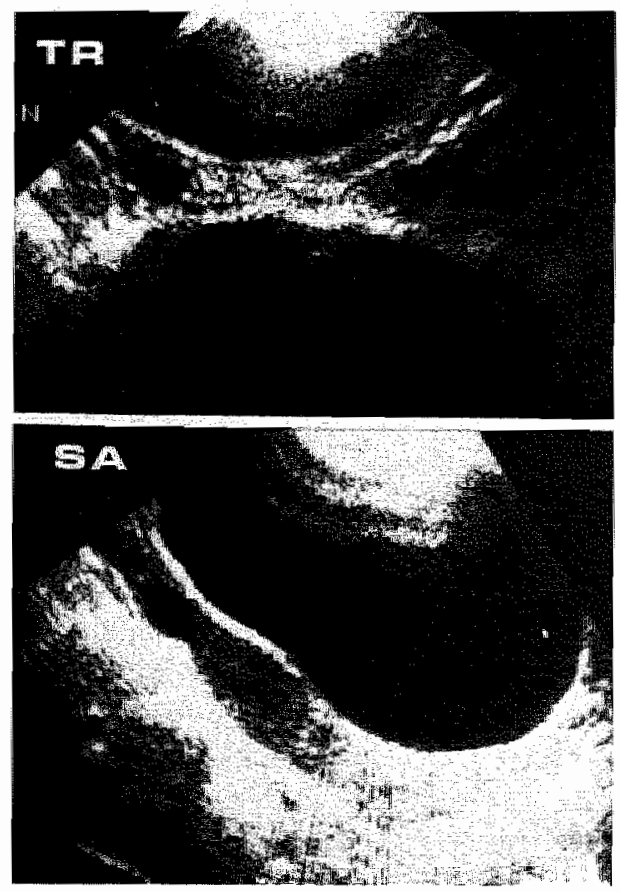

Fig. I1 5. Example of an extreme cranial position of the follicle in the transverse (TR) and sagittal (SA) section
Fig. II 4. Various positions of the follicle with respect to bladder, uterus and abdominal wall in the transverse section ( $\mathrm{F}=$ follicle).

A: high lateral position

B: intermediate positions, beneath or at some distance from the bladder wall

$C$ : behind the uterus 
- The high lateral and high cranial positions (fig. II.4 a,b and II.5) required maximal tilting of the transducer. Especially when the abdominal wall was flat, there could be loss of contact between transducer and skin which impeded optimal depiction. In both positions of the follicle, maximal tilling of the bladder was required.

- Position behind the uterus (fig. II.4c). The correct observation could be hampered by the mere interposition of an absorbant medium and increment of the distance between object and transducer. Also angular loss could cause a poor display of the margins of the follicle.

- Position underneath a sharply convex part of the bladder wall. The bladder shape varied between individuals and depended on the bladder filling. Mostly the convexity was equal over the whole surface of the bladder. When the follicle was situated beneath an extremely convex part of the bladder wall, problems could arise in keeping the beam rectangular to the bladder wall, which caused angular loss underneath. In the present investigation the incidence of problematic locations in the first 64 cycles ( 23 subjects) was $10 / 64$. This caused failure to ascertain a suspected follicle rupture in 3 cases. In these cases, a post-rupture state was clefinitely seen one day later. Later in the study, these failures were absent, presumably on account of increased experience.

4) Refraction, caused by the curvatures of abdominal wall, bladder wall and follicle wall, must be supposed to cause distortion of the ultrasound picture.

The influence of this factor must be variable and its effect on the reliability of measurements could not be estimated and even less eliminated.

\section{Methodological sources of error}

As described in chapter I, this group comprises the errors by the scanning method, the method of measuring the diameters and calculation of the volume out of the mean diameter.

The standard directions of scanning, parallel to and at right angles to the body axis were a compromise between accuracy and a workable schedule of routine measurements.

Especially in ovoid follicles, it would theoretically be better to scan along the axis of the follicle, rather than along the body axis.

The choice of the greatest diameter from fotographs and a anteroposterior diameter, at al right angle to this largest diameter, is always to some extent arbitrary and thus implies a source of error.

For the calculation of the volumes, not the formula $4 / 3$ pi. $r_{1} \cdot r_{2} \cdot r_{3}$ (Campbell et al, 1973) but for practicall reasons the equation for the volume of a sphere was chosen: 4/3, pi, $r^{3}$. The radius was for this purpose replaced by the mean radius: $4 / 3$. pi..$^{3}$ (Queenan et al, 1980). In case of occasional deviations from the spherical shape, this procedure contains a source of error in the volume estimation.

\subsection{Calibration experiments}

The number, diversity and complexity of the sources of error made it difficult to estimate the net effect of an individual factor on the accuracy of measurements.

Apart from the absolute extent of an error in the measurement of a diameter or a volume, 
Whe relative (inter-observation) error determined the usefuness of the method for the investigation of follicular growth.

In order to provide a basic reliability of the measurements, every step of the procedure was standardized as far as possible (Chapter 2.4 ).

In an effort to quantify the relative errors and to obtain an indication about the extent of errors, a series of calibration experiments was performed, in vitro and in vivo.

1) In witro a group of rubber balloons was measured under strictly defined circumstances by two observers. The balloons were made of nubber glove fingertips and filled with destilled water. By choosing different sizes and different degrees of filling, a variety in shape and volume was achieved, simillar to that of the Graafian follicle. Before filling, the dry weight of the balloons was determined. After filling and carefully drying the cxterior of the balloons, they were weighed again and the volume was calculated. The balloons then were suspended in a fixed position in a water bath of $50-60^{\circ} \mathrm{C}$ (fig. II.6),

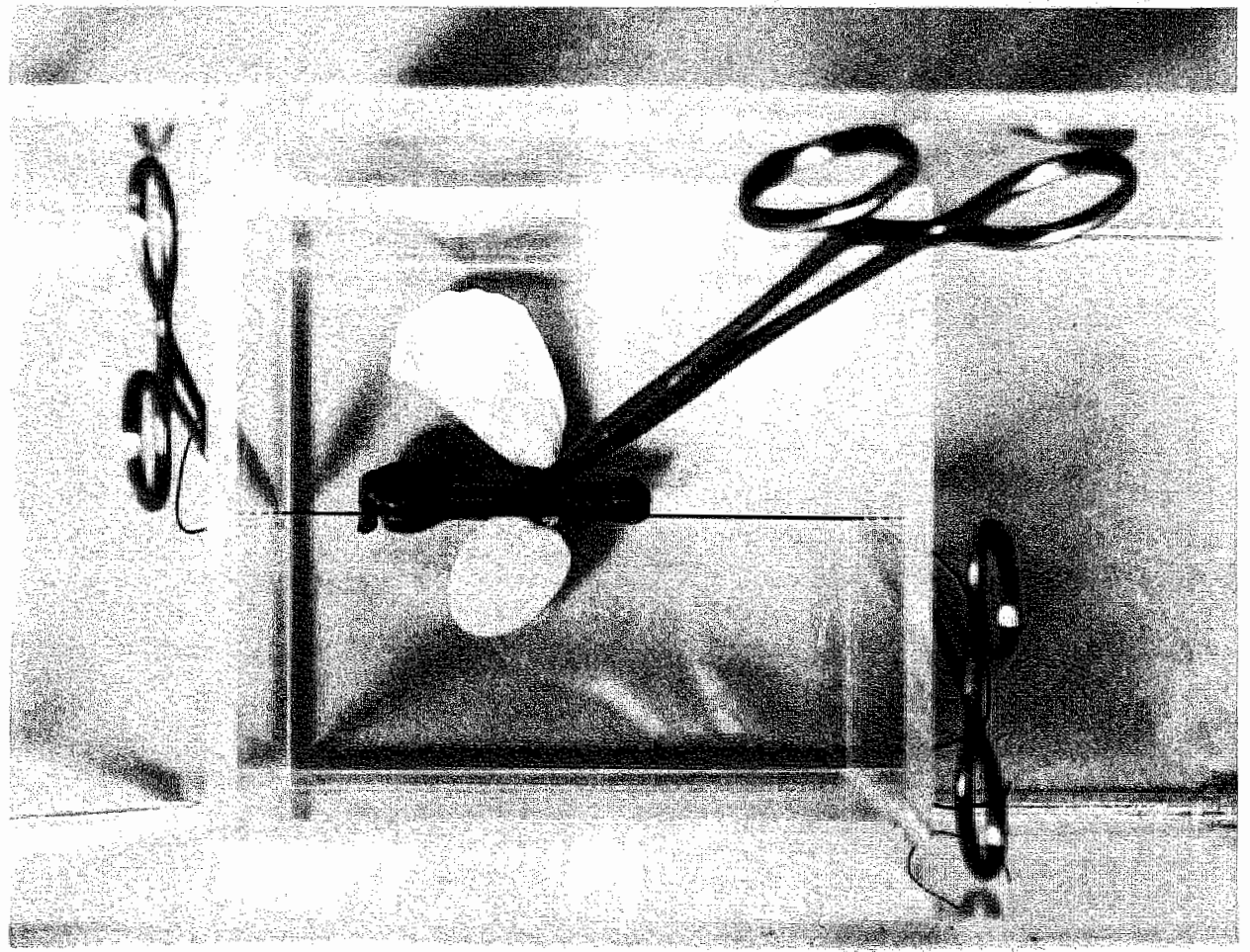

Fig. II.6. Set-tup of the in vitro experiments. A rubber balloon was mounted on an inner frame, preventing movements. The frame then was placed in a water bath.

the temperature providing a sound velocity equal to that in the human body. The measurements were performed witls the $3.5 \mathrm{MHz}$ compound B-scan in two rectangular directions, but arbitrarily with respect to the optimal axis of the balloons. Photographs were taken of tomograms at an interwal of $2 \mathrm{~mm}$. The diameters were measured from 
the photographs, identical to the procedure of the in vivo measurement of follicles. From the mean diameter, the volume was calculated $\left(4 / 3\right.$ pi. $\left.{ }^{3}\right)$, which was compared to the weighed volume.

The potential sources of error, active in this controlled experiment were : the effect of beam width, the settings of the equipment, camera distortion, the measurement of an arbitrary set of diameters in case of asymmetrical objects, the choice of margins on the photographs, and the interobserver variation in the latter. Compared with the in vivo situation, the influence of refraction was absent.

2) In vitro a similar group of balloons was measured by 2 observers using the B-mode sector scanner. In 2 directions at right angles three estimates were made of the largest cross sections. The remaining of the procedure was identicall to that, described in experiment 1 . Hence, the same set of error sources were supposed to be active. The only differences were in the scanning method. Comparison of the results of experiments 1 and 2 was supposed to represent a controlled comparison of the two methods.

3) In vivo a sample was taken of so-called "vector-measurements". This newly introduced term can be defined as "measurements along the follicle axis", opposite to "standardmeasurements" referring to the body axis. In a series of follicles in vivo, the direction of the largest and smallest diameters was determined by means of the real time sector scanner. The follicle sizes were measured along these axes, which can be considered to be more optimal than measurements according to the body axis. In the same session the follicles were also measured in the standardized way along the body axis, neglecting the actual shape and position of the follicle.

4) In vivo, follicles were measured in the standardized way. The procedure was repeated after a short time (30 to $90 \mathrm{~min}$ ). Assuming that the growth of the follicle during this time span was neglectible, the variables in this setting were: the degree of bladder filling and its effect on shape of the follicle and refraction of the beam, the observers accuracy. the observers choice of settings of the equipment and the measurement from photographs.

5) In vivo, identical follicles were measured during the same session by onc observer with compound B-scan (standardized) and by at second observer with real-time sector scan (not-standardized). All observations were photographed.

Variables were the settings of the equipment, differences in resolution between the two methods, the observers choice of margins, and the effect of eventual movements of the ovary.

Four out of 30 observations had to be removed from the samples, because the quality of display by the real time method was too bad to allow measurement.

\section{Results}

The results of the various calibration experiments are summarized in table II 4. Statistical interpretation has been carried out in different ways and deserves some comment first. 


\begin{tabular}{|c|c|c|c|c|c|c|c|c|}
\hline & & \multicolumn{2}{|c|}{ number } & \multirow[t]{2}{*}{ Pearsont } & \multicolumn{2}{|c|}{$\begin{array}{l}\text { deviation (\% of } \\
\text { reference vol.) }\end{array}$} & \multirow[t]{2}{*}{$\begin{array}{l}\text { systemalic } \\
\text { error }(p)\end{array}$} & \multirow{2}{*}{$\begin{array}{c}\text { \%o of measurements } \\
\text { deviang less than } \\
\text { 15\% from reference } \\
\text { vol. }\end{array}$} \\
\hline & & & & & mean & $S D$ & & \\
\hline \multirow[t]{2}{*}{1.} & Weighed wolume vs. & Obs.l & 40 & 0.990 & +5.6 & 9.4 & 0.012 & 85 \\
\hline & (in vitro) & Obs.II & 40 & 0.979 & +5.9 & 11.9 & 0.027 & 80 \\
\hline \multirow[t]{2}{*}{2 . } & Weighed volume vs. & Obs. I & 20 & 0.964 & -12.8 & 13.5 & 0.001 & 60 \\
\hline & (in vitro) & Obs.II & 20 & 0.965 & .9 .3 & 11.4 & 0.025 & 60 \\
\hline 3. & $\begin{array}{l}\text { standardized vs. } \\
\text { "vector" ( } B \text {-mode } \\
\text { compound, in vivo) }\end{array}$ & & 22 & 0.932 & -2.8 & 12.6 & 0.94 & 68 \\
\hline 4. & $\begin{array}{l}\text { Identical follicles, } \\
\text { time interval } \\
\text { (B-mode compound, } \\
\text { in vivo) }\end{array}$ & & 25 & 0.974 & 4.9 & 13.9 & 0.85 & 68 \\
\hline 5. & $\begin{array}{l}\text { Identical follicles } \\
\text { (B-morle compound vs. } \\
\text { sector, in viwo) }\end{array}$ & & 26 & 0.972 & -10.0 & 16.6 & 0.02 & 46 \\
\hline
\end{tabular}

The first method of interpretation was the analysis of linear correlationship between groups of paired measurements. This was practised by O'Herlihy et al (1980a) for the evaluation of differences between ultrasound and aspiration measurements of follicle volumes and by O'Herlihy et al (1980b) and Ylöstalo et al (1981) for comparison of compound and sector-scan measurements in the same follicles.

This search for a linear correlation, however appeared not to be the most critical approach. Ideally the pairs of measurements should be identical. In linear correlation analysis, relatively large deviations from this ideal are allowed in individual measurements, before the linear correlation is disturbed.

In the present series, this analysis was only performed for the purpose of comparison with the reports, mentioned above.

In all of the present experiments, the Pearson correlation coefficients for the volumes were higher than 0.95 and the significtnces were invariably 0.0001 (table II.4.). This applied also to the comparison of compound and sector scan measurements. The linear correlation for the volumes was better than those of O'Herlihy et al (1980b) and Ylöstalo et al (1981) for the mean diameters (0.944 and 0.728 respectively).

It seemed to be more adequate to consider the relative deviation of each calculated volume from that of its partner in the matched pair. The mean relative deviation was expressed as the mean of percentual deviations from the reference measurement (table II.4.). As reference measurements were chosen the weighed volume in sample 1 and 2 , the standardized measurement in sample 3 , the first compound measurement in sample 4 and the B-mode compound measurement in sample.5. In this way, a series of relative deviations 
emerged for each experiment.

In the two in witro experiments ( 1 and 2), comparing weighed wollume of balloons with compound and sector scanner measurements, there was a marked difference in accuracy. The mean relative deviation of the compound B mode scanner (experiment 1) was between 5 and 6 percent for both the observers, while in the sector scanner series (experiment 2) the mean deviation was 12.8 and 9.3 percent respectively. After joining the results of the two observers in both experiments, the Mann-Whitney $U$ test indicated that the difference between compound $B$ mode and real time sector scanning in this setting was significant ( $p$ $=0.0011)$. In the in vivo experiments 4 and 5 , concerning measurement of identical follicles by $\mathrm{B}$ mode compound scan and sector scan, there was a considerable mean volume deviation of 10 percent between the two methods ( $\exp 5$ ). The mean deviation between compound $B$ measurements performed on the same follicle, in vitro, within a short time interval was only $4.9 \%$ (experiment 4 ).

Also these results suggested a considerable difference between the two ultrasound methods, in a sense that the compound $B$ scan technique gives more accurate results as far as the present equipment is concerned.

A further analysis of experiment 1 seemed to be adequate because this experiment appeared to be representative for the follicle measurements in the remainder of the study. The balloons in the sample $(n=40)$ had a median wolume of $4.95 \mathrm{~cm}^{3}$ (mean diameter 21.2 $\mathrm{mm})$, range $1.50 \mathrm{~cm}^{3}(9.3 \mathrm{~mm})$ to $12.85 \mathrm{~cm}^{3}(29.1 \mathrm{~mm})$. The absolute error in the calculated volume was $0.45 \pm 0.44 \mathrm{~cm}^{3}$ (mean $\pm \mathrm{SD}$ ) for observer 1 and $0.48 \pm 0.49 \mathrm{~cm}^{3}$ (mean \pm SD) for observer 2 . Although it could be expected that the relative error would increase in the smaller volumes, this was not found. The absolute volumes and the relative errors showed no linear correlation (observer $1, r=0.4197, p=0.365$; observer $2, r=0.265, p=$ 0.531 ; Pearsons' test for linear correlation).

A remark is necessary on the wide variation in relative volume deviations, expressed as standard deviation. This remark applies to all experiments but will also be concentrated on experiment 1. Although the failures appear to be large, the results can be considered as favourable for the following reason: the volumes were calculated out of measured diameters. It should be realized that an error of 1 millimeter in an object of $20 \mathrm{~mm}$ mean diameter caused a volume deviation of $15 \%$. A great deal of the variation was caused by extreme failures: 6 volumes deviated between $16 \%$ and $26 \%$ in observer 1 and 8 results failed by 16 to $40 \%$ in observer 2 . The largest volume deviation of $40 \%$ was found in a balloon of 23.4 $\mathrm{mm}$ mean diameter, so that the error in diameter was $2.6 \mathrm{~mm}(11 \%)$. Calculated for the mean diameter the relative error in experiment 1 , observer 1 amounted $2.55 \pm 2.26 \%$ $(\operatorname{mean} \pm \mathrm{SD})$.

A third approach was to calculate the fraction of measurements in which the measured volume did not deviate more than $15 \%$ from the reference volume. The limit of $15 \%$ was chosen in view of the earlier reports of Renaud et al (1980) and Kerin et al (1981), from which it could be concluded that the minimal growth rate of the mean diameter in the last four days before follicle rupture is $2 \mathrm{~mm} / \mathrm{day}$. This growth rate of the diameters corresponds with a minimal daily growth of the volume, accounting for $53 \%$ at a mean diameter $13 \mathrm{~mm}$, and $31 \%$ at a mean diameter of $21 \mathrm{~mm}$. For the whole range of follicle sizes during the last: 4 days before ovulation, a method that is as accurate as $\pm 15 \%$ of the volume can be 
supposed to be at least able to register follicular growth. The B-mode scan experiments showed that at least 80 to $85 \%$ of all measurements reached this limit of accuracy. The performance of sector scanning in this respect was less adequate.

Finally, from the calibration experiments, some conclusions could be drawn about the possibility of systematic errors. In a series of identical pairs of measurements, the probability that an object is measured larger or smaller than its reference, had to be estimated as 0.5 , unless there were systematic errors. The probability for a normal distribution was calculated for the negative/positive ratio of differences in all the experiments. Systematic errors were supposed to be present when this p-value for the normal distribution was 0.05 or less. Table II. 4 shows that systematic errors appeared to be present in both the in vitro experiments ( 1 and 2 ) and in the combination of B-mode compound and B-mode sector scanner (5). In the in vitro experiments both methods measured the majority of the balloons smaller than the weighed volume. In experiment 5 , the sector scanner measurements were systematically smaller than those of the compound B mode scanning. The cause of these systematic errors could not easily be detected, because of the complexity of the system. It was likely that they were for the major part due to the equipment, as the errors were not influenced by the choice of the scanning method nor by the choice of the observer. The finding of a systematic error in the comparison of the two methods on identical follicles (exp. 5) suggested that there were also systematic differences between the two methods. These could have been situated in the equipment or in the observers management of the device (i.e. settings, choice of margins on the photograph, choice of the transsection planes).

As could be expected in an accurately performed experiment, a systematic error was absent in experiment 3 and 4 in which identical measurements on identical objects were compared.

\section{Discussion}

In the vitro experiments the accuracy of the B-mode compound scanner for measurement of the volume of small objects was significantly higher than that of the sector scanner. Of course this applied only to the equipment used in this investigation.

The accuracy of the B-mode compound scanner was considered acceptable, as the mean crror did not exceed $6 \%$ of the volume in any of the experiments for both the observers and as in 80 to $85 \%$ of the measurements the error in the calculated volume was at least smaller than the reported minimum daily growth rate of the preovulatory follicle. The aceuracy should however not be overvalued. The wide variation of the results (aberrations of up to $40 \%$ of the reference volume) should make one cautious against the interpretation of individual measurements.

In spite of maximal efforts to eliminate systematic error sources from the ultrasound equipment, the photographic device and the observers methods, systematic errors were still present. This emphasizes the necessity of a careful control of all the steps in the procedure, and justifies doubts about the results of investigations, in which this aspect was neglected. 


\section{Chapter III}

\section{Observations, related to the ultrasonographical evidence of follicle rupture: definitions and incidence}

\section{Introduction}

It appears to be logical to consider follicular growth and follicle rupture in the natural, chronological sequence.

However, as the definition and interpretation of ultrasound changes around the moment of follicle rupture are essential also for the description of follicle growth, it seems better to discuss these changes and the definitions first.

Related items like the so-called cumulus oophorus and the left right distribution of ovulations are added to this chapter.

\subsection{Review of the literature}

Whereas the earliest reports on ultrasonographical observation of the ovaries only roughly described the cyclic changes (Scheer and Goldstein, 1973; Kratochwil et al, 1972), Hackeloèr et al (1977) were the first to draw attention to the possibility of detecting the moment of ovulation by serial observations.

However, they did not give a clear-cut definition of ultrasonographical signs of ovulation. In the subsequent reports on ultrasound necognition of the moment of ovulation, two different approaches to the problem of the ultrasound definition of ovulation could be distinguished: the recognition of the early corpus luteum or the disappearance of a preexilsting follicle.

Recognition of the early corpus luteum was maintained as a criterium for ovulation in the further reports of Hackeloër and Robinson (1978) and Hackeloèr et al (1979). Others adopted this approach (Terinde et al, 1979; Beck et al, 1981). Striking similarities between ultrasound appearance and histologic structurc of the early corpus luteum and the assumption that the ultrasound features of the corpus luteum would be identical in all cycles were the basis of this definition.

With increasing experience, however, the assumed ultrasound features appeared not to be constant enough to provide a reliable definition. Cyst formation immediately after ovulation, instead of the "early corpus luteum" appearance, was reported in considerable numbers by Hackeloer et al (1979) and Terinde et al (1979). The direct observations in a limited number of ovulations, confirmed that the morphology of the ovary immediately after follicle rupture exhibits a wide variation (De Crespigny et al, 1981 b). Their ultrasonographical 
observations were in agreement with the reports of direct observations of ovulation in the human and in primates (Edwards, 1973; Stähler et al, 1974; Nigi. 1977); the degree and the specd of emptying of the follicle and the aspect of the resulting structures were variable.

More recent was the tendency to rely upon the disappearance of the preexisting structure for the ultrasonographical detection of the moment af the ovulation, whatever the remaining structure might be (O'Herlihy et al, 1980b; Renaud et al, 1980; Garcia et al, 1981). Queenan et al (1980) distinguished four different entities that could be observed after follicle disappearance: replacement with structures similar to the histolop appearance of the "early corpus luteum", replacement with an irregular cyst, gradus tecreasing within 6 days; filling of the follicle with low density structures while the siz . ained constant or increased slowly; full collapse of the follicle followed by formation a cyst within a few days. Ovulation was supposed to have occurred when these essential changes took place in a preexisting follicle.

Kerin et al (1981) also defined ovulation as the loss of the preexisting follicle structure, and reported that only in some cases an "early corpus luteum" formation appeared, identified by its semitransonic properties as described by Hackelöer and Robinson (1978). Reviewing these recent reports, it seemed reasonable to abandon the efforts to interpret the ultrasound structures of the post ovulatory state with criteria adopted from histology.

Already in the earliest investigations there was a search for a specific marker of the impending ovulation. Hackelöer and Robinson (1978) described a small echogenic structure on the inner surface of the follicle immediately before the ovulation in 16 out of 20 cycles. Based on the similarity with the histologic appearance of the cumulus oophorus they supposed that the ultrasound structure was identical to this histologic substrate. Moreover, they suggested that the "cumulus" could act as a useful marker of the impending owulation as it was only seen shortly betore the "early corpus luteum". Although this theory was never established, Beck et al (1981) took for granted that the described ultrasound structure represented the cumulus oophorus.

Other investigations threw doubt upon these interpretations. Kerin et al (1981) also saw these structures, but only in $26 \%$ of the cycles and already from a diameter of $18 \mathrm{~mm}$. In their report the interval of the occurrence of the so-called cumulus to the ovulation was not considered and the anatomical substrate of the structure was not discussed. O'Herlihy et al (1980b) even doubted the real existence of the ultrasound phenomenon: they noticed it occasionally but found no redationship to other events. De Crespigny at al (1981b) did observe a "cumulus-like" structure in one out of 7 cases in which the period of the ovulation was monitored continuously. They stressed that in their view it could not be distinguished from artifact. It can be concluded that the real existence of the phenomenon, its anatomical substrate and its usefulness for the prediction of the ovulation are doubtful.

Flattening of the follicular shape prior to ovulation was suggested to be a sign of follicular maturation by Hackelöer and Robinson (1978) and appeared a potential indicator for the forthcoming rupture of the follicle. However, de Crespigny et al (1981b) who observed follicles contimuously, attributed this flattening merely to the influence of environmental pressure. 
A sudden preovulatory increase or decrease of the follicular size near the moment of rupture was found by Renaud et al (1980) and interpreted a potential marker of follicular rupture. It appeared not to be consistent in other investigations (OHerlihy et al, $1980 \mathrm{~b}$; de Crespigny et al, 1981b).

\section{Ultrasonographical signs of follicle rupture}

In the present investigation no attempt was made to define the ultrasound characteristics of the early corpus luteum, or to base a definition of ultrasound evidence of ovulation upon the appearance of this structure. First, it was thought that the interpretation of ultrasound pictures is potentially misleading. Secondly, no generally applicable definition of the ultrasound features of the corpus luteum was found.

In agreement with the opinion of Queenan et al (1980) the absence of a pre-existent follicle was adopted as the only characteristic of follicle rupture, regardless of the structures that replaced this follicle. The presumptive hypothesis was that this follicle disappearance coincided with or was identical to ovulation. In the days preceding this event, the ultrasound picture of the ovary was very constant in a qualitative sense. Provided that the ovary was observed daily, there was a constant number of follicles, which were easily recognized and distinguished. Only the follicle size changed. Compared to this "prerupture" period, the changes accompanying follicle rupture were usually dramatic and not to be overlooked. For an experienced observer, there was usually no doubt about the moment of observation of the ruptured state of the follicle. The postrupture ultrasound structures were subdivided in three categories:
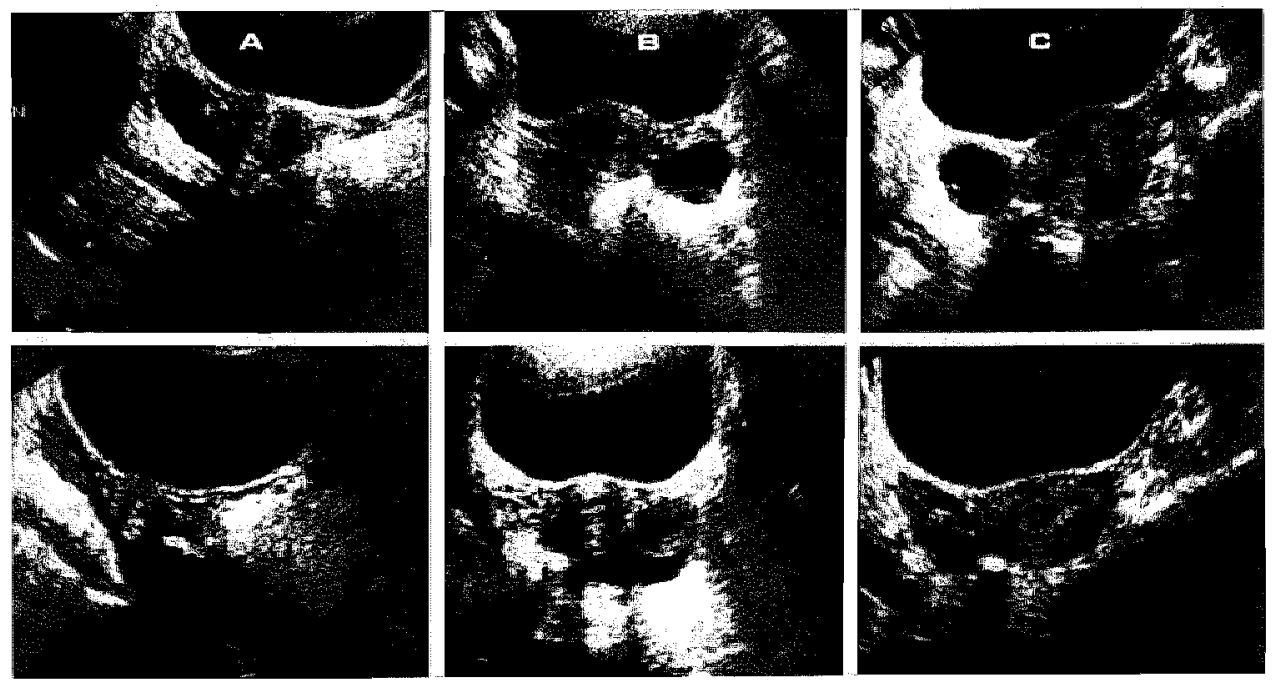

Fig. III. 1. Three main types of ovarian appearance after follicle rupture.

A: the follicle is replaced by a solid looking structure, equally filled with low density echo's

B: a smaller and irtegular cystic structure remains after rupture

$\mathrm{C}$ : the follicle is teplaced by a spongeous area

1) A solid looking structure, totally filled with semitransonic material (fig. III.1a);

2) A transonic cyst, much smaller than the pre-existent structure, irregularly shaped and thick-walled. (fig. III.1b); 
3) an ared of spongy appearance, composed of multiple, small transonic areas, interspaced with semitransonic structures (fig. III.1c).

A mong the cycles of this investigation, 167 fulfilled three criteria: they were ovulatory according to hormonal critcria (a LH peak and/or a luteal progesterone increase), follicle rupture was established by ultrasound and the type of post-rupture morphology could be determined with certainty.

The distribution of post-rupture appearances in this group is summarized in table III. 1.

Table III.1.

Appearance after tollicle rupture with respect to type of cycle

\begin{tabular}{|c|c|c|c|c|}
\hline & solid (I) & $\begin{array}{c}\text { Type } \\
\text { transonic (2) }\end{array}$ & spongeous (3) & total \\
\hline \multicolumn{5}{|l|}{ cycle } \\
\hline spontaneous & 53 & 13 & 39 & 105 \\
\hline anti-oestrogens & 15 & 12 & 11 & 38 \\
\hline other & 17 & 7 & 0 & 24 \\
\hline total number & 85 & 32 & 50 & 167 \\
\hline total $(\%)$ & $50.9 \%$ & $19.2 \%$ & $29.9 \%$ & $100 \%$ \\
\hline
\end{tabular}

The solid (1) appearance was seen most frequently: $50.9 \%$; the transonic (2) and spongeous (3) type occurred in 19.2 and $29.9 \%$ of the cases respectively.

All subjects with 3 or more cycles were reviewed. There was no recognizable preference of any subject for any type of post-rupture appearance. There were no significant differences between the types of postrupture appearance with respect to progesterone at the moment of follicle rupture and progesterone in the luteal phase. The preovulatory diameters were significantly larger in the transonic and spongeous types than in the solid type: $p=0.001$ and $p=0.016$ respectively (Mann-Whitmey $U$ test), while there was no significance in this respect between the transonic and the spongeous type $(p=0.290)$. As the investigation concentrated on the preovulatory events, the question whether one ultrasound aspect can pass into another in the course of the luteal phase, remained unanswered.

\subsection{The "cumulus oophorus"}

This phenomenon deserved special interest, It was noticed by many investigators in the field, while its anatomical substrate and its usefulness for the prediction of ovulation were disputed.

The structure concened is a small echodense area of a few millimeters diameter, usually situated on the inner surface of the follicte wall and extending into the follicular fluid. In the present series such a structure was encountered for one or more days in 25 (15.2\%) out of the 164 cycles which were correctly observed and registrated in this respect. Based upon our obscrvations, two remarks can be made with respect to the interpretation of the authors mentioned:

1. Although the so-called cumulus was definitely a preovulatory sign, the prevalence of the 


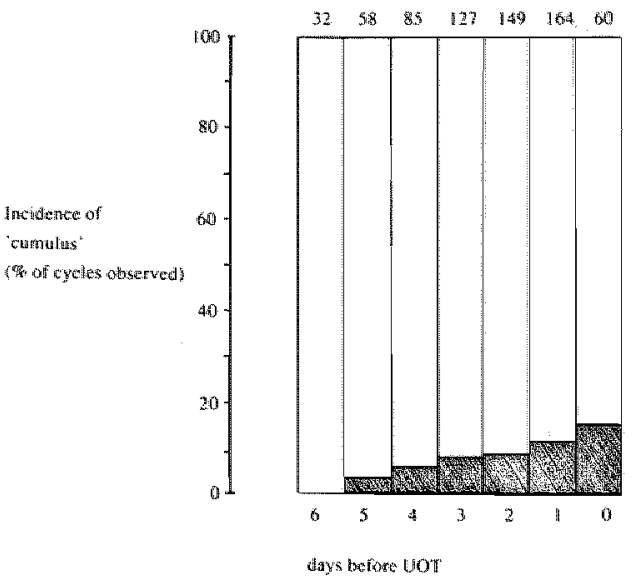

Fig. III.2. Relative incidence of the so-called "cumulus oophorus" on consecutive days of the cycle. Day 0 is the day of ultrasound evidence of follicle rupture. Numerals on top indicate the number of cycles, observed on a particular day.

phenomenon on the day preceding the ovulation could not be confirmed. There were many cases where "cumulus"-like features appeared up to 5 days before follicle rupture. Fig. III. 2 shows that this accounted for $6 \%$ of all cycles, and that this fraction increased steadily as follicle rupture came near.

2. The interpretation, that the so-called cumulus represents the anatomical cumulus oophorus seemed to be speculative, as the anatomical substrate of the ultrasound phenomenon has not been demonstrated. In a few cases in the present series, a remarkable evolution was seen of these structures, especially in larger follicles. Fig. III.3 shows a
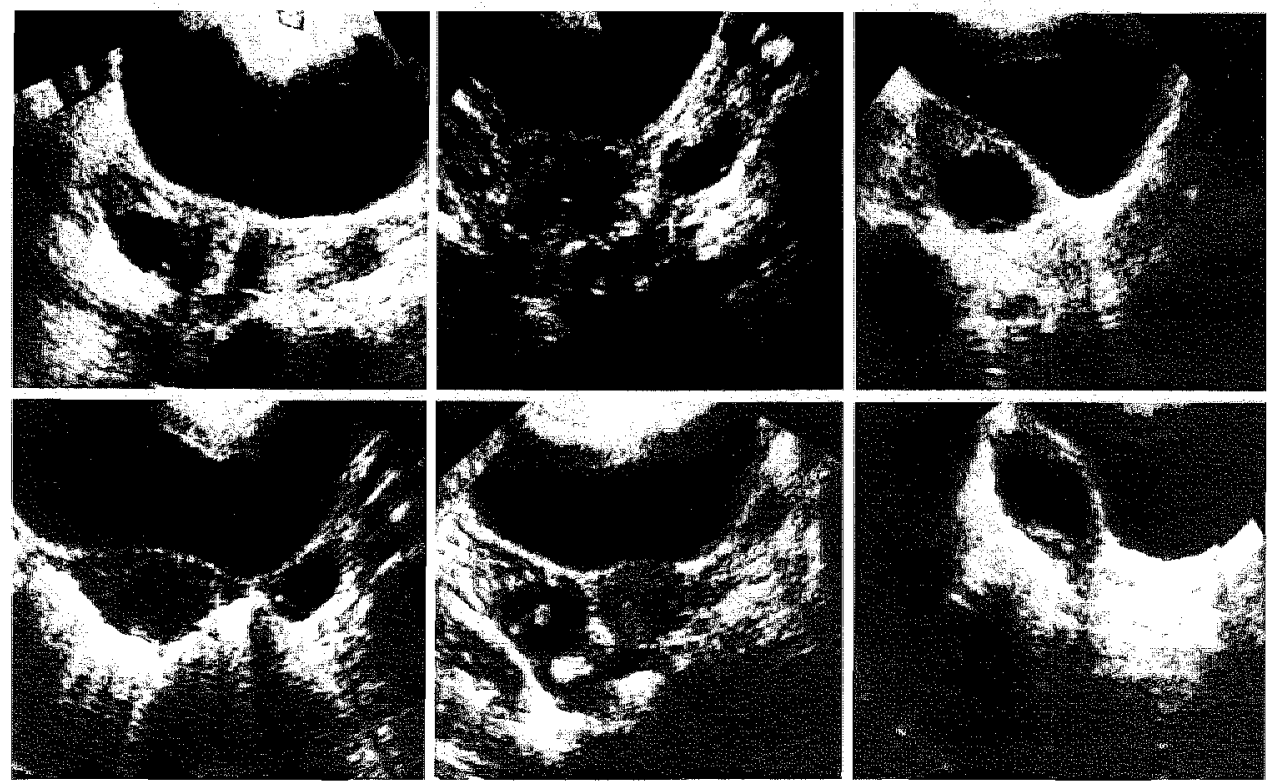

Fig. II1.3. Variation in ultrasound appearance of appendices of the follicular wall.

Upper row: an echodense point shaped structure and blisters of warious size

Lower row: large blisters, resembling loose fragments of follicular wall. 
variety of ultrasonic structures on the inner surface of the follicular wall. The most frequent finding was the small, point-shaped appearance, like that described by Hackelöer et al (1977). But allso larger fragments of irregular echodense material could incidentally be found. Although it is hazardous to interprete ultrasound images analogous to histological or anatomical pictures, the resemblance with loosened parts of the follicular wall was striking. In some cases there was an evolution within one follicle from the "cumulus" type through a blister-form into a large, irregular shaped appendix of the wall (fig. III.4.).
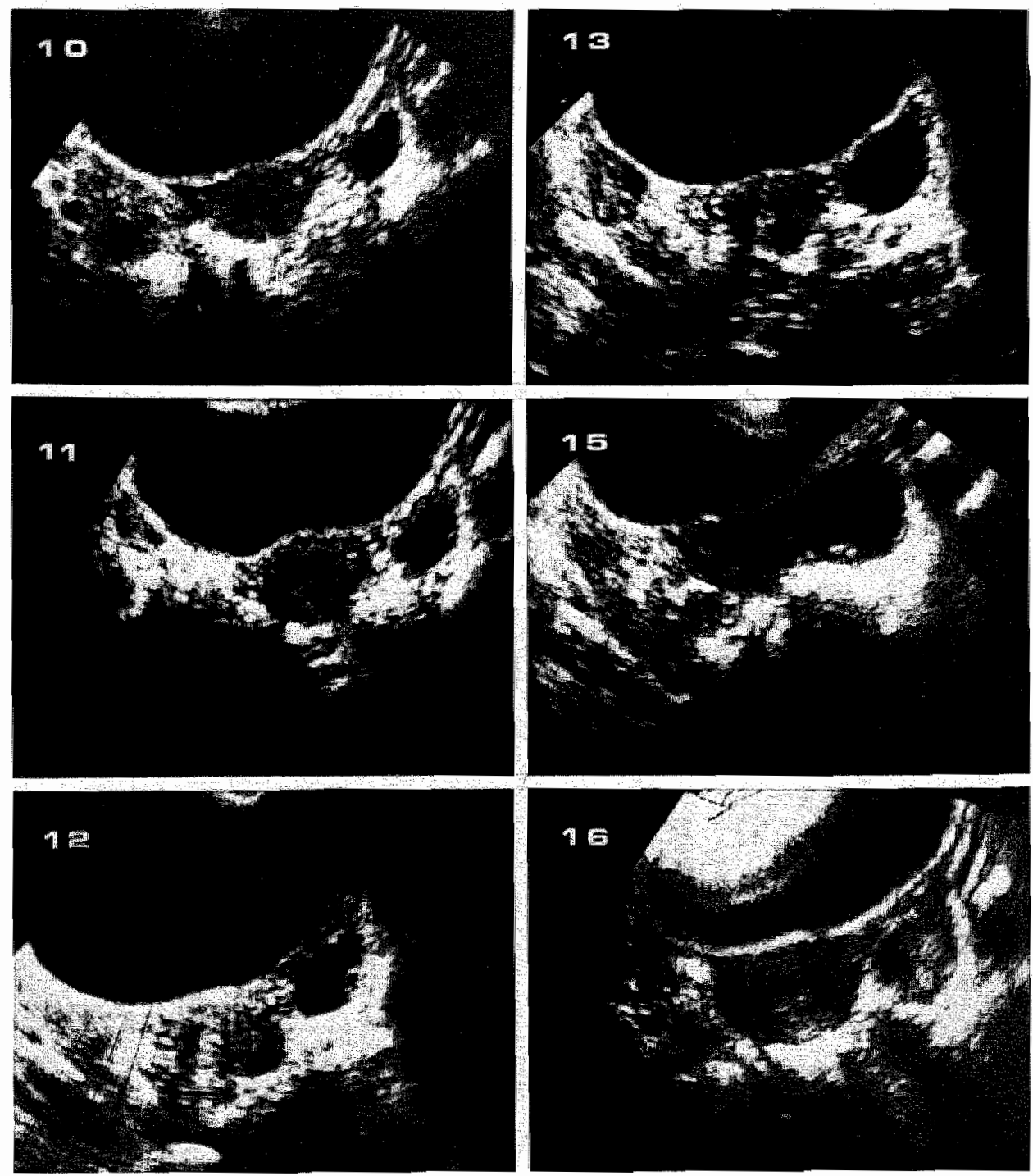

Fig. III.4. A series of transverse sections of a preovulatory follicle taken from day 10 to day 16 of the menstrual cycle, illustrating the early appearance and the evolution of a so called "cumulus oophonus". On day 11 an echodense structure, resembling the "cumulus oophorus" appears on the lateral surface of the follicle. On day 12 and 13 it transforms into a blister-like structure. On day 15 a much larger irregular structure resides on the botion of the follicle. 


\section{Definitions of Ultrasonographical Ovulation Time (UOT) and Ultrasonographical Ovulation Period (UOP)}

Technically it was possible to observe the very moment of follicle rupture by means of ultrasound (de Crespigny et al, $1981 \mathrm{~b}$ ). This could only be accomplished at the expense of very long standing ultrasound sessions, and was not feasible in a routine setting of ultrasound ovulation detection. In the present investigation the frequency of observations was increased when follicle rupture seemed to be imminent, so that the interval between the last ultrasound observation and the actual follicle rupture was as short as possible. For the management of data, two definitions were applied:

- Ultrasonographical Ovulation Period (UOP): the interval between the last observation of an intact follicle and the first observation of the ruptured state. The results of the efforts to shorten this UOP are shown in fig. III.5, presenting the distribution of UOP in the entire group of ovulatory cycles. In the subgroup of spontaneous cycles the mean UOP was $20.0 \mathrm{~h}$, the median $22.4 \mathrm{~h}$ and the range 2 to $33 \mathrm{~h}$.

- Ultrasonographical Ovulation Time (UOT): the monent, situated halfway between the two observations defining the UOP. This UOT was assumed to be the best estimate of the moment of the follicle rupture.

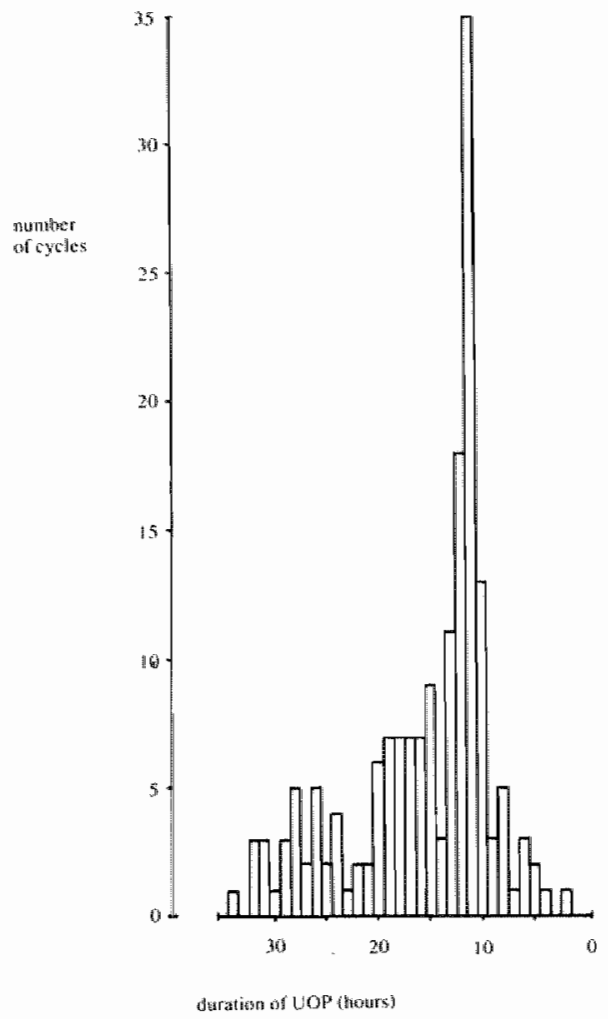

Fig. III.5. Distribution of ult rasound ovulation periods (UOP) throughout $173 \mathrm{cycles}$ 
In all calculations and considerations about time intervals between the supposed moment of ovulation and other events, the duration of the UOP was assumed to represent the maximal variation of the supposed moment of ovulation.

\subsection{The location of follicle rupture}

Beside the ultrasound appearance of the owary after follicle rupture, the location of the rupturing follicle was the most elementary information provided by serial ultrasound observations. In the present investigation larger series of cycles were observed in the same subject. The right/left distribution of ovulations could be expected to be at random. Kerin ct al (1981) found in 56 cycles ( 56 subjects) a right/left ratio of $27 / 29$.

In present material, the location of the ovulation was considered in 155 cycles ( 43 subjects). Cycles with bilateral ovulations and those, in which the post-rupture morphology could not be ascertained were excluded. None of the subjects had a history of oophorectomy, and in all of them two ovaries could be identified ultrasonographically. Of the 155 single ovulations, 65 were located on the left and 90 were located on the right side. This left/right distribution of $65 / 90$ has a probability for the normal distribution of 0.044 , so that the difference was significant. A reason for this asymmetry was not obvious.

In fig. III.6 the 22 subjects, who had four or more subsequent monofollicular cycles observed, were arranged according to the right/left ratio in a sequence of ovulations. Two conclusions could be drawn from this distribution pattern within 23 subjects:

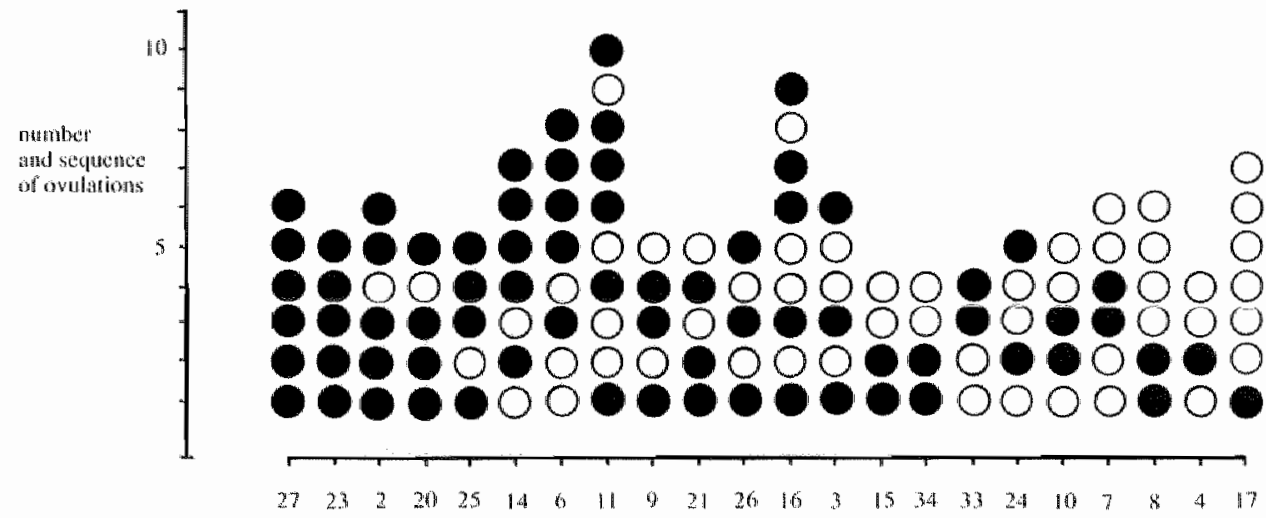

subjow's.

Fig. III.6. Sequences of single ovulations in subjects who had four or more cycles investigated. Solid circles represent right-sided, open circles left-sided ovulations.

- Except for the subjects 27 and 23 who ovulated only on the right side there was no recognizable pattern in the location of subsequent ovulations within one subject, at least for the time of the observations. This means that the location of the ovulation in one cycle had in generall no predictive value for the next cycle.

- Ten out of the 22 subjects demonstrated that it was not seldom to see the ovulation recur three to seven consecutive cycles on the same side. 
After establishing the left-right difference in location, a search was made for correlations between the side of the ovulation and other parameters. Using the Mann-Whitney U test. in spontaneous cycles no significant correlation could be found with mean preovuliatory oestradiol-17-beta $(p=0.830)$, progesterone at the moment of follicle rupture $(p=0.882)$ and progesterone in the luteal phase $(\mathrm{p}=0.184)$. 


\section{Chapter IV}

\section{Follicular growth}

Follicular growth can be observed by means of ultrasound as soon as follicular size comes within the reach of the ultrasound resolution.

The subject of follicular growth can be subdivided into a few topics: the recognition of the follicle and the onset of follicular growth: growth pattern and its variations; the ultimate preovulatory diameter and its eventual predictive value for the impending ovulation.

\subsection{Review of the literature}

\subsubsection{Detection of ovaries and follicles}

Recognition of the ovaries as areas with a fairly constant pattern of coarse, low density echoes was generally considered to be easy. Their position was mostly adjacent to the wall of the distended bladder, at a distance of 1-2 cm lateral or latero-caudal to the wterus (Hackelöer et al, 1979; Kerin et al, 1981).

Also in patients with a history of adhesions or pelvic surgery, detection was easy (O'Herlihy et al, 1980a).

Problems with the detection arose when the position was in the pouch of Douglas or cranial to the fundus uteri. These positions were not rare according to Hackeloër et al (1977). Also obesity could provide a serious difficulty (O'Herlihy et al, 1980b). Beck et al (1981) summarized the causes for failure of detection as: excentric position of the uterus; location of the ovary behind the uterus or above the uterine fundus; extreme obesity and insufficient bladder filling.

Failure rates in the detection of the ovaries were variable throughout the previous reports. In the group of O'Herlihy al (1980b) 2 out of 24 patients were excluded from real-(ime observations because of obesity. By means of compound-B-scanning detection proved to be possible in both of these patients. Garcia et al (1981) noticed unreliable observitions in one out of 23 patients. In the early part of their study, Robertson et al (1979) had two misinterpretations in 24 cycles. They attributed these fallures manly to insufficient skill. Beck et al (1981) reported that in $10 \%$ of 135 cycles at least one owary could not bo detected. Other authors made no mention of failures of this kind. However, it should be noticed that in part of the investigations, subjects were selected with respect to a normal gynaecologic history and normal pelvic examination (Hall et al, 1979; Freundll et al, 1981; Queenan et al, 1980).

Most authors agreed that a mean diameter of $10 \mathrm{~mm}$ is a threshold for detection of a follicle within the ovary. Below this threshold, cyst-like structures can eventually be recognized, but measurement would not be accurate, because the size was below the reliable resolution of the equipment (Hackeloër and Robinson, 1978; Hackeloär et al, 1979; Nitschke-Dabelstein et al, 1980; O'Herlihy et al, 1980b; Kerin ot al, 1981). Moreover, cysts of less than $10 \mathrm{~mm}$ mean diameter appeared not to be reproducible in subsequent observations. Only two investigators described the measurement of smaller follicles. Renaud 
el al (1980) measured follicles from a mean diameter of $8 \mathrm{~mm}$. Ylostalo et al $(1979,1981)$ had the experience, that, even with the real time technique, visualization and correct measurement was possible at a diameter of $5106 \mathrm{~mm}$. Referring to the limitations of diagnostic ultrasound, indicated previously (chapter II), there is at least some doubt about the reliability of these measurements.

\subsubsection{The development and recognition of dominance}

Although the recognition of the dominant follicle, i.e. the follicle that is predestined to ovulate was not specifically subject of this investigation, it requires some attention. In the literature, there were two different approaches to the development of dominance of one follicle over all others: the biosynthetic and the morphological one.

The recruitment of the cohort of oocytes, that will develop in a certain cycle, probably takes place at the end of the foregoing cycle, under the influence of the slowly rising FSH levels (Ross et al, 1970; Jones and Wentz, 1976). In vivo and in vitro studies indicated that in any stage of follicular dewelopment, the local concentrations of gonadotropins and steroid hormones predicted the future of a follicle: those with high oestrogen concentration and many FSH receptors were going to dominate and suppress the neighbouring follicles which in turn had a relatively high androgen content. Dominant, or 'pre-ovulatory' follicles. appeared to play an active role in inducing the atresia of 'non-ovulatory' follicles by suppressing FSH receptors and enhancing the androgen production by the theca cells (Payne and Runser, 1958; Goldenberg et al, 1972; Bärd et al, 1974; McNatty and Sawers, 1975; McNatty et al, 1975; Fowler et al, 1977; Bomsel-Helmreich et al, 1979; McNatty et al, 1979).

The main morphological feature indicating the dominance of certain follicles over others was the number of granulosa cells, apparently corresponding to the oestrogen-producing capacity. The number of granulosa cells was also the determinant factor for the resumption of meiosis in vitro (McNatty et al, 1979). Of the average number of 14 follicles at any moment of a cycle, only 1 or 2 had these morphologic and biosynthetic dominant properties.

In the carly follicular phase follicular size appeared to be of little importance for the recognition of the follicle which was going to ovulate in the end. Dominant biosynthetic characteristics were found in follicles as small as $\mathbb{m m}$ and as large as $15 \mathrm{~mm}$ (McNatty et al, 1979). In general, the decision as to which of the follicles was going to be dominant was made early in the follicular phase with a follicular size of 3 to $8 \mathrm{~mm}$ (McNatty et al, 1979). In the preovulatory phase of the cycle, atretic follicles eventually reached sizes, comparable to the preovulatory ones, although they usually remained smaller (Fowler et al, 1977; McNatty et al, 1979). Distinguished by the property to yield oocytes with a massive and viscous cumulus of granulosa cells, dominant follices had at laparoscopy a significantly larger diameter than atretic ones: $15.2 \pm 4.3 \mathrm{~mm}(\mathrm{SD})$ versus $9.2 \pm 2.6 \mathrm{~mm}, \mathrm{p}=0.005$ (Lopata et al, 1978). Bomsel-Helmreich et al (1979) distinguished dominant and atretic follicles by biochemical criteria. They found that the largest diameter at the onset of the oestrogen-peak was $10.5 \mathrm{~mm}$. From this moment (three days before ovulation) and from this diameter onward, the growthof biochemically dominant follicles was faster than of atretic ones. Similar indications were reported from the ultrasound inwestigation by Kerin et al (1981). They found that no follicles, other than those which subsequently ovulated, 
attained a mean diameter of more than $14 \mathrm{~mm}$. They suggested that a follicle, growing beyond this size was therefore identifiable as the one destined to undergo ovulation. The remaining follicles would fail to reach the size of $14 \mathrm{~mm}$.

Summarizing the latter two reports it was suggested that the dominant follicle could be discriminated from the atretic by a faster growth rate and by passing the limit of $14 \mathrm{~mm}$ mean diameter.

\subsection{The pattern of follicular growth during the spontaneous cycle}

The growth of the mean diameter was generally thought to be linear, at least until the day of the LH peak (O'Herlihy et al, 1980b; Hackelöer et al, 1979; Freundl et al, 1981; Kerin ef al, 1981; Robertson et al, 1979; Queenan et al, 1980). The growth rate of this diameter was 2 to $3 \mathrm{~mm} /$ day according to Renaud et al (1980) and Hackelöer and Robinson (1978). Ylöstalo et al (1979) recorded a growth rate between 1 to 4 mm daily. No significant differences in growth rate between individuals were found by Renaud et al (1980). Kerin et al (1981) reported that the mean diameter of $14 \mathrm{~mm}$ was reached on the fourth dary before ovulation in $60 \%$ of the cycles, and on day 3 or 2 before ovulation in the remainder. In combination with the wide range of preovulatory diameters $(18$ to $30 \mathrm{~mm})$ this suggests a large difference between cycles with respect to the datlly growth rate.

There was some controversy about the conduct of the follicle during and after the LH peak. Continuation of the linear growth pattern, deceleration and acceleration of growth were described. The follicle size would stay constant or even decrease before ovulation took place, according to Hackeloer et al (1979). However these authors did not define ultrasonographical signs of ovulation and therefore arranged their data according to the LH peak found in daily assays. O'Herlihy et al (1980b) and Queenan et al (1980) applied a strict definition for ultrasonographical signs of ovulation and they found no deceleration in growth rate following the $\mathbb{L} \mathbb{H}$ peak. The remaining investigators of the spontaneous cyclle have not observed the follicular growth beyond the LH peak: some supposed that the occurrence of an L.H peak proved that a cycle was ovulatory and that the temporal relationship between $\mathrm{LH}$ peak and ovulation was very constant, as established in previous, indirect investigations. Hence, they referred the follicle growth to the "moment" of the $\mathrm{LH}$ peak. Presumably, their main purpose was to evade a definition for ult rasound evidence of ovulation (Kerin et al, 1981). Neither of them however mentioned the theoretical problems in defining the moment of the LH peak, so that this procedure remains doubuful. Renaud ct al (1980) observed a linear growth until the moment of disappearance of the follicle. Occasionally an acceleration of follicular grow th was observed, immediately preceding ovulation.

Another topic was the possibility of bifollicular development, i.e. full development up to ovulation of more than one follicle in the spontancous cycle, and the relationship between dominant and subordinate follicles. Kerin et al (1981) who especially investigated the relationship between dominant and subordinate follicles, did not describe bifollicular development in their series. Howewer. Freund et al (198.1) observed the phenomenom of bifollicular development in 8 out of 20 spontaneous cycles. The dominant character of both follicles was indicated by their sizes, but also by the much higher oestradiol production in these cycles, compared to those with unifollicular development.

OHerlihy et al (1980b) reported a double follicular development in 16 out of 54 cycles. ${ }^{\mathrm{n}}$ 
13 of them, one of the follicles disappeared before reaching a diameter of $16 \mathrm{~mm}$. In 3 of them both follicles proceeded to ovulation within the same 24 hour period. Queenan et al (1980) saw 2 dominant follicles in 2 out of 23 cycles and observed ultrasound signs of ovulation on the same day in one, but with an interval of 24-48 hours in another subject.

The preovulatory follicle diameter, i.e. the diameter at the last observation before signs of rupture were seen, showed a wide variation in spontaneous cycles. The findings in previous reports are summarized in table IV. 1 . Although some reports might be less representative because of the small size of the samples (Robertson et al, 1979; Ylostalo et al, 1979; Renaud et al, 1980) the ranges in preovulatory size were similar. Exceptional were only the results of Y'löstalo et al (1979). Providing that they observed the same follicles as the remaining authors, the large aberration seems to be based on systematic differences. In the remaining reports, although ranges in ultimate sizes were similar, the mean preovulatory sizes varied widely. This could be based on true biologic variation, but could also be influenced by sample size or methodological differences. It is therefore regrettable, that the standardization of equipment setting and measuring procedures is virtually neglected in all these reports. For that reason it is not clear to what extent the differences were based upon true variations in preovulatory size.

Considering the larger series of table IV.1. the impression is gained that the mean preovulatory diameter of the follicle is about $20-23 \mathrm{~mm}$, and that the re is a range as large as $14 \mathrm{~mm}$ around this mean.

Table IV.1.

Preovulatory follicle diameters in spontaneous cycles

\begin{tabular}{|c|c|c|c|c|c|}
\hline Author & $\begin{array}{c}\text { number of } \\
\text { cycles }\end{array}$ & $\begin{array}{c}\text { number of } \\
\text { subjects }\end{array}$ & $\begin{array}{c}\text { mean } \\
\text { dianeter } \\
\text { (mm) }\end{array}$ & $\begin{array}{c}S D \\
(m m)\end{array}$ & $\begin{array}{l}\text { Range } \\
(\mathrm{mm})\end{array}$ \\
\hline O'Horlibyetal, $1980 \mathrm{~b}$ & 53 & 33 & 20 & 2 & $17-24$ \\
\hline Karinetal, 1981 & 56 & 56 & 23 & - & $18-30$ \\
\hline Robertson ed al, 1979 & 12 & 11 & 25 & $\cdots$ & $-\cdots$ \\
\hline Queenan et al 1,1980 & 23 & 18 & 21.1 & 3.5 & $14-28$ \\
\hline Renatid et at 1980 & 10 & 10 & 27 & 3 & $\cdots$ \\
\hline Hackelör/Robinson, 1978 & 28 & 28 & 19.7 & $-\cdots$ & $18-24$ \\
\hline Ylostaloelal, 1979 & 7 & 7 & 12.8 & 1.4 & $10.9-16$ \\
\hline Smithet al, 1980 & 20 & 13 & 25.5 & - & ansom \\
\hline
\end{tabular}

$(-$ unknown $)$

\subsubsection{The pattern of follicle growth after clomiphene citrate}

Except in the recent reports by $\mathrm{O}^{\prime} \mathrm{Herlithy}$ et al (1982) and Smith et al (1980) concerning 28 cycles in 17 patients and 20 cycles in 11 patients, no large series of patients with this medication were investigated with respect to the follicular growth pattern. Clomiphene-stimulated follicles developed normally and showed no morphological differences, compared to spontaneously developing ones ( $\mathrm{O}^{\prime} \mathrm{Herlihy}$ et al, 1982). The 
preovulatory diameters were not significantly different from those in spontaneous cycles (Smith et al; 1980; O'Herlihy et al, 1982). Only Youstalo et al (1979) reported a significant difference of the preovulatory follicle diameter between spontaneous $(12.8 \mathrm{~mm})$ and clomiphene induced ( $15.4 \mathrm{~mm}$ ) follicles ( 12 cycles). As mentioned before, the discrepancy between their results and those of all remaining authors was so obvious that there can be serious doubt about the reliability of their method.

O'Herlihy et al (1982) found a significantly higher growth rate in the last 4 days preceding ovulation in clomiphene induced cycles, compaired with spontaneous cycles. As far as follicular growth was concerned, this was in their view the only sign of stimulation.

There was no agreement about the incidence of bifollicular development in clomiphene induced cycles. The incidence of bifollicular development within series of clomiphene induced cycles diverged from 25 to $40 \%$ (O'Herlihy et al, 1982; Smith et al, 1980; Queenan et $\mathrm{al}_{2}, 1980$ ). This incidence did not clearly differ from the 8 in $20 \mathrm{cycles}_{\text {, }}$ found by Freundl et al (1980) in spontaneous cycles. However, O'Herlihy et al (1982) concluded from the comparison between their own series of spontaneous and induced cycles, that bifollicular development was more frequent in induced cycles.

\subsection{Follicular growth pattern in the present series}

\subsubsection{Methods}

In the present investigation follicular growth was observed with the main purpose of revealing and describing the pattern of growth just before follicular rupture, i.e. the growth of the Graafian follicle. An example of follicle growth is presented in a series of pictures, taken in one cycle (figure IV.1.). Before discussing the results, some methodologic details of this study should be established.

The number of growth curves considered in this chapter was somewhat smaller than could be expected from the total of cycles in the investigation. Cycles were excluded from this part of the study for two reasons. Ultrasound investigations started on that day of the cycle which was estimated to be approximately five days before the ovulation. In some instances this estimation was wrong and the start of the observations was too late. Cycles with less than three ultrasound obserwations were deleted for the calculation of mean growth curves and growth rates. This concerned 8 spontaneous and 4 anti-oestrogen stimulated cycles. Another 13 cycles were excluded from the evaluation of growth curves and growth rates because they revealed possible cycle abnormalities, discussed in chapter V1. Thus, 92 out of the 111 spontaneous and 34 out of the 40 antioestrogen induced cycles remained in 27 and 16 subjects respectively, which comprised 645 and 192 follicle measurements. In cycles with bifollicular development, only the data of the largest of the follicles were considered. This concerned 2 out of 93 spontaneous and 8 out of 34 anti-oestrogen induced cycles.

The general remark on the unequal distribution of cycles per subject (chapter II) applied also specifically to the consideration of follicle growth in the present chapter. The distributions of the number of cycles/subject in the cycles contributing to the growth curves were essentially the same as those presented in chapter $\|$ I, fig. II. I. Hence, at disproportionate influence of subjects with large series of cycles was present. It was difficult to estimate to what extent the growth curves were representative for the population. 

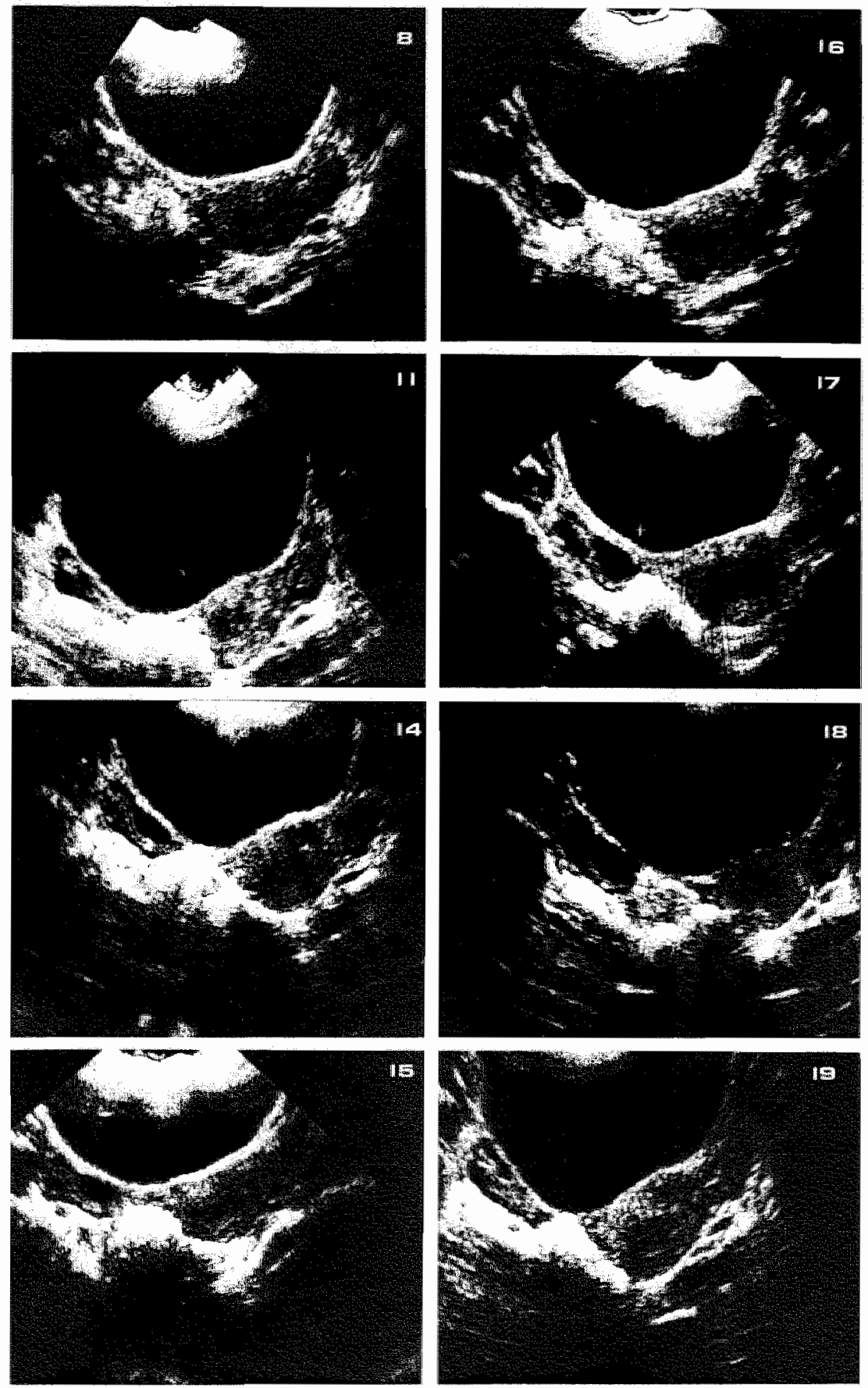

Fig. IV.1. Serial pictures in the transwerse section of the growth and rupture of at follicle in the left ovary.

Pictures were taken during a spontaneous cycle in a healthy volunteer. White numerals in the right upper corner indicate the day of the cycle. 
In earlier reports, no useful procedures were found to describe general characteristics of follicular growth in groups of cycles. The following two parameters were chosen and will be introduced briefly. All the measurements were synchronized acoording to the ultrasonographically estimated moment of ovulation (UOT). This moment is "hour zero" in the graphical displays and in the calculations.

1. The "mean growth curve" for groups of cycles.

By randomization analysis (Zerbe, 1979) of all follicle sizes (y) of a group and the time of the measurements $(x)$, a plot of the mean growth curve ( \pm 1 Standard Deviation) was provided. By variance analysis the differences in mean levels of growth curves of distinguished groups could be tested for significance in any chosen time period.

2. A "growth rate" was calculated for each cycle. As will be shown in this chapter, the mean growth curves appeared linear, at least during the last 3 to 4 days before UOT. The "growth rate" can be defined as a normalized average growth coefficient ( $\mathrm{mm} / \mathrm{day}$ ) of the subsequent measurements in a cycle. The "growth rate" (B) was obtained by using the formula for the slope of the regression line in linear regression analysis:

$$
B=\frac{\sum\left(\left(x_{i}-\bar{x}\right)\left(y_{i}-\bar{y}\right)\right)}{\sum\left(x_{i}-\bar{x}\right)^{2}}
$$

where $x$ and $y$ represent the time of the measurement with respect to UOT and the mean follicular diameter and $\bar{x}$ and $\bar{y}$ the mean of the times of the measurements and the mean of the mean follicular diameters in a cycle. As mentioned before, cycles with less than three measurements were excluded.

\subsubsection{Results}

\subsubsection{Follicular growth pattern}

Mean growth curves were calculated for several groups. The significance of differences between mean growth curves, indicated by the p-values in this section, was determined by a test for equality of mean levels of response, described by Zerbe (1979).

Fig. IV.2. compares the mean grow th curves of 43 cycles in 8 volunteers and 50 spontancous cycles in 19 patients. The mean curves were not different $(p=0.43)$.

In both groups, follicular growth appeared to be linear in the last 72 hours before follicle rupture. Before this moment there were interruptions of the linear pattern. Presumably this irregularity was an artifact. The irregularities occur at 24 hour distances and coincide with accunnulations of measurements in a time period with relatively few observations. These accumulations originated from the concentration of observations during the daytime. The number of measurements increased towards UOT, so that the validity of the curves was supposed to be optimal only in the last 72 hours. 


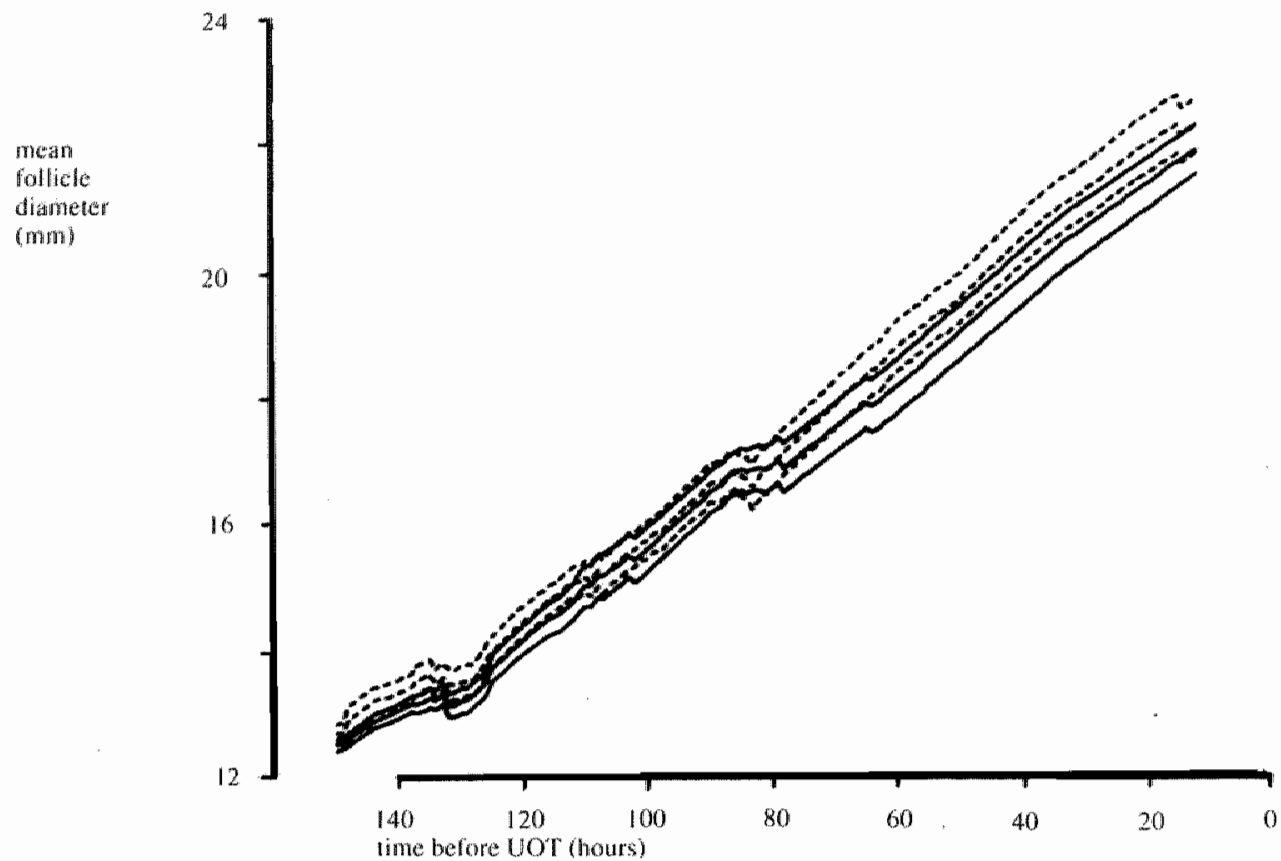

Fig. IV.2. Follicle growth curves (mean \pm SD) in 43 cycles in 8 healthy volunteers (solid lines) and 50 spontaneous cycles in 19 patients (donted lines)

The entire group of 93 spontaneous cycles was subdivided with respect to the location of the follicle: left or right sided (fig. IV.3.). The ultimate preovulatory size was larger and the growth curve was at a higher level in the left sided follicles (solid lines). The left/right difference in the mean growth curves was significant $(p=0.008)$.

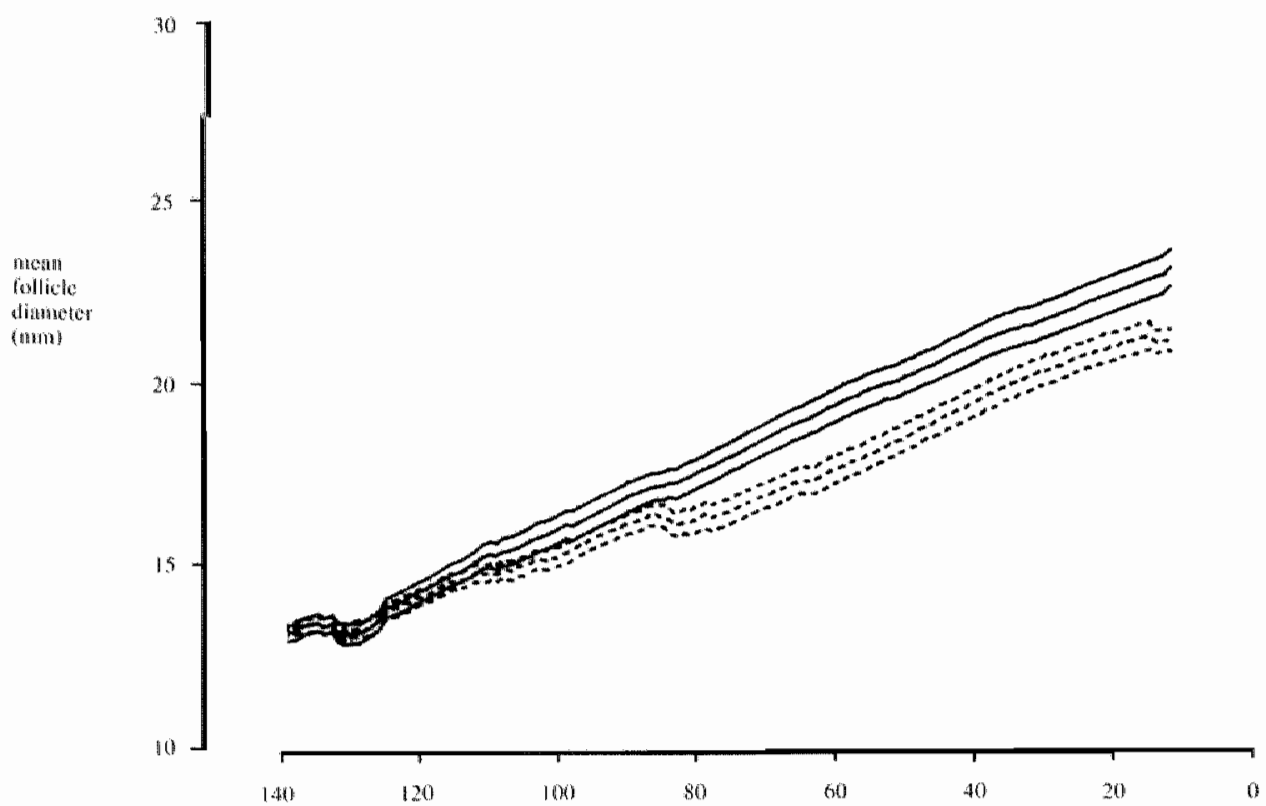

Fig. IV.3. Follicle growth curves (meàn \pm ISD) of left sided (solid line) and right sided (dotted line) follicles in spontaneous cycles 
Follicular growth patterns in 93 spontaneous and 34 anti-oestrogen induced cycles were compared in fig. IV.4.

Figure IV. 4 B shows the mean growth curves for the entire groups. Both groups exhibited a limear growth pattern during the last 85 hours before UOT. The difference between the curves was significant $(p \times 0.001)$ between 90 and 0 hours. This difference already existed in the segment 120 to 90 hours before UOT $(\mathrm{p}=0.001)$.
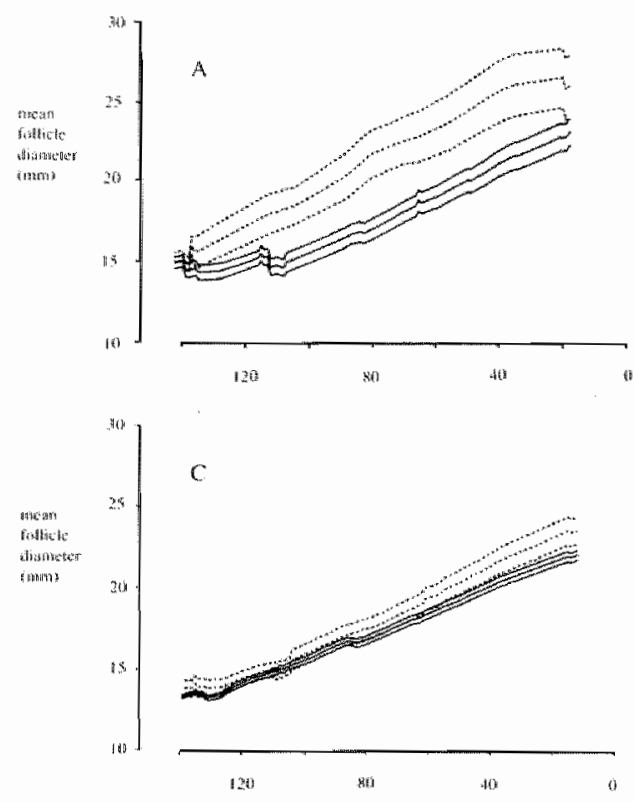

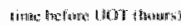
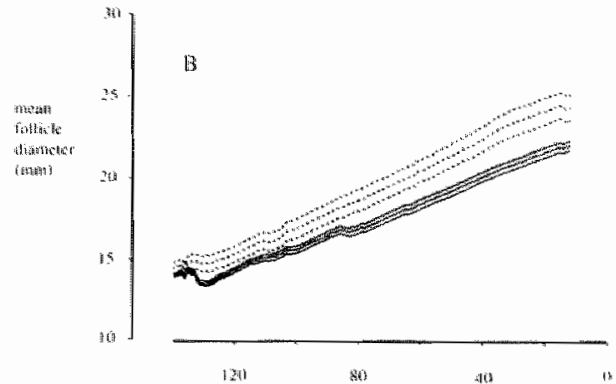

Fig. IV.4. Follicular growth curves for comparison of the follicular growth pattern in spontancous and antioestrogen induced cycles

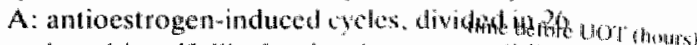
cycles with unifollicular development (selial) and 8 cycles with bifollicular development (dotted lines)

B: spontaneots cycles $(n=93$, solid lines) and anti-oestrogen induced cycles $(n=34$, dotted lines)

C: the growth curves in spontaneous (solid lines) and ant t-oestrogen induced cycles (dotted lines) after removal of the bifollicular cycles

Further evaluation of both groups indicated that the differences were mainly caused by the phenomenon of bifollicular development. In fig. IV.A A the induced group is subdivided in 26 unifollicular (solid) and 8 multifollicular cycles (donted). The dilicrence was significan! $(p \cdot 0.015)$. In both groups the slope of the mean growth curve appeared similar, but in "bifollicular cycles" growth started earlier.

After subtraction of all bifollicular cycles (fig. IV.4C), the difference between the mean growth curves in induced and spontaneous cycles was still present, but no longer significant $(\mathrm{p}=0.11)$.

The conclusion can be drawn that the mean follicular growth curve did not differ between spontaneous and induced cycles, unless there was bifollicular development.

Some othet remarks have to be made on the subject of bifollicular development.

The incidence of bifollicular or trifollicular development was 2 in 93 spontaneous and 8 in 34 antioestrogen induced cycles. This incidence was too low to allow general conclusions about the pattern of multifollicular devellopment. The following observations appeared to be useful: The bifollicular cycles in the anti-oestrogen induced group were noticed in three out of 8 individuals. To a certain degree there seemed to be an individual tendency towards multifollicular development. There were indications that the cxtent of multifollicular development in these persons was dose-dependent. Together with the finding that follicular 
sizes in bifollicular dewelopment were increased, this suggested that bifollicular development may be a sign of hyperstimulation.

The experience in the present series confirmed that in general afollicle can be expected to grow out to the preovulatory size of $20 \mathrm{~mm}$ or more when it has passed the limit of $14-16$ $\mathrm{mm}$ (Kerin et al, 1981, O'Herlihy et al, 1980b). This limit seemed to be also valid in the bior trifollicular development. However the outgrowth to preovulatory diameters did not guarantee in all cases, that a follicle would rupture. In two instances it was observed that the second of a pair of follicles did not rupture together with its accompanying follicle. Instead, a fast outgrowth was observed, similar to that described in chapter VI for single follicles.

For methodological reasons we have omitted measurement of the second and third follicles in a cycle systematically. First, the experience was that the measurement of accompanying follicles could be hampered because their shape could become irregular, apparently by the pressure of adjacent follicles. This was suspected to cause important inaccurary of measurements. Secondly, the accurate measurement of all follicles in a multifollicular situation , especially before it had become clear which of the follicles was dominant, turned out to be so time consuming, that it was hardly bearable for the subject concerned.

\section{The growth rate per cycle}

The growth rates for different groups of cycles are summarized in table IV.2.

The mean growth rate in spontaneous cycles (1.99 mm/day) was much lower than in antioestrogen induced cycles $(2.32 \mathrm{~mm} / \mathrm{day})$. This difference was however not statistically significant ( $p=0.393$, Mann-Whitney U test). The variation in growth rate per cycle was very wide for both types.

Table IV 2.

Growth rates per cycle for different types of cycles

\begin{tabular}{|c|c|c|c|c|}
\hline \multirow[t]{2}{*}{$\begin{array}{l}\text { rype } \\
\text { of yeles }\end{array}$} & \multirow[t]{2}{*}{$\begin{array}{c}\text { number of } \\
\text { cycies }\end{array}$} & \multicolumn{2}{|c|}{$\begin{array}{c}\text { growth rate percycle } \\
(\text { mmlday })\end{array}$} & \multirow[t]{2}{*}{$\begin{array}{c}\text { Mann-Whitney' } \\
\text { Utest }\end{array}$} \\
\hline & & mean & range & \\
\hline spontaneous & 93 & 1.99 & $0.70-4.10$ & \multirow{3}{*}{$p=0.393$} \\
\hline anti-oestrogen & 34 & 2.32 & $0.33-4.40$ & \\
\hline induced & & & & \\
\hline \multicolumn{5}{|l|}{ spontaneous } \\
\hline left-sided & 43 & 2.08 & $0.73-3.95$ & \multirow{2}{*}{$p=0.824$} \\
\hline right-sinled & 50 & 2.02 & $0.70-4.10$ & \\
\hline \multicolumn{5}{|l|}{ spontaneous } \\
\hline volunteers & 43 & 1.89 & $0.70-3.36$ & \multirow{2}{*}{$p=0.114$} \\
\hline patients & 50 & 2.07 & $0.73-4.10$ & \\
\hline
\end{tabular}


Mean growth rates in lef- and right- sided ovulations were almost identical $(2.08$ and 2.02 $\mathrm{mm} /$ day), although the mean growth curves were significantly different, apparently on account of a slower start of growth in right-sided follicles in the period between 120 and 80 hours before UOT (fig. IV.3.).

Comparing the spontaneous cycles in volunteers and patients these relations were the reverse. Mean growth curves did not differ significantly ( $p=0.43$, Zerbe, 1979) but the mean growth rate was slower in volunteers, although not to a significant level (1.89 vs 2.07 $\mathrm{mm} / \mathrm{day} ; \mathrm{p}=0.114$, Manm-Whitney $\mathrm{U}$ test). Comparing the mean growth rate of approximately $2 \mathrm{~mm} /$ day with the results of the calibration experiments, especially experiment 1 (chapter 2.6.), a preliminary conclusion can be drawn about the optimal observation interval. For a follicle of 20 mm mean diameter, the error in the calibration experiment was $0.5 \pm 0.45 \mathrm{~mm}$ (mean \pm SD). Supposing that the calibration experiment is representative for the in viwo situation, the mean growth rate does not exceed the error ( 2 SD) within 12 hours. Hence, an observation frequency of more than 2 times daily seems to be useless to obtain information about follicle growth. Of course, repeated measurements can be of value in order to improve the accuracy of an observation.

\subsubsection{The onset of the preovulatory phase in follicular growth}

In the observation of small size follicles (10 to $12 \mathrm{~mm}$ diameter) two specific problems were met. First, the sizes were small in relation to the transversal resolution of the present ultrasound equipment, which means that the accuracy of measurements should not be overestimated. Secondly, the experience was that in the stage of development in which the follicles are of small size, there nearly always are multiple follicles. From a prospective point of view, all these small structures should be measured. Apart from the time consuming character of this procedure, it proved often to be impossible to distinguish one follicle from another by the lack of landmarks in the ovaries. Therefore observations of growth in this range of follicle sizes had only a qualitative character.

Although the present investigation concentrated on the events in the preovulatory phase, there were some observations on follicle development before this phase, which could be important for the understanding of the physiology.

The observations originated from cycles, in which ultrasound investigations started carlier than the fifth day before folicle rupture, and from those which were anovulatory.

In the period preceding the fast growth of the last 5 days before follicle rupture, and in some longstanding observations of anovulatory cycles it was common to see many small follicles in the ovary. Out of this group, an individual follicle showed a tendency 10 grow out to a larger size. This growth often ceased at about $12 \mathrm{~mm}$ mean diameter. The size then remained constant or even diminished. After one or two days another follicle of the group took over the tendency to grow. This process sometimes repeated itself several times until a follicle proceeded to grow to a preovulatory size and ruptured. The impression was that, once a follicle had exceeded the diameter of 12 to $14 \mathrm{~mm}$, the growth continucd to larger diameters. In four anovulatory cycles not further incorporated in the present series, (3) subjects), the described process of rise and fall of small follicles was seen to continue antil an anovulatory bleeding intervened.

In 10 cycles in 8 subjects, follicular growth was observed and follicles were measured for longer than 6 days before follicle rupture. The growth curves of the follicles that finally 


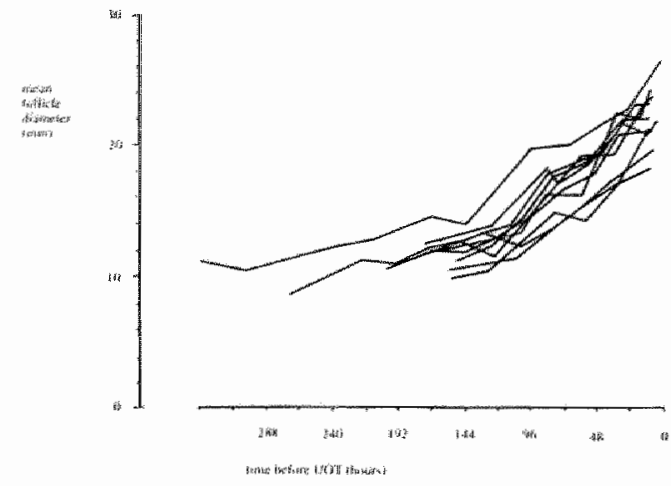

Fig. IV.5. Growth curves in 10 cycles $(8$ subjectsy, observed for more than six days

ruptured are shown in fig. IV.5. The growth pattern of follicles was to some extent uniform. At the level of 10 to $13 \mathrm{~mm}$. mean diameter, there was only minimal growth. The transition to the faster preovulatory growth was at 144 to $96 \mathrm{~h}$ ( 6 to 4 days) before follicle rupture. Although the growth curves of fig. IV.5. were suggestive and were congraent to the observers experiences throughout the study, the significance of the changes in follicular growth between day 6 and day 4 before UOT could not be proven. The number of observations in this time period was too low and variation was too wide to allow multiple regression analysis.

\subsubsection{The ultimate preovulatory diameters}

As stated in chapter IV.1.3., in previous reports a wide variation was found in the diameter before the follicle ruptured. Although a part of the variation could possibly be explained from the diversity in methods and equipment, the general impression was that on account of this variation, the preovulatory follicular size was not useful as a tool for the prediction of spontaneous ovulation.

In the present study, this wide variation in preovulatory diameters was confirmed (fig. IV.6.). Theoretically, a part of the variation could be based upon differences in observation interwal. There was however a poor linear correlation between preovulatory follicle size and duration of UOP: $r=0.231 ; p=0.076$ (Pearsons two tailed test). A non-linear correlation was not likely in view of the configuration of the scattergram.

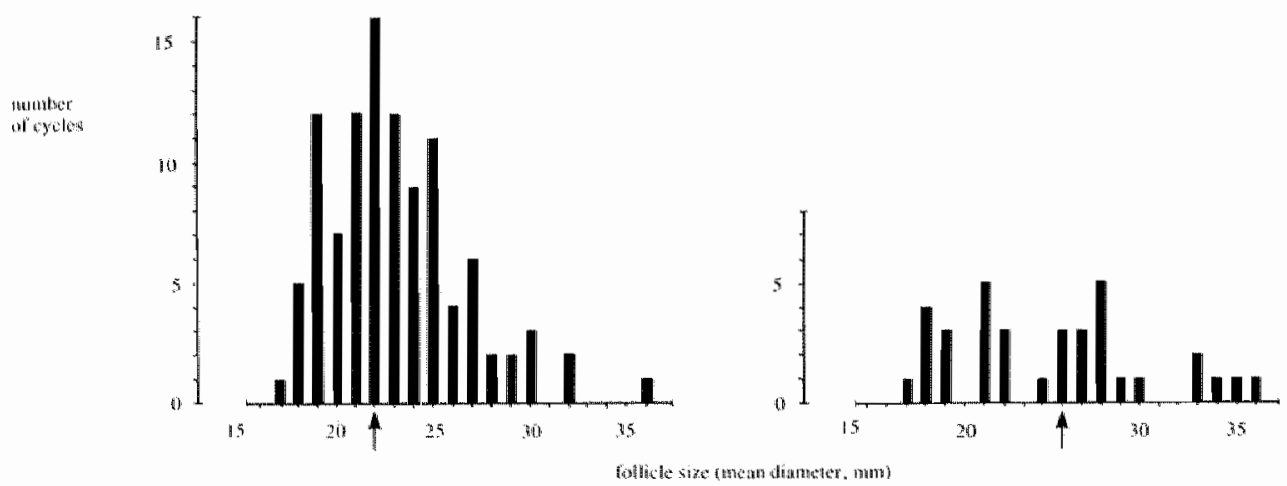

Fig. IV.6. Distributions of ultimate preovulatory follicle diameters. The left graph represents 105 spontaneous, the right graph 35 anti-oestrogen induced cycles. Arrows indicate the median values 


\subsubsection{Within subject variation in follicular growth}

The impressive variation of ultimate preovulatory diameters in the entire population appeared to exclude the prediction of the time of avulation by measuring merely the follicular size.

In the course of the present study it became clear that there was to some extent a specific pattern of follicular growth in each individual. To illustrate this, subsequent follicle growth curves in two subjects are shown in fig. IV.7. In the left subject, the variation in growth in five subsequent spontaneous cycles was limited, while in the right subject the subsequent growth curves in seven cycles were completely different. At first glance, this suggested a specific growth conduct in these two individuals. An effort was made to characterize the pattern of growth in subsequent cycles in the same subject by the following criteria:

- the range of the mean preovulatory diameters per subject

- the mean growth rate per subject.

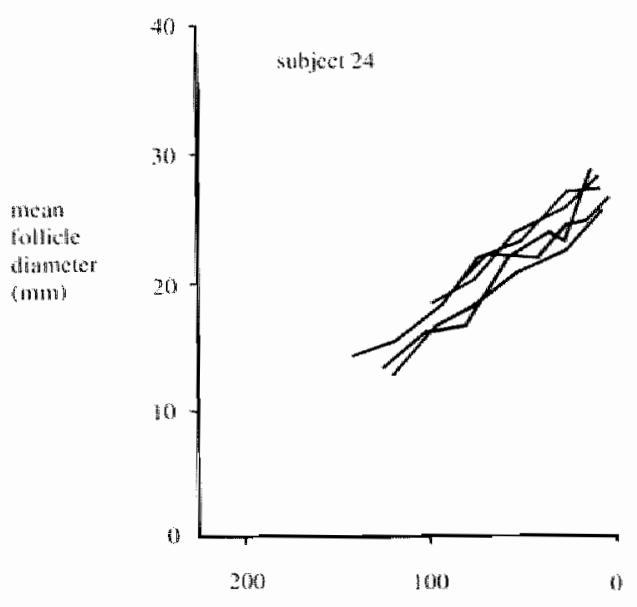

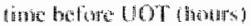

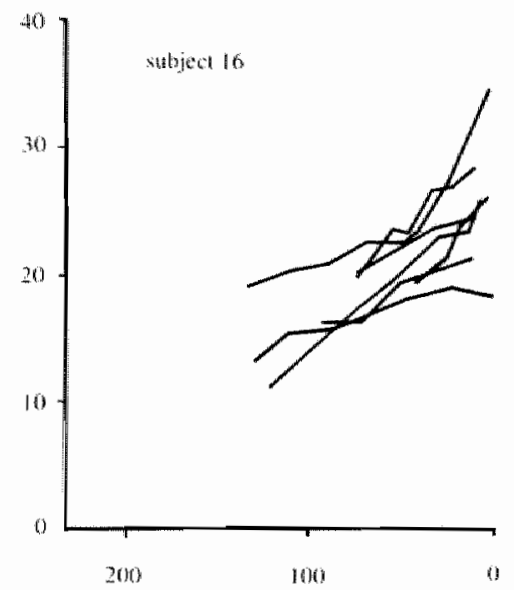

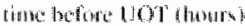

Fig. IV.7. Illustration of individual wariation in follicular growth pattern. Subject 24 showed a very constant growth pattern in subsequent cycles. In subject 16 an exureme variation was found.

The range of preovulatory diameters was only considered in subjects with at least three cycles observed. These ranges are shown in fig. IV.8. Each individual appeared to have a specific range of preovulatory diameters, which was much smaller than the range of the entire population. The composition of individual ranges in the small anti-oestrogen induced group appeared not to be different from the larger spontaneous group.

Furthermore, there was no evident relationship between the extent of the range and the preovulatory size. In other words, it was not apparent that subjects with large preovulatory diameters exhibited proportionally larger ranges. 
subject

number

Gati-bestrogen

induced

cycles)

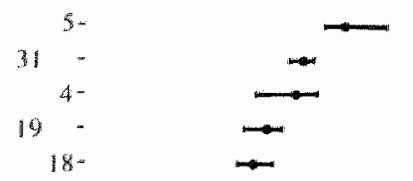

subject

montron:

(spontancous

cyelles)

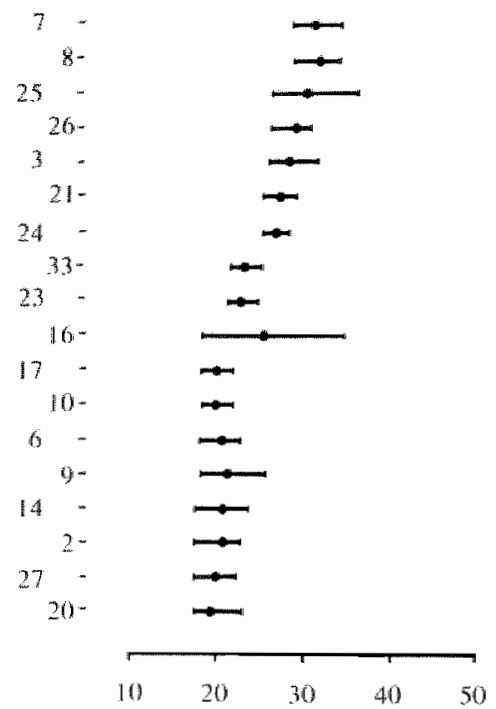

mean fullicle diancte $(\mathrm{mm})$
Fig. IV 8. The individual variation in ultimate preowulatory diameters in subjects who had at least 3 cycles observed. Range and mean of the preovulatory diameters in each subject are indicated.

The histogram of fig. IV.9. summarizes the inner subject ranges for spontaneous and induced cycles. It shows that in 9 out of 23 subjects the range was less than $4 \mathrm{~mm}$. In 9 subjects it was 4 to $6 \mathrm{~mm}$, and in the remaining 5 the variation was very large (6 to $16 \mathrm{~mm}$ ).

Variation in preovulatory follicle diameters can originate from four sources. First of all, there can be true differences in follicle size before rupture. The remaining three are potential sources of error: the error in the measurements; differences between cycles, based upon different observation intervals (UOP); and the fact that the moment of follicle rupture in a particular cycle is not exactly known but estimated by the UOT. To what extent these error sources can contribute to differences in preovulatory diameters can be tentatively cstimated.

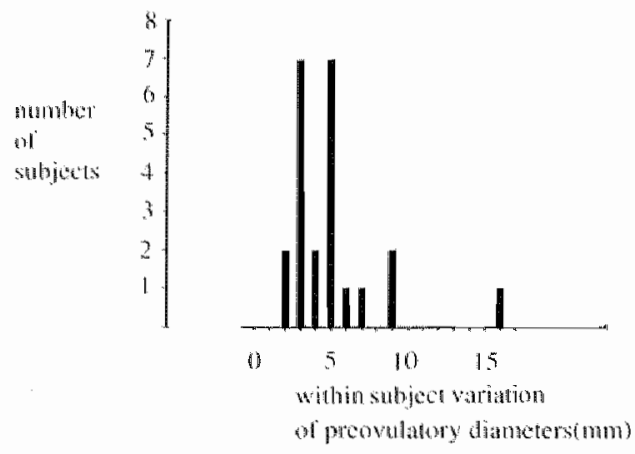

Fig. IV 9. Distribution of the within subject variation (ranges) of ultimate preovulatory diameters in the subjects of fig. IV.8. 
For calculating the error in the measurements, the in vitro experiment 1 (chapter 11.6.$)$ comparing the weighed volume of a phantom and the calculated volume by means of compound B mode scan, is supposed to be representative for the in vivo situation. The relative error for the mean diameter in this experiment was $2.55 \pm 2.26 \%$ (mean $\pm \mathrm{SD}$ ). The extent of the error was independent of the actual size. For a follicle of 20 mm mean diameter, this would account for an absolute error of $0.5 \pm 0.45 \mathrm{~mm}$ (mean \pm SD); the difference between two follicles would be $0.9 \mathrm{~mm}$ within $2 \mathrm{SD}$.

The differences in observation intervals between cycles can be taken from the distribution of UOP (chapter III.4.). In spontaneous cycles the UOP was $20.0 \pm 6.2$ hours (mean \pm $\mathrm{SD}$ ). For two follicles, growing at the mean growth rate of $2.0 \mathrm{~mm} / \mathrm{day}$, the difference in diameter, based upon the difference in observation interval, could be approximately $1 \mathrm{~mm}$ within $2 \mathrm{SD}$.

For the evaluation of the extent of the error introduced by the estimation of the moment of follicle rupture (UOT), it is necessary to suppose that follicle ruptures are randomly distributed over the 24-hour period. Furthermore we consider a group of cycles in which the observation interval is uniformly 20 hours, instead of $20.0 \pm 6.2$ hours (mean $\pm S D$ ). In this group of cycles, the distribution pattern of follicle ruptures over the 20 hour observation period would resemble a rectangular distribution with a mean of 10 hours and a standard deviation of 5.8 hours. Supposing that the growth rate is $2 \mathrm{~mm} / \mathrm{dlay}$, the error in the measurement based upon the estimation of UOT would be approximately $1 \mathrm{~mm}$ within $2 \mathrm{SD}$.

Hence it can be tentatively concluded that within 2 standard deviations the contribution of these methodological sources of error to the difference between preovulatory diameters of follicles with a size of about $20 \mathrm{~mm}$ is approximately $3 \mathrm{~mm}$. In 6 out of the 8 subjects exhibiting a mean preovulatory diameter between 19 and $22 \mathrm{~mm}$ (fig. IV.9.) the ramge of diameters was wider than $3 \mathrm{~mm}$, indicating a true within-subject difference in preovulatory follicle size.

The mean growth rate per cycle was obtanned by the method described in chapter IV.2.1. An individual mean growth rate, i.e. the mean of the growth rates in a series of cycles in one subject, was only calculated in subjects with at least three cycles and with an observation length of at least four days per cycle. Nine subjects fulfilled these criteria. The number of cycles per subject was 4 to 7 , the total mumber of cycles 43 . Fig. IV.10. shows the relationship between individual mean growth rate and individual mean preovulatory diameter. There was a tendency, although not significant, for larger mean growth rates to occur in subjects with large preovulatory diameters. This suggests that differences in ultimate preovulatory size originated mainly from differences in growth rate, while the duration of the preovulatory growth phase seemed rather constant, confirming the impression gained in chapter 4.2.2.2.

\subsubsection{Predictability of the day of follicle rupture}

As mentioned in chapter III, the predicting value of the so called "cumulus oophorus" can be neglected. In this study no other specific indicator of the impending follicle rupture was encountered.

Hence, only two other potentially predictive parameters for the day of follicle rupture remained in the uttrasound observation of follicle growth: ultimate follicle size and follicle growth pattern. The wide range of preovulatory diameters precluded the use of follicular size for prediction of the ovulation according to Queenan et al (1980), O"Herlihy et al 

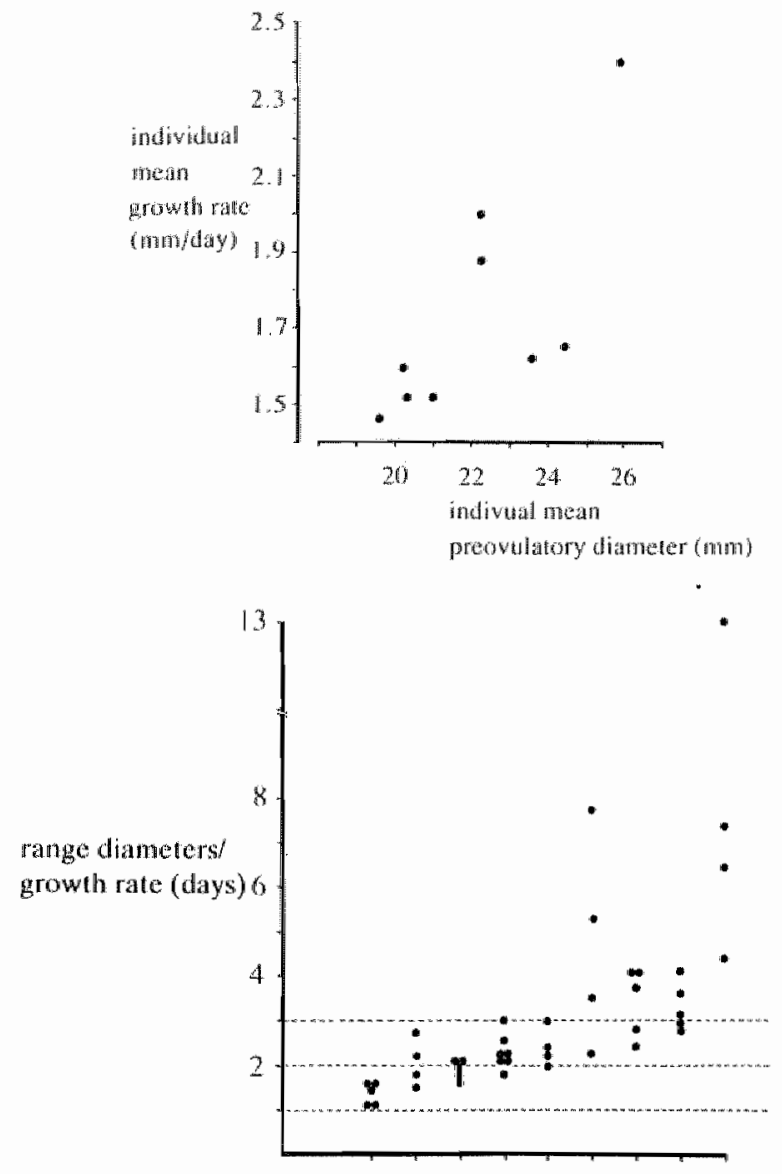

$242621 \quad 172320 \quad 3 \quad 2 \quad 16$ subject number
Fig. IV. 10. The relationship between individual mean growt hate and individual mean preovulatory diameter in 9 subjects who had at loast three cycles investigated for at least 4 days per cycle

Fig. IV.11. The coefficients of individual range of preovulatory diameter / growth rate per cycle, arranged according to subject. Subjects are those, mentioned in chapter IV.2.2.4. and identical to those in fig. IV. 10. Total of 43 cycles, 9 subjects.

(1980a, b) and Garcia et al (1981). The report of Bryce et al (1982), who found retrospectively a good predictability of the ovulation $(1.4 \pm 1.2$ days when a follicle diameter of $20 \mathrm{~mm}$ was reached), secms to be defective in methodological aspects: a small sample (14 cycles, 14 subjects), an inadequate definition of follicle size (hargest diameter) and a peculiar definition of the day of ovulation (subtracting 1 day from the day of follicle rupture). The possibility that each patient had her own pattern of follicular development was suggested by Garcia of al (1981) but this possibility has not been investigated in a longitudinal study up to now.

In the present study, follicle size was of major interest. Moreover series of cycles in the same subject were investigated. An effort was made to test the usefulness of follicle size for the prediction of the ovulation, based upon the supposed relatively constant pattern of follicle growth within one subject.

The description of predictability was problematic. Within the limits of the present data the hypothesis was necessary that the inner subject variation was sufficiently established by retrospective investigation of three to seven subsequent cycles per subject. Furthermore, predictability had to be defined. A good proposal seemed to be: the time span within which 
the follicle rupture can be predicted. The predictability, expressed as days, was supposed to be at best equal to the coefficient of the range of preovulatory follicle sizes $(\mathrm{mm})$ divided by the growth rate of the follicle ( $\mathrm{mm} / \mathrm{day}$ ). In practice this means that, when the range of previous preovulatory sizes was $3 \mathrm{~mm}$ and the growth rate was $1.5 \mathrm{~mm}$ /day, the highest precision of a prediction was plus or minus 1 day. Of course this definition can be challenged but it appeared to fit optimally for the retrospective analysis of the present data.

The definition was only applied to those subjects in whom a sufficient number of cycles was observed for a sufficient time in order to calculate an individual mean growth rate, i.e. the group of nine subjects, introduced earlier (chapter IV 2.2.4.).

For each of the 43 cycles in these 9 individuals the coefficients between the individual range of preovulatory diameters and the mean growth rate per cycle was calculated. A composite picture of these coefficients, arranged per subject is shown in fig. IV. I1. In 5 of the 9 subjects there were interindividual, rather than intercycle differences. Assuming that a coefficient of 3 or less indicates a reasonable predictability ( $\pm 1 / 2$ day), this predictability on follicle size alone was achieved in 5 out of 9 subjects. In the remaining, prediction of the day of ovulation by mere follicle size was illusory. A prospective study will however be necessary to evaluate the usefulness of this predictability. Especially, the possibility of improvement of the prediction in successive cycles in the same subject deserves attention.

Apart from the follicle size at a certain moment of the cycle, the follicle growth pattern could be a potential tool for the prediction of the day of ovulation. More specifically, the tendency of follicles to exhibit a constant preovulatory growth phase, starting from a diameter of about $14 \mathrm{~mm}$ and lasting 4 to 5 days irrespective of the ultimate diameter, could be of help in the prediction. The present data are not sufficient to prove the general validity of this hypothesis. Nevertheless, the need for a method to manage the timing of homologeous artificial insemination or planned cohabitation in the present group of patients seemed to justify a trial of ovulation prediction, using the combination of the former two principles as hypotheses: First that a follicle would in general take about five days to grow from $14 \mathrm{~mm}$ to its ultimate size; secondly that the preovulatory size could be expected to be in the vicinity of the values in previous cycles in the same subject. To evaluate the result of this approach, the intervals between the first insemination and the time of UOT were retrospectively compiled in the distributions of fig. IV.12. In a group of 67 spontancous cycles (2l subjects), $58 \%$ of the first inseminations were between 24 hours before and $\llbracket 2$ hours after UOT. These inseminations cam be considered as well-timed and the ovulation prediction in these cycles as succeeded. In the group of 30 anti-oestrogen induced cycles (15 subjects) the result was less favourable: $36 \%$. The impression was that this was partly caused by the fact that the presence of larger ovaries and more numerous cystic structures beside the dominant follicle made the anti-oestrogen induced cycles less manageable by ultrasound and furthermore by the smaller series of cycles per subject.

Although the figure of $58 \%$ well timed predictions in spontaneous cycles looks favourable. two aspects need to be mentioned which seem to improve the practical usefullness of the method. First, in the data of fig. IV.12 also those inseminations are included, which were performed in the first or second cycle of a subject. It can be supposed that these first predictions which were based upon the average results of previous observations in other 


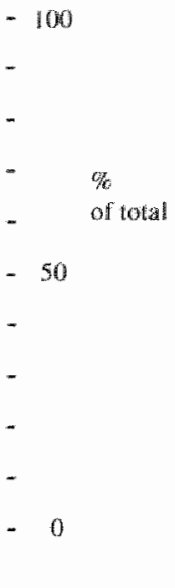

time before wOT (hotrs)

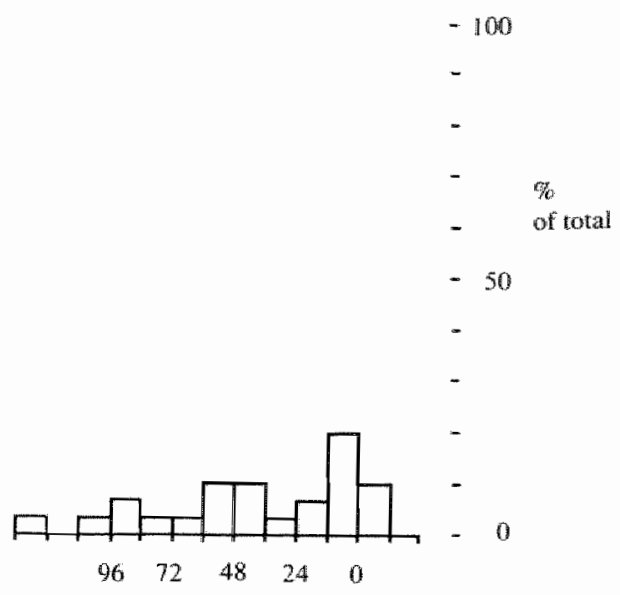

time before UOT (hours)

Fig. IV.12. Relative distributions of the interwals between the first artificial insemination (AlH) and UOT

Left: spontaneous cycles $(n=67)$

Right: anti-nestrogen induced cycles $(n=30)$

subjects, were less accurate than the later predictions. Secondly, after the first insemination the monitoring of the follicle was continued. When the follicle failed to rupture, insemination was repeated, usually after 24 hours. Mostly, these second inseminations were very close to the moment of follicle rupture.

\section{Discussion}

Applying the statistical procedures, proposed in this chapter, the average follicular growth appeared linear during the last 4 days before follicular rupture. Although not statistically significant, in the period from day 6 to day 4 before UOT, the growth rate was lower and growth curves were not linear.

The mean grow th curves of spontaneous and anti-oestrogen induced cycles were significantly different. The growth rate in anti-oestrogen induced cycles was higher and preovulatory diameters were also larger than in spontaneous cycies, although not significant. Differences wero mainly caused by cycles that showed bifollicular development. Mean growth curves and growth rates showed no significant differences in spontaneous cycles between left and right sided follicles and between volunteers and patients.

The wide range of preovulatory diameters was in agreement with earlier reports. Within. subject variability was however limited in about half of the subjects, which might provide a reasonable predictability of the day of follicle rupture. The data with respect to predictability were preliminary and could act as a pilot study for a prospective investigation on this issue. The practical results of ovulation prediction based upon premises about inner-subject variability were hopeful. 


\section{Chapter V}

\section{Time relationships between UOT and other events of the menstrual cycle}

\section{Introduction}

In the previous chapters, we assumed that ultrasound evidence of follicle rupture represented ovulation. If this assumption is correct, ultrasound provides a method for ovulation detection which has several advantages compared to the conventional methods; the information gained by ultrasound is direct: the accuracy of the method can be increased by increasing the frequency of observations; the method is non invasive and can be supposed to be harmless.

In this chapter, an attempt will be made to establish the time relationship between ultrasound signs of follicle rupture and the Luteinizing Hormone ( $L H$ ) peak, the latter being considered the most reliable of hormonal methods for detection of ovulation. "Thereafter, other hormonal parameters like the oestradiol-17-betta peak, progesterone levels in the second phase of the cycle, and non hormonal parameters like duration of the cycle phases, the occurrence of midpain and the temperature shift in the BBT will be related to the ultrasound estimation of the moment of ovulation.

5.1. Review of the literature

5.1.1. The LH surge and peak for the detection and prediction of ovulation

\subsubsection{Difficulties in defining the LH surge and L.H peak}

Shortly after the development of Radion Immuno-Assay (RIA) for the determination of serum hormone levels it was apparent that the LH surge and peak would become the most useful parameters for the detection and prediction of ovulation (Ross et al 1970, Yussman et al, 1970). A methodologic problem in the application of the LH peak remained essentially unsolved: the difficulty of defining the moment of the LH peak and LH surge on account of thuctuations in LH level and variability of L.H peak configuration. Another problem, the possibility of variations in the LH peak-ovulation interval will be discussed when the practical use of the LH surge and peak is reviewed.

Interpretating LH levels, one has to take two dynamic qualities of the LH-relcase into account: the pulsatile pattern of the release and the possibility of a diurnall rhythm. Furthermore, the configuration of the LH peak and its variation can play a role in the reliability of a definition of the $\mathrm{LH}$ surge or peak. The existence of high frequency oscillations of serum LH values was first revealed in the Rhesus monkey by Dierschke et al (1970), and in the human by Midgley and Jaffe (1971) and Yen et al (1972). In the rat the oscilations 
were independent of the presence of gonads and were supposed to be an intrinsic quality of the hypothalamus (Schuling and Gnodde, 1976). In the human the oscillations had a characteristic shape: a fast increase, taking 10 to 15 minutes and a slow decrease over 1 to 2 hours (Yen et al, 1972). Pulse frequency and amplitude were variable, depending on the phase of the cycle (Midgley and Jaffe, 1971), the frequency being thigh (3.2 pulses/6 hours) and the amplitude low $(56 \pm 12 \%)$ during the follicular phase and the reverse (1.6 pulses/6 hours; $333 \pm 170 \%$ ) in the luteal phase (Santen and Bardin, 1973). Based upon this oscillatory character of LH levels, a sharp definition of the LH surge is difficult to give. It becomes even more difficult because in most investigations the pattern of LH determinations is discontinuous. Most authors took the oscillations into account. They used definitions for the LH surge, in which an increase of the LH level of 50 to $100 \%$ above the foregoing value was required for the recognition of the LH surge (WHO Task Force Study, 1980 , Djabanbackeh et al, 1981; Testart et al, 1981; Kerin et al, 1981).

A diurnal rhythm in LH lewels in man was first demonstrated by Midgley and Jaffe (1968) and Faiman and Winter (1971). Others failed to find a consistent pattern in the day and night levels of LH (Krieger et al, 1972; Boyar et al, 1972; Alford et al, 1973). Possibly the contradictory results were based upon the differences in sample frequency of L.H. Kapen et al (1973) found episodic overnight fluctuations in LH levels around midcycle which resembled the REM-non REM sleep stages. Furthermore, in two cases a sudden increase of L.H was found around the moment of awakening. These fluctuations however did not result in differences in basal LH levels during day and night. The diurnal variations seemed not to be important for the definition of LH surge and peak and were mostly not taken into account.

The duration of the LH peak was estimated to be between 24 and 48 hours (Thomas et al, 1970; Midgley and Jaffe, 1971; Johansson et al, 1971; Yen et al, 1972). The peak level was sustained for 16 to 20 hours, while both the increase and decrease took 12 hours (Johansson and Wide, 1969). The configuration of the LH peak was controversial in two respects: the symmetry of the peak and the possibility of biphasic peaks. The LH peak was found to be symmetrical by Johansson and Wide (1969). Recently however, Djahanbackch et al (1980) and "Testart et al (1981) found by means of frequent sampling, that the imterval from the surge to the peak level varied from $2-29$ hours, and concluded that the peak should be asymmetrical.

Biphasic LH peaks were demonstrated by Thomas et al (1970), while others found a uniform strape (Midgley and Jaffe, 1968; Johansson and Wide, 1969; Weick ef al, 1973). A more recent report by Landgren et al (1977) which cannot be challenged on account of a low sample frequency confirmed the existence of a biphasic pattern in a part of the cycles. Terazaw et al (1980) suggested an individual preference for either the monophasic or biphasic shape.

\subsubsection{The L.H peak as a method for detection of the ovulation}

Essential for the cvaluation of the reliability of the LH peak for this purpose are the methods of LH-sampling, the definition of the LH-peak and the ovulation detection method to which the LH peak was referred.

Many authors employed daily assays in plasma and serum or 24 hour urine excretion measurements (Abraham et al, 1972, Dodson et al, 1975; Croxatto et al, 1977; Parerstein et al, 1978; Ben Aderet et al, 1977; Edwards et al, 1980; Kerin al, 1981). It is not clear 
from many of the reports, whether the authors thave realized that the "moment of the peak value" can only be estimated but not determined by discontinuous measurements: the potential inaccuracy of such a procedure is two times the observation interval, provided that the exact configuration of the LH peak in an individual cycle would be known. Many authors in the field of temporal relationships during the cycle simply defined "the peak" as the highest value in a series, without discussing methodologic problems (Ben Aderet et al. 1977; Hosseinian and Kim, 1976; Younger et al, 1978; Queenan at al, 1980; O'Horliby et al, 1980b).

The nost adequate method for diminishing the inaccuracy was to increase the frequency of determinations. However, this was the most expensive way, so that results were mostly derived from small populations (Yussman and Taymor, 1970; Yussman et al, 1970; Thomas et al, 1970; Landgren et al, 1977; Djahanbackch et al, 1980; Landgren et al, 1980; Frydman et al, 1981).

The other approach was: averaging the data of large numbers of cycles and constructing definitions which tried to adjust the discontinuous way of determination optimally to the theoretical configuration of the LH peak (Pauerstein et al, 1978; Kerin et al, 1981). This method is statistical and can be expected to improve the estimation of "the time of the L.H peak". There is however one important disadvantage: possible variations between cyeles or between individuals can be overlooked.

Several investigations in the past 15 years have shown that the interval between the L.H peak and ovulation is rather short and rather constant. For the estimation of the value of these investigations, the method of ovulation detection should be taken into account. Roughly speaking, there are two categories.

- The indireet methods: histologic dating of endonetrium or corpus luteum (Noyes et al, 1950; Corner et al, 1956), or estimating the day of ovulation by the temperature shift in BBT.

- The direet methods, using observation of the ovaries by laparoscopy, laparotomy or ultrasound.

The indirect methods, developed in an era in which there were few technical facilities for direct obserwation, cannot be supposed to be very accurate (Buxton and Engle, 1950; Noyes and Haman, 1953; Johansson et al, 1971; Lundy ed al, 1974; Morris ot al, 1976; Koninckx et al, 1977) Investigators, who based their calculations of LH peak-ovulation intervals on these indirect methods were Yussman and Taymor (1970) and Paucrstein et al (1978). The first group found an interval of 4 to 16 hours, using a 8 -hourly assay. Paucrstein et al reported an interval of 9 tw 2 hours (SEM) performing daily assays, and applying an interpolation method for the "moment of the LH peak".

Most of the recent studies in this field used direct methods of ovulation detection and frequent LH sampling. In these studies, the LH peak-ovulation interval appeared to be variable. Daily laparotomy was applied in a group of Rhesus monkeys by Wick et al (1973). They found a mean interval between the $\mathrm{LH}$-peak (threc-hourly assays) and ovulation of 37 hours (range 28 to 56 hours). In the human frequent laparotomy or laparoscopy was performed recently. The WHO Task Force Report (1980) estimated the interval LH peak-ovulation to be $9 \frac{1}{2}$ to 23 hours (mean 16.5). Also Djahanbackch (1981) and Testart and Frydman (1982) concluded that the LH pealk-ovulation intervat should be 
variable. Both conclusions were however based upon the wide variation in the surge-peak interval of LH.

\section{1. 1.3. The LH surge as a method for prediction of the ovulation}

For the purpose of ovulation prediction the LH peak seemed to be less adequate than the LH surge for several reasons: the actual peak value showed an enormous variation (Cargille Et al, 1969; Coutts et al, 1974; Briet, 1978; Landgren et al, 1980), so that the recognition of the peak value could only be retrospective, even when using a continuous sampling mode. Secondly, the interwal between LH peak and ovulation was short compared to the time required for the assay which was a disadwantage in view of the retrospective character of the peak definition. Rapid radio-immunoassay (RIA) methods (Miyata et al, 1970; Isojima ct al, 1970; Thomas and Ferin, 1970; Younger et al, 1978) can evade this objection, but they require extensive laboratory facilities. Finally, the interval between LH peak and ovulation recently appeared to be more variable than originally thought (Weick et al, 1973 ; WHO Task Force Study, 1980; Djahanbackch ef al, 1981). Hence, the LH surge, the first detectable rise of LH at the start of the LH peak, has been more widely investigated for prediction of the ovulation.

In the most recent investigations a high frequency (6 to 8 hourly) of rapid RIA determinations was applied (Testart et al, 1980; Djahanbackch et al, 1980; WHO, 1980; Frydman et al, 1981). Definitions for the $\mathrm{LH}$ surge varied with respect to the threshold vallue and the amount of increase above this threshold, required for the detection of the start ot: the LH surge. Differences were however small.

Referring the LH surges to direct methods of ovulation detection, laparoscopy/tomy and ultrasound, the following intervals were detected: 23.6 to 38 hours (mean 32 hours) in 107 cycles (WHO Task Force Study, 1980); 32 to 48 hours in 14 cycles (Djahanbackch et al, 1981).

These results did not suggest a strict reliability of the LH surge for accurate prediction of the ovalation. A nother application, the predictability of the period in which an ovum is fortilizable in vitro, appeared to be more hopeful. "Testart et al (1981) found a majority (9/14) of the oocytes fertilizable when aspiration was performed between 33 and 36 hours from the moment of the LH-SIR (surge initiating rise); this was in agreement with the results of Djahanbackch ce al (1981).

Surveying the reports mentioned, a preliminary conclusion seems to be justified: with refinement of the methods and climination of the disadvantages of indirect methods of ovulation detection, the conception of a strict temporal relationship between the LH peak and ovulation was not rejected. A considerable intercycle variation was however apparent. Due to the improvement of detection of both the LH surge and the ovulation, this variation could not merely be attributed to methodological causes.

\section{1 .1 .4 . Reports on the temporal relationship between ultrasound evidence of ovulation and LH surge and -peak}

The carliest observations of ultrasound signs of follicle rupture in relationship with the LH surge and peak confirmed to some exten the supposed time relation between the LH peak 
and owulation and the biologic variation of this interval. De Crespigny et al (19816) tried to determine the LH surge in three hourly urine samples. Follicles were observed by ultrasound almost continuously. In nine cycles the carliest follicle ruptures took place less than 27 hours after the LH surge, while the latest was at 35 hours after the surge. Testart ef al (1981) found that six out of ten follicles had ruptured between 28 to 35 hours after the Surge Initiating Rise (SIR) of LH. These results were to some extent contrary to those of the same investigators in another group of 14 cycles not exposed to ultrasound: the optimal fertilizability of oocytes aspirated between 33 and 35 hours after the SIR (Testart et al, 1980). This contradiction brought them to the idea of premature owulations, presumably caused by the ultrasound observation (Testart et al, 1982; see chapter 1).

Ultrasound signs of follicle rupture (by daily observations) were related to the day of the LH peak by Queenan et al (1980). The peak was assumed to be on the day of the highest level of LH in early morning urine samples. (RIA). After correction for the supposed delay in the LH peak detection caused by the sampling method, they calculated that the LH peak preceded ovulation by 12 to 36 hours. The supposed prediction range of the LH peak, based on the literature and the observation range of follicle rupture fitted together in only $3 / 4$ of the cycles. The low observation frequency and the method of LH peak detection in this study appear to be insufficient to allow conclusions.

Two other investigations were even less conclusive on account of the methods used. Follicle disappearance was found on the day of the highest LH level or one day after it by Renaud et al (1980). The number of cycles was ten, the samples and obserwations were daily and the LH peak was defined as the highest value in a series. OHerlihy et al (1980b) found no ovulation preceding, and all ovulations within the 48 hours following the peak value of $\mathrm{LH}$ (RIA in daily serum samples; 53 cycles). They reported no further details on the LH peakovulation relationship.

\subsubsection{The oestradiol-17-beta peak}

\subsubsection{Relationships between oestradiol-17-beta and other parameters of the cycles}

The best reflection of follicular development during the proovulatory phase of the cycle is probably provided by the serum oestradiol-17-beta values. Oestradiol-17-beta was the main oestrogen produced by the ovary (Baird and Guevara, 1969). More than 90\% of the circulating oestradiol-17-beta was derived from the preovulatory follicle (Baird and Fraser, 1974) and the oestradiol - 17 beta / oestrone ratio increased from 0.7 in early follicular phase to 1.9 during the oestrogen peak (Baird and Guevara, 1969).

In the follicular fluid, oestradiol-17-beta was the only oestrogen. Its concentration is related to follicle diameter McNatty et al, 1975; Bomsel-Helmreich et al, 1979). Also peripherallevels would be correlated with follicular diameter (Hackelöer et al, 1979; Ylostaloet 'al, 1979), or with the total volume of all follicles (Smith et al, 1980), although these relationships showed a wide variation (Freundl et al, 1980).

There are many reports concerning the possible interrelationship between oestradiol 17 beta levels and other parameters of the menstrual cycle.

The duration of the follicular phase of the cycle would be positively correlated to the mean oestradiol levels (Broom et a!, 1981) but inversely correlated to the height of the ocstradiol peak (Landgren et al, 1980). With respect to the luteal phase duration the situation would 
be somehow the reverse: high oestradiol peak levels were related to a long duration of the luteal phase (Sherman and Korenman, 1974; Edwards et al, 1980) and high luteal progesterone levels (Radwanska et al "1980b). In agreement with this, in vitro progesterone production by the granulosa was found to be oestradiol dependent (Edwards, 1973; McNatty et al, 1975). On the other hand however, high oestradiol levels during luteal phase were thought to shorten the luteal phase and lower progesterone production by a locall luteolytic effect (Karsch and Sutton, 1976; Aulletta et al, 1978). The existence of a luteolytic effect in the human was disputed by others (Bacic et al, 1970; Gore et al, 1973; Gautray et al, 1981).

\subsubsection{Preovulatory oestradiol-17-beta production and the configuration of the peak}

The oestrogen level in the early preovulatory phase was low. In the mid follicular phase a gradual, linear increase took place, followed by a fast, exponential increase towards the peak (Dhont et al, 1974; Schoemaker et al, 1978). This rise started about two days before the LH peak and was not accompanied by any important change in the LH levels (Landgren et al, 1977). The actual levels and peak values of oestradiol varied widely (Coutts al, 1974; Briet, 1978). The peak value was about five times the lowest preovulatory level and about three times the luteal level (Korenman and Sherman, 1973).

The configuration of the oestradiol-17-beta peak was not symmetrical, contrary to that of the LH peak. The increase was relatively slow, taking two to four days, the decrease was steep (Black et al, 1972; Korenman and Sherman, 1973; Landgren et al, 1977; BomselHelmreich et al, 1979).

Although there was not a definite pulsatile pattern in oestradiol release, frequent sampling revealed marked fluctuations (Koreman and Sherman, 1973; Landgren et al, 1977).

These short term fluctuations could theoretically explain any aberrant configuration of the oestradiol peak, especially when the frequency of determinations was low (Warren, discussion to Pauerstein et al, 1978).

\subsubsection{Definitions of the oestradiol-17-beta peak and surge.}

Variations in the peak level and the gradual increase towards the peak make it theoretically difficult to define the surge of oestradiol-17-beta. The peak value could only be identified after the steep decline had occurred.

As lar as the oestradiol-17-beta peak was applied in the literature, the definition of the peaks was in general straightforward: the highest in a series of oestradiol assays (Ben Aderet et al, 1977; Koninckx et al, 1977; Pauerstein et al, 1978; Descomps et al, 1980). Problems in identifying the peak were not mentioned. A more detailed definition was applied by the WHO Task Force (1980). In this study the peak was identified as the highest value which was at least twice the baseline and was preceded and followed by a lower value.

An effort to define the oestradiol-17-beta surge was made by the WHO Task Force (1980): Assaying oestradiol-17-beta in 24 hour urine samples or early moming samples, the oestradiol surge was defined as an increase to at least $150 \%$ of the base line. After this increase, the levels proceeded to the peak value without an intermediary decrease. Adlercreutzet al (1980) defined the oestradiol surge as an increase of more than twice the standard deviation of the base line. 


\subsubsection{The interval between oestradiol-17-beta peak and -surge and the owulation}

Comparable to the LH peak, the value of obserwations on this item is highly influenced by the method of ovulation detection. "The interval between the oestradiol-17-beta surge and ovulation was estimated to be 82.5 hours (90\% confidence limits $54-100.5$ hours) by WHO Task Force (1980). Adlercreutz et al (1980) reported a good prediction of the ovulation by the oestradiol-17-beta surge, the failure rate being only $11 \%$. The practical value of this procedure has still to be established.

A variation in interval between oestradiol-17-beta peak and ovulation was apparent. especially from the investigations that used direct methods of ovulation detection. WHO Task Force (1980) estimated the mean peak - owulation interval to be 24 hours, the $90 \%$ confidence limits being 16.9 to 32 hours. The ovulation was detected by laparotony. Most authors who referred to the day of the LH peak reported the oestradiol-17-beta peak to occur on the day before the LH peak. However, a wide variation was found: from two days before the LH peak to the day of the LH peak itself (Mishell et al, 1971; Lundy et al, 1974; Guerrero et al, 1976; Koninckx et al, 1977).

In two reports, the oestradiol-17-beta peak was compared to the ultrasound signs of follicle disappearance. Both of them described small samples ( 10 and 13 cycles) and considered the day of the highest level in daily samples as the day of the peak. The oestradiol-17-beta peak was found between two days before and one day after the disappearance of the follicle (Renaud et al, 1980; Robertson et all, 1979).

\subsubsection{Progesterone}

Progesterone had a steady low plasma concentration of $0.2-0.8 \mathrm{ng} / \mathrm{ml}$ during the follicular phase of the cycle. Around the time of ovulation it started increasing towards high levels in the midluteal phase (Cargille et al, 1969; Yussman and Taymor, 1970; Dhont et al, 1974). Two aspects of this progesterone production have to be reviewed: the initial rise of progesterone and the midluteal progesterone level.

\subsubsection{The initial progesterone rise}

The first report on the start of progesterone production was by Neill et al (1967). They could find an increase only 48 hours after the LH peak. This finding was corrected by Cargille et al (1969), Goebelsman et al (1969); Johansson and Wide (1969) and Yussman et at (1970) who detected a slight, but discrete progesterone rise before the indirect signs of ovulation. Since then it has become clear that the start of the LH peak induced luteinization of the granulosa cells (Delforge et al, 1972). In the peripheral blood, the first rise of progesterone coincided with the first steep rise of LH levels (Thorneycroft ct al, 1974; Landgren et al, 1977; Pauerstein et al, 1978; Djahanbackch et al, 1981; Garcia et al, 1981). Laborde et "al (1974) found even a "pre-LH" increase of progesterone levels, which they referred to an extra ovarian source like the adrenals. This finding has not been corroborated.

Little is known about fluctuations of progesterone secretion in the period of the initial rise. There was no distinct diurnal rhythm in secretion although variations during the day could occur to the amount of $50 \%$ of the pre-peak levels (Rünnebaum et al, 1972). According to Johansson et al (1968), Moghissi et al (1972) and Laborde et al (1976) the increased rate of progesterone secretion during the period of the ovulation could be supposed to be linear. 
Two aspects of the initial progesterone rise remain of potential interest: its possible usefulness for the detection of ovulation and the possible physiologic implications of the progesterone level at the moment of ovulation. The progesterone level at the moment of ovulation, detected by different methods, varied from 1.0 to $2.3 \mathrm{ng} / \mathrm{ml}$ (Laborde et al, 1976; Yussman and Taymor, 1970; Johamsson and Wide; 1969). Based upon indirect ovulation detection a considerable variation of the level at the moment of ovulation was suspected (Yussman and Taymor, 1970; Moghissi et al, 1972). Also Garcia et al (1981) who estimated the time of ovulation by laparoscopy, considered the progesterone level at the moment of avulation to be uncritical.

It was suggested by Johansson et al (1968) and by Guerrero et al (1976) that the initial progesterone rise could be of value for the prediction of ovulation. In view of the reported variability this application is doubtful.

Only suggestions are available about the possible physiologic role of progesterone levels around the moment of ovulation. Progesterone could play an important role in regulating the LH release during the LH peak. In vitro, progesterone enhanced the $L H$ release under certain circumstances (Lasley et al, 1975; Shaw et al, 1975; Leyendecker et al, 1976; Chang and Jaffe, 1978; March et al, 1979). In the rabbit, progesterone first facilitated the LH release and later inhibited it, thus regulating the duration of the LH peak (Sawyer and Everett, 1959). A similar regulating effect was suggested in the human (March et al, 1979). A number of events in the genital tract around ovulation appeared to be influenced by the balance of steroid homnones. Cervical mucus quality was oestrogen dependent and progesterone antagonized the oestrogen effect. Nitschke-Dabelstein et al (1980) suggested that too high intial progesterone levels could have an adverse effect on mucus quality and hence could be suspected to impair fertility.

Ovum and sperm transport in the female genital tract is a complex of events, depending on muscular activity, the composition of fluids and ciliary activity. All these functions appeared to be influenced by the oestrogen-progestagen balance (Coutinho and Maia, 1970; Odor and Blandau, 1973; Critoph and Dennis, 1977; Croxatto et al, 1978; Jansen, 1978; Jansen, 1980; Korenaga and Kadota, 1981). Although in vitro the effect of changes in the hormone balance on separate functions are known, the influence of disturbances in vivo on fertility remain speculative.

It can be eoncluded that a preovulatory progesterone rise, as an expression of the LH. induced luteinization is certain. A variation in the peripheral progesterone levels during the period of the ovulation is likely. The extent of this variation and the role of progesterone around the ovulation in the human is uncertain.

\subsubsection{Progesterone during the luteal phase and its use for the diagnosis of luteal phase defect}

Progesterone was produced in the Uuteal phase by the luteinized granulosa cell layer (Baird of 1,1975 ). After a rapid rise of the progesterone levels following the ovulation, a plateau was reached on the 6th to 8 th day after the LH peak. This plateau had a variable duration (3-10 days) and was followed by a decline to low levels at the end of the cycle (Ross et al, 1970; Dhont et al, 1974; Landgren et al, 1980). In case of pregnancy, progesterone levels would further increase on day 8,10 after ovulation (Jones and Wentz, 1976). The progesterone levels during the plateau phase were extremely variable between cycles and between individuals (Rosset al. 1970; Cargille et al, 1969; Coutts et al, 1974; Landgren et al, 1981: Alberda, 1981). 
Together with the variability of the luteal phase duration (Dhont et al, 1974; Landgren et al, 1980) and the uncertainty in most investigations about the exact day of ovulation, this variability of progesterone levels justifies a critical approach to investigations that aim to settle the diagnosis luteal phase deficiency by progesterone determinations.

The relationship between progesterone levels in the luteal phase and the quality of the menstrual cycle with respect to fertility has been investigated by a number of authors: all of them supposed that the level of progesterone reflects the function of the corpus luteum. Israel et al (1972) never found progesterone levels below $3 \mathrm{ng} / \mathrm{ml}$ in the midluteal phases of cycles that revealed secretory endometrium. They considered a progesterone level of $3 \mathrm{ng} /$ $\mathrm{ml}$ or more at any moment of the lutal phase as an indication for an ovulatory cycle. Abraham et al (1974) investigated the progesterone levels which indicated not only an ovulatory cycle, but also an adequate corpus luteum function with respect to fertility. In their view the presence of an LH peak and a luteal phase duration of 12 to 16 days were required to consider the cycle as adequate. A mean plasma progesterone level of $5 \mathrm{ng} / \mathrm{ml}$ in three determinations between 5 and 8 days after the LH peak was found in these cycles. Radwanska and Swyer (1974) applied single midluteal progesterone determinations in women with hormonal causes for infertility and compared them with a control group. Levels below $10 \mathrm{ng} / \mathrm{ml}$ were only found in a large number ( $60 \%$ of the cycles) in the infertility group. The authors concluded that the finding of a progesterone level above $10 \mathrm{ng} / \mathrm{ml}$ in a single determination, was an indication for a sufficient corpus luteum function.

Neither of these authors mentioned the possibility of false negative results, caused by inadequate timing of the progesterone assays. Moreover, all of them accepted the so-called luteal phase deficiency (LPD) as a definite entity among the causes for infertility. This entity of LPD was introduced by Jones (1949) and was originally defined by the finding of an endometrium more than two days out of phase with the day of the cycle. Other definitions were: a hyperthermic plateau or an LH peak-menstruation interval shorter than a certain limit (Strott et al, 1970; Sherman and Korenman, 1974; Driessen. 1981): defective steroidogenesis by the corpus luteum, either in levels or in duration, resulting in inadequate endometrium development and failure to implantate (Jones, 1976; Andrews, 1979). The condition would account for 3,5 to $8.1 \%$ of all infertility cases (Jones, 1976; Rosenberg et al, 1980) and for approximately $35 \%$ of all lirst trimester abortions (Jones, 1976).

However, Alberda (1981) could not find significant differences between supposed L..PD patients and control group, comparing prolactin, progesterone, oestradiollevels and endometrium biopsies. Driessen (1981) studied cycles in which endometrium biopsies were out of phase with the day of the cycle. He failed to find differences in progesterone levels between these cycles and those with "normal" endometrium biopsies. Also the relevance of a low luteal progesterone level was doubtful. Alberda (1981) remarked that in order to explain longstanding infertility, low progesterone levels should be found in all successive cycles within the same individual. In none of the series of three cycles per subject did he find progesterone values which were repetitively in the low range. Reviewing the literature, there appear to be many uncertain and unproven premises for the diagnosis of luteal phase deficiency and for its relevance as a cause of infertility. In our view the relevance of the entity still remains to be proven. 

parameters

The duration of the luteal phase is extremely variable. According to Dhont et al (1974) and Landgren et al (1980) this period ranged from 8 to 17 days. A total of $31 \%$ of all cycles exhibited a luteal phase duration of less than 12 or more than 15 days.

The search for relationships between luteal phase duration and other parameters has resulted in findings which were often contradictory. Landgren et al, (1980) found no correlation between luteal phase duration and luteal LH or FSH levels. The correlation between progesterone levels in the luteal phase and its duration was only weak. In contrary, VandeKerckhove and Dhont (1972) found a positive correlation between luteal phase duration and luteal phase LH levels, suggesting that the corpus luteum is $\mathbf{L H}$ dependent. Ross et al (1974) reported in a small series that low progesterone levels coincided with short luteal phases.

The relations between preovulatory events and luteal phase parameters have been subject to many investigations. High preovulatory oestradiol levels were correlated with longer luteal phases (Ross et al, 1974; Landgren et al, 1980). The same was true for high preovulatory FSH levels (Strott et al, 1970; Ross et al, 1974). In general, the authors concluded that short luteal phases result from inadequately stimulated follicles. However. reviewing the detailed report of Landgren et al (1980), it should be remarked that although the correlations between a number of preovulatory and postovulatory variables were significant, the correlation coefficients did not exceed 0.6 , so that a causal relationship cannot be concluded.

\subsubsection{The relation between midpain and ovulation}

The existence of midpain in some part of the menstrual cycles has not been doubted since the first description of this phenomenon by Fehling (1881). It would occur in approximately one out of three cycles (Hann et al, 1979; O'Herlihy et al, 1980c; Kerin et al, 1981).

There was however no unanimity about its cause and its exact temporal relationship to the moment of ovulation.

According to Jeffcoate (1969), the pain would originate from the postovulatory spill of blood and follicular fluid on the peritoneum. Charlewood (1958) suggested that preovulatory congestion of the ovary was the main cause of the pain. Also in more recent reports there was no agreement about the cause. Hann et al (1979) concluded from the presence of fluid in the cul de sac at the moment of midpain that it was an ovulatory or postowulatory symptom caused by this fluid. O'Herlihy et al (1980c), using ultrasound, found all but one out of 34 follicles intact at the moment of midpain. Moreover, in the majority of cases (77\%), midpain occurred on the day of the LH peak. In their view it was a preovulatory symptom, presumably caused by contraction of perifollicular smooth muscle, induced by the LH rise.

\subsubsection{Basal Body Temperature (BBT) as a method of ovulation detection.}

The temperature rise in the BBT recording was widely used as a method of ovulation detection in the field of natural family planning (Billings et al, 1972; Hilgers and Baily, 1980), in the evaluation of ovulation induction (Schwartz and Jewelewicz, 1981) and for the timing of artificial insemination (Steiman and Taymor, 1977; Nunley et al, 1978). 
Several criteria have been applied to detect the day of the ovulation:

1. Nadir, the last low point in the temperature curve before the rise towards a hyperthermic plateau starts (WHO Scientific Report, 1967);

2. Coverline, the line just above the preshift temperature readings (Guerrero and Rojas, 1975);

3. FDHP, the first day of the hyperthermic plateau (Buxton and Engle, 1950).

The accuracy of the ovulation detection by B BT has been discussed for two reasons. The incidence of monophasic BBT in cycles, which were apparently ovulatory according to hormonal parameters, was as high as $22 \%$ in some reports (Johansson et al, 1972; Moghissi, 1976). Furthermore, discrepancies of up to five days were found between the ovulation detection by BBT and by other parameters like the LH peak (Morris et al, 1976) or histological dating of the corpus luteum (Brewer and Jones, 1947; Buxton and Engle, 1950).

\subsection{The relationships between ultrasound evidence of follicle rupture and other events of the menstrual cycle}

\section{Introduction}

Ultrasound observation of the large number of cycles in this investigation was accompanied by a very expensive and time consuming schedule of hormone determinations. There were two reasons which appeared to justify this procedure.

Strictly speaking, it is still hypothetical that ultrasound signs of follicle rupture coincide with or represent ovulation. One method to make this hypothesis acceptable is to demonstrate the temporal relationships with other events of the cycles. Furthermore many earlier investigations can be challenged in this respect because the series were small (Robertson et al, 1979; Renaud et al, 1980), the definitions of ultrasound evidence of ovulation were not strict (Hackeloèr et al, 1979; Kerin et al, 1981) or the methodological problems in the definitions of hormone peaks were not considered (Renaud et al, 1980; Queenatn et al, 1980).

If ultrasound evidence of follicle rupture could be proven to represent ovulation, the ultrasound technique would provide a mon-mvasive and rather comfortablic method of ovulation detection. Many details of time relationships with for instance hormonal parameters would be open to investigation.

The LH surge and peak, the oestradiol-17-beta peak and the initial progesterone rise were selected for comparison with the time of ultrasonographical events.

\subsubsection{Definitions}

\section{The LH surge and peak}

Applying a low sample frequency like the 24 hour sampling in the present study, the detections of the surge, i.e. the first sign of the increase of LH, and the peak, i.e. the moment of the highest level were necessarily only estimations. In order to make the best use of the available determinations the following definitions were designed. 
- The LH-surge:

The first value in a series, that excecded all foregoing values by $100 \%$ or more (fig.

V.1.).To cxclude misinterpretations, the following restrictions were built in:

- minimum of determinations: 4

- minimum of preceding values: 1

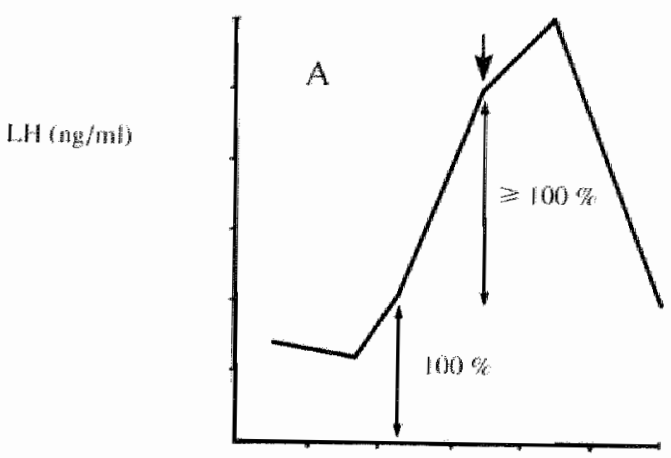

linte (alays)

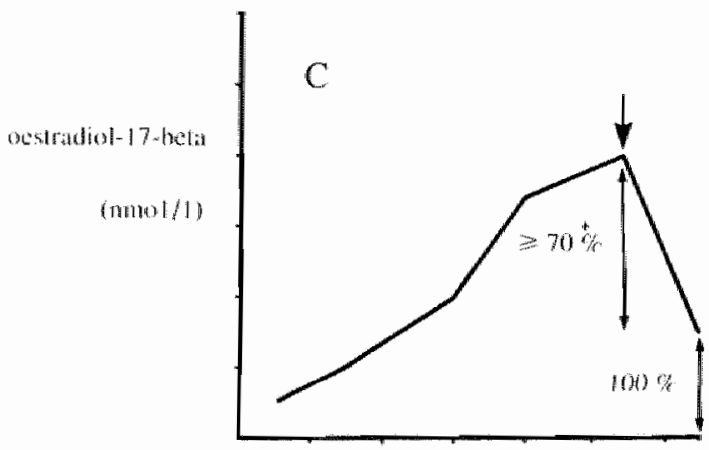

Lime $(d i g y)$

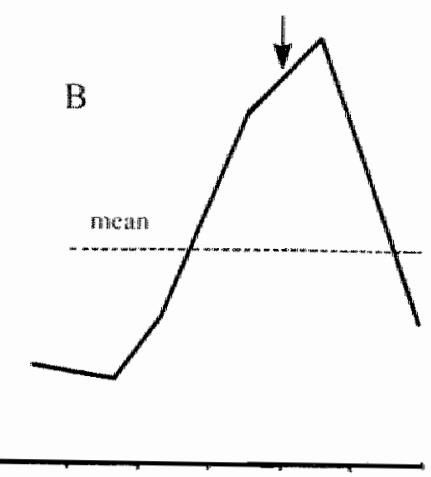

line (days)

Fig. V.I. Graphic representation of the definitions for LH surge (A), LH peak (B) and oestradiol-17-beta peak (C). Arrows indicate the time of the surge and peaks

- The L H peak.

the middle between the LH values that exceeded the mean LH level. If only one value was found above the mean level the time of this determimation was considered as the timc of the $\mathrm{L} H$ peak. In case of two or three such values, the time between the two extreme values was assumed the best estimate of the time of the LH peak.

The following restrictions were assumed:

- there had to be a L.H surge

- A maximum of five values were considered for the calculation of the mean LH level. If more than 5 values were avalable, the last 5 values were chosen for the definition.

In the definition of the LH surge, the limit of $100 \%$ excess above the preceding values was chosen as a condition for the recognition of a surge. This choice was based upon the reports of Yen et al (1971) and Santen and Bardin (1973) concerning the pulsatile character of the 1..H release. Although no definite conclusion can be drawn from these reports about the 
general pattern of the pulse amplitude in the entire population of subjects and cycles, a limit of $100 \%$ appeared to be sufficient to prevent these fluctuations from being recognized as surges.

The efficacy of the limit of $100 \%$ was evaluated in 111 spontaneous cycles in 28 subjects. They were ovulatory according to ultrasound observation and/or progesterone increase in the luteal phase. Table V.1. shows the distribution of the maximal LH increments between two subsequent determinations. In 12 cycles, the LH determinations did not fulfil the

Table V.1.

Distribution of the maximall changes between two subsequent LH and oestradiol-17-beta determinations in spontaneous cycles; (effects of lowering the discriminatory limit in the definitions for LH surge and oestradiol peak)

\begin{tabular}{|c|c|c|c|}
\hline LH surge & $\begin{array}{c}\text { number of cycles } \\
\text { (spontaneous) }\end{array}$ & oestradiol-17-beta peak & $\begin{array}{c}\text { number of cycles } \\
\text { (sponreanows) }\end{array}$ \\
\hline $\begin{array}{l}\text { limit of excess above all } \\
\text { preceding values }(\%)\end{array}$ & & $\begin{array}{l}\text { limit of excess above the } \\
\text { following value }(\%)\end{array}$ & \\
\hline 100 or more & 90 & 100 or more & 73 \\
\hline $90-100$ & 3 & $90-100$ & 8 \\
\hline $80-90$ & 1 & $80-90$ & 3 \\
\hline $70-80$ & 3 & $70-80$ & 9 \\
\hline $60-70$ & 0 & $60-70$ & 2 \\
\hline 60 or less & 2 & 60 or less & 8 \\
\hline insufficient number & & insufficient number & \\
\hline of determinations & 12 & of determinations & 8 \\
\hline total & 111 & & 111 \\
\hline
\end{tabular}

accessory criteria of the definition for the LH surge. Of the remaining 99 cycles, 97 cxhibited a $\mathrm{LH}$ value that exceded all foregoing by at least $70 \%$. In the majority (90) the cxcess was more than $100 \%$. This illustrates that in a large group of cycles, the increase of LH levels at the beginning of the LH peak is sharp enough to be detected with a 24 hour-assay. As shown in fig. V.2., the increase above the preceding value was by far more than $100 \%$ in most of the cycles (median $200-250 \%$ ). On the other hand, it should be remarked that using our definition and our method of sampling, no LH surge was detected in 9 out of 99 cycles which were ovulatory according to ultrasound observation and/or progesterone increase.

The LH peak has a duration of 24 to 48 hours, and its shape is more or less symmetrical (Yen et al, 1972; Midgley and Jaffe, 1971; Thomas et al, 1970, Johansson et all, 1971; Djahanbachkh et al, 1981). Determining the LH level once daily, one can expect to fund 1 , 2 or 3 LH values, belonging to the peak. The number of peak values found, can be supposed to depend on the time relations between the sequence of liH assays and the LH peak. Out of 90 spontameous cycles, $50 \%$ showed two LH values that exceeded the mean level. The incidence of one and three of these values was $32 \%$ and $18 \%$ respectively. 

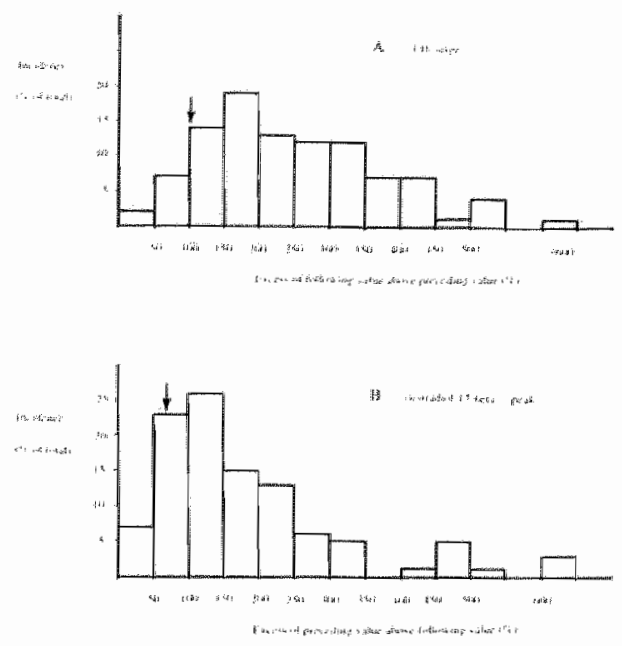

Fig. V.2. Distributions of the relative increase of LH-values and the relative decrease of oestradiol-17-beta values between two assays A. the maximal increase of $L H$ level between two subsequent dererminations ( $n=99$ spontaneous cycles)

B. the maximal decrease of oestradioll-17-beta level between two subsequent determinations. $(\mathrm{n}=103$ spontaneous cycles)

Arrows indicate the position of the limits, excluding the lower $10 \%$ of the cycles

Based upon these definitions two other variables were calculated:

the time intervals between LH surge and UOT, and between LH peak and UOT.

\section{- Oestradiol-17-beta peak}

The shape of the oestradiol peak, a slow increase followed by a sharp decline, appeared to be much less defined than the shape of the LH peak. Due to this fact the applicability of any definition for the oestradiol-17-beta peak could be discussed. Theoretically, only the last value before the decline seemed to be suited for a definition. To select this value a definition was designed which was analogeous to that of the LH surge:

- The oestradiol-17-beta peak is the first value in a series that exceds the following value by $70 \%$ or more.

Resriction: mimimum of following values: 1.

Contrary to the $\mathrm{LH}$ release, in the ocstradiol release no definite pulsatory pattern was demonstrated, which could be useful as a treshold in the definition. Nevertheless, in the case of the oestradiol-peak there was a need to prevent artifacts (incidental fluctuations, the interassay variability, eventual mistakes in sampling, storage or assaying) being described as peaks. In the definition of the LH surge, a $100 \%$ limit was chosen for the definition because this seemed to be the maximal range of the short term variations. This $100 \%$ limit turned out to exclude $10 \%$ of the cycles from having a well defined LH surge. In case of the oestradiol peak definition, the decrease percentage at which $10 \%$ of the peaks was excluded, was arbitrarily chosen as a limit. According to the data in table V.1., this limit appeared to be a $70 \%$ decrease. Fig. V.2 shows the distribution of decrease percentages, found in 111 spontaneous cycles. In 8 cycles, the accessory requirements of the definition were not fulfilled. In the remaining 103 , the decrease percentages generally were lower than the increase percentages of the LH surge (median 100-150\%). This inclicates that the decline of the oestradiol peak is relatively less steep than the increase of the LH 
surge, i.e. the oestradiol-17-beta peak is less well defined.

Based upon the definition of the oestradiol-17 beta peak, other valrables were calculated:

- the actual value of the oestradiol-17-beta peak

- the mean of preovulatory oestradiol-17-beta values. In case of more than 5 cleterminations, the last 5 were chosen for this calculation

- the time interval between the oestradiol-17-beta peak and UOT.

\section{- Progesterone at the moment of UOT and during the luteal phase}

Progesterone was determined at the beginning and at the end of the ovulatory period, i.e. in the blood sample, taken at the last observation of an intact follicle and at the first observation of follicle rupture. Referring to Laborde et al (1976) we considered the progesterone increase in this period as linear. The estimation of the progesterone level at the moment of ovulation resulted from interpolation between these two values.

During the luteal phase of the cycle one progesterone determination was performed in a standardized period of the cycle: day 5,6 or 7 after the ultrasound evidence of follicle rupture. By doing so the determination was supposed to be in the first part of the plateau phase of progesterone.

\section{Follicular phase and luteal phase}

The follicular phase was defined as the period from and inchuding the first day of the menstrual bleeding until the day of the ultrasonographically estimated follicular rupture. The luteal phase was defined as the period from and including the day of the estimated ovulation until the first day of the menstrual bleeding.

The definitions of Ultrasonographical Ovulation Time (UOT) and Ultratsonographical Ovulation Period (UOP) were mentioned in chapter III.

\section{Midpain}

The incidence of midpain was carefully recorded. The definition was a suddenly occurng pelvic pain, often continuing as a pelvic discomfort for several hours. The time of this onset of a painful discomfort was defined as the moment of midpain.

Of course this definition cannot exclude the subjective qualification of pain sensations, and as such it is not as exact as one could desire. Moreover, the group of subjects was selected. Most of the subjects were preoccupied with the physiology of the cycle, because they were treated for infertility or because they volunteered in the investigation. As the investigation proceeded, they became experts in interpreting the wltasound appearance of the preovulatory follicle. Thus, the frequency of the phenomenon of midpain may be overdrawn in comparison with the normal population. In order to avoid induction of false interpretations of the ultrasound pictures, the questioning for midpain was systematically done before each ultrasound observation. 


\subsubsection{Results}

\subsubsection{The LH surge and peak: temporal relationship with UOT}

According to the reports, mentioned before, the time distance between $\mathrm{LH}$ surge and peak and ovulation would be rather constant. This study amed to describe the relationships, based upon the UOT. With special interest, the possibility was considered that the supposed constant intervals were not applicable to all cycles. The distribution of LH surge-UOT and LH peak-UOT intervals will be described in spontaneous and induced cycles. Spontaneous and anti-oestrogen induced cycles will be compared with respect to these intervals. The relationstip between LH surge-UOT and LH peak-UOT interval in individual cycles will be described. Also, the effect of the applied method of $\mathrm{LH}$ peatk detection on the distribution of the peaks and the possibility of biologic variation will be discussed.

\section{Table V.2.}

Descriptive data of LH surge-UOT and LH peak-UOT intervals in spontaneous $(\mathrm{n}=90)$ and anti-oestrogen induced $(n=25)$ cycles (Mann-Whitney $U$ test for nonparametric distributions)

\begin{tabular}{lllccccc} 
& $\begin{array}{l}\text { Type of } \\
\text { cycles }\end{array}$ & mean & max & min & st dev & sterror & $\begin{array}{c}\text { Mann-Whimey } \\
\text { Utest }\end{array}$ \\
\hline $\begin{array}{l}\text { IntervalLH-surge } \\
\text { UOT(hours) }\end{array}$ & spont. & 28.3 & -97 & 15 & 19.2 & 2.0 & $\mathrm{p}=0.749$ \\
& induced & 27.9 & -109 & 14 & 23.9 & 4.8 & \\
Interval-LH-peak & spont. & 18.4 & -74 & 24 & 12.5 & 5.5 & $\mathrm{p}=0.515$ \\
UOT(hours) & induced & 18.7 & -68 & 14 & 17.4 & 3.5 & \\
\hline
\end{tabular}

The descriptive data of the LH surge and peak - UOT intervals are presented in table V.2.ln spontancous cycles the mean interval LH surge-UOT was 28.3 hours \pm 19.2 hours (SD). The mean LH peak-UOT interval amounted $18.4 \pm 12.5$ (SD) hours. In induced cycles the intervals were 27.9 hours \pm 23.9 (SD) and 18.7 hours \pm 17.4 (SD) respectively. Using the Mann-Whitney U test for nonparametric distributions no significant differences were found between spontaneous and induced cycles. Figure V.3. shows the distribution of the LH surges and peaks with respect to UOT in spontaneous cycles. The cumulative distributions in spontancous and anti-oestrogen induced cycles are presented in fig. $W .4$. It appeared that the wide variation, indicated by the standard deviation was partly caused by a small group of cycles. The majority (77/90) of the LH surges in spontaneous cycles was situated between 42 and 0 hours and 8190 of the LH peaks between 36 and 0 hours before UOT. In four cycles, the LH surge was found beyond UOT, in the sample taken at the moment of the observation of a ruptured follicle. So these findings were probably due to the relatively low sampling and scanning frequency. In nine cycles, the LH-surge was situated more than 48 hours before UOT. In six of them, also the LH peak remained more than 48 hours before UOT. This considerable shift could not only be explained by methodological aspects of LH peak determination. It will be further discussed in chapter VT. The distributions of both the LH-surge and the LH peak showed a phasic, wave-shaped pattern. The L.H-surges were cumulated around 36 and 12 hours before UOT and the LH 

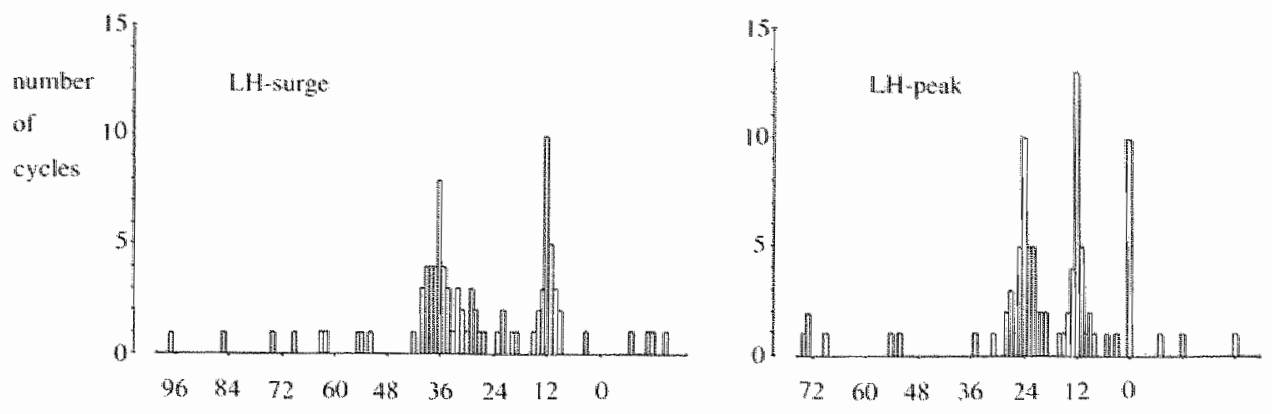

Time betere uot hours)

Fig. V.3. Distribution of LH surge and LH peak with respect to the monent of UOT (honr zero)

A LH surge

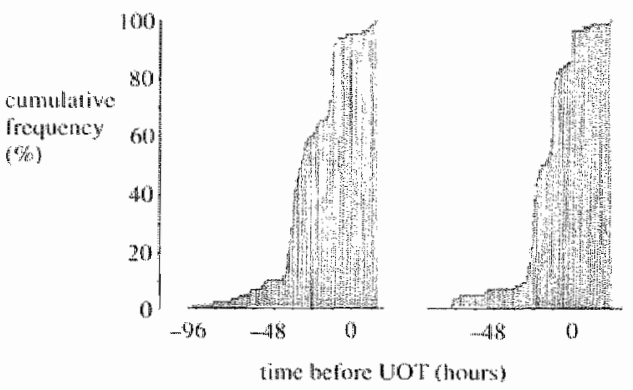

C LH surge

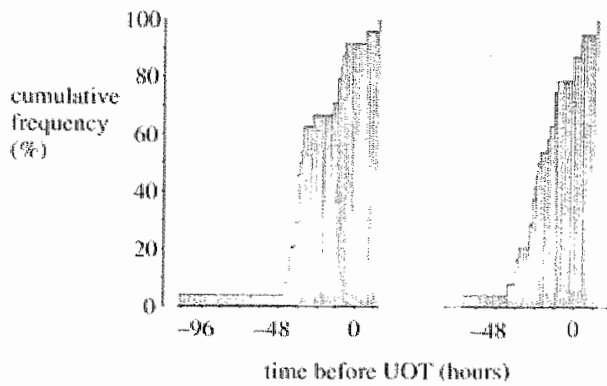

Fig. V.4. Cumulative frequency of L.H surge and $L H$ peak occurrence with respect to UOT' $A$ and B: spontaneous cycles $(n=90)$

$C$ and $D$ : anti-oestrogen induced cycles $(n=25)$

Hour zero is the monent of UOT in all cycles

peaks around 24, 12 and 0 hours before UOT (fig. V.3.). Also in the induced cycles this pattern was apparent (fig. V.4.). Although this phenomenon looked disurbing at first glance, it appeared to originate from the periodicity of observations. Fig. V.5 represents the distribution of the moments during the 24 hours-period at which LH surge, LI peak and supposed moment of ovulation were situated. Observations were limited to approximatcly one third of the 24 hour period. By definition this was reflected in the time of occurrence of the LH surge. The times of UOT were by definition situated between wo observations, i.e. mostly during the night time. The more complex definition of the LH peak caused a 12 hour rhythm: part of the LII peaks were situated at the moment of observation, another part between two observations. It is evident that these artificial cumulations are transmitted to the distributions of LH surge-UOT and $L H$ peak-UOT intervals.

The wide range of the LH peak and LH surge-UOT intervals could rise doubts about the adequacy of the definitions or the uniformity of the shape of the LH peak. Therefore, the relationship between LH surge and LH peak in the individual cycle had to be considered. In fig. V.6 all the LH surges in the group of spontaneous cycies were ranked according 10 the duration of the LH surge-UOT interval. The temporal relation with the corresponding 

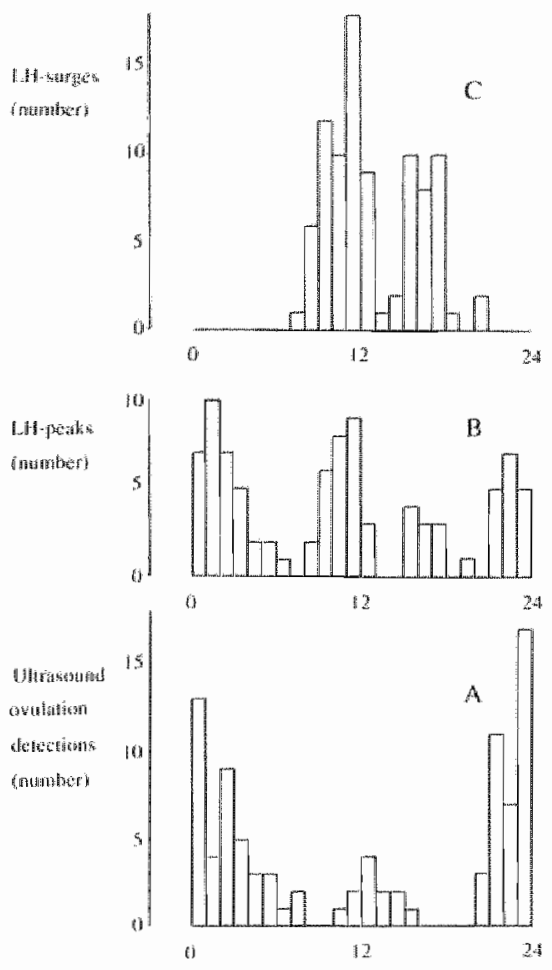

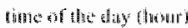

Fig. V.5. Distributions of UOT (A), LH peaks (B) and LH sturges (C) over the 24 hours period. A method dependent, phasic distribution is apparent.

LH peak is also shown in this figure. It appears that when the LH surge-UOT interval was large, the LH peak was in general shifted to the right with respect to the LH surge. When the LH surge was detected short before UOT, it mostly coincided in time with the LH peak detection. This phenomenon in the sample of spontaneous cycles confirmed the expectation, that with the use of 24 -hour frequency of assays, the detection of the LH surge was rather inaccurate. The value, considered to be the surge, could actually be a value in the increase of the peak. In one third of the cases however it belonged to the centre of the peak. The fact that the highest value was found 0-36 hours after the surge confirmed that the duration of the LH peak was approximately 24 to 48 hours. In three cycles the LH surge was later than the LH peak. In these cases, the first value that belonged to the peak, was less than $100 \%$ above the preceding value. Also this phenomenon can be considered to be a failure of the LH surge definition.

An effort was made to differentiatte between methodologic variation and biologic variation of the LH peak-UOT interval. A considerable methodologic variation had to be taken into account because of the relatively low sampling frequency. For the LH surge the estimation of the maximal possible variation was easy: a LH surge, detected at a certain moment, might ultimately have been detected during the 24 hours before or after this particular moment. Thus the maximal methodologic variation of this parameter was 48 hours. Similarly, the maximal variation of the supposed moment of ovulation was unambiguous: the moment of follicle rupture was estimated to be the mid-point between two ultrasonic 


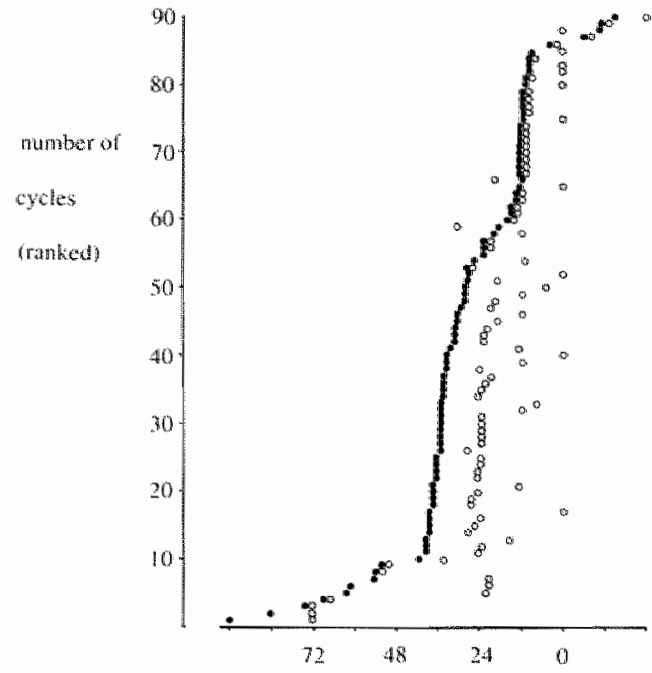

Time before UOT (hovis)

Fig. V.6. Relation between LH surges and peaks in individual cycles. Cyles are ranked according to the duration of the LH surge-UOT interval. Solid circle indicates the moment of the LH surge, the open circle indicates the time of the corresponding $\mathrm{LH}$ peak.

Time zero is the time of UOT.

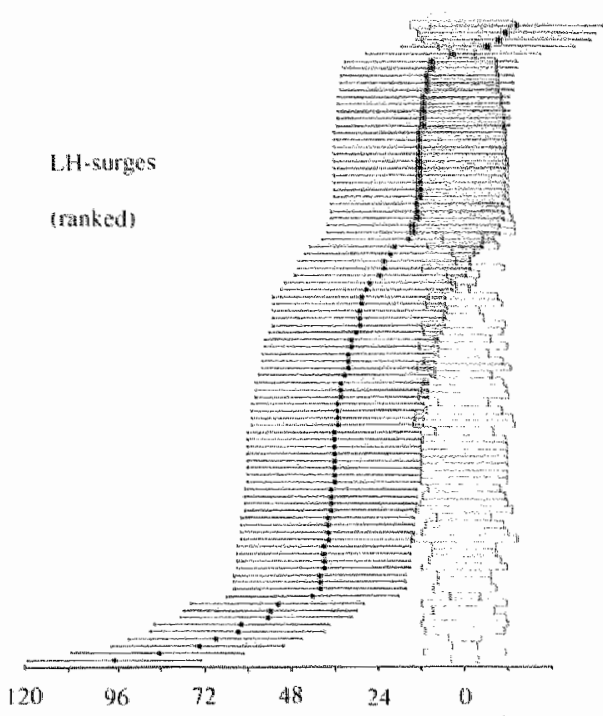

T'inc betore UOT (hours)

Fig. V.7. Graphic representation of the maximum methodologic variation in LH surge detection $(\longmapsto)$ and the variation in defection of the ultrasound signs of owulation $(\square)$ in each indiwidual cycle $(n=90$; spontaneous cycles). Cycles are ranked according to the LH surge-UOT interval

observations. The maximal variation of the UOT was equal to the duration of the period between observations (UOP). For the LH peak, the maximal variation depended on the number of values involved: if one or three $\mathrm{LH}$ values exceeded the mean $\mathrm{LH}$ level, the maximal variation was 48 hours; if there were two values, the variation was 24 hours. For the LH surge, the relationship between the maximal variation of the surge detection and the UOP was studied (fig. V.7.).

Two groups of cycles can be distinguished: those cycles which showed overlap between the LH surge variation and UOP $(66 \%)$ and those in which there was no overlap (34\%).

Within each of these two groups, nothing can be said about the intercycle variation. The fact however, that there is one group that showed overlap and another in which there was no overlap, in our view is a definite indication for the existence of biological variation in the LH surge-UOT interval. The extent of this variation cannot be derived from our data.

\section{Discussion}

The relationship of the LHH surge and peak and the ultrasonographical signs of ovulation was very close in spontaneous and in induced cycles as well. This confirmed the findings from earlier studies, applying other methods for detection of the ovulation. Conversely, the hypothesis that the ultrasonographical observation of follicle rupture is related to the moment of owulation, was supported by this relationship.

Although the mean intervals LH surge-UOT and LH peak-UOT were comparable to the results of earlier investigations, the variation of these intervalls was very wide. The daily 
determination of $\mathrm{LH}$ was an important cause of variation, as was shown by the phasic pattern in the distribution of the LHA surge/peak - UOT intervals. This makes daily LH determinations less adequate for prediction or detection of the ovulation in individual cycles. On the other hand, the low frequency of assays could not fully explain the actual variations found in the LH surge - UOT interval. To a certain degree this variation must originate from biological differences in the time relation between LH surge and ovulation. An important limitation of the use of LH surge or peak determination for ovulation prediction was the presence of a group of cycles in which the interval LH peak-ovulation was more than 48 hours.

\subsubsection{The oestradiol-17-beta peak: temporal relationship with UOT}

The oestradiol-17-beta peak was imvestigated in 93 spontaneous and 22 anti-oestrogen induced cycles (24 and 14 subjects respectively). The descriptive data of the oestradiol-peakUOT interwal and the actual height of the peak are summarized in table V.3. There was a significant difference in the actual values of the oestradiol peak between spontaneous and induced cycles: 0.70 and $2.29 \mathrm{mmol} / \mathrm{l}$ respectively (p 0.001 , Mann-Whitney $U$ test). The intervals oestradiol-17-beta peak-LOT did not differ significantly: 23 . 1 hours \pm 18.8 (SD) in spontancous and 31.4 hours \pm 27.8 (SD) in anti-oestrogen induced cycles $(p=0.247$. Mann-Whitmey U test).

Table V.3.

Descriptive data of the oestradiol-17-beta peak-UOT interwal and the level of the peak in 93 spontaneous and 22 anti-oestrogen induced cycles (Mann-Whitney U test for nonparametric distributions)

\begin{tabular}{|c|c|c|c|c|c|c|c|}
\hline & $\begin{array}{l}\text { type of } \\
\text { cycles }\end{array}$ & mean & $\max$ & $\min$ & stidev & sterr & $\begin{array}{c}\text { Mann-Whiney } \\
\text { Utest }\end{array}$ \\
\hline \multirow[t]{2}{*}{$\begin{array}{l}\text { Interval oest peak } \\
\text { UOT (hours) }\end{array}$} & spont & 23.1 & -78 & 17 & 18.8 & 1.9 & \multirow{2}{*}{$p=0.247$} \\
\hline & induced & 31.4 & .109 & 7 & 27.8 & 5.9 & \\
\hline \multirow{2}{*}{$\begin{array}{l}\text { Level oestrad peak } \\
\text { (nmol/l) }\end{array}$} & spont. & 0.70 & 1.45 & 0.18 & 0.28 & 0.03 & \multirow{2}{*}{$p<0.001$} \\
\hline & induced & 2.29 & 8.80 & 0.39 & 2.40 & 0.50 & \\
\hline
\end{tabular}

The distribution of the oestradiol peak-UOT and LH peak-UOT intervals did not differ significantly in a group of 81 spontancous cycles $(p=0.169$, Mann-Whitmey $U$ test $)$. Only $39 \%$ of the oestradiol peaks according to the definition applied in this series, preceded the L.H peak, as is shown in fig. V.8.

\section{Discussion}

The oestradiol peak -UOT interval was not sugnificantly different from LH peak-UOT interval. The oestradiol peak did not generally precede the LH peak, as was concluded by Landgren et a (1977). The variation in oestradiol peak-UOT intervals was wide. "The actuat value of the oestracliol peak was significantly higher in anti-oestrogen induced cycles than in spontaneous cyeles. 


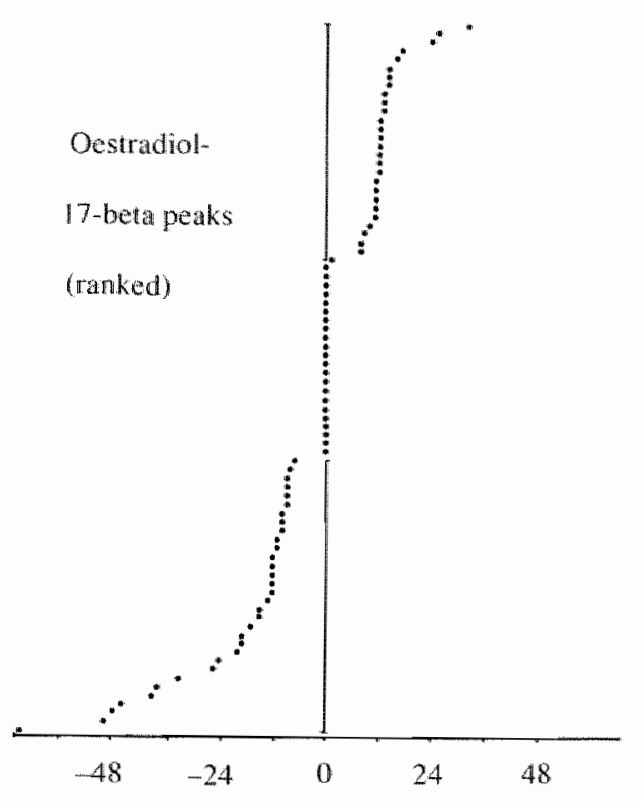

Time before LH-peak (hours)
Fig. V.8. Temporal relationship between oestradiol-17-bet peaks and LH peaks $(n=82$; spontaneous cycles). Time zero is the time of the LH peak. Cycles are ranked according to the oestradiol peak-LH peak interval.

\subsubsection{Progesterone}

Progesterone was assayed according to the schedule, mentioned in chapter V.2.L. Although it was tried to determine the progesterone ievels in all of the 111 spontaneous and 40 antioestrogen induced cycles, this aim was not attained. In fact progesterone at UOT was available in 88 spontaneous and 23 anti-oestrogen induced cycles and progesterone in the luteal phase in 100 and 38 cycles respectively. The remainder of the results was missing on account of failures in sampling, storage or assaying.

In 10 of the cycles investigated, pregnancy occurred. In six of them progesterone at UOT was known ( 3 spontaneous and 3 anti-oestrogen induced cycles) and in eight of them progesterone during the luteal phase ( 3 spontaneous and 5 anti-oestrogen induced). The interpolated progesterone levels at UOT are summarized in table V.4. In spontaneous cycles the mean ovulatory progesterone level was $5.6 \mathrm{nmol} / 1(1.8 \mathrm{ng} / \mathrm{ml})$, similar to that found by Laborde et al (1976) and somewhat lower than reported by Yussman and Taymor

Table V.4.

Descriptive data of progesterone values at UOT and on day 5-7 after UOT in spontaneous and anti-oestrogen induced cycles (Mann-Whitney $U$ test)

\begin{tabular}{|c|c|c|c|c|c|c|c|c|}
\hline & $\begin{array}{l}\text { rype of } \\
\text { cycles }\end{array}$ & number & mean & $\max$ & $\min$ & $s / d e v$ & sterror & $\begin{array}{c}\text { Mamn-Whimey } \\
\text { Utess }\end{array}$ \\
\hline \multirow[t]{2}{*}{$\begin{array}{l}\text { Progeste rone at } \\
\text { UOT (nmol/di) }\end{array}$} & spontaneous & 88 & 5.6 & 17.0 & 1.0 & 3.2 & 0.3 & \multirow{2}{*}{$p<0.001$} \\
\hline & induced & 23 & 10.2 & 36.0 & 1.4 & 7.6 & 1.6 & \\
\hline \multirow{2}{*}{$\begin{array}{l}\text { Progesterone luteal } \\
\text { phase (nmol/1) }\end{array}$} & spontaneous & 100 & 46.5 & 120.0 & 10.0 & 20.5 & 2.1 & \multirow{2}{*}{$p<0.001$} \\
\hline & induced & 38 & 73.1 & 175.0 & 20.0 & 39.1 & 6.8 & \\
\hline
\end{tabular}


(1970). There was a significant difference in progesterone levels at UOT beween spontaneous and induced cycles: 5.6 and $10.2 \mathrm{nmol} / 1$ respectively $(\mathrm{p} 0.001$, Mann-Whitney U test).

The variation in owulatory progesterone levels was very wide, as illustrated in fig. V.9. There was no significant difference in progesterone at UOT between spontaneous cycles in volunteers and patients ( $p=0.479$, Mann-Whitney U test). Progesterone at UOT in cycles which turned out to be conceptive $(n=6)$ were not significantly different from the remaining. cycles ( $p=0.594$, Mann-Whitney U test).

Owulatory progesterone levels were arranged according to subject in those subjects who had three or more cycles investigated (fig. V.10.). The variation appeared to be mainly intercycle and not between subject variation, although in a few subjects the spread of progesterone levels in subsequent cycles was small.

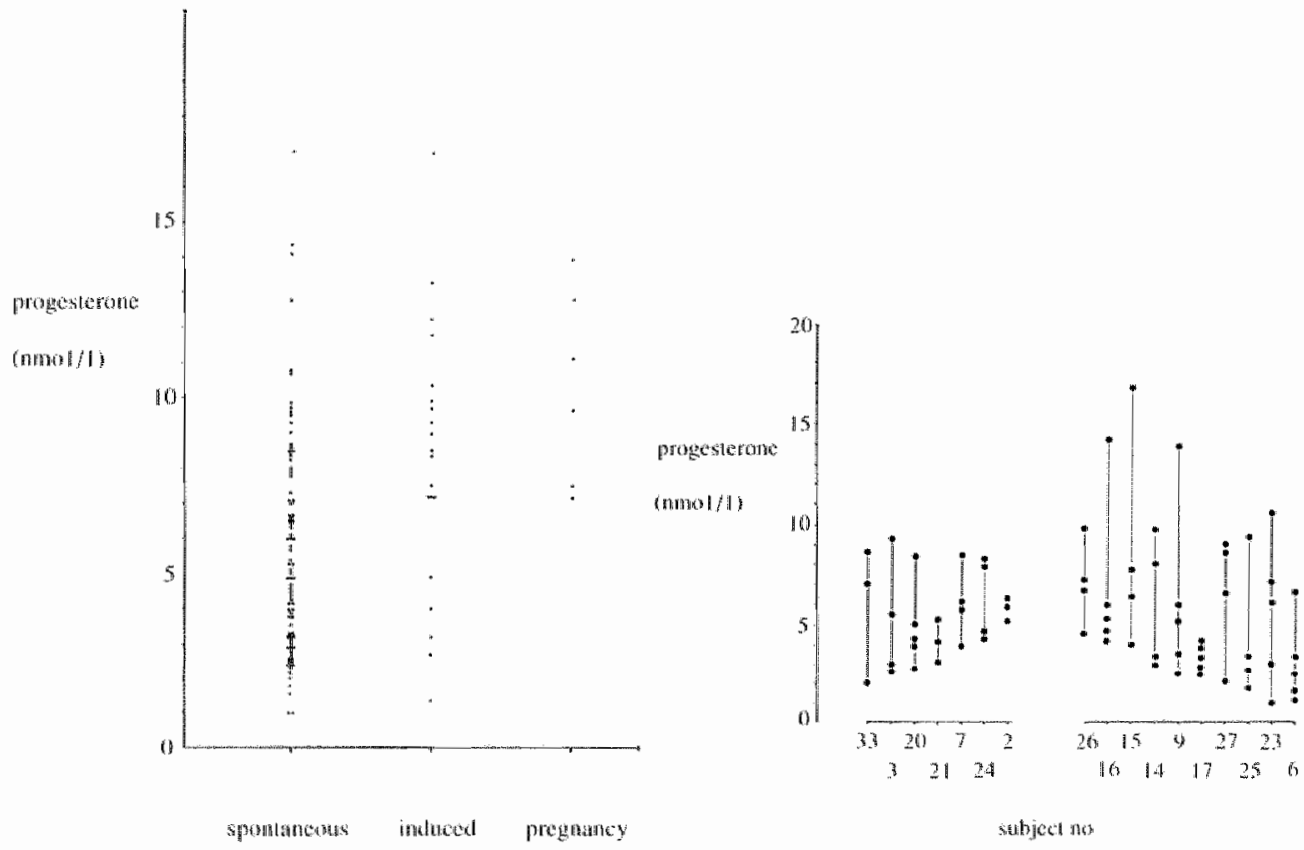

Fig. V. 9. Progesterone levels, interpolated for the estimated time of ultrasound signs of ovulation (UOT). Groups are spontaneous cycles (left), anti-oestrogen induced cycles (midetle) and cycles in which pregnancy occurred (right)
Fig. V. 10. Progesterone levels interpolated for the moment of UOT, arranged by subject. Groups are: healthy wolunteers (left) and patients (right). Only spontaneous cycles are concerned.

The luteal progesterone levels were significantly higher in induced than in spontaneous cycles (table V.4). The mean progesterone level was $46.5 \mathrm{mmol} / \pm 20.5$ (SD) and 73.1 mmol/1 \pm 39.1 (SD) in spontaneous and anti-oestrogen induced cycles respectively ( $\mathrm{p} \times 0.001$, Mann-Whitney U test).

The luteal progesterone levels in conceptive cycles were not different from the not conceptive group ( $p=0.155$, Mann-Whitney $U$ test $)$. Also there was no difference between luteal progesterone levels in volunteers and patients in spontaneous cycies $(p=0.387$, 
Mann-Whitney $U$ test). As in the case of ovulatory progesterone levels, there was a wide variation in the luteal progesterone levels (fig. V.11.). This variation was also found in series of cycles of the same individual (fig. V.12.).

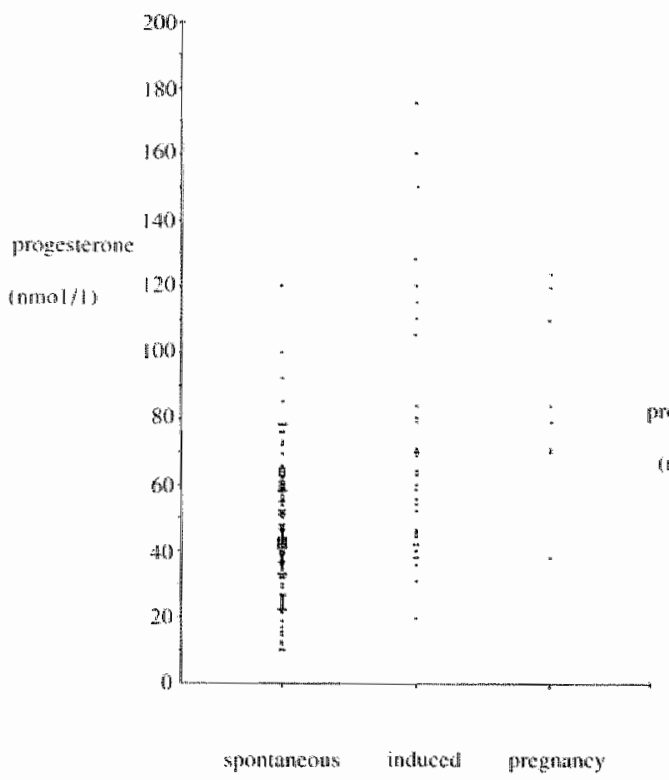

Fig. V.11. Progesterone levels on day 5-7 after ultrasound signs of ovulation. Groups are spontaneous cycles (left) antioestrogen induced cycles (middle) and cycles in which pregnancy occurred (right)

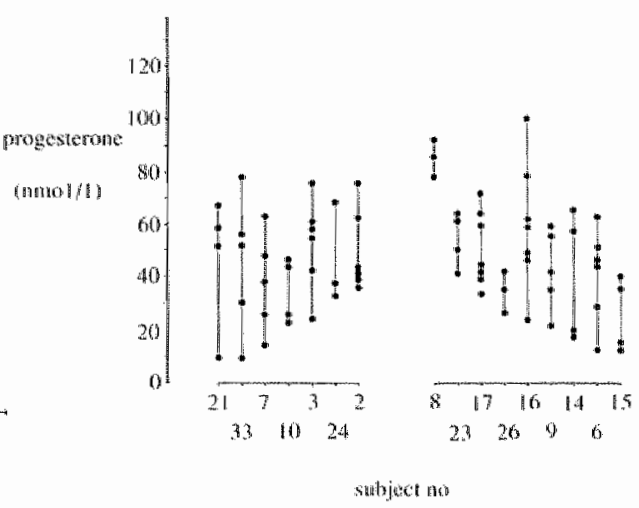

Fig. V.12. Progesterone levels on day $5-7$ after ultrasound signs of ovulation, arranged by subject.

Only spontaneous cycles were considered. Groups are: healthy volunteers (left) and patients (right).

\section{Discussion}

The mean level of progesterone at the estimated moment of ovulation was similar to those, found in earlier reports. Variation in this progesterone level, the overall as well as the inner subject variation, was wide. The ovulatory progesterone level as a marker of the time of ovulation appeared to be useless. The wide variation in luteal progesterone levels was confirmed in this investigation in which the time relationship between ovulation and sampling was uniform.

It is interesting that the report of Israel et al (1972) who found no single progesterone level below $3 \mathrm{ng} / \mathrm{ml}(10 \mathrm{nmol} / \mathrm{l})$ in ovulatory cycles, was confirmed. Also in the present series no progesterone below this level was encountered.

In contrary, the theory of Radwanska and Swyer (1974) that a progesterone level below 10 $\mathrm{ng} / \mathrm{ml}(32 \mathrm{nmol} / \mathrm{l})$ in a single mid-luteal determination was indicative for luteal dysfunction appeared to be doubtful. Approximately $25 \%$ of the cycles cxhibited such a low level, volunteers and patients alike. If the theory of Radwanska and Swyer would be true, it would mean that one in four cycles also in healthy volunteers has a deficient luteal phase. Although the counterpart cannot be proven, it seems more likely to search for a good definition of luteal deficiency than to assume that such a high proportion of all spontancous cycles is defective. 


\section{2 .2 .4 . Relationships between preovulatory and postovulatory parameters of the menstrual cycle}

In the group of 111 spontaneous cycles ( 28 subjects) and 40 antioestrogen induced cycles (19 subjects) a study was done to what cxtent a correlation existed between preovulatory and postovilatory parameters.

The cycles were ovullatory according to at least one out of three criteria: the existence of a LH peak, ulltrasonographical signs of follicle rupture, luteal progesterone increase.

Table V.S.

Cross tabulation of correlation coefficients ( $r$; Pearson two-tailed test) and their significance (p) between preovulatory and postovulatory variables of the cycle. The number of cycles is indicated $(n)$.

Spontancous cycles are represented in table V.5A; anti-oestrogen-induced cycles in table V.5B.

$(\mathrm{x})$ indicates a weak correlation $(\mathrm{x} x)$ indicates a moderate or strong correlation.

\begin{tabular}{|c|c|c|c|c|}
\hline TableV.SA & & $\begin{array}{l}\text { progesterone } \\
\text { at } U O T\end{array}$ & $\begin{array}{l}\text { progesterone } \\
\text { luteal phase }\end{array}$ & $\begin{array}{l}\text { whimase diameter } \\
\text { of follicle }\end{array}$ \\
\hline $\begin{array}{l}\text { LH surge-UOT } \\
\text { interval }\end{array}$ & $\begin{array}{l}r \\
n \\
p\end{array}$ & $\begin{array}{l}0.516 \times \\
75 \\
0.001\end{array}$ & $\begin{array}{l}-0.017 \\
90 \\
0.874\end{array}$ & $\begin{array}{l}0.323 \\
81 \\
0.003\end{array}$ \\
\hline $\begin{array}{l}\text { LH peak-UOT } \\
\text { interwal }\end{array}$ & $\begin{array}{l}r \\
n \\
p\end{array}$ & $\begin{array}{l}0.576 \times \\
75 \\
0.001\end{array}$ & $\begin{array}{l}-0.162 \\
90 \\
0.127\end{array}$ & $\begin{array}{l}0.514 \times \\
81 \\
0.001\end{array}$ \\
\hline $\begin{array}{l}\text { oestradiol } \\
\text { peak-UOT } \\
\text { interval }\end{array}$ & $\begin{array}{l}r \\
n \\
p\end{array}$ & $\begin{array}{l}0.175 \\
63 \\
0.170\end{array}$ & $\begin{array}{l}0.144 \\
73 \\
0.223\end{array}$ & $\begin{array}{l}0.315 \\
64 \\
0.011\end{array}$ \\
\hline $\begin{array}{l}\text { mean oestradiol } \\
\text { level }\end{array}$ & $\begin{array}{l}r \\
n \\
p\end{array}$ & $\begin{array}{l}0.196 \\
63 \\
0.123\end{array}$ & $\begin{array}{l}-0.125 \\
75 \\
0.568\end{array}$ & $\begin{array}{l}0.213 \\
64 \\
0.092\end{array}$ \\
\hline $\begin{array}{l}\text { ultimate diameter } \\
\text { of folliche }\end{array}$ & $\begin{array}{l}r \\
\text { n } \\
p\end{array}$ & $\begin{array}{l}0.609 \times \\
76 \\
0.001\end{array}$ & $\begin{array}{l}-0.100 \\
98 \\
0.325\end{array}$ & \\
\hline
\end{tabular}

\begin{tabular}{|c|c|c|c|c|}
\hline TableV.5B & & $\begin{array}{l}\text { progesterone } \\
\text { at Uor }\end{array}$ & $\begin{array}{l}\text { progesserone } \\
\text { luteal phase }\end{array}$ & $\begin{array}{l}\text { whimate diamnerer } \\
\text { of follicle }\end{array}$ \\
\hline $\begin{array}{l}\text { LH surge-UOT } \\
\text { interval }\end{array}$ & $\begin{array}{l}r \\
n \\
p\end{array}$ & $\begin{array}{l}0.536 \times \\
21 \\
0.012\end{array}$ & $\begin{array}{l}-0.08 \| \\
25 \\
0.700\end{array}$ & $\begin{array}{l}0.491 \\
24 \\
0.015\end{array}$ \\
\hline $\begin{array}{l}\text { LH peak-UOT } \\
\text { interval }\end{array}$ & $\begin{array}{l}i \\
n \\
p\end{array}$ & $\begin{array}{l}0.460 \\
21 \\
0.037\end{array}$ & $\begin{array}{l}-0.147 \\
25 \\
0.483\end{array}$ & $\begin{array}{l}0.562 \times \\
24 \\
0.004\end{array}$ \\
\hline $\begin{array}{l}\text { oestradiol } \\
\text { peak-UoT } \\
\text { intervall }\end{array}$ & $\begin{array}{l}r \\
n \\
p\end{array}$ & $\begin{array}{l}0.548 \times \\
17 \\
0.023\end{array}$ & $\begin{array}{l}0.064 \\
22 \\
0.777\end{array}$ & $\begin{array}{l}0.413 \\
20 \\
0.070\end{array}$ \\
\hline $\begin{array}{l}\text { mean ocstradiol } \\
\text { lewel }\end{array}$ & $\begin{array}{l}r \\
\text { n } \\
p\end{array}$ & $\begin{array}{l}0.868 \times x \\
17 \\
0.001\end{array}$ & $\begin{array}{l}0.417 \\
23 \\
0.047\end{array}$ & $\begin{array}{l}0.306 \\
29 \\
0.106\end{array}$ \\
\hline $\begin{array}{l}\text { Uitimate diameter } \\
\text { of follicle }\end{array}$ & $\begin{array}{l}r \\
n \\
p\end{array}$ & $\begin{array}{l}0.474 \\
19 \\
0.040\end{array}$ & $\begin{array}{l}0.118 \\
36 \\
0.493\end{array}$ & \\
\hline
\end{tabular}


The preovulatory parameters included time intervals between ultrasound observations and hormonal events:

- LH surge - UOT interval

- LH peak-UOT interval

- Oestradiol peak - UOT interval

- mean oestradiol level

The postovulatory parameters were:

- progesterone level at UOT

- progesterone level in the luteal phase, day 5-7 after UOT

- Uuteal phase duration.

The ultimate mean follicular diameter was compared with both pre- and postowulatory parameters.

A two-tailed Pearsons" test for linear correlation was performed on each pait of these variables (table V.5A and V.5B).

Except the correlation between mean preovulatory oestradiol level and progesterone at UOT in the induced cycles $(r=0.868, p=0.001)$, no strong correlations were found. Weak positive correlations are indicated in the tables. They existed between the intervals LH peak-UOT, LH surge-UOT and oestradiol peak-UOT on one side and the level of progesterone at UOT on the other side. "The latter correlation was not present in the spontaneous cycles. The ultimate mean follicular diameter correlated only weakly witli progesterone at UOT and LH peak-UOT interval and a correlation failed with the mean preovulatory oestradioll level.

It seemed useful to review also the most basic parameters of the cycle, the duration of the follicular and luteal phases, applying the ultrasound method of ovulation detection. As the day of the ovulation arbitrarily the day was chosen at which the UOT was situated. As most ultrasonic obserwations were performed during the day time, most of these UOT were situated during the night time, just before or just after midnight. Thus, in most cases there was a maximal possible variation of one day. Only in those cases, in which the two observations, defining the UOP, took place on the same calendar day, the accuracy of the estimation of the day of ovulation was optimal. In the present series, this applied to $20 \%$ of the cycles.

The total cycle duration, the length of follicular and luteal phases are summarized itn table V.6. for spontaneous and anti-oestrogen induced cycles.

The follicular phase duration showed a wider range than the luteal phase duration in both types of cycles. In spontaneous cycles the follicular phase varied between 7 and 25 days, the luteal phase between $9-17$ days. In anti-oestrogen induced cycles these figures were 9 24 and $9-19$ days respectively. The considerable range of the luteal phase was in agreement with the findings of Landgren et al (1980) who used the LIH peak for detection of the ovulation.

Comparing the warious phases between spontaneous and induced cycles, the total cycle length was prolonged in the induced group. This lenghtening was statistically significant ( $\mathrm{P}$ $=0.001$, Mann-Whitney $U$ test). It was based upon prolonging of both the follicular and luteal phases, but only the follicular phase prolongation was significant $(p=0.006$, Mann Whitney U test).

In both types of cycles, the cycle duration and the follicular plase duration showed a 
Table V.6.

General characteristics of cycle length, duration of the follicular and luteal phases, referring to the day of ultrasonic evidence of ovulation; All durations are expressed as days. Data in spontaneous and anti-oestrogen induced cycles are compared with the Mann-Whithey $U$ test.

\begin{tabular}{|c|c|c|c|c|c|c|}
\hline & \multicolumn{2}{|c|}{ cycle length } & \multicolumn{2}{|c|}{ follicular phase } & \multicolumn{2}{|c|}{ luteal phase } \\
\hline & spontaneous & induced & spontaneous & induced & spontaneous & induced \\
\hline number of cyles & 100 & 33 & 109 & 39 & 98 & 32 \\
\hline mean duration & 27.1 & 28.9 & 13.6 & 14.8 & 13.6 & 14.2 \\
\hline st dev. & 2.9 & 3.0 & 2.9 & 2.8 & 2.1 & 2.0 \\
\hline range & $21-41$ & $23-35$ & $7-25$ & $9-24$ & $9-17$ & $9-19$ \\
\hline $\begin{array}{l}\text { Mann Whitney } \\
\text { U test }\end{array}$ & \multicolumn{2}{|c|}{$p=0.001$} & \multicolumn{2}{|c|}{$p=0.006$} & \multicolumn{2}{|c|}{$p=0.183$} \\
\hline
\end{tabular}

Table V.7.

Cross tabulation of correlation coefficients ( $r=$ Pearsons two tailed test) and their significance $(\mathrm{p})$ between duration of cycle phases and preovulatory and postovulatory parameters. Number of cycles is indicated ( $\mathrm{n}$ )

Upper: spontancous cycles

Lower: anti-oestrogen induced cycles

\begin{tabular}{|c|c|c|c|c|c|c|}
\hline & & $\begin{array}{l}\text { mean pre- } \\
\text { ovulatory } \\
\text { oestradiol }\end{array}$ & $\begin{array}{l}\text { aesiradiol } \\
\text { peak level }\end{array}$ & $\begin{array}{l}\text { preowulatory } \\
\text { follicle size }\end{array}$ & $\begin{array}{l}\text { progesterone } \\
\text { at UOT }\end{array}$ & $\begin{array}{l}\text { progesterone } \\
\text { luteal phase }\end{array}$ \\
\hline $\begin{array}{l}\text { follicular } \\
\text { phase } \\
\text { duration }\end{array}$ & $\begin{array}{l}r \\
n \\
p\end{array}$ & $\begin{array}{l}0.060 \\
102 \\
0.546\end{array}$ & $\begin{array}{l}0.221 \\
73 \\
0.059\end{array}$ & $\begin{array}{l}0.507 \\
98 \\
0.620\end{array}$ & $\begin{array}{l}0.064 \\
85 \\
0.56\end{array}$ & $\begin{array}{l}0.0604 \\
109 \\
0.532\end{array}$ \\
\hline $\begin{array}{l}\text { Jufleal } \\
\text { phase } \\
\text { dutration }\end{array}$ & $\begin{array}{l}r \\
n \\
p\end{array}$ & $\begin{array}{l}0.041 \\
92 \\
0.697\end{array}$ & $\begin{array}{l}0.036 \\
66 \\
0.015\end{array}$ & $\begin{array}{l}-0.259 \\
88 \\
0.027\end{array}$ & $\begin{array}{l}-0.2530 \\
76 \\
0.907\end{array}$ & $\begin{array}{l}0.012 \\
98\end{array}$ \\
\hline $\begin{array}{l}\text { cycte } \\
\text { duration }\end{array}$ & $\begin{array}{l}r \\
n \\
p\end{array}$ & $\begin{array}{l}0.0514 \\
94 \\
0.622\end{array}$ & $\begin{array}{l}0.166 \\
68 \\
0.118\end{array}$ & $\begin{array}{l}-0.121 \\
88 \\
0.259\end{array}$ & $\begin{array}{l}-0.151 \\
76 \\
0.192\end{array}$ & $\begin{array}{l}-0.212 \\
100 \\
0.834\end{array}$ \\
\hline $\begin{array}{l}\text { follicular } \\
\text { phase } \\
\text { duration }\end{array}$ & $\begin{array}{l}\mathrm{r} \\
\mathrm{n} \\
\mathrm{p}\end{array}$ & $\begin{array}{l}0.253 \\
32 \\
0.162\end{array}$ & $\begin{array}{l}0.217 \\
20 \\
0.357\end{array}$ & $\begin{array}{l}0.272 \\
36 \\
0.108\end{array}$ & $\begin{array}{l}0.140 \\
22 \\
0.533\end{array}$ & $\begin{array}{l}0.021 \\
39 \\
0.898\end{array}$ \\
\hline $\begin{array}{l}\text { Iutoul } \\
\text { phatsc } \\
\text { dutation }\end{array}$ & $\begin{array}{l}\text { r } \\
n \\
p\end{array}$ & $\begin{array}{l}0.039 \\
26 \\
0.849\end{array}$ & $\begin{array}{l}-0.025 \\
17 \\
0.925\end{array}$ & $\begin{array}{l}-0.343 \\
30 \\
0.064\end{array}$ & $\begin{array}{l}0.050 \\
17 \\
0.850\end{array}$ & $\begin{array}{l}0.140 \\
32 \\
0.446\end{array}$ \\
\hline $\begin{array}{l}\text { cycle } \\
\text { durtion }\end{array}$ & $\begin{array}{l}r \\
n \\
p\end{array}$ & $\begin{array}{l}0.3602 \\
27 \\
0.065\end{array}$ & $\begin{array}{l}0.290 \\
18 \\
0.244\end{array}$ & $\begin{array}{l}0.690 \\
30 \\
0.717\end{array}$ & $\begin{array}{l}0.155 \\
17 \\
0.552\end{array}$ & $\begin{array}{l}0.157 \\
33 \\
0.383\end{array}$ \\
\hline
\end{tabular}


significant linear correlation: $r=0.742, p=0.001$ and $r=0.761, p=0.001$ for spontancous and induced cycles respectively. There was no strong linear correlation between the durations of the follicular and luteal phases in spontaneous $(r=-0.277, p=0.006)$ and induced cycles ( $r=-0.280, p=0.121$; Pearsons two-tailed test).

The relationships between the duration of cycle phases and oestradiol-17-beta peak level, ultimate follicle diameter, progesterone at UOT and lutal phase progesterone are summarized in table V.7.A total lack of limear comrelation between each pair of these variables was found.

The follicular/luteal phase ratio (F/L ratio) was calloulated for the spontaneous and antioestrogen cycles. The mean F/L ratio in the two groups were $0.942 \pm 0.433$ (SD) and 0.908 $\pm 0.462(\mathrm{SD})$ respectively which difference was not significant $(\mathrm{p}=0.789$, Mann-Whitney $U$ test). Contrary to the findings of Landgren et al (1980), in both groups linear comrelations were totally absent between the F/L ratio's and mean preovulatory oestradiol-17-beta, progesterone at the ovulation, progesterone in the luteal phase and preovulatory follicle size.

\section{Discussion}

The relevance of the correlations between preovulatory and postovulatory parameters is questionable. None of them was strong enough to conclude a causal relationship between variables. The weak correlation between the LH peak-UOT intervals and the progesterone level at UOT is probably caused by the fact that the LH peak initiates luteinization. It supports the opinion that luteinization and ovulation are independent effects of the LH peak. A number of relationships between cyche phase durations and hormonal parameters, reported earlier, were not found in this series using the present definitions.

\subsubsection{Temporal relationship between midpain and UOT}

The incidence of midpain in 173 cycles, ovulatory by ultrasound criteria, was $54(31.4 \%)$, which was in agreement with the figures of Hann ef al (1979) and $\mathrm{O}^{\prime}$ Herlihy et al (1980). In only three cases, such a pain sensation was felt twice in the same cycle. Of the 24 subjects. who had three or more cycles investigated, seven never experienced midpain (4 to 9 cycles) In the remaining 17, the incidence varied from 1 in 6 cycles to 4 in 6 cycles. None of the subjects had midpain in all of the cycles.

The incidence was lower in spontaneous than in induced cycles: $27.9 \%$ and $47.5 \%$ respectively, the difference being statistically significant $(\mathrm{p}=0.020$, Mann-Whitney $\mathrm{U}$ test). There was no difference in incidence between the groups left-sided and right-sided ovulations ( $p=0.825$, Mann-Whitney $U$ test) and no significant difference could be found in preowulatory diameter between cycles with and without midpain $(p=0.341$, MannWhitney U test).

The mean interval between the moment of midpain and the estimated moment of ovulation was -6.5 hours, the range in these intervals was -64 to +15 hours. Fig. V.13 shows the distribution of these intervals. The wide variation cannot be explained from the observation interval of UOP, so that a real variation should be supposed. The midpain - ovulation interval was not different for the groups of spontancous and the total group of inducod cycles $(p=0.167$, Mann-Whitney $U$ test) but a significant difference was found between the spontaneous and the anti-oestrogen induced groups $(p=0.011$, Mann-Whitney $U$ test $)$ 


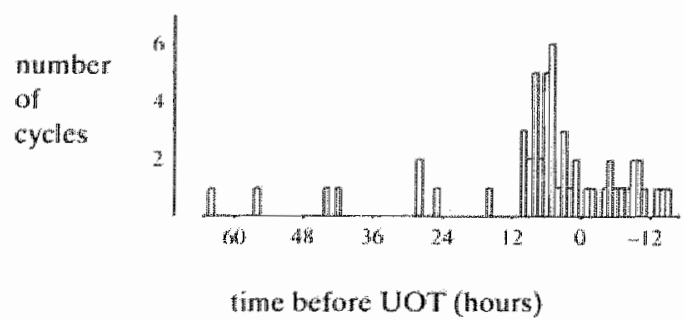

Fig. W.13. Distribution of the time intervals berween midpain and the moment of UOT (hour zero); $n=54$ cycles

in a sense that in anti-oestrogen induced cycles, the interval was longer. There was no correlation between the preovulatory diameter and the midpain - ovulation interval $(\mathrm{r}=$ $0.009, p=0.454$ Pearsons test).

To answer the question whether midpain is a preovulatory symptom, the use of the UOP secms not to be optimal. Therefore the cases of midpain were subdiwided in classes with respect to their occurrence: before the observation of a still intact follicle (definite preovulatory), between the last observation of an intact follicle and the observation of the ruptured state (possibly preovulatory or perovulatory) and after the observation of a ruptured follicle (definite postovulatory). Table V.8 shows the occurrence of midpain with respect to these three phases. It can be concluded that generally midpain was a preovulatory symptom. In a minority of the present cases (14 in 54), the possibility remained that it was a sign of ovulation, while only in rare instances ( 2 in 54 ) such sensations were reported definitely after follicle rupture.

Table V.8.

Occurrence of midpain with respect to the ultrasonographic signs of follicle rupture

\begin{tabular}{lcccc}
\hline & with follicle intact & during UOP & with follicle rupured & total \\
\hline number of cases & 38 & 14 & 2 & 54
\end{tabular}

\section{Discussion}

The symptom of midpain occurred in $31.4 \%$ of all cycles with ultrasound signs of follicle nupture. "The incidence in induced cycles was higher than in spontaneous ones. In the majority of cases it was a preovulatory symptom and did not represent the follicle rupture itself. The relationship with fluid in the cull de sac was not explicitely investigated but the impression was that considerable amounts of free fluid were not related to the occurrence of midpain. A relationship with preovulatory follicular size was absent. The mean interval between midpain and ovulation was rather short, but this interwal had a wide range. Furthermore the incidence of midpain was low. It can be concluded that midpain is not reliable for ovulation detection.

\subsubsection{Rellationship between the temperature shift in the BBT and the day of UOT}

In a group of 2 volunteers and 18 patients, Basal Body Temperature was recorded during 21 spontaneous and 26 antioestrogen-induced cycles. All cycles were ovulatory according to two endocrine criteria: the presence of a LH-peak and a luteal progesterone rise. In 43 
of them also the day of ultrasound evidence of follicle rupture was established with certainty. Reason for the failure in the remaining 4 were lack of follicle rupture (3) and doubts about follicle rupture (1), which was definitely seen one day later.

The temperature recordings were submitted to 2 observers, who were unaware of the ultrasonographical data. The observers interpreted the recordings according to the criteria: nadir, coverline and first day of hyperthermic plateau (definitions see chapter VI.1.6.). Moreover, one of them was asked to detect the day of ovulation without a definition: the so-called "eye balling" method.

Table V.9.

Detection rates of ovulation by four BBT criteria, compared to detection by ultrasound The plus and minus signs indicate the presence or absence of detection; $(n=47$ cycles $)$

\begin{tabular}{|c|c|c|c|c|c|c|c|c|}
\hline & \multicolumn{2}{|c|}{ Nadir } & \multicolumn{2}{|c|}{ FDHP } & \multicolumn{2}{|c|}{ Coverline } & \multicolumn{2}{|c|}{ Eye-balling } \\
\hline & + & - & + & - & + & - & + & - \\
\hline Ultrasound + & 34 & 9 & 35 & 8 & 32 & 11 & 40 & 3 \\
\hline UItrasound - & 2 & 2 & 3 & 1 & 1 & 3 & 3 & 1 \\
\hline
\end{tabular}

The detection rates of the four methods are presented in table V.9. By the nadir, coverline and FDHP methods, detection rates were lowest: 34,32 and 35 out of 43 ovulations respectively. Only by the "eye balling" method a detection rate of 40 out of 43 was attained, but the value of this high detection rate was questionable in view of the low accuracy. The distributions of the estimated days of the ovulation by BBT criteria, compared to the day of UOT are shown in fig. V.14.A nearly symmetrical distribution, with the median at day

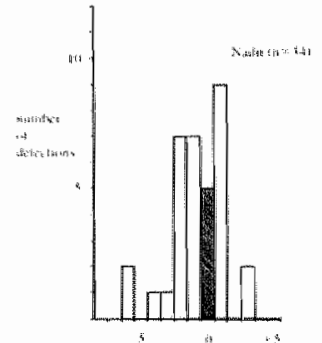

istis

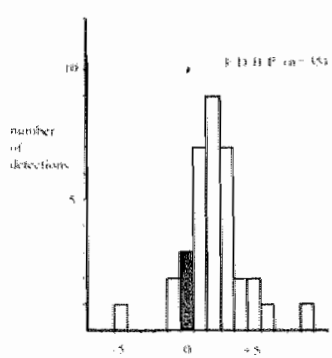

Nist
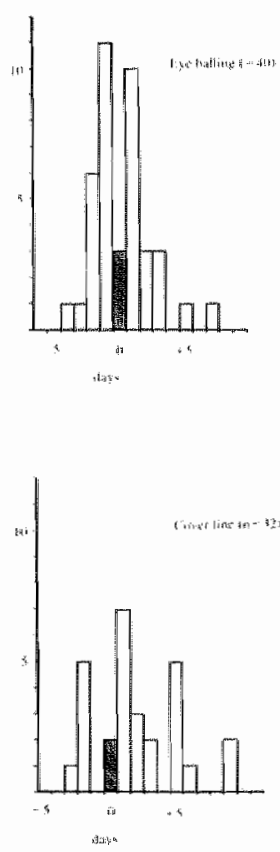

Fing. V.14. Detection of the day of ovulation by 4 BBT criteria, related to the day of UOT. Day 0 is the day of UOT" 
UOT +2 was obtained by the FDHP method. The range was however considerable: 7 days, if the wo extremes were excluded. For the remaining three methods, the ranges were compatrable, but the distributions were asymmetrical. Correct detection of the day of UOT did not exced $15 \%$ in any of the methods.

\section{Discussion}

Estimation of the day of ovulation by BBT appears not to be a reliable method, compared to ultrasonographical observations. Only the first day of hyperthermic plateau (FDHP) criterium seems to be useful, provided that a certain range is allowed. 


\section{Chapter VI}

\section{Aberrant cycles, diagnosed by the combination of ultrasound observations and hormonal parameters}

One of the main advantages of ultrasound follicle observation above other direct methods is the noninvasive character as mentioned in chapter 1 . This gives way to prospective case studies, composed of large series of observations. The comparison of frequent observations of the ovarian structure with hormonal parameters was not possible until the application of diagnostic ultrasound. Theoretically, it can be expected that occasional aberrations in the relation between hormonal and structural parameters will be revealed by this approach. The present investigation was focussed to such aberrations.

\subsection{Review of the literature}

Up to now, the indications that there are subtle disturbances of the menstrual cycle, which can only be revealed by comparison of hormonal and morphological findings, originated mainly from laparoscopic studies.

By studying the ovaries at laparoscopy during the luteal phase, several authors concluded that a condition called "Luteinization of Unruptured Follicle "(LUF) was not infrequent in patiens with unexplained infertility. In recent papers on ultrasonographical observations, a limited number of unexpected phenomena were reported, which have not yet been explained.

Both entities will be reviewed separately.

1. The Luteinization of Unruptured Follicle (LUF) Syndrome was first reported by Marik and Hulka (1978), Koninckx et al (1978) and Brosens et al (1978). The condition was defined by the lack of a stigma of ovulation at laparoscopic inspection during the luteal phase, while peripheral signs of luteinization were present.

The pathophysiologic mechanism would be the lack of follicle rupture. The etiology was supposed to be in the inadequate stimulation of the granulosa cell layer in the follicular phase of the cycle (Marik and Hulka, 1978; Koninckx et al, 1978). Subtle disorders in cycle parameters were supposed to be connected with LUF: a delayed luteinization and a delayed BBT rise (Koninckx et al, 1978), low steroid contents in the peritoneal fluid (Koninckx et al, 1978) and a significant elevation of FSH in the two days following the LH peak (Koninckx et al, 1981). On account of the high incidence in patients with unexplained infertility (30\%-50\%; Marik and Hulka, 1978; Koninckx et al, 1978, 1980) the condition of LUF was thought to be an important cause of infertility.

Although the anatomical substrate of the laparoscopically diagnosed LUF syndrome, the entrapped ovum, has not been described yet, the existence of the condition seems 10 be widely accepted.

One important methodological problem remained. There were doubts on the reliability of a single laparoscopic observation of the ovaries in the luteal phase (Portuondo et al, 
1981). Uncertainty about the presence or absence of a stigma of ovulation was frequent (30\%, Dmowsict al, 1980). On the other hand, a stigma of ovulation could repithelialize within tew days after ovulation (Koninckx et al, 1980). It is therefore that in wiew of Koninckx el al (1980) a diagnostic tool, other than llaparoscopy is needed for this syndrome.

2. In a few reports on ultrasonographical follicle observation, unexpected growth conduct of follicles was mentioned. The observations were fragmentary and tit was not clear whether they had any significance. Hackelöer et al (1979) described two cycles whth prolonged follicular ( 19 days) and short luteal phases ( 10 days). The ultrasound observations, combined with oestradiol sampling suggested two waves of follicular growth, the first of which was stopped before ovulation took place. In another cycle, a follicle of $22 \mathrm{~mm}$ diameter failed to ovulate.

Quecnan et al (1980) reported the incidental finding of a follicle growth rate as high as $13 \mathrm{~mm}$ over a 24 hour period prior to hormonal evidence of ovulation. Renaud et al (1980) observed occasionally an accelerated growth shortly before follicle rupture, while Hackelöer et al (1979) suggested that a deceleration of the growth after the LH peak was common. In the field of HMG-HCG ovulation induction Seibel et al (1981) reported a generalized increase of follicle size throughout the ovaries following $\mathrm{HCG}$ administration, which they interpreted as a mode of ovulation, specific to hyperstimulation. Of different nature were the supposed aberrations, reported by Polan et al (1982). In $35 \%$ of a small group of cycles $(n=14)$ in infertility patients $(n=14)$, they found an asynchrony between hormonal events and follicle growth. The perks of LH and oestradiol-17-beta (daily assays) were more than two days before follicle rupture, progesterone elevations started earlier than in "normal" cycles or were absent and follicles were characterized by decreased sizes, compared to "normal" cycles. All "abnormal" cycles exhibited a biphasic BB"T and normal cycle duration. The authors supposed that these cycles represented abnormal or inadequate ovulation. In view of the reported wide variation of preovulatory follicle sizes (chapter IV), the significance of the reported aberration in follicle size is questionable. Also it is doubtful whether the "normal" time relationships between hormonal and ultrasound events, are established in a small sample of nine cycles, as was supposed by the authors. Newertheless, this report is an indication that the re may be aberrations in follicle development, expressed as discrepancies between hormonal and ultrasound events.

\subsection{Apparently aberrant cycles in the present study, definitions and incidence}

In the course of the present study the attention was drawn by cycles which were apparently aberrant. In part, they had properties, similar to the laparoscopically diagnosed LUF syndrome and the supposed aberration reported by Polan et al (1982). In part, they were definitely different.

Retrospectively the present aberrations were subdivided in two types.

type I: cycles with a delay of follicle rupture with respect to hormonal events (LH and oestradiol-17-beta peak): "delayed ovulation" type.

type II: cycles with failure of follicle rupture but otherwise normal cycle characteristics. 
Table VI.1.

Incidence of "aberrant" cycles type I and II.

The subject numbers, the diagnosis with regard to infertility at the start of ultrasound observations, the total number of cycles/subject and the medication are indicated.

\begin{tabular}{|c|c|c|c|c|c|c|c|}
\hline & \multirow{2}{*}{$\begin{array}{l}\text { subject } \\
\text { number }\end{array}$} & \multirow{2}{*}{$\begin{array}{c}\text { ype of } \\
\text { infervility }\end{array}$} & \multirow{2}{*}{$\begin{array}{c}\text { number of cyctes } \\
\text { studied }\end{array}$} & \multirow[t]{2}{*}{ medication } & \multicolumn{3}{|c|}{ type of cycle } \\
\hline & & & & & "norpwal" & $y$ & H \\
\hline & 9 & male & 5 & no & 4 & 1 & - \\
\hline & \multirow[t]{2}{*}{12} & \multirow[t]{2}{*}{ male } & 4 & no & 1 & $\cdot$ & 3 \\
\hline & & & 3 & clomiphene & 2 & 1 & - \\
\hline & \multirow[t]{2}{*}{15} & \multirow[t]{2}{*}{ malle } & 4 & no & 1 & 2 & 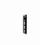 \\
\hline & & & 2 & clomiphene & 1 & 1 & . \\
\hline & 16 & male & 7 & no & 6 & 1 & . \\
\hline & 25 & male & 4 & noo & 3 & 1 & - \\
\hline & \multirow[t]{2}{*}{27} & \multirow[t]{2}{*}{ mate } & 5 & no & 4 & 1 & - \\
\hline & & & 1 & clomiphene & 1 & - & - \\
\hline & 39 & male & 1 & clomiphene & $=$ & $=$ & $!$ \\
\hline total & 7 & & 36 & & 23 & 8 & 5 \\
\hline
\end{tabular}

\section{Incidence:}

The supposed abnormalities were never seen in the 43 spontaneous cycles in 8 volunteers. In the remaining 68 spontaneous and 40 Clomiphene induced cycles in 35 infertility patients they occurred in 13 cycles. Table V1.1. shows that 7 out of 35 patients were involved. All had entered the study with the diagnosis male infertility.

Type I aberration occurred in 6 subjects, three times in one patient and once in the remainder.

Type II was encountered in 3 subjects: it was repeated three times in one of them; in another patient only one cycle was observed during the study.

In four of the seven subjects $(9,16,25$ and 27) an aberrant cycle occurred only once in a larger series of cycles (4-7 cycles/subject).

Two of the seven subjects (12 and 15 ) exhibited more frequently "aberrant" than "normal" cycles ( 4 out of 7 and 4 out of 6 ). The latter circumstance means that the intluence of wo subjects, 8 of the 13 aberrant cycles, is too predominant to allow general conclusions with respect to incidence and other quantitative aspects like hormone levels and time relationships. This applies especially to type II aberrations.

6.3. Features of "aberrant" cycles type I ("delayed ovulation")

This type was thought to be characterized by an early LH peak an early start of luteinization and lowered midluteal progesterone levels. Unlike the cycles, described by Polan at (1982), follicle growth was increased between the LH peak and follicle rupture. In those cycles in which a BBT was recorded, there was a biphasic curve.

Unfortunately, like in the report of Polan et al (1982), the significance of most of the aberrant features was hard to prove. The features of type 1 aberration are now discussed separately. In fig. VI.1. the follicle growth, the hormone profiles and the BBT in a representative cycle are shown. 
Gullele

diamerer (nrm)

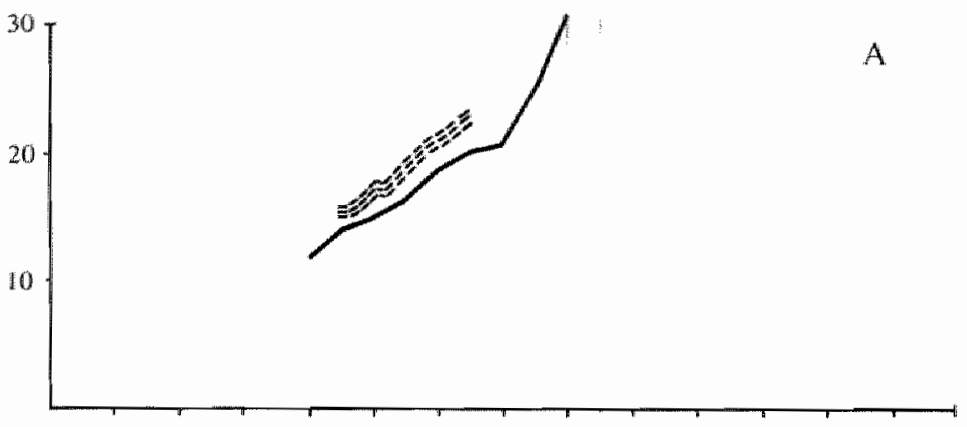

L. 14

(ogg/mal)

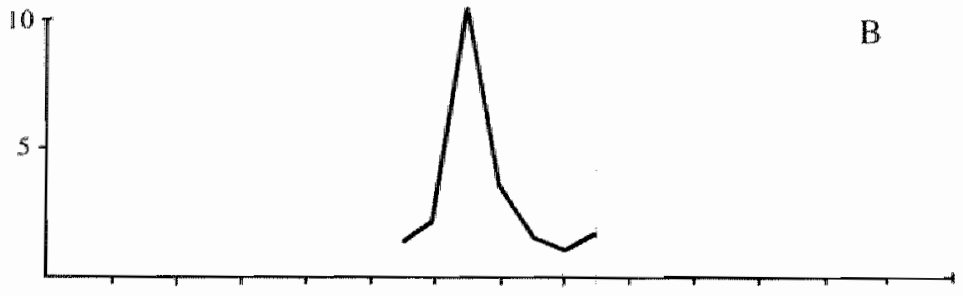

oestrindiol 17 -beta (nomollL)

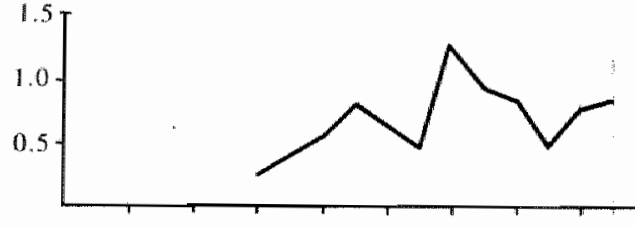

\section{Progesterone} (nnol/tas)

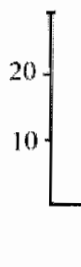

D

BBT ( Colstus)

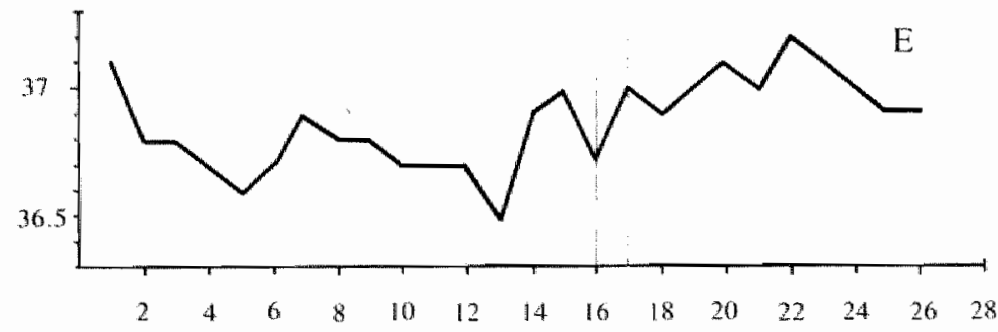

dxys of the eyole

Fig. VI. 1. Composite picture of a "delayed ovulation" type (I) of cycle aberration showing the follicle growth curve (A), the LH (B), oest tadiol 17-beta (C) and progesterone (D) values and the BBT (E). Verticall lines on day 16 indicate the margins of the Ultrasound Ovulation Period (UOP). Dotted lines in fig. A represent the growth (mean \pm SD) of "normal" folliclles, synchronized with respect to the LH peak 
- An early LH peak, related to the ultrasound evidence of follicle rupture.

All hormone determinations in the group of "aberrant" cycles were performed according to the same protocol which was used in "normal" cycles. Reviewing the LH peak-UOT intervals in the preceding chapter (fig. V.3. and V.4.), six LH peaks in the spontaneous group and two peaks in the anti-oestrogen induced group were earlic than 48 hours before UOT (72-48 hours). This LH peak-UOT interval of 48 hours was arbitrarily chosen as the limit of "normality". Due to the low sampling frequency and the small number of cycles concerned, significance could not be proven for the whole group. Only in three of them, it could be stated that the peaks occurred definitely earlier than 48 hours before UOT, also if the maximal methodologicall variation was taken into account.

Theoretically, it would be possible that the early LH peaks were merely false interpretations of the relevant series of $\mathrm{LH}$ values. This is unlikely because the concomitant oestradiol peaks were also moved forward with respect to the UOT. The time intervals between the LH peak and the oestradiol peak in type 1 cycles (mean -5.7 hours) and the intervals in the group of "normal" cycles (mean +3.9 hours) were not significantly different $(\mathrm{p}=0.179$, Mann-Whitney U test).

- Increased follicle growth following the LH peak. This was the second main feature of the type I aberration. Like the early L.H peak, also the existence of this feature could not statistically be proven. In the group of spontancous cycles the growth rates per cycic were higher in "aberrant". than in "normal" cycles of the same subjects: mean $3.00 \mathrm{~mm} /$ day, range $2.25-4.09$ versus $2.32 \mathrm{~mm} /$ day, range $1.15-3.79$ : the difference was however not significant $(p=0.163$, Mann-Whitney U test).

In the representative case (fig. VI. I.) the increase of follicle growth after the LH peak is illustrated. Although statistical significance was absent, in practice it was possible to recognize the type I cycles by the increase of follicle growth before follicle rupture.

\section{- Progesterone levels and luteal phase duration.}

For spontaneous cycles the progesterone at UOT, progesterone on day $5-7$ after follicle rupture and the duration of the luteall phasc were compared with "normal" cycles. It could be supposed that the 5 subjects who exhibited "aberrant" cycles (type I) would be different from the remaining subjects, who had only "normal" cycles; in other words, it could be doubted whether the cycles or the subjects were aberrant. Therefore, the "normal" cycles were subdivided in two groups:

1. cycles in subjects who had only "normal" cycles

2. cycles in subjects who had "normal" but also "aberrant" cycles, type I or II.

Progesterone at UOT, progesterone in the luteal phase and luteal phase duration were compared between each of these two groups of "normal" cycles and the "aberrant" cycles (type 1). The results are shown in table VI.2.

Progesterone at UOT was significantly increased in the "aberrant" cycles of type $I$, compared to both groups of normal cycles (10.1 vs 5.4 and 5.0 nmolll). Progesterone on day $5-7$ of the luteal phase was significantly lower (25.0 vs 48.0 and 47.7 nmol/1). Lutcal phase duration in aberrant cycles was shortened to a significant level (12.0 ws 13.7 and 14.2 days). Differences between the two groups of "normal" cycles were not found. The increased progesterone levels at UOT can be interpreted as a result of an earlier 
Table VI.2.

Comparison of "normal" and "aberrant" cycles type I by luteal phase parameters.

Group 1: "normal" spontaneous cycles in subjects who never exhibited "aberrant" cycles Group 2: "notmal" spontancous cycles in subjects who also exhibited "aberrant" cycles Group 3: "aberrant" cycles of the "delayed ovulation" type

a. Proygesterone at the estimated moment of follicle ruphure

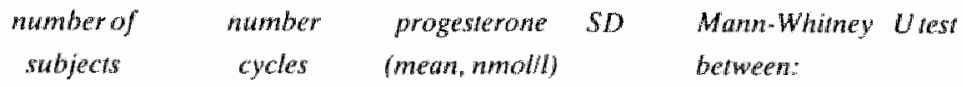

$\begin{array}{lrrrrrr}\text { group 1 } & 23 & 63 & 5.4 & 2.7 & \text { group 1-2 } & p=0.410 \\ \text { group 2 } & 5 & 14 & 5.0 & 2.4 & \text { group 2-3 } & p=\times 0.001 \\ \text { group 3 } & 5 & 6 & 10.1 & 3.4 & \text { group 1-3 } & p=0.003\end{array}$

b. Progesterone on day $5-7$ afrer folliche rapume

\begin{tabular}{|c|c|c|c|c|c|c|}
\hline & $\begin{array}{c}\text { number of } \\
\text { subjects }\end{array}$ & $\begin{array}{c}\text { number of } \\
\text { cycles }\end{array}$ & $\begin{array}{l}\text { progesterone } \\
\text { (mean, nmoll) }\end{array}$ & $S D$ & $\begin{array}{l}\text { Mann-Whisney } \\
\text { between: }\end{array}$ & Utest \\
\hline group 1 & 23 & 74 & 48.0 & 20.3 & group 1.2 & $p=0.958$ \\
\hline group 2 & 5 & 14 & 47.7 & 14.6 & group 2-3 & $p=0.005$ \\
\hline group 3 & 5 & 6 & 25.0 & $\| 1.2$ & group $1-3$ & $p=0.007$ \\
\hline
\end{tabular}

c. Luseal phase duration (days)

\begin{tabular}{|c|c|c|c|c|c|c|}
\hline & $\begin{array}{c}\text { number of } \\
\text { subjects }\end{array}$ & $\begin{array}{c}\text { number of } \\
\text { cycles }\end{array}$ & $\begin{array}{l}\text { Inteal phase } \\
\text { (mean, days) }\end{array}$ & $S D$ & $\begin{array}{l}\text { Mann-Whitney } \\
\text { bermeen: }\end{array}$ & Utest \\
\hline group 1 & 23 & 73 & 13.7 & 2.2 & group 1-2 & $p=0.481$ \\
\hline group 2 & 5 & 16 & 14.2 & 1.1 & group 2.3 & $p=0.001$ \\
\hline group 3 & 5 & 6 & 12.0 & 1.2 & group $1-3$ & $p=0.022$ \\
\hline
\end{tabular}

stat of luteinization. The shortening of the luteal phase was not impressive but nevertheless statistically significant. The progesterone levels in the luteal phase however were lowered to such an extent, that the luteal phase quality in the aberant cycles could be doubted.

\section{- BBT}

In three of the "aberrant cycles" type I a BBT was recorded, showing a biphasic curve. The only abnormality that could possibly be indicated in these records was a slow rise of the temperature at the shift. The nadirs coincided with the moment of the LH peaks.

\section{Discussion}

Many aspects of the type I "aberration" remained uncertain. The two main features, the carly $1 \mathrm{H}$ peak and increased follicle growth following the LH peak, were not significant, probably on account of the low numbers. The aberrant progesterone levels and luteal phase durations were a strong indication that the concerning cycles were different from "normal". It was however unclear whether the arbitrarily chosen limit of 48 hours (LH peak-UOT interval) was correct. It is likely that there is no sharp demarcation between but a gradual transition from "early" to "well timed" LH peaks. 
Also the question of the clinical importance of the supposed aberration remained open. Theoretically the "aberrant" cycles could be subfertile for two reasons. The shorrened luteal phase with low progesterone lewels can represent luteal deficiency. On the other hand, it is possible that the ova, set free after the late follicle rupture, are not fertilizable in view of the reported critical time relationship between the $\mathrm{LH}$ peak and fertilizability (Steptoe and Edwards, 1970; Niwa and Chang, 1975; Testart et al, 1980, 1981).

There are similarities between the present type I "aberration" and the disturbances reported by Polan of al (1982): the early LH peak and early luteinization with respect to follicle rupture. The major difference is in the follicular growth pattern. Polan et al found "delayed ovulation" especially in retarded follicle growth. Like the present, also their study gives an indication that there may be subtle cycle disturbances, characterized by abnormal temporal relationships between hormonal and ultrasound events.

Only further investigation employing higher sample frequencies of L.H, for instance 8 hourly, can reveal the significance and exact features of these disturbances.

Intriguing is the fact that type I "aberrant" cycles only occurred in subjects who had subfertile husbands, but whose mernstrual cycle was essentially normal and that they were not found in volunteers. An explanation for this phenomenon is not obvious.

\subsection{Features of aberrant cycles type II ("failure of follicle rupture")}

Contrary to the type I aberration, in which the demarcation of the "aberrant" against the "normal" cycles remained doubtful, in type II aberration this was not problematic. It could be defined by one striking ultrasound feature: the failure of the follicle to rupture. Problems in the description of this aberration were of a different kind: it was encountered in only three subjects, five cycles, and hormone patterns were not well comparable to those of normal cycles, because the reference point, the day of follicle rupture, was absent.

Fig. VI.2. shows the follicle growth, hormone patterns and BBT in a representative case.

Fig. IV.3. displays the impressive ultrasound pictures of follicle development in two subsequent cycles in one subject. The common features of the five aberrant cyctes type II were:

\section{- Failure of follicle rupture and characteristic development in the luteal phase}

Initially, follicle growth looked normal, the growth rate being $23 \mathrm{~mm} /$ day for the mean diameter. This is better illustrated in the pictures of fig. VI.3. than in the graphic of fig. VI.2. In the vicinity of the LH peak a fast increase of follicle size took place, which was more extensive than that in type I cycles. Instead of rupturing, the follicles reached impressive sizes within a few days: 35 to $52 \mathrm{~mm}$ mean diameter (volume 22.4 to 73.5 $\mathrm{cm}^{3}$ ). This size persisted usually until the end of the cycle. The cysts then decreased totally within a few days or persisted into the next cycle (fig. VI.3.). Patients had a variable amount of complaints from these large cysts: usually there was considerabic discomfort but also symptoms could be minimal not withstanding the size of the cysts.

\section{- LH peak}

Invariably, the cycles showed normal LH peaks around the 14-th day of the cycle. The peaks appeared to have a close time relation to the start of the increased growth rate. 


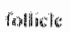

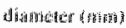

H. Hil

[ngingli
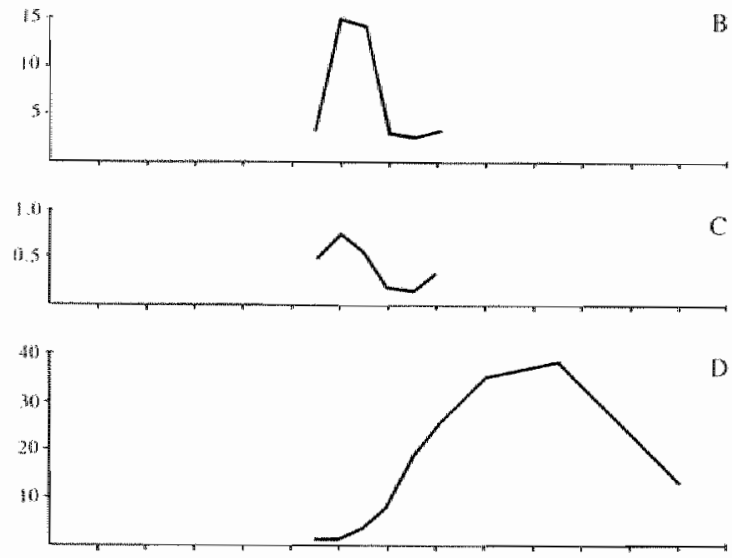

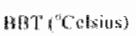

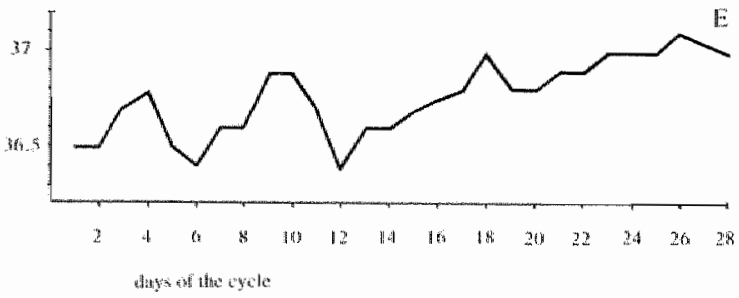

Fig. V1.2 Composite picture of a "failure of follicle rupure" aberration (ype II).

Further legends see fig. VI.1.

The mean LH levels in the period of the peak did not differ significantly from those in normal cycles. Oestradiol determinations were too few to estimate the general pattern. The mean duration of the cycles was 27 days (range 26-29), the second period, from the LH peak to the next menstrual period was in the average 15 days (range 14-15).

\section{- Progesterone}

As in all "normal" and type I cycles, the start of luteinization was closely related to the LH peak. Instead of the progesterone determination on a fixed day after follicle rupture a total of $4-5$ progesterone determinations were performed with two days interva? throughout the second part of the cycle, starting on the fourth day after the LH peak. 

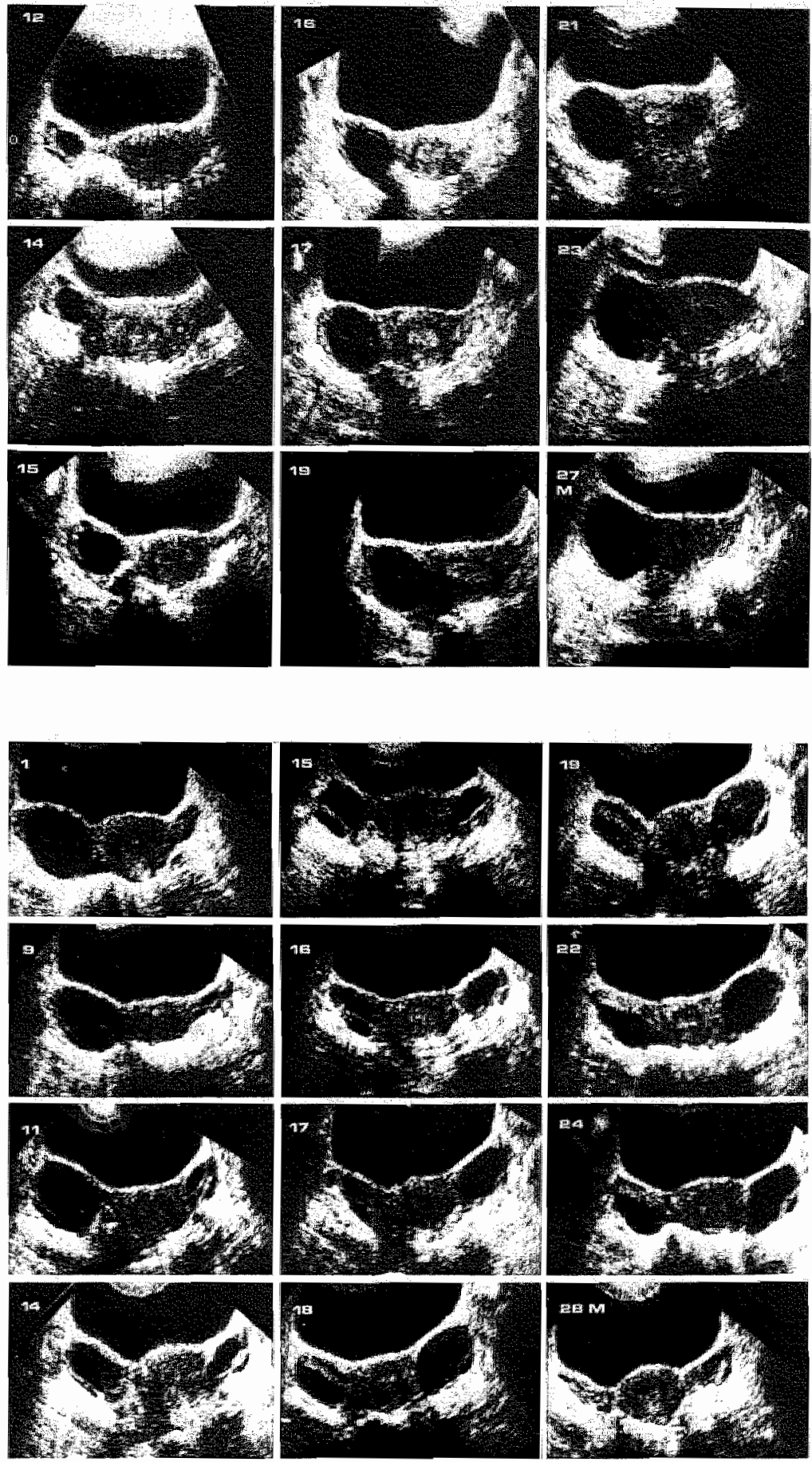

Fig. VI 3. Serial pictures of the events during two subsequent cycles in subject 12 , exhibiting the "failure of follicle rupture" cycle aberration. White numerals indicate day of the cycle, $M$ indicates the first day of menstrual bleeding. 
The mean progesterone level per cycle ranged from 23.4 to $31 \mathrm{nmol} / \mathrm{l}$. As mentioned before, the mean mid-luteal progesterone level in the normal cycles anounted 46.5 nmol/. Although these figures were not well comparable, and the observed cycles of type II were few, this seemed to allow the preliminary conclusion that these cycles showed luteinization and that the luteal progesterone levels were in the lower range of normal.

\section{- BBT}

A BBT was recorded in three cycles and showed a biphasic pattern (fig. V1.2.).

\section{Discussion}

The type II aberration represents undoubtedly a special mode of anovulation: failure of follicle rupture, accompanied by large outgrowth of the cysts and evidence of a nearly normal luteinuzation.

Contrary to the laparoscopically diagnosed UUF syndrome, in the ultrasonographical aberation the failure of follicle rupture seems to be beyond discussion.

Intriguing is the possible relationship between this type II aberration and the laparoscopical entity of Luteinized Unruptured Follicle (LUF) syndrome. Both entities have two essential features in common: the absence of follicle rupture and the otherwise normal cycle characteristics. Not congruent however are the observations with respect to follicular size. In none of the reports mentioned, the size of the "unruptured follicles" at laparoscopy was noticed to be abnormal. Since the impressive size of the persistent follicles was a constant feature in our small series, this puts doubt on the correctness of the interpretation of the laparoscopic observations. In view of this discrepancy, one has to conclude that ultrasound investigation should be an indispensable part of further research on the LUF syndrome. It could show that many of the cycles, supposed to exhibit LU:, have ultrasonographically a normal follicle rupture.

A relationship between "delayed ovulation" (type 1) and "failure of follicle rupture" (type II) can be suspected on account of the common feature of the sharp increase follicular growth around the $\mathbb{L} H$ peak. Although nothing is known about the etiology, both conditions could be based upon the same principal failure: the unability of the follicte to react 'normal' to the $\mathbb{I} H$ peak or another ovulatory stimulus. The cause could be situated somewhere in the ovary because hormone patterns appeared not evidently abnormal in the late follicular phase of these "abnormal" cycles. The question whether or not these aberrations are caused by an inadequate stimulation of the follicle during the early follicular phase remains unsolved.

Two practical conclusions can be drawn from the findings in this chapter. First, female infertility cannot be called "unexplained" unless thorough ultrasound observation of follicle growth pattern is performed.

Secondly, the finding of large ovarian cysts in young females can be caused by persistent growth of an originally "normal" follicle. Surgical treatment of this condition should not be undertaken until after this possibility has been cxcluded by serial ultrasound examinations. 
After accomplishing the present study, efforts were made to treat the conditions, especially in the two patients in whom the aberrations recurred. Clomiphene, clomiphene with HCG and the HMG-HCG combination were applied in various dosages and schedules. It was disappointing that none of the treatment schedules was able to correct the cycle. In most cycles the aberration recurred in spite of the medication. 


\section{Chapter VII}

\section{The possible role of ultrasound in monitoring ovulation induction by Human Chorionic Gonadotropin (HCG)}

\section{Introduction}

HCG is the placental analogon of the pituitary Luteinizing Hormone (LH). It has been used since its isolation from the pituitary (Gemzell et al, 1958) and from urine(Donini et al, 1964) in efforts to substitute for the endogenous LH production. The purpose was to stimulate follicular growth in cases, where this growth was supposed to be insufficient "or to trigger the ovulation when the endogenous triggering was supposed to be insufficient of when a predictable ovulation was desired. After a short review on phatmacokinetics, the potential adverse effects of HCG administration and the problem of timing will be discussed.

\subsection{Review of the literature}

\subsubsection{Pharmacokinetic aspects of HCG}

The immunological and biological properties of LH and HCG are quite similar (Franchimont, 1970). They were bound to the same receptor and had the same effect on the activity of the granulosa cells (Kammerman et al, 1972; Channing and Kammerman. 1973). Transport and metabolism however were different (Yen et al, 1968). For HCG, there appeared to be a two-compartment distribution, which caused a very slow and biphasic disappearance; the disappearance rate ( $(1 / 2)$ being 11.2 hours and 23.4 hours for the two compartments. The disappearance rate of LH was much shonter: 34 to 233 minutes, depending on the phase of the cycle (Santen and Bardin "1973). In spite of the much slower disappearance rate of HCG compared to LH, the renal clearance of the former was much higher (Keller, 1966).

In view of the slow disappearance, a single injection of 3000 IU of $\mathrm{HCG}$ would be more than adequate to achieve hormone patterns and levels, similar to those of the L.H peak (Yen et al; 1968). There is a great wariation in the dosages, found in the literature. Mostly they were ruuch higher; 5000 or $10.000 \mathrm{IU}$ were occasionally administered repeatedly. (Kistner, 1966; Brown et al, 1969; Evans and Townsend, 1976; Lopata et al, 1978; Schmidt et al, 1981; Cabau and Bessis, 1981). The reason for this higher dosage was merely empirical. It was supposed that the follicle after stimulation by Human Menopausal Gonadotropin (HMG) or clomiphene was less sensitive to gonadotropin stimuli (Klopper ef al, 1974:

Brown et al, 1969). 


\subsubsection{Potential adverse effects of preovulatory $\mathrm{HCG}$ administration}

Many indications were found in recent reports that the untimely administration of HCG can disturb the menstrual cycle. The effects can be encountered in the follicular and the luteall phase as well.

When administered in the early follicular phase, HCG caused no signs of luteinization in the peripheral blood (Strott et al, 1969; Friedrich et al, 1975). On the contrary, postposition of the ovulation, degeneration of early follicles and thecal luteinization were described by Tamada and Matsumoto (1969) and Friedrich et al (1975).

Also in the preovulatory phase of the cycle, the administration of HCG should be well imed. In the Rhesus monkey, Williams and Hodgen (1980) deseribed that HCG thad the desired effect (an ovulation followed by a normal luteal phase) only when administered during the endogenous gonadotropin peaks. Administration before the surges caused atresia of follicles and occasionally long lasting cycle disturbances. It appeared that the follicle was only susceptible to HCG during a short, circumscript stage of its development. In the human, a comparable study fails, but there is evidence that the human preovulatory follicle goes through a number of short, different functional states and that the time of administration of HCG is critical. Bomsel-Helmreich et al (1979) found a quick change of the morphology and hormonal contents of the follicle in the preovulatory phase, while Schoemaker et al (1978) reported a sequence of different functional states in this short period. A premature administration of HCG interfered with the ability of the follicles to achieve their biosynthetic potential and arrested growth (Bomsel-Helmreich et al, 1979). Beside the possible disturbance of the normal ovulation, there were also doubts on the influence of HCG on the quality of the luteal phase. Edwards and Steptoe (1975) and Edwards et al (1980) reported a shortening of the luteal phase in virtually all cycles, an elevation of luteal phase prolactin levels in some cases and a disturbance of endometrial biopsy findings in cycles in which oocytes were removed after HCG triggering. Much of their failures to establish pregnancies in vitro were contributed to these apparently adverse effects of HCG. However, other possible explanations for the supposed luteal deficiency were manyfold: the luteolytic action of high preovulatory oestrogen levels (Edwards et al, 1980), a sudden increase of testosterone levels during the HCG injection, persisting throughout the luteal phase (Wu, 1978), an elevation of prolactin, caused by high oestrogen levels of by the anaesthesia during the procedure of oocyte recovery (Edwards et all, 1980; Garcia et al, 1981) or the effect of the removal of part of the granulosa (El Fouly et al, 1970; Garcia et al, 1981).

It must be cmphasized that Edwards et al have always used arbitrary and empirical schemes for ovulation induction until they decided to abandon the induction and return to the spontancous cycle for oocyte recovery. Other authors have continued the use of HCG, preceded by HMG or Clomiphene, and did not report adverse effects at all (Lopata et al, 1978; Thebault et al, 1980; Kerin et al, 1981).

\subsubsection{The practice of HCG application in ovulation induction}

Supposing that the correct timing of the HCG injection for triggering of the ovulation is essential, the practice of many HCG induction programs was unsatisfactory. Schedules for the administration were mostly empirical. 
After tollicular growth induction with clomiphene, HCG was generally administered on the day that users of clomiphene alone showed indirect signs of ownlation. This and similar procedures were applied in the reports of Kistner (1966), Edwards (1973), Polink et al (1973), Garcia et al (1977), Swyer et al (1975), Radwansk et al (1980b). The arbitruriness of these schemes with respect to the follicular development might be the cause of the disappointing results reported by Kistner (1977) and Radwanska ef al (1980b). More recently, Lopata et al (1978), Thébault et al (1980), Persson et al (1980), Hoult et all (1981) and O'Herlihy et al (1982) reported good results of the clomiphene-HCG combination. They applied oestrogen monitoring or ultrasound observation for the timing of $\mathrm{HCG}$ administration.

After pretreatment with HMG, some authors also applied fixed schedules for tinting of HCG (Steptoe and Edwards, 1970). Oestrogen and oestradiol levels were however generally used for the timing of the HCG administration (Schwartz and Jewelewicz, 1981; Hull et al 1979, Radwanska et al, $1980 \mathrm{a}$ ). There are some unsolved problems in this monitoring by oestrogens. First, the fixed character of the schedules disregards the possibility of individual variation in the reaction to ovulation inducing agents (Klopper et al, 1974; Schwartz and Jewelewicz, 1981). Because the success of treatment, was judged by pregnancy rates and indirect methods of ovulation detection, which are both multifactorial events, no reliable data are available on the failures to ovulate. Secondly, the supposition that the oestrogen peak indicates the moment of optimal follicular maturity was possibly not valid in many of the cases (Talbot et al, 1976). There seemed to be a variable resistance to exogenous gonadotropins (Talbot et al, 1976; Klopper et al, 1974). In gonadotropin induced cycles. higher oestrogen levels appeared to be necessary for successful ovulation (Brown et all, 1969) and in practice the therapeutic range between normal ovulation and hyperstimulation was narrow (Taymor et al, 1970). The Graafian follicle would produce relatively morc oestrogens in stimulated than in spontaneous cycles. The atresia of not dominant follicles could be diminished in stimulated cycles, so that the number of immature, but oestrogen producing follicles was higher, diminishing the usefulness of the oestrogen level as a parameter for maturity of the Graafian follicle.

\subsubsection{The interval between the HCG injection and ovulation.}

Only those reports were taken into account in which a direct method of ovulation detection was applied.

After HCG pretreatment, Edwards and Steptoe (1975) and Talbot al (1976) observed that the majority (about $2 / 3$ ) of all follicles had ovulated when laparoscopy was performed at 44 hours after the HCG injection. When the observation interval was reduced to 30$)-36$ hours only a minority (about 1/3) had ruptured. Laparoscopy between 29 and 31 hours revealed no ovulations (Steptoe and Edwards, 1970). Similar results were found by Thébault et al (1980), Persson et al, (1980). They saw no ovulations at laparoscopy performed 35 to 37 hours after $\mathrm{HCG}$. For the purpose of oocyte recovery for in vitro fertilization, most authors agreed that 36-39 hours after HCG was the optimal time for laparoscopy (Lopata et al, 1978; Talbot et al, 1976; Edwards and Steptoe, 1975).

Contrary to the minimum time lapse between the HCG administration and ovulation, little is known about the variation in the maximum of the interval. Presumably this was caused by the use of laparoscopy, which allowed only one observation per cycle. Indications are 
found in the report of Tabot et (1976) and of Testart and Frydman (1982): intact follicles were seer up to 41 and 44 hours after the stimulus.

\subsubsection{Contributions of the ultrasound observation to the timing of $\mathrm{HCG}$ administration}

Ultrasound observation of the follicle could theoretically serve as a method to select the optimal time for the HCG administration. The requirement would be that there is a follicle size which indicates that a follicle has reached the optimal maturity to owulate on HCG. Two approaches can be distinguished in the studies on this issue.

Retrospectively, Seibel et al (1981), Schmidt et al (1981) and Ylöstalo et all (1981), studied the ult rasound findings in HMG-HCG induced cycles, which were monitored by oestrogens. The mear follicle diameters at wich HCG was administered waried widely: 13 to $24 \mathrm{~mm}$. Also a wide variation was found in the ultimate preovulatory diameters: 15 to $28 \mathrm{~mm}$. Obvious signs of luteal deficiency, although not well-defined, occurred only when $\mathrm{HCG}$ was administered at 13 or 14 mm mean diameter. The concllusion was that $15 \mathrm{~mm}$ mean diameter was optimal for the administration of HCG (Seibel ef a1, 1981; Ylostalo et al, 1981). However, it should be noticed that in these studies little attention was paid to standardization of the equipment and the procedure of measurement.

There were a fow reports on efforts to time the HCG administration based upon ultrasound observations alone. Nitschke-Dabelstein et al (1980) started with a low dose of HMG and increased the dose untill follicular reaction was seen by ultrasound. A very unpredictable sensitivity to HMG was noticed. HCG injection was planned at a follicular diameter of 20 $1022 \mathrm{~mm}$, which was supposed to be the mean preovulatory diameter in spontaneous and clomiphene induced cycles. In all 22 cycles, ovulation was observed either within 24 hours $(n=11)$ or within 48 hours $(n=11)$. No hyperstimulation was seen and the pregnancy rate was 6 in 13 patients.

Sallam et al (1982) reported a group of 61 cycles in 22 patients, monitored with real time uttrasound. HCG was administered at anean follicle diameter of $20-25 \mathrm{~mm}$ (nean 21.3 ). The results were favorable: 59 ovulations in 61 cycles; 12 single pregnancies in 22 patients. In 3 cycles HCG was witheld because of imminent hyperstimulation or multiple pregnancy.

Hoult at al (1981) monitored clomiphene induced cycles by ultrasound. HCG was given on the day after follicle diameter of $16-17 \mathrm{~mm}$ was measured. Laparoscopy for oocyte recovery was pertormed 36 hours after HCG. Compared to spontaneous cycles, monitored by LH determinations, the results in terms of oocyte recovery and fertilization rates were significantly improved. It is noteworthy that "premature ovulations", i.e. ovulations before 36 hours were not scen if HCG was given before the endogenous LH clevations. In clomiphene induced cycles in formerly anovulatory patients, O'Herlihy et al (1982) reported a successful timing of the HCG injection by ultrasound. They used the mean follicle diameter of $18 \mathrm{~mm}$ as an indication for follicular maturity, based upon the fact that this was the mean diameter at 36 hours before the ovulation in control cycles. Although they did not describe ultrasound observations of the events after the HCG administration, their pregnancy rate $(67 \%$ within 6 months of treatment) suggested, that their approach was adequate to induce ovulations. 
In many patients who were involved in the investigation, the infertility was caused by poor sperm quality. In these subjects, it was tried to time Artificial Insemination Homologeous (AIH) as close as possible to the moment of ovulation. In the course of the investigation, at. trial was started to control the time of the expected ovulation by means of $\mathrm{HCO}$ triggering. The fact that sperm qualities were poor made it impossible to judge the rate of successful ovulations from the pregnancy rate. In fact, only one pregnancy was achieved in 38 cycles (1.4 subjects).

\section{Subjects and Methods}

The group comprised 14 subjects. A total of 38 cycles were observed, 25 were spontaneous until the HCG injection, 13 were induced by means of clomiphene (12) or tamoxiphene (1). Of these 38 cycles, 21 were included in the original group of 178 cycles (table II.1.). The remaining $17 \mathrm{cycles}$ were studied after the main part of the investigation was finished. Arbitrarily a dose of 10.000 IU of HCG was chosen in one injection.

In view of the reports on the quickly changing functional states of the follicle in the preovulatory phase, the potential adverse effects of badly timed HCG administration on the further development of the cycle and the disappointing results of arbitrary $\mathrm{HCG}$ medication, we supposed, that timing of the injection was essential for the success of induction.

The aim was to estimate the optimal timing of the $\mathrm{HCG}$ injection from ultrasound observation of follicular growth. Theoretically the injection should be given just before the LH surge. In view of the wide interindividual variation of follicular growth curves, it was tried to individualize the estimation. In each of the subjects an individual follicular diameter was chosen at which the LH peak could be expected within 24 hours. The estimation of this follicle size was based upon at least 2 previous cycles. Essentially this was an effort to estimate the functional state of the follicle merely from the follicular diameter. For the success of this approach, a sufficient growth rate and a low intercycle variation within one subject were necessary. To estimate the discrimatory value of follicle size, all subjects with three or more cycles were reviewed (fig. VII.1.). The mean and the ranges of the maximal diameters, measured in the periods between 36 and 60 hours before the L.H peak and between 12 hours before and 12 hours after the peak were compared. As can be seen, half of the subjects with spontaneous cycles exhibited a certain overlap of the follicle diameter ranges, in 3 out of 8 to such an extent that discrimination could be supposed to be absent. In the other half there was no overlap. In five subjects with clomiphene induced cycles, the ranges of follicle sizes in the observed periods did not overlap. The impression was that, in general ( 18 out of 21 subjects), the follicle diameter could be adequate to discriminate the period immediately preceding the LH peak. Depending on the individual, the optimal diameter to plan the HCG injection within 24 hours ranged from $13-22 \mathrm{~mm}$ in spontaneous and from $17.24 \mathrm{~mm}$ in Clomiphene induced cycles respectively.

In practice, the diameter at which HCG was going to be in jected was established as the mean diameter 36-60 hours before the LH peak in at least two previous cycles in the 

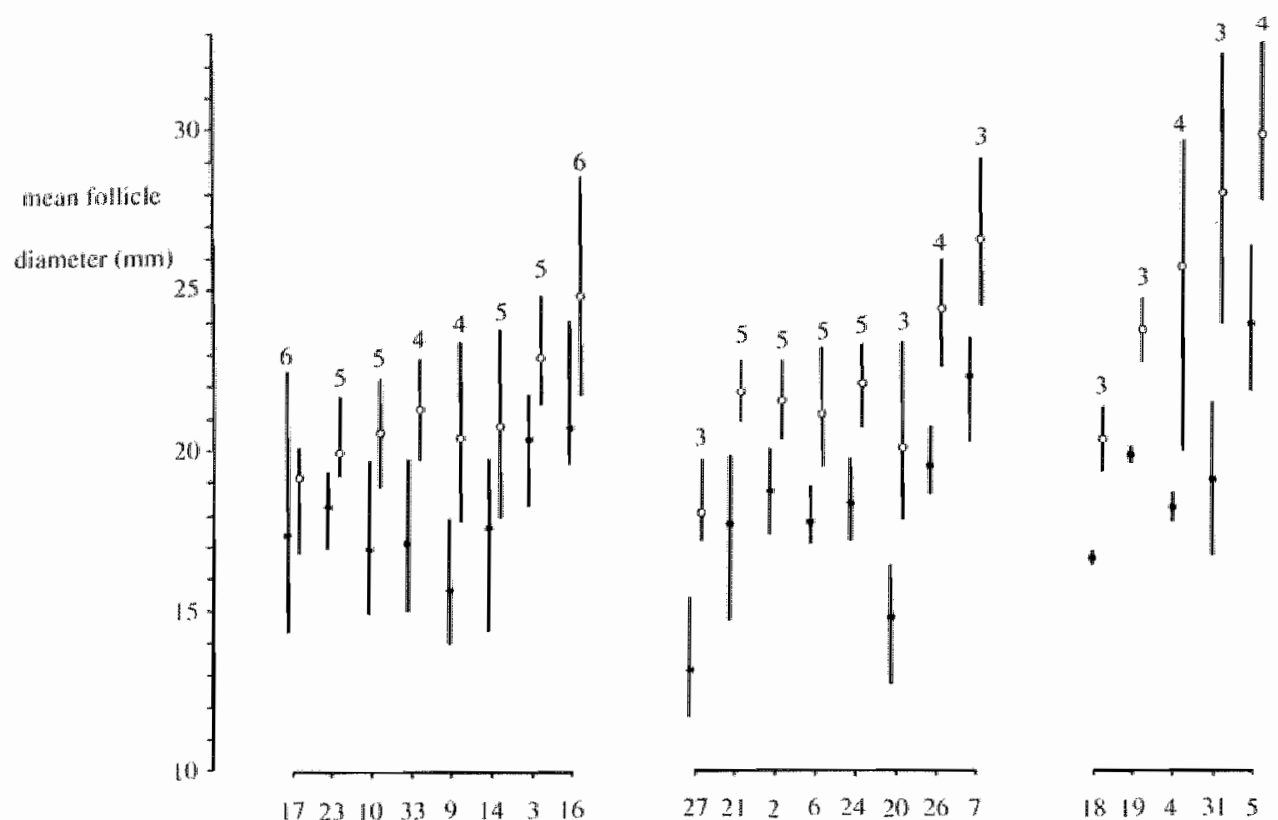

subjoct number

Fig. VII I. Range and mean of follicle diameters for each subject, observed during three or more cycles without HCG. Bars indicate the ranges. Solid circles indicate the mean follicle diameters between 36 and 60 hours before the LH peak; open circles represent the mean diameters between 12 hours before and 12 hours after the LH peak. Numerals above the bars indicate the number of cycles. Groups are:

leftspontaneous cycles, overlap of ranges

middle: spontaneous cycles, without overlap

right: anti-oestrogen induced cycles

concerning subject. In the group of 14 subjects these critical diameters ranged from 17 to $23 \mathrm{~mm}$. As soon as the follicle reached this size, the HCG injection was arranged around midnight of that day. Before the injection a last biood sample was taken for LH assay in order to detect the cycles, in which the HCG administration was too late. The ovulation was expected at about 36 hours after the in jection, i.e. during the day time, when intensive monitoring could be done. The ultrasound observations were performed on that day at very short intervals (lig. VII.2.)

\section{Resulits}

In 32 of 38 cycles, the triggering of the ovulation was considered successful in a sense that the $\mathrm{HCO}$ injection was before the appearance of the LH-surge and that a normal looking follicle rupture followed.

In three of the 38 cycles, the HCG injection was after the LH surge. This resulted in follicle rupture within 24 hours after the injection. Presumably, the HCG administration added nothing to these ovulations. In another three cycles a phenomenon, identical to the "failure of follicle rupture" (chapter VI) followed the injection. Instead of rupturing, the follicle showed a manyfold increase in size while luteinization was apparently normal: we supposed 
that this aberration was caused by an HCG injection too far before the LH perk, but this hypothesis could not be proven. If the hypothesis woutd be true, it would mean that in the human a badly timed $\mathrm{HCG}$ injection can disturb the cycle and presumably abolish the fertility in a cycle, as was found in the Rhesus monkey by Williams and Hodgen (1980).

In the 32 "successful" inductions ( 12 subjects) the observation interval (UOP) was $12 \pm 7.7$ hours (mean $\pm \mathrm{SD}$ ), the median being 9 hours and the range 3 to 24 hours. It should be remarked here that one of the subjects (subject no. 11) contributed to the series with 11 cycles. Another 6 subjects had 2 to 4 cycles investigated and 5 subjects only one cycle). A disproportionate influence of one subject on the results was possible. With regard to the UOP however, short and long untervals were distributed at random.

The HCG-UOT intervals in 32 cycles are shown in fig. VII.2. They are arranged according to the duration of UOP and synchronized on the moment of the HCG administration. The observation interval UOP is indicated for each cycle. As can be seen from this figure, the

mumber of cydies crantikedi

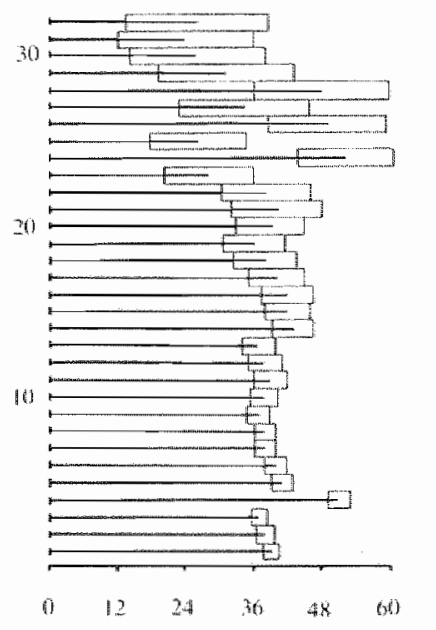

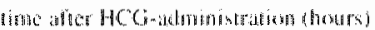

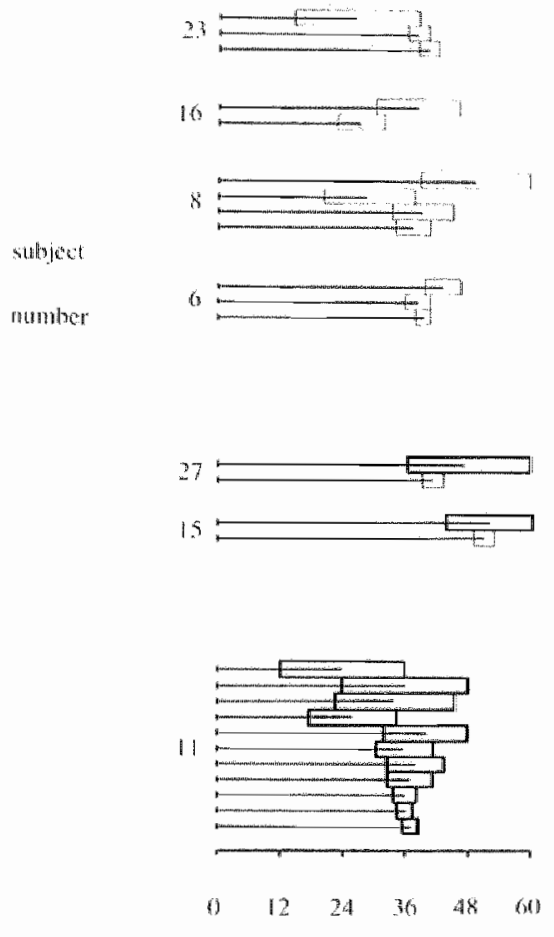

I
Fig. VII.2. Graphic representation of the events following HCG injection in 32 cycles $(12$ stubjects)

Hour zero is the moment of HCG administration. The end of the horizontal line indicates the moment of UOT. Closed boxes indicate the ultrasound observation period (UOP). Cycles are ranked according to the duration of UOP.
Fig. VII, 3. The results of $\mathrm{HCG}$ administration, arranged according to subject: only subjects with 2 or more cycles are considered.

Clomiphene induced cycles are distinguished by bold-lined UOP-interval. Further legends see fig. VII.2. 
HCG-UOT intervals appeared to be rather constant, especially in the cycles with short UOP. The mean duration of the HCG-UOT interval was 36.7 hours \pm 6.8 (SD), the median 37 hours. Taking only those cycles into account in which the UOP was shorter than 12 hours ( 20 cycles in 11 subjects) the mean HCG-UOT interval was 39.2 hours \pm 3.2 $(\mathrm{SD})$, range $36-51$ hours. The short $\mathrm{HCG}$-UOT intervals were all found in cycles with the Iong observation intervals (UOP). The shortest HCG-UOT interval was $24 \pm 12$ hours, the longest $51 \pm 1.5$ hours. Because not all the UOP overlapped, it must be concluded that there was a definite variation in the HCG-UOT interval.

For subjects who had 2 or more cycles studied, the cycles were arranged individually and differentiated with regard to the use of medication (fig. VII.3.). This figure illustrates the random distribution of long and short UOP over the subjects. With respect to the innersubject wariation and the effect of anti-oestrogen medication on the HCG-UOT interval. no conclusions seem to be allowed. Only in one subject (8) not all UOP overlapped, so that in this subject, there appeared to be a definite inner subject variation. Two subjects (15 and 27) had a spontaneous and a clomiphene induced cycle. A difference between the HCG-UOT intervals could not be concluded.

For an estimation of the practical value of the HCG induction for the accurate prediction of the owulation, the intervals between the first Artifical Insemination Homologeous (AIH) and UOT were calculated. They were compared to the intervals, achieved by prediction on follicle growth alone (chapter IV). Fig. VII. 4 shows the distribution of the interwals between the first $\mathrm{AIH}$ and UOT in both groups. In the HCG group all inseminations but two were within a period of 24 hours around the moment of UOT, which was better than without HCG ( $53 \%$ within \pm 24 hours). However, it should be remembered that in 3 out of $38 \mathrm{HCG}$ induced cycles, the induction failed and in another 3 the ovulation was unexpectedly within 24 hours after the HCG administration.

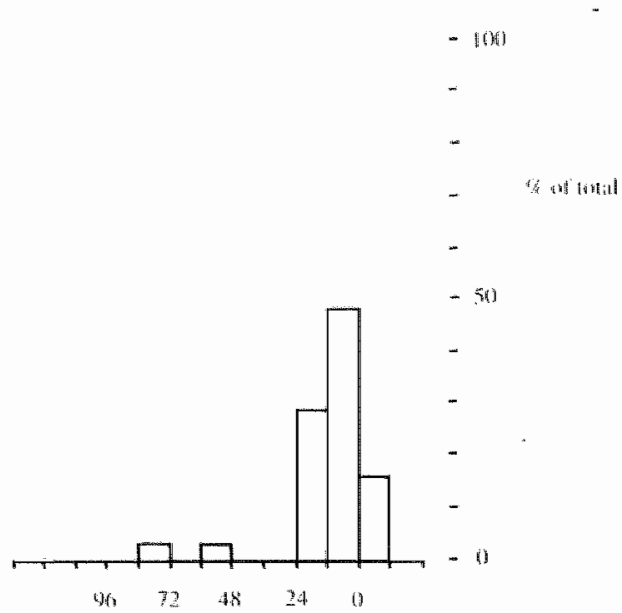

mae befre 100 thomst

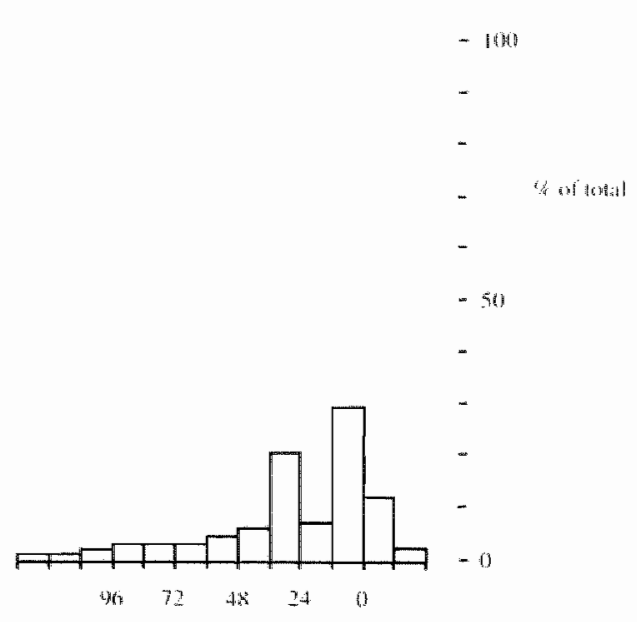

time berone vor hous:

Fig. VII.4. Relative distribution of first artificial inseminations (AIH) with respect to UOT. Time zero is UOT. left: after HCG triggering $(\mathrm{n}=32)$

right: spontancous and anti-oestrogen induced cycles without $\mathrm{HCG}(\mathrm{n}=97)$. 
In view of the possible luteal insufficiency, supposed to be caused by the $\mathrm{HCO}$ triggering of the ovulation (Edwards et al, 1980), it was of interest to estimate the quality of the luteal phase in the present cycles. In view of the fact that all patients were infertile on accourt of inferior sperm qualities, the pregnancy rate seemed to be not useful for this purpose.

Therefore the progesterone values and the duration of the luteal phase were considered. The obtained data were compared with analogeous groups of cycles without preovulatory HCG medication. As can be derived from table VII.1., there was a slight difference in the progesterone level at UOT between anti-oestrogen alone and anti-oestrogen-HCO treated cycles but not to a significant level. The remaining parameters did not differ for any of the groups of cycles. Thus, with respect to these three parameters, there were no signs of deficiency of the luteal phase.

Table VII.1.

Luteal phase parameters with and without ovulation induction by means of preovulatory HCG (10.000 IU). Numbers of cycles are indicated (n)

\begin{tabular}{|c|c|c|c|c|c|c|c|c|}
\hline & & \multicolumn{3}{|c|}{ number $H C G$} & \multicolumn{4}{|c|}{ HCG preovilatory } \\
\hline & & $n$ & mean & $S D$ & $n$ & mean & $S D$ & $\begin{array}{l}\text { Mann- } \\
\text { Whiney } \\
\text { Utest }\end{array}$ \\
\hline \multirow{2}{*}{$\begin{array}{l}\text { Progesterone at the } \\
\text { estimated ovulation } \\
\text { time (nmol/l) }\end{array}$} & spontaneous & 85 & 5.6 & 3.2 & 16 & 5.9 & 2.7 & $p=0.399$ \\
\hline & anti-oestrogens & 22 & 10.2 & 7.6 & $\llbracket 3$ & 6.2 & 2.2 & $p=0.093$ \\
\hline \multirow{2}{*}{$\begin{array}{l}\text { Progesterone at day } \\
5-7 \text { of the luteal } \\
\text { phase (nmol/l) }\end{array}$} & spontaneous & 96 & 46.5 & 20.5 & 19 & 52.7 & 21.4 & $p=0.581$ \\
\hline & anti-oestrogens & 33 & 73.1 & 39.0 & 13 & 71.9 & 37.6 & $p=0.393$ \\
\hline \multirow{2}{*}{$\begin{array}{l}\text { Luteal phase } \\
\text { duration (days) }\end{array}$} & spontaneous & 98 & 13.6 & 2.1 & 19 & 13.7 & 1.1 & $p=0.973$ \\
\hline & anti-oestrogens & 32 & 14.2 & 2.0 & 13 & 15.2 & 3.3 & $p=0.153$ \\
\hline
\end{tabular}

\section{Discussion}

The results of this study demonstrate that $\mathbb{H C G}$, combined with ultrasonographical timing of the administration is apparently a useful aid to obtain predictable owulations. According to the literature, the time of administration should be shortly before the endogenous LH peak. In this study it was tried to estimate the day before the LH peak by ultrasound measurement of follicle size and comparison with earlier cycles of the same subject. Based upon experience in other groups of cycles in this study, the day before the LH peak appeared to be detectable in most of the subjects by use of the follicle size. There were six failures in 38 cycles ( 14 subjects). In three of the failures, a clear reason for failure could be found in the fact that the endogenous LH surge had already passed.

The interval HCG-ovulation in those cycles with an adequately short observation interval was in the same range as reported in the literature. An intercycle variation was evident. Further investigation is necessary on the inner-subject variation of the $\mathbb{H C G}$-ovulation interval. 
After the well timed applications of HCG, there was no evidence for insufficiency of the luteal phase. The findings of Lopata et al (1978) and $\mathrm{O}^{\prime} \mathrm{Herl}$ hy et al (1982), that the application of HCG did not cause luteal deficiency, was affirmed in this investigation, however by different parameters: progesterone determinations and luteal phase duration instead of the pregnancy rate. Although the pregnancy rate in the report by $O^{\prime}$ Herlihy et al (1982) was favorable, it was not clear to what extent the use of a fixed diameter for HCG adminuistration could have caused failures in their series. Based on the present results we assume that there is an individual range of follicle diameters in which the $\mathrm{HCG}$ administration is optimal. Furthermore, the presence of failures despite the efforts to time the HCG injection by intensive ultrasound monitoring, seems to be a recommendation for control of the ovulation by direct methods, at least in those patients in whom HCG triggering fails to achicve pregriancy.

The potential value of HCG administration after ulltrasound monitoring in the field of Artifical Insemination and in vitro fertilization is evident. It appears to be possible, by means of limited investigations with a non-invasive technique, to design a schedule of treatment for each individual, by which the moment of follicle rupture becomes predictable, while other qualities of the cycle remain unchanged. 


\section{Summary}

The growth pattern of ovarian follicles during the last period before their rupture was the subject of a prospective, standardized study, applying ultrasound visualization. A careful description of the ultrasound changes was the first aim. Simultaneous determination of hormonal parameters was expected to reveal temporal and other quantitative relations between structural changes in the ovary and endocrinological aspects of the cycle.

By serial observation of cycles in most of the individuals, it was hoped to detect individual characteristics in either follicular growth pattern or hormonal events or both.

In chapter I, a review was given of recent developments in the ultrasound investigation of the preovulatory follicle. The application fields were defined as : detection and prediction of the ovulation, cycle research and monitoring of ovulation induction.

The current opinions in these fields and the recent contributions of ultrasound studies were summarized. Incidentally, the possible adverse effects of diagnostic ultrasound on the development of the follicle and the oocyte were mentioned. Reviewing the recent reports on follicle growth, the results showed a variability to such an extent, that careful standardization of measurements appeared to be necessary.

An inventory was given of the potential sources of error, based upon reports about fetal crown-rump length and fetal bladder volume measurements, and extended with elements specific to the ultrasound measurements of follicles.

In chapter II the compositon of the groups of 43 subjects and 178 cycles, the distribution of individual series of cycles, the schedulle of obserwations and the technical specifications of the equipment were presented. Attention was paid to the standardization of methods and equipment settings, on the basis of the inventory of error sources, made in chapter 1 . Specific practical problems in the detection and measurement of follicles were illustrated. By performing a series of phantom measurements in vitro and standardization measurements in vivo, an effort was made to quantify the effect of error sources. The most striking conclusions were:

- The B mode compound scanning method achieved significantly better results than the B mode sector scanning facility of the present equipment.

- The errors, expressed as volume errors, were considerable, especially because of the wide spread. However, the result appeared reasonable, taking into account that a twodimensional method was applied to estimate volumes.

- In view of the large spread of results it would be safe not to overvalue the accuracy of the ultrasound method in the measurement of small objects like follicles.

- In spite of all efforts to eliminate systematic errors, they remained demonstrable.

Chapter III dealt with the ultrasonographical signs of follicle rupture. Three types of post rupture appearance were distinguished. Of them the solid type was the most frequent, accounting for approximately $50 \%$. The spongeous and transonic types occurred less frequently but were significantly related to larger preovulatory follicles sizes. A role for the so called "cumulus oophorus" in ovulation prediction was denied. "Cumulus"-like structure appeared, starting from day 5 before follicle rupture, in daily increasing frequency.

Furthermore, the "cumulus oophorus" showed more differentiation in shape and size than 
formerly reported. An unexplained preference for ovulations on the right side was found in the present series of cycles. The individual sequences of ovulation showed no recognizable pattern with respect to the side.

Follicle growth pattern was reviewed in chapter IV. For the management of the data two statistical procedures were described, resulting in different characteristics of follicle growth: mean growth curves and growth rate per cycle. The results of these procedures demonstrated wide variation of follicular growth throughout the distinguished groups. Statistically significant differences were only found in the mean growth curves of groups, not between growth rates or preovulatory diameters.

Although not significant, the results suggested a typical growth pattern, irrespective of growth rate or ultimate diameter. Preovulatory growth seemed to start between day 6 and day 4 before UOT in all cycles and to be linear after day 4 before UOT.

Predictability of the day of follicle rupture on the basis of follicle growth was retrospectively studied within subjects who had large series of cycles investigated. The predictability seemed reasonable in some of the subjects. Practical results of owulation prediction looked promising.

In chapter $V$, time relationships between hormonal events of the cycle and UOT were considered. Problems in defining the hormone peaks were discussed.

The temporal relations of the LH surge, LH peak and oestradiol-17-beta peak with UOT were in accordance with current opinions. This led to the conclusion that ultrasound evidence of follicle rupture was closely related to ovulation. Based upon the wide variation in peak-UOT intervals and the evident influence of the sampling rhythm on the distribution, accurate detection of the ovulation by 24 hour samples in individual cycles appeared to be impossible. In spite of considerable methodological variation it could be concluded that there was a biologic variation in the LH surge-UOT interval. Progesterone at the moment of UOT showed such a wide variation that it appeared to be useless for ovulation detection. The variation was intercycle, rather than between individuals. Anti-oestrogen induced cycles showed a significantly elevated progesterone at the moment of UOT, compared to spontaneous cycles. This was apparently related to the signiticantly higher preovulatory oestradiol llevel as also a good linear correlation was found between mean preovulatory oestradiol and perovulatory progesterone levels in induced cycles.

Progesterone levels in the luteal phase, determined at a well defined time distance from UOT were widely spread. The usefulness of single progesterone determinations for diagnosing luteal phase deficiency was doubted.

The duration of the cycle and of luteal and follicular phases was calculated. A wide variation in luteal phase duration was found in agreement with earlier reports. A significant prolongation of cycle duration in anti-oestrogen induced cycles, appeared to be mainly caused by the prolongation of the follicular phase.

The search for linear correlations between preovulatory and postovulatory parameters and the duration of cycle phases was in generall not successfull. Noteworthy were the weak correlations between progesterone at UOT and peak-UOT intervals in both types of cycles, suggesting that the start of luteinization and follicle rupture were two independent phenomena. Also the total lack of correlation between luteal phase duration and midluteal progesterone levels was striking. 
Midpain occurred in $31.4 \%$ of all cycles, but was significantly more frequent in induced cycles. It was mainly a preovulatory symptom at a variable distance from UOT:Its occurrence was not related to follicle size.

The estimation of the day of ovulation by BBT had only a poor correlation with the ultrasound observations, leading to the conclusion that the BBT is a doubtful tool for the accurate detection of the day of ovulation.

In chapter VI two types of presumably aberrant cycles were described, which were encountered in the course of the study.

Type I was tentatively defined by the features early LH peak, possibly aberrant follicle growth and early luteinization. Only the latter feature was significant in comparison with "normal" cycles. Furthermore these cycles showed significantly lowered luteal progesterone levels and shortened luteal phases.

Type II was characterized by failure of the follicle to rupture. Instead, it grew out to impressive sizes, which persisted throughout the luteal phase. The cycle parameters LH peak, luteal progesterone production, cycle duration and BBT showed no obvious abnormalities.

Possible relationships with the laparoscopically diagnosed LUF syndrome were discussed.

A trial to time the HCG injection for the achievement of predictable ovulations was presented in chapter VII. Based upon the experience in earlier cycles, an individual follicle diameter was chosen for the administration of HCG. Apart from 6 failures in 38 cycles (14 subjects), the time of follicle rupture was within narrow limits around 36 hours after HCG.Luteal phase parameters in the HCG treated cycles were not different from those in comparable cycles without $\mathrm{HCG}$. 


\section{Samenvatting}

Het onderwerp van het in dit proefschrift beschreven prospectieve, gestandardisecrde onderzoek was het verwolgen van het groeipatroon wan de follikel door middel van echoscopie in de laatste 5 dagen vóor de ovulatie.

Het eerste doel was een zorgvuldige beschrijving van de follikelgroei. Verder werden gelijktijdig met de echoscopische waarnemingen hormonale parameters bepaald teneinde relaties, met name in de tijd, te beschrijven tussen structurele verandering in de ovaria en endocrinologische aspecten van de cyclus.

$\mathrm{Bij}$ het merendeel van de onderzochte personen werden longitudinaal series van menstruele cycli vervolgd in de hoop individuele kenmerken in follikelgroe, hormonale parameters of beide te ontdekken.

In hoofdstuk I werden de recente ontwikkelingen op het gebied van echoscopisch onderzoek van de preovulatoire follikel besproken. Als toepassingsgebieden van deze onderzoeksmethoden werden onderscheiden: detectie en predictie van de ovulatie, onderzoek van de cyclus en het bewaken van ovulatie inductie. De bestaande opvattingen over deze onderwerpen en de bijdrage die echoscopie tot op heden heeft geleverd werden samengevat. Zijdelings werden de mogelijke ongewenste effecten van echoscopische diagnostiek op de ontwikkeling van de follikel en de oocyt besproken.

Op grond van de grote spreiding in de resultaten van recente onderzoekingen betreffende follikelgroei, leek zorgvuldige standaardisatie van de meetprocedure noodzakelijk. Potentiële foutenbronnen bij de echoscopische meting van follikels werden geinventariseerd, analoog aan literatuurgegevens omtrent de nauwkeurigheid van foetale kop-stuit lengte metingen en aangewuld met aspecten die specifiek geacht werden voor de meting van follikels.

Hoofdstuk II geeft een overzicht van de samenstelling van de groep van 43 onderzochte personen en 178 onderzochte cycli, de verdeling van het aantal cycli per individu, het onderzoekschema en de technische specificaties van de gebruikte apparatuur. De standaardisatie van de methode en de afstelling van de apparatuur, gebaseerd op de potentiele foutenbronnen, werden uitvoerig besproken.

Praktische problemen, specifiek voor het detecteren en meten van follikels werden toegelicht.

Er werd getracht door middel van fantoommetingen in vitro en standaardisatic metingen in vivo, de omvang van de meetfouten te kwantificeren. De belangrijkse conclusies waren:

- de metingen met de onderhavige B-mode compound scanner waren significant nauwkeuriger dan die, uitgevoerd met behulp van de $\mathbb{B}$-mode sector scanner, behorend bij de gebruikte apparatuur;

- de meetfouten, uitgedrukt in volume eenheden waren aanzienlijk. Met name de spreiding van de afwijkingen was groot. Rekening houdend met het feit dat deze volumina gemeten werden met behulp van cen twee-dimensionele methode, leken de resultaten echter acceptabel;

- met het oog op de grote spreiding in de procentuele afwijkingen dient de nauwkeurigheid van de echoscopische volumemeting van objecten ter grootte van de preovulatorire 
follikel niet overschat te wordem;

ondanks de pogingen systematische fouten te elimineren, bleven deze aanwezig.

In hoofdstuk III werden de echoscopische tekenen wan follikel ruptuur ingedeeld in drie typen. Het solide type was in de onderzochte groep het meest frequent: $50 \%$. Het sponsachtige en het transsone type traden minder frequent op, doch werden significant vaker gezien bij grote follikel diameters.

Het bleek onmogelijk aan de hand van het optreden van de zogenaamde "cumulus oophorus" de dag van follikel ruptuur te voorspellen. Structuren, overeenkomend met de "cumulus" werden tot 5 dagen voor de ruptuur wan de follikel gezien en de incidentie steeg in de daaropvolgende dagen. De vorm en de afmetingen van de "cumulus oophorus" bleken meer variabel dan tot nu toe beschreven. Er werd een voorkeur gevonden voor rechtszijdige ovulaties. Een verklaring hiervoor ontbreekt. In series van ovulaties binnen een individu bleek er geen herkenbaar links-rechts patroon te bestaan.

In hoofdstuk IV werd het groeipatroon van de follikel beschouwd. De meetresultaten werden volgens twee methoden bewerkt: per groep werden gemiddelde groeicurven bepaald; per cyclus werd de groeisnelheid berekend. Er bleek een grote spreiding te bestaan in follikel groei in de onderscheiden groepen van cycli. Statistisch significante verschillen tussen groepen cycli bestonden met betrekking tot de gemiddelde groeicurven. Groeisnelheden en preovulatoire diameters versehilden niet significant. Binnen zekere grenzen leken enkele aspecten wan follikelgroei, ongeacht groeisnelheid en uiteindelijke follikeldiameter, constant. De preovulatoire groeifase leek te beginnen tussen 6 en 4 dagen vóór UOT, en de gemiddelde groei vanaf dag 4 vóór UOT leek lineair.

Retrospectief werd de woorspelbaarheid van de dag van follikel ruptuur op basis van follikelgroei onderzocht. Bij een gedeelte van de personen met grote series onderzochte cycli bleek deze voorspelbaarheid redelijk. De praktische resultaten van ovulatievoorspelling op basis van follikelgroei leken veelbelovend.

Hoofdstuk $\mathrm{V}$ behandelde de tijdsrelaties tussen hormonale gebeurtenissen in de cyclus en UOT. Problemen bij het definiëren van hormoonpieken werden besproken. De gevonden tijdsrelaties tussen LH surge, LH piek en 17-beta-oestradiol piek enerzijds en UOT anderzijds kwamen overeen met bestaande opvattingen. Geconcludeerd werd dat echoscopische tekenen van follikel ruptuur in de tijd nauw samenhangen met de ovulatie. Ten gevolge van de grote spreiding in de piek-UOT intervallen en de duidelijke invloed van het discontinue karakter van de observaties op de resultaten, leek nauwkeurige ovulatie detectie met behulp van een 24-uurs bepaling van LH onmogelijk. Ondanks de aanzienlijke methodologische spreiding kon een biologische spreiding in de LH surge-UOT intervallen aangetoond worden.

Er was een zodanig grote spreiding in progesteron spiegels op het moment van UOT, dat deze hormoonspiegel ongeschikt leek voor ovulatie detectie. De verschillen in progesteron spiegels bestonden hoofdzakelijk tussen cycli en waren in mindere mate interindividueel. In anti-oestrogeen geinduceerde cycli was het progesteron niveau op het moment van UOT significant hoger dan in spontane cycli. Dit leek gerelateerd aan een eveneens. significante verhoging van de gemiddelde preovulatoire 17-beta-oestradiol spiegels. Een grote spreiding werd gevonden in de progesteron spiegels, bepaald binnen een scherp 
omschreven periode na UOT. De bruikbaarheid van enkelvoudige progesteron bepalingen voor het vaststellen van de kwaliteit van de luteale fase werd in twijfel getrokken.

De lengte van de cyclus en de luteale en folliculaire fasen werd berekend. Er bleek een grote spreiding te bestaan in de lengte van de luteale fase. Een significante verlenging van de cyclus in anti-oestrogeen geìnduceerde cycli, vergeleken met spontane cycli berustte grotendeels op een verlenging van de folliculaire fase.

Lineaire correlaties tussen preovulatoire en postovulatoire parameters van de cyclus waren op enkele uitzonderingen na afwezig. Opmerkelijk waren de zwakke lineaire correlaties tussen progesteron op het moment van. UOT enerzijds en de intervallen tussen de $\mathrm{LH}$ en 17 beta oestradiol pieken en UOT anderzijds. Dit suggereerde dat het begin van de luteinisatie en de ovulatie twee in de tijd onafhankelijke fenomenen zijn. Ook het ontbreken van een correlatie tussen de hoogte van de luteale progesteron spiegel en de duur van de luteale fase was opvallend.

Middenpijn werd aangegeven in $31.4 \%$ van de cycli. De incidentie was significant hoger in geinduceerde cycli. In de meeste gevallen was middenpijn een preovulatoir symptoom. Het tijdsinterval tussen middenpijn en UOT was variabel. Het optreden van middenpijn was niet gerelateerd aan de grootte van de follikel.

De detectie van de dag van ovulatie door middel van basale temperatuur curven correleerde slecht met echoscopische bevindingen. Dit leidde tot de conclusie dat de waarde van de basale temperatuur curve voor nauwkeurige ovulatie-detectie twijfelachtig is.

In hoofdstuk VI werden twee typen van kennelijk afwijkende cycli beschreven.

Type I was moeilijk af te grenzen van "normale" cycli. De kenmerken van deze afwijkingen waren: een vroege LH pick, mogelijk afwijkende follikelgroei en vroege luteinisatie. Alleen het laatste kenmerk verschilde significant van "normaal". Bovendien waren de luteale progesteron spiegels significant verlaagd en de luteale fase significant verkort in de afwijkende cycli.

Type II werd gekenmerkt door het uitblijven van follikel ruptuur. In plaats hiervan trad er een sterke groei op, waarna de ontstane cysten gedurende de luteale fase persisteerden.

De parameters LH piek, luteale progesteron spiegels, cycluslengte en Basalc

Temperatuurcurve waren niet duidelijk afwijkend in deze cycli.

Mogelijke relaties van deze afwijkingen met het LUF syndroom, gediagnostiseerd door middel van laparoscopie, werden besproken.

In hoofdstuk VII werd een poging beschreven om de optimale tijd voor HCG injecties te bepallen, teneinde een voorspelbare ovulatie te verkrijgen. Op basis van de ervaringen in woorafgaande cycli werd per individu de optimale follikeldiameter bepaald, waarbij HCG injectie plaats diende te vinden. Afgezien van een zestal mislukkingen in 38 cyclii (14 personen), lag het moment van follikelruptuur binnen nauwe grenzen rond 36 uur na de HCG-injectie. De luteale fase parameters in de met HCG behandelde cycli verschilden niet van die in vergellijkbare groepen cycli zonder $\mathrm{HCG}$. 


\section{List of abbreviations}

$\begin{array}{ll}\text { AIH } & \text { Artificial Insemination Homologeous } \\ \text { BBT } & \text { Basal Body Temperature } \\ \text { dB } & \text { Decibel } \\ \text { FDHP } & \text { First Day of Hyperthermic Plateau } \\ \text { FSH } & \text { Follicle Stimulating Hormone } \\ \text { HCG } & \text { Human Chorionic Gonadotropin } \\ \text { HMG } & \text { Human Menopausal Gonadotropin } \\ \text { IU } & \text { International Unit } \\ \text { LH } & \text { Luteinizing Hormone } \\ \text { LPD } & \text { Luteal Phase Deficiency } \\ \text { LUF } & \text { Luteinization of Unruptured Follicle } \\ \text { MHz } & \text { Megaherz } \\ \text { REM } & \text { Rapid Eye Movement } \\ \text { RIA } & \text { Radio Immuno Assay } \\ \text { SD } & \text { Standard Deviation } \\ \text { SEM } & \text { Standard Error of the Mean } \\ \text { SIR } & \text { Surge Initiating Rise } \\ \text { SPTA } & \text { Spatiall Peak Tomporal Average } \\ \text { UOP } & \text { Ultrasonographical Ovulation Period } \\ \text { UOT } & \text { Ultrasonographical Ovulation Time }\end{array}$




\section{References}

Abdulla U, Campbell S, Dewhurst C J, Talbert D, Lucas M, Mullarkey M Effect of diagnostic ultrasound on maternal and fetal chromosomes

Lancet 1,$829 ; 1971$

Abdulla $\mathrm{U}$ The safety of ultrasound In: Handbook of Clinical Ultrasound Eds: De Vhieger M et al John Wiley and sons New York: 1978

Abraham G E, Odell W D, Swerdloff R S, Hopper K Simultaneous radioimnunoassay of plasma FSH, LH, 17-hydroxyprogesterone, and oestradiol-17-beta during the menst rual cycle J Clin Endocr 34, 312; 1972

Abraham G E, Maroulis G B, Marshall $\mathbf{J} \mathbf{R}$ Evaluation of ovulation and corpus luteum function using measurements of plasma progesterone

Obstet Gynecol 44, 522;1974

Adlercreutz H, Lehtinen T, Kairento A-L Prediction of ovulaton by urinary estrogen assays I Steroid Biochem 12, 395; 1980

Alberda A T Infertiliteit en corpus luteum insufficientie

Thesis, Erasmus Universiteil Rotterdam, The Netherlands; 1981

Alford F P, Baker H W G, Burger H G, de Kretser D M, Hudson B, Johns M W, Masterton J P, Patel Y C, Rennie G C Temporal patterns of integrated plasma hormone levels during sleep and wakefulness II. Follicle Stimulating Hormone, Luteinizing Hormone, testosterone and estradiol

J Clin Endocrinol Metab 37, 848; 1973

American Imstitute for Ultrasound in Medicine; Committee on Bioeffects Who's afraid of a hundred milliwatts per square centimeter ( $100 \mathrm{~mW} / \mathrm{cm} 2, \mathrm{SPTA})$ ?

American Institute of Ultrasound in Medicine, Washington; 1979

Andrews W C Luteal phase defects

Fertil Steril 32, 501; 1979

Aulletta F J, Agins H, Scommegna A Prostaglandin F mediation of the inhibitory effect of estrogen on the corpus luteum of the rhesus monkey

Endocrinology 103, 1183; 1978

Bacic M, Wesselius de Casparis $\mathbf{A}_{4}$ Dicafalusy $\mathbf{E}$ Failure of large doses of ethinyl estradiol to interfere with early entbryonic development in the human species

Am J Obstet Gynecol 107, 531; 1970

Baird D T, Guevara A Concentration of unconjugated estrone and estradiol in peripheral plasma in nompregnant women throughout the menstrual cycle, castrate and postmenopausal women and men J Clin Endocr 29, 149; 1969

Baird D T "The endocrinology of ovarian steroid secretion Europ J Obster Gynec Reprod Biol 4, 31; 1974

Baird D T, Fraser I S Blood production and ovarian secretion rates of estradiol-17-beta and estrone in women throughout the menstrual cycle

J Clin Endocrinol Metab 38, 1009; 1974

Baird D T, Baker T G, McNatty K P, Neal P Relationship between the secretion of the corpus luteum and the length of the follicular phase of the ovarian cycle

J Reprod Fertil 45,$611 ; 1975$ 
Bauman J $\mathbb{E}$ Basal Body Temperature: unreliable method of ovulation detection Fentil Steril 36, 729, 1981

Beck $\mathrm{L}_{\text {, Terinde }}$, Freumd $\mathrm{G}$ Dilagnostik der Ovulation durch Ultraschall Dtsich Med Wochenschr 106, 1363; 1981

Ben-Aderet N, Potashnik G, Lunenfeld B, Kraiem Z, Grunstein S, Shalit A Correlation of hormonal profile and owarian morphologic features during the periovulatory period in humans

Fertil Steril 28,$361 ; 1977$

Benjamin If Basal Body Temperature recordings in gynaecollogy and obstetrics J Obstet Gynecol Br Emp 67, 177; 1960

Bertrand P V, Coleman J $R$, Crooke A C, Macnaughton M C, Mills I H Human ovarian response to gonadotrophing with different ratios of Folficle-StimulatingHormone: Luteinizing Hormone assessed by different parameters

J Endoerinol 53,$231 ; 1972$

Bitlings E In, Billings J J, Brown J B, Burger H G Symptoms and hormonal changes accompanying: owulation

Lancet 1,$282 ; 1972$

Btack W P, Martin B T, Whyte W G Plasma progesterone concentrations as an index of ovulation and corpus luteum function in normal and gonadotrophin-stimulated menst rual cycles

J Obstet Gynaecol Br Cwith 79, 363; 1972

Bomsell-Helmreich O, Gougeon A, Thebault A, Saltareli D, Milgrom E, Frydman R, Papiernik E Healthy and atretic human follicles in the preovulatory phase: differences in evolution of follicular morphology and steroid content of follicular fluid

J Clin Endocrinol Metab 48, 686; 1979

Bots R S G M Fysische, dynamische en instrumentele aspecten bij de toepassing van real-time Bscan technieker

In: Echoscopie in de verloskunde en gynaecologie

Eds: Bal Het al

Publifan bw. Maastricht; 1982

Boyar R, Perlow M, Hellman L, Kapen S, Weitzman $\mathbf{E}$ Twenty-four hour pattern of Luteinizing Hormone secretion in normal men with sle ep stage recording

J Clin Endocrinol Metab 35,73; 1972

Brewer J 1, Jones $\mathrm{H} 0$ The time of ovulation

Am J Obstet Gynec 53, 637; 1947

Briët J W Hormoonspiegels gedurende de menstruele cyclus Thesis, Nijmegen, The Netherlands; 1978

Broom T J, Matthews C D, Cooke I D, Ralph M M, Seamark R F, Cox L. W Endocrine profiles and fertility status of human menstrual cycles of varying follicular phase length Fertil Steril 36, 194; 1981

Brosens I A, Koninckx P R, Corveleyn P A A study of plasma progesterone, oestradiol-17-beta, prolactin and LH levels, and of the luteal phase appearance of the ovaries in patients with endometriosis and infertility

Br J Otstiet Gynaecol 85, 246; 1978 
Brown J B, Exans J H, Adey F D, Taft H P, Townsend L Factors involved in the induction of fertile ovulation with human gonadotrophins

J Obstet Gynaecol Br Cwith 76, 289; 1969

Bryce R L, Shuter B, Sünosich M J, Stiel J N, Picker R H, Saunders D M The value of ultrasound, gonadotropin, and oestradiol measurements for precise ovulation detection Fertil Sterill 37, 42; 1982

Buckton K E, Barker N V An investigation into possible chromosome damaging effects of ultrasound on human blood cells

Br J Radiol 45,$340 ; 1972$

Buxton C L, Engle E T The time of owulation A correlation between Basal Temperature, the appearance of the endometrium, and the appearance of the ovary

Am J Obstet Gynecol 60, 539; 1950

Cabau A, Bessis $\mathbf{R}$ Monitoring of ovulation induction with human menopaussil gonadotropin and human chorionic gonadotropin by ultrasound

Fertill Steril 36, 178; 1981

Campbell S, Whadimiroff $\mathbf{J} \mathbf{W}$, Dewhurst $\mathbf{C} \mathbf{J}$ The antenatal measurement of fetal urine production J Obstet Gynaecol Br Cwlth 80,680; 1973

Campenhout J van, Vauclair R, Maraghi K Gonadotropin-resistant ovaries in primary amenorrhea Obstet Gynecol 40,$6 ; 1972$

Cargille C M, Ross G T, Yoshimii T

Daily variations in plasma Follicle Stimulating Hormone, Luteinizing Hormone and Progesterone in the normal menstrual cycle

J Clin Endocr 29, 12; 1969

Chang $\mathbf{R}$ J, Jaffe $\mathbf{R}$ B Progesiterone effects on gonadotropin release in women pretreated with estradiol

J Clin Endacrinol Metab 47, 119; 1978

Channing C P, Kammerman S Effects of hCG. Asialo-hCG and the subunits of hCG upon Iuteinization of monkey granulosa cell in culture

Endocrinology 93,$1035 ; 1973$

Charlewood G P Mittelschmerz or ovulation pain

S Afr Med J 32, 261; 1958

Child S Z, Carstensen $\mathbf{E} \mathbf{L}$, Smachlo $\mathrm{K}$ Effects of ultrasound on drosophila. I. Killing of eggs exposed to travelling and standing wave fields

Uitrasound Med Biol 6, 127, 1980

Corner $\mathbf{G}$ W The histological dating of the human corpus futeum of menstruation Am J Anat 98, 337; 1956

Coutinho E M, Maia H The influence of the ovarian steroids on the response of the human falliopian tubes to neurbypophyseal hormones in vivo

Am J Obstet Gynecol 108, 194; 1970

Coutts J R T, Dodson K, Macnaughton M C Hormone profiles in normally menstruating and infertille women

Europ J Obstet Gynec Reprod Biol 4/1 Suppl, 169; 1974 
Crespigny $\mathrm{L}$ Ch de, $\mathrm{O}$ Herthy $\mathrm{C}$, Robinson $\mathrm{H} P$ Utrasonic observation of the mechanism of human owulation

Am J Obstet Gynecol 139, 636; 1981 a

Crespigny I I Ch de, $O^{\prime} H$ Herlihy $\mathrm{C}$, Hoult $\mathrm{IJ}$, Robinson $\mathrm{H} \mathrm{P}$ Ultrasound in an in witro fertilization program

Fertill Steril 35, 25; $1981 \mathrm{~b}$

Critoph F N, Deninis $\mathrm{K} J$ Cilliary activity in the human oviduct

BrJ Obstet Gynaecol 84, 216; 1977

Crooke A C, Butt W R, Palmer R, Morris R, Edwards R L, Taylor C W, Short R V Effect of human pituitary-folicle-stimulating hormone and chorionic gonadotrophin in Stein-Leventhal syndrome BrMed J 1, 1119; 1963

Croxatto H-D, Delgado M, Lados C, Croxatto H B Correlation between corpus luteum morphology and endocrine profile

Fertil Steril 28, 362; 1977

Croxatto H B, Ortiz M E, Diaz S, Hess R, Balmacedla J, Croxatto H-D Studies on the duration of egg transport by the human oviduct

II. Ovum lacation at various intervals following luteinizing hormone peak

Am J Obstet Gynecol 132,629; 1978

Delforge J P $\mathbf{P}_{*}$ Thomas K, Roux F, Cameiro de Siqueira J, Ferin J Time relationships between gramulosa cells growth and futeinization, and plasma luteinizing thormone discharge in thuman.

1. A morphometric analysis

Fertil Steril 23, 1, 1972

Dhont M, VandeKerckhove D, Vermeulen A, Vandeweghe $M$ Daily concentrations of plasma L.H, FSH, cstradiol, estrone and progesterone throughout the menstrual cycle

Europ I Obstet Gynec Reprod Biol 4/1 Suppl, 153; 1974

Djahanbackch O, McNeilly A S, Hobson B M, Templeton A A A rapid Luteinizing Hormone radioimnunoassay for the prediction of ovulation

Br J Obsiter Gynaecol 88, 1016; 1981

Diersehke D J, Bhattacharya A N, Atkinson L. E, Knobil E Circhoral oscillations of plasma LH levels in the ovariectomized Rhesus Monkey

Endocrinology 87,$850 ; 1970$

Dmowski W P, Rao R, Scommegna A The luteinized unruptured follicle syndrome and endometriosis

Fertil Steril 33, 30; 1980

Dodson K S, Coutts J R T, Macnaughton M C Plasma sex steroid and gonadotrophin patterns in human menstrual cycles

BrJ Obstet Gynaecol 82, 602; 1975

Donald I Use of ultrasonics in diagnosis of albdominal swellings

Br Med J2, 1154, 1963

Donini P, Puzzuoli D, Montezemolo R Purification of gonadotrophin from human menopatusal urine Acta Endocrinol 45,$321 ; 1964$

Döring G K Ueber die Zuverlässigkeit der Temperaturmethode zu Emphängnisverhütung Disch Med Wochenschr 92, $1055 ; 1967$ 
Dorrington J H, Young S Moon, Armstrong D T Estradiol-17-beta biosymthesis in cultured granulosa cells from hypophysectomized immature rats; stimulation by follicle stimulating hormone Endocrinology 97,$1328 ; 1975$

Driessen $\mathbf{F}$ Luteal insufficiency and infertility in spontaneously menstruating women Thesis, Utrecht, The Netherlands; 1981

Edwards R G Studies on human conception

Am J Obstet Gynecol 117,587; 1973

Edwards R G, Steptoe P C Induction of follicular growth, ovulation and Uuteinization in the human ovary

J Reprod Fertil (Suppl) 22, 121; 1975

Edwards R G, Steptoe P C, Purdy J M Establishing full-term human pregnancies using cleaving embryos grown in vitro

Br I Obstet Gynaecol 87, 737; 1980

El-Fouly M A, Cook B, Nekola M, Nalbandov A V Role of the ovum in follicular lutenization Endocrinology 87,$288 ; 1970$

Evans J, Townsend $L$ The induction of ovulation

Am J Obstet Gynecol 125, 321; 1976

Faiman C, Winter J S D Diurnal cycles in plasma FSH, testosterone and cortisol in men

J Clin Endocr 33, 186; 1971

Fehling H Zur Kasuistik des Intermenstrualschmerzes

Arch Gynaekol 17, 338; 188॥

Fleischer A C, Daniell J F, Rodier J, Lindsay A M, James A E Sonographic monitoring of ovarian follicular development

J Clin Ultrasound 9, 275; 1981

Fowler R E, Chan S T H, Walters D E, Edwards R G, Steptoe P C Steroidogenesis in human follicles approaching ovulation as judged from assays of follicular fhuid

I Endocrinol 72,$259 ; 1977$

Franchimont $\mathbf{P}$ A study of the cross-reaction between Human Chotionic and pituitary Luteinizing Hormones (HCG and LH)

Eur J Clin Invest 1,$65 ; 1970$

Freund G, Terinde R, Distler W, Baumeister A, Herberger J, Kozlowski $\mathbf{P}$ Serum levels of oest radiol17-beta and luteinizing hormone related to follicular growth as monitored by ultrasound in women with normal menstrual cycles

Acta Endocrinol 96, 370; 1981

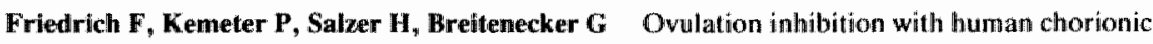
gonadotrophin

Acta Endocrinol 78, 332;1975

Fryduman R, Feinstein M C, Testart J, Thébault A, Labbé A, Grenier J, Roger M, Scholler R Réceuij d"ovocytes humains en phase préovulatoire. Intérêt du dosage radio-inmunologique rapide de la $\mathrm{LH}$ plasmatique

J Gyn Obst Bïol Repr 10, 127; 1981 
Garcia J, Jones $G \mathrm{~S}$, Wentz A $\mathbb{C}$ The use of Clomiphene citrate

Fertil Steril 28, 707; 1977

Garcia I $\mathbb{E}$, Jones $\mathbf{G}$, Wright $G \mathbf{L}$ Prediction of the time of ovulation

Fiertil Steril 36,$308 ; 1981$

Gautray J P, Brux J de, Tajehner G, Robel $\mathbb{P}_{\text {, }}$ Mouren M Clinical investigation of the menstnual cycle. III. Clinical, endometrial and endocrine aspects of the luteal defect

Fertil Sterill 35, 296; 1981

Gemzell $C A_{*}$ Dicafalusy $\mathbf{E}$, Tillinger $\mathbf{G}$ Clinical effect of human pituitary follicle-stimulating hormone (FSH)

J Clin Endocrinol Metab 18, 1333; 1958

Goebelsmann U, Midgley A R, Jaffe R B Regulation of human gonadotropins: VII. Daily individual urinary estrogens, pregnanediol and serum luteinizing and follicle stimulating hormones during the menstrual cycle

$J$ Clin Endoer 29, 1222; 1969

Goldenberg R L, Vaitukaitis J L L Ross G T Estrogen and Follicle Stimulating Hormone interactions on follicle growth in rats

Endocrinology 90,$1492 ; 1972$

Gore B Z, Caldwell B V, Sperof L Estrogen-induced human luteolysis

J Clin Endocrinol Metab 36, 615; 1973

Guerrero R V, Rojas O I Spontaneous abortion and aging of human ova and spermatozoa New Eng J Med 293, 573; 1975

Guerrero R, Aso T, Brenner P F, Cekan Z, Landgren B-M, Hagenfeldt K, Diczfalusy E Studies on the pattern of circulating steroids in the normal menstrual cycle

1. Simultaneous assays of progesterone, pregnenolone, dehydroepiandrosterone, testosterone, dihydrotestosterone, androstenedione, oestradiol and oestrone

Acta Endocrinol 81, 133; 1976

Hackelöer $\mathbf{B}$ J, Nitschke S, Daume E, Sturm G, Buchholy $\mathbf{R}$ Ultraschalldarstellung von Ovarveritnderungen bei Gonadotropinstimuliering

Geburtshilfe Fravenheilkd 37, 185; 1977

Hackeloer I J, Robinson IH P Ultraschalldarstellung des wachsenden Follikels und Corpus luteum im normalen physiologischen Zykluse

Geburtshilfe Frateriheilkd 38,$163 ; 1978$

Hackeloer B J, Flleming R, Robinson H P, Adam A H, Coutts J R T Correlation of ultrasonic and endocrinologic assessment of human follicular development

Am I Obstet Gynecol 135, 122; 1979

Hall D A, Hann L E, Ferrucei J T, Black E B, Braitman B S, Crowley W F, Nikrui N, Kelley J A Sonographic morphology of the normal menstrual cycle

Radiology 133, 185; 1979

Hann L E, Hall D A, Black E B, Ferrucci J T Mittelschmer; Sonographic demonstration JAMA 241, 2731; 1979

Hillgers T W, Bailey A Natural family planning II. Basal body temperature and Estimated Time of Ovulation

Obstet Gynecol 55,$333 ; 1980$ 
Hoeks A P G, Ruissen C J, Smeets F A M De beamscanner: een meetsysteen voor

ultrageluidbundels

Polytechnisch tijdschrift 34,$2 ; 1979$

Hosseinian A H, Kim M H Predetermination of ovulation timing by Luteinizing Hormone assay

Fertil Steril 27, 369; 1976

Hoult I J, Crespigny de L. C, O'Herlihy C, Speirs A Li, Lopata A, Kellow G, Johnston I, Robinson II P Ultrasound control of Clomiphene/Human Chorionic gonadogropin stimulated cycles for oocyte recovery and in vitro fertilization

Fertil Steril 36,$316 ; 1981$

Hull M G R, Savage P E, Jacobs H S Investigation and treat ment of atmenorrhoea resulting in normal fertility

Br Med J 1, 1257; 1979

Hull $\mathbf{M} \mathbf{G} \mathbf{R}$ Ovulation failure and induction

Clin Obstet Gynaecol 8,$753 ; 1981$

Insler V, Melmed H, Eichenbrumer I, Setr D M, Lunenfeld B The cervical score. A simple semiquantitative method for monitoring of the menstrual cycle

Int J Gynaecol Obstet 10,223;1972

Isojüma S, Naka O, Koyama $\mathbf{K}$, Adlachi $\mathbf{K}$ Rapid radioimmunoassay of human luteinizing hormone using polymerized anti-hurnan chorionic gonadiotrophin as immunoadsorbent

J Clin Endocr 31, 693; 1970

Israel R, Mishell D R, Stone S C, Thorneycroft I H, Moyer D L Single luteal phase serum progesterone assay as an indicator of ovulation

Am J Obstet Gynecol 112, 1043; 1972

Jansen R P S Fallopian tube isthmic mucus and owum transport

Science 201, 349; 1978

Jansen R P Cyclic changes in the human fallopian tube isthmus and their functional importance Ant I Obstet Gynecol 136, 292; 1980

Jeffcoate T NA Pelvic pairy

Br Med J 3,$431 ; 1969$

Jewelewica $\mathbf{R}$ Management of infertility resulting from anovulation Am J Obstet Gynecol 122, 909; 1975

Johansson E D B, Neill J D, Knobil E: Periovulatory progesterone concentration in the peripherall plasma of the Rhesus monkey with a methodologic note on the detection of ovulation Endocrinology 82,$143 ; 1968$

Johansson $\mathbf{E}$ D B, Wide $\mathbf{L}$ Periovulatory levels of plasma progesterone and luteinizing hormone in women

Acta Endocrinol 62, 82; 1969

Johansson E D B, Gemzell C The relation between plasma progesterone and total urinary oestrogens following induction of ovulation in women

Acta Endocrinol 62,$89 ; 1969$ 
Johansson E D B, Whde $\mathrm{L}$, Gemzell $\mathrm{C}$ Luteinizing Hormone (LH) and progesterone in plasma and LH and oestrogens in urine during 42 normal mensitrual cycles

Acta Endocrinol 68, 502; 1971

Johansison E D B, Lairsson-Cohn U, Genzell C Monophasic basal body temperature in ovulatory menstrual cycles

Am J Obstet Gynecol 113,933; 1972

Jones G ES Some newer aspects of the management of infertility

JAMA 141,$1123 ; 1949$

Jones $\mathbf{G S}$ The luteal phase defect

Fertil Steril 27, 351; 1976

Jones $\mathbf{G ~ S , ~ W e n t z ~ A ~ C ~ T h e ~ s t r u c t u r e ~ a n d ~ f u n c t i o n ~ o f ~ t h e ~ c o r p u s ~ l u t e t u m ~}$

Clin Obster Gynecol 3* 43; 1976

Kammerman S, Canffeld R E, Kolema J, Channing C P The binding of iodinated hCG to porcine gramulosa cells

Endocrinology 91,$65 ; 1972$

Kapen S, Boyar R, Hellman L, Weitzman E D Episodic release of luteinizing hormone at midmenstrual cycle in normal adult women

J Clin Endocrinol Metab 36, 724; 1973

Karsch F J, Sutton GP An intra-ovarian site for the luteolytic action of estrogen in the rhesus monkey

Endocrinology 98, 553; 1976

Keller P J The renal clearance of follicle-stimulating and luteinizing hormone in postmenopausal women

Acta Endocrinol 53, 225; 1966

Kemman $\mathbf{E}$, Tarakoli F, Shelden R M, Jones J R Induction of ovulation with menotropins in women with polycystic ovary syndrome

Am J Obstet Gynecol 141,58; 1981

Kerin J F, Edmonds D K, Warnes G M, Cox L. W, Seamark R F, Matthews C D, Young G B, Baird D T Morphological and functional relations of graafian follicle growth to ovulation in women using ultrasonic, laparoscopic and biochemical measurements

Br J Obstet Gynaecol 88, $81 ; 1981$

Kistner $\mathbf{k}$ W Use of clomiphene citrate, human chorionic gonadotropin, and human menopausal gonadotropin for induction of ovulation in the human female

Fertil Steril 17, 569; 1966

Kistner R W Sequential use of clomiphene citrate and human menopausal gonadotropin in ovulation induction

Fentil Steril 27,$72 ; 1976$

Klopper A, Aiman J, Besser M Ovarian steroidogenesis resulting from treatment with menopausal gonadotropin

Europ J Obstet Gynec Reprod Biol 4, 25; 1974

Koninckx P R, Goddeeris P G, Lauweryns J M, Hertogh R C de, Brosens I A Accuracy of endometrial biopsy dating in relation to the mideycle Luteinizing Hormone peak

Fertil Steril 28, 443; 1977 
Koninckx P R, Heyns W J, Corveleyn P A, Brosens 1 A Delayed onset of lutcinization as a cause of infertility

Fertil Steril 29,$266 ; 1978$

Koninckx P R, De Moor P, Brosens I A Diagnosis of the luteinized unruptured follicle syndrome by steroid hormone assays in peritoneal fluid

Br J Obstet Gynatecol 87,$929 ; 1980$

Koninckx P R, Brosens I A, Verhoewen G, De Moor P Increased postovulatory plasma follicle stimulating hormone levels in the luteinized unnuptured follicle syndrome: a role for inhibin?

Br J Obstet Gynaecol 88, 525; 1981

Korenaga M, Kadota $T$ Changes in mechanical properties of the circular muscle of the isthmus of the human fallopian tube in relation to hormonal domination and postowulatory time

Fertil Steril 36, 343; 1981

Korenman S G, Sherman B M Further studies of gonadotropin and estradiol secretion during the preovulatory phase of the human menstrual cycle

J Clim endocrinol Metab 36, 1205; 1973

Kratochwil A Die Ultraschalluntersuchung in der Gynäkologie

Geburtshilfe Franemheillkd 28,634; 1968

Kratochwil A, Urban G, Friedrich F Ultrasonic tomography of the owaries

Ann Chir Gynaec Fenn 61, 211; 1972

Kremkau F W, Witcofski R L Mitotic reduction in rat liver exposed to ultrasound JCU 2,$123 ; 1974$

Krieger D T, Ossowski R, Fogel M, Allen $\mathbf{W}$ Lack of circadian periodicity of human serum FSH and LH levels

J Clin Endocrinol Metab 35, 619; 1972

Kun L, Bosze P Die Bedeutung der Ultraschalluntersuchung für die Diagnose des polycystischen Ovars

Geburtshilfe Franenheilkd 33,452; 1973

Laborde N, Carbil M, Cheviakofr S, Croxatto II D, Pedroza E, Rosner J M The secretion of progesterone during the periovulatory period in women with certified ovulation

J Clin Endocrinol Meiab 43, 1.157; 1976

Landgren B-M, Aedo A-R, Nunez M, Cekan S Z, Diczifalusy E Studies on the pattern of circulating steroids in the normal menstrual cycle

4. Periovulatory changes in relation to the LH surge

Acta Endocrinol 84,$620 ; 1977$

Landgren B-M, Undén A-L, Diczfalusy E Hormonal profilte of the cycle in 68 nomally menstruating women

Acta Endocrinol 94, 89:1980

Lasley B L, Wang C F, Yen S S C The effects of estrogen and progesterone on the functional capacity of the gonadotrophs

I Clin Endocrinol Metab 41, 820; 1975

Lenton E A, Eston G A, Cooke I D Problems using basal body temperature recordings in an infertility clinic

Br Med J 1, 803; 1977 
Leyendecker G, WIdt $L_{\text {, }}$ Gips H, Nocke W, Plotz E I Experimental studies on the positiwe feedback cffect of progesterone, 17-alpha-hydroxyprogesterone and 20-alpha-dihydroprogesterone on the pituitary release of $\mathrm{LH}$ and $\mathrm{FSH}$ in the human female Arch Gynäk 221,$29 ; 1976$

Lifebeskind D, Bases $\mathbf{R}$, Mendez F, Elequin F, Koenigsberg M Sister chromatid exchanges in human lymphocytes after exposne tio diagnostic ulltrasound science 205,$1273 ; 1979$

Lopata A, Brown J B, Leeton J F, Talbot J M, Wood C In vitro fertilization of preovalatiory oocytes and embryo transfer in infertile patients treated with clomiphene and human chorionic gonadotropin Fertil Steril 30,$27 ; 1978$

Lundy $\mathrm{L}$, Lee S G, Levy W, Woodruff D, Wu C-H, Abdalla M The ovulatory cycle. A histologic, thermal, steroid, and gonadotropin correlation

Obstet Gynecol 44, 14; 1974

Macintosh I J C, Davey D A Chromosome aberrations induced by an ultrasonic fetal pulse detector Br Med J 4, 92;1970

Macintosh I J C, Brown R C, Coakley W T Ultrasound and "in vitro" chromosome aberrations Br J Radiol 48, 230; 1975

Magyar D M, Boyers S P, Marshall J R, Abraham G E Regular menstrual cycles and premenstrual moliminat as indicators of ovulation

Obstet Gynecol 53,$411 ; 1979$

March C M, Goebelsmann U, Nakamura $\mathbf{R}$ M, Mishell D R Roles of estradiol and progesterone in eliciting the midcycte Luteinizing Hormone and Follicle Stimulating Hormone surges

J Clin Endocrinol Metab 49, 507; 1979

Marik J, Hulka J Luteinized unruptured follicle syndrome: a subtle cause of infertility Fertill Steril 29,270; 1978

Marshall J Cerwical mucus and basal body temperature method of regulating births Lancel 2,$282 ; 1976$

McNatty K P, Sawers R S, McNetly A S A possible role for prolaction in control of steroid secretion by the human Gratafian follicle

Nature 250, 653; 1974

McNatty K P, Hunter W M, McNelly A S, Sawers R S Changes in the concentration of pituitary and stefoid hormones in the follicular fluid of human graafian follicles throughout the menstrual cycle J Endocrinol 64,$555 ; 1975$

McNatty K P, Sawers R S Relationship between the endocrine environment within the graafian follicle and the subsequent rate of progesterone secretion by human granulosa cells in vitro J Endocrinol 66,$391 ; 1975$

MeNatty K P, Baird D T, Bolton A, Chambers P, Corker C S, MClean H Concentration of oestrogens and androgens in human ovarian venous plasma and follicular fluid throughout the menstrual cycle I Endiocrinol 71,$77 ; 1976$

MeNatty K P, Smith D M, Makris A, Sathanondh R, Ryan K J The microenvironment of the human antral follicle: Interrelationships among the steroid levels in antral fluid, the population of granulosa cells, and the status of the oocyte in vivo and in vitro

$\mathrm{J}$ Clin Endocrinol Merab 49, 851; 1979 
Midgley $\mathbf{A} \mathbf{R}$, Jaffe $\mathbf{R}$ B Regulation of human gonadotropins: Correlation of serum concentrations of Follicle Stimulating and Luteinizing Hormones during the menstrual cycle

J Clin Endoct 28, 1699; 1968

Midgley A R, Jaffe R B Regulation of human gonadotropins: X. Episodic fluctuation of LH during the menstrual cycle

J Clin Endocr 33, 962; 1971

Mishell D R, Nakamura R M, Crosignani P G, Stone S, Kharma K, Nagata Y, Thorneycroft II II

Serum gonadotropin and steroid patterns during the normal menstrual cycle

Am J Obstet Gynecol 111,60; 1971

Miyata J, Taymor M L, Levesque L, Lymelburner $\mathbf{N}$ Timing of ovulation by rapid luteinizing hormone assay

Fertil Steril 21,$784 ; 1970$

Moghissi K S, Syner F N, Evans T N A composite picture of the menstrual cycle

Am J Obstet Gynecol 114, 405; 1972

Moghissi K S Accuracy of Basal Body Temperature for ovulation detection

Fertil Steril 27, 1415; 1976

Morris N M, Underwood L E, Easterling W Temporal relationship between BBT" nadir and luteinizing hormone surge in normal women

Fertil Steril 27. 780; 1976

Neill J D, Johansson E D B, Datta J K, Knobill E Relationship between the plasma levels of Luteinizing Hormone and progesterone during the normal menstrual cyclle

J Clin Endocr 27, 1167; 1967

Nigi II Laparoscopic observations of follicular rupture in the Japanese macaque J Reprod Fert 50, 387; 1977

Nitschke-Dabelstein S, Sturm G, Hackeloër B J, Daume E, Buchholz R Welchen Stellenwert besitzt die endokrinologische Uberwachung in der Gonadotropinstimulierung anovulatorischer Patientinnen - ein Vergleich zwischen endokrinologischen und ultrasonographischen Parametern

Geburtshilfe Frauenheilkd 40, 702; 1980

Niwa K, Chang M C Fertilization of rat eggs in vitro at various times before and after ovulation with special reference to fertilization of ovarian oocytes matured in culture

J Reprod Fertil 43, 435; 1975

Noyes R W, Hertig A T, Rock J Dating the endometrial biopsy

Fertil Steril 1,$1 ; 1950$

Noyes R W, Haman J O Accuracy of endometrial dating

Fertil Steril 4,$504 ; 1953$

Nunley W C, Kitchin I D, Thiagarajah Homologous insemination

Fertill Steril $30,510,1978$

Odor D L, Blandau R J Egg transport over the fimbrial surface of the rabbit oviduct under experimental conditions

Fertil Steril 24, 292; 1973

Ogino $\mathbf{K}$ Ovulationstermin und Konzeptionstermin

Zentralbi Gynaekol 54, 464; 1930 
O'Herlihy C, Crespigny L Ch de, Lopata A, Johnston I, Hoult I, Robinison H Preovulatory follicular size: comparison of ult rasound and laparoscopic measurements

Fertill Steril 34, 24; $1980 a$

O'Herillyy $\mathrm{C}$, Crespigny $\mathrm{L} J \mathrm{~J}$ Ch de, Robinson H P Monitoring ovarian follicular development with reall-time ultrasound

Br J Obstet Gynaecol 87,$613 ; 1980 \mathrm{~b}$

O'flerihy C, Robinson H P, Crespigny L J Ch de Mittelschmerz is a preovulatory symptom

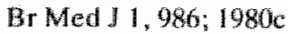

O'Lerlihy C, Pepperell R J, Robinson H P Uitrasound timing of Human Chorionic Gonadotropin administration in Clomiphene-stimulated cycles

Obstet Gynecol 59,$40 ; 1982$

Pauerstein C J, Eddy C A, Croxatto H D, Hess R, Siler-Khodr T M, Croxatto H B Temporal relationships of estrogen, progesterone, and luteinizing hormone fevels to ovulation in women and infrahuman primates

A.m J Obstet Gynecol 130, 876; 1978

Persson P' H, I ledholm P, Sundström P, Wramshy HI Ultrasonic determination of the optimal time for harvesting human eggs

Arch Androl 5, 93; 1980

Pironen 0 Uterine size measured by ultrasound during menstrual cycle

Acta Obstet Gynecoll Scand 54, 242; 1975

Polan M I., Totora M, Caldwell B V, DeCherney A H, Haseltine F P, Kase N Abnormal ovarian cycles as diagnosed by ultrasound and serum estradiol levels

Fertil Steril 37, 342; 1982

Poliak A, Smith J J, Romney S L. Clinical evaluation of clomiphene; clomiphene and human chorionic gonadotropin; and clomiphene, human chorionic goandotropin, and estrogens in anovulatory cycles Fertil Sterill 24,$921 ; 1973$

Portuondo J A, Agustini A, Herran C, Echanojauregui A B The corpus luteun in infertile patients found during lapantoscopy

Fertil Steril 36, 37; 1981

Prins G, Zaneveld L, J D, Schumacher G F B Functiona biochemistry of cervical mucus.

Human ovulation

Ed: E S E Hafez, Elsevier Biomedical Press 313; 1979

Queenan J T, O'Brien G D, Bains L M, Simpson J, Collins W P, Campbell S Ultrasound scanning of ovaries to detect ovulation in women

Fentil Steril 34, 99; 1980

Radwanska E, Swyer G I M Plasma progesterone estimation in infertile women and in women under treatment with Clomiphene and Chorionic Gonadotrophin

J Obstet Gynaecol Br Cwlth 81, 107; 1974

Radwanska F, Hammond J, Ilammond M, Snith P Current experience with a standardized method of human menopausal gonadotropin $/$ human chorionic gonadotropin administration

Fertil Steril33, 510; 1980a 
Radwanska E, Smith P, Hammond J Correlation between preovulatory serum extradiol and nid luteal progesterone levels during induction of ovulation with Clomid and $\mathrm{HCG}$

J Reprod Med 24, 79; $1980 \mathrm{~b}$

Renaud R L, Macler J, Dervain I, Ehret M-C, Aron C, Plas-Roser S, Spira A, Pollack H Echographic study of follicular maturation and owulation during the normal menstrual cycle

Fertil Steril 33, 272; 1980

Rohertson D $\mathbf{M}_{*}$ Steele S J The neasurement of plasma oestradiol and progesterone in women with amenorthoea treated with gonadotrophins

Acta Endocrinol 69, 608; 1972

Robertson R D, Picker R H, Wilson P C, Saunders D M Assessment of ovulation by ultrasound and plasma estradiol determinations

Obstet Gynecol 54, 686; 1979

Rohinson H P Sonar measurement of fetal crown-rump length as means of assessing maturity in first trimester of pregnancy

Br Med J 4, 28; 1973

Robinson H P, Fleming J E E A critical evaluation of sonar "crown-rump length" measurements Br J Obstet Gynaecol 82, 702; 1975

Roger M, Grenier J, Houlhert C, Castanier M, Feinstein M-C, Scholler $\mathbf{R}$ Rapid radioimmunoassays of plasma LH and estradiol-17-beta for the prediction of ovulation

J Steroid Biochem 12,$403 ; 1980$

Rönnberg L, Ylöstallo P, Jouppila P Ultrasound to time insemination Lancet 1,$669 ; 1978$

Rosenberg S M, Luciano A A, Riddick D H The luteal phase defect: the relative frequency of, and encouraging response to, treatment with vaginal progesterone

Fertill Steril 34, 17; 1980

Ross G T, Cargille G M, Lipsett M B, Rayford P L, Marshall J R, Strott C A, Rodbard D Pituitary and gonadal hormones in women during spontaneous and induced ovulatory cycles

Rec Prog Horm Res 26, 1; 1970

Rünnebaum B, Rieben W, Bierwirth- $\mathbf{*}$. Mönstermann A M, Zander J Circadian variations in plasma progesterone in the luteal phase of the menstrual cycle and during pregnancy

Acta Endocrinol 69,$731 ; 1972$

Sallam H N, Marinho A O, Collins W P, Rodeck C H, Campleel S Monitoring gonadotrophin therapy by real-time ultrasonic scanning of ovarian follicles

BrJ Obstet Gymaecol 89, 155; 1982

Santen R J, Bardin C W Episodic Luteinizing Hormone secretion in man: pulse analysis, clinical interpretation, physiologic mechanisms

J Clin Invest 52,$2617 ; 1973$

Sawyer C H, Everett J W Stimulatory and inhibitory effects of progesterone on the retease of pituitary ovulating hormone in the rabbit

Endocrinology 65,$645 ; 1959$

Scheer K, Goldstein D P Use of ultrasonography to follow regression of theca futtein cysts Radiology 108, 242; 1973 
Schmidt W, Holst T von, Garoff L, Gabelman J, Kublit F Monitoring of HMG-stimulated follicular dewelopment by real-time ultuasound

Europ 1 Obstet Gynec Reprod Biol 12,95: 1981

Schoemaker J, Wentz A C, Jones G S, Dubin N H, Sapp K C Stimulation of follicular growith with "pure" FSH in patients with anowulation and elevated $\mathrm{LH}$ lewels

Obstet Gynecol $51,270,1978$

Schuillaig $\mathbf{G ~ A , ~ G n o d d e ~ H ~ P ~ S i t e ~ o f ~ o r i g i n ~ o f ~ t h e ~ p u l s a t i l e ~ s e c r e t i o n ~ o f ~ L u t e i n i z i n g ~ H o r m o n e ~ i n ~ l o n g - ~}$ term ovariectomized rats

J Endocer 70, 97; 1976

Schwartz $M$, Jewelewicz $R$, Dyrenfurth I, Tropper $P$, Vande Wiele $\mathbb{R} \mathbb{L}$. The use of human menopausal and chorionic gonadotropins for induction of owulation

An J Obstet Gynecol 138,801; 1980

Schwarta $\mathbf{M}$, Jewelewica $\mathbf{R}$ The use of gonadotropins for induction of ovulation

Fertil Steril 35,$3 ; 1981$

Seibel M M, McArdle C R, Thompson I E, Berger M If, Taymor M L The role of ultrasound in ovulation induction: a critical appraisal

Fertil Steril 36,$573 ; 1981$

Shaaban N, Klopper A A study on monitoring of gonadotropin therapy by the assay of plasmaoestradiol and progesterone

J Obstet Gynaecol Br. Cwith 80, 783; 1973

Shaw $\mathbf{R} \mathbf{W}$, Butt $\mathbf{W} \mathbf{R}$, London $\mathbf{D} \mathbf{R}$ The effect of progesterone on FSH and LH response to LHRH in normal women

Clin Endocrinol 4, 543; 1975

Sherman B M, Koremman S G Measurement of plasma LH, FSH, estradiol and progesterone in disorders of the human menstrual cycle: The short luteal phase

J Clin Endocrinol metab 38, 89; 1974

Smit-Koppert C, Coelinght Bennink H J T T Ovariële follikelrijping tijdens de normale menstruele cyclus on bij ovullatic-inductic

Ned Tijdschr Geneesk 126, 719; 1982

Smith D I1, Picker R H, Sinosich M, Saunders D M Assessment of ovulation by ultrasound and estradiol levels during spontaneous and induced cycles

Fertil Steril 33, 387; 1980

Sthhler E, Spätling L, Bethqe H D, Daume $\mathbf{E}$, Buchinglz. $\mathbf{R}$ Induction of ovulation in human ovaries in vitro

Arch Gynák 217,1;1974

Starup J, Sele V, Henriksen B Amenorrhoea associated with increased production of gonadotrophins and a morphologically normal ovarian follicular apparatus

Acta Endocrinol $66.248 ; 1971$

Steiman R P, Taymor M L. Artificial Insemination Homologous and its role in the management of infertility

Fertil Steril 28, 146; 1977 
Steptoe P C, Edwards R G Laparoscopic recovery of preovulatory human oocytes after priming of ovaries with gonadotrophins

Lancet 1,$683 ; 1970$

Strott C A, Yoshimi T, Ross G T, Lipsett M B Ovarian physiology: Relationship between plasma LH and steroidogenesis by the follicle and corpus Juteum; Effect of HCG

J Clin Endocr 29.1157; 1969

Strott C A, Cargille C M, Ross G T, Lipsett M B The short luteal phase

I Clin Endocr 30, 246; 1970

Swyer G II M, Radwanska E, McGarrigle H G Plasma oestradiol and progesterone estimation for the monitoring of induction of owulation with clomiphene and chorionic gonadotrophin

Br J Obstet Gynaecol 82, 794; 1975

Talbot J M, Dooley M, Leeton J, Lopata A, McMaster R, Wood C Gonadotrophin stimulation for oocyte recovery and in vitro fertilization in infertile women

Aust NZ J Obstet Gynaecol 16, 111;1976

Tamada $T$, Matsumoto $S$ Suppression of ovulation with human chorionic gonadotropin

Fertil Steril 20, 840;1969

Taubert H-D, Jürgensen O, Stumpe A Die Behandlung der anowulatorischen Sterilität mit Gonadotropinen (mit zwei kasuistischen Berichten über Fünflingschwangerschaften)

Med Monatsschr 31, 79; 1977

Taymor M L, Yussman M A, Gminski D Estrogen monitoring in ovulation induction Fertil Steril 21,$759 ; 1970$

Taymor M L ${ }_{*}$ Seibel M, Borten M, Smith D Use of rapid RIA for LH in the harvesting of maturing human oocytes

Arch Androl 5, 79; 1980

Terazawa E, Rodriguez-Sierra J F, Dierschke D J, Bridson W E, Goy R W Positive feedback effect of progesterone on Luteinizing Hormone $(\mathrm{LH})$ release in cyclic female Rhesus monkeys. LH response occurs in two phases

I Clin Endocrinol Metab 51,$1245 ; 1980$

Terinde J, Distler W, Freund G., Hertherger J Hormonelle und ult rasonographische Kontrolle der spontanen Ovulation bei Patientinnen mit primärer und sekundarer Sterilităt Arch Gynaekol 228, 168;1979

Testart J, Thébault A, Frydman R, Papiernik E Irtrafollicular máturation of human oocyte in vitro Arch Androl 5, 72; 1980

Testart J, Frydiman R, Feinstein M C, Thebault A, Roger M, Scholler R Interpretation of plasma Luteinizing Hormone assay for the collection of mature oocytes from women: defirition of a Lutcinizing Hormone surge-initiating rise

Fertil Steril 36,$50 ; 1981$

Testart $\mathbf{J}$, Friedman $\mathbf{R}$ Minimum time lapse between luteinizing hormone surge or human chorionic gonadotropin administration and follicular rupture Fertil Steril 37, 50; 1982

Testart J, Thébault A, Frydman $\mathbb{R}$ Premature ovulation after ovarian ultrasonogmaphy Br J Obstet Gynaecol 89, 694; 1982 
Thebaull A, Testart J, Castanier A M, Frydman R Follicular fluid, oocyte maturation, and hormonal periphtheral Jewels after clomphene hCG treatment in women

Arch Androl 5, 75; 1980

Thomas K, Ferin J A new rapid radioimmunoassay for HCG $(\mathrm{LH}, 1 \mathrm{CSH})$ in plasma using dioxan J Clin Endocrinol Metab 28, $1667 ; 1968$

Thomas $\mathbf{K}$, Walckiers $\mathbf{R}$, ferin J Biphasic pattern of LH midcycle discharge IClin Endocr 30,$269 ; 1970$

Thorneycroft I H, Sribyatta B, Tom W K, Nakamura R M, Mishell D R Measurementof serum LH, FSH, progesterone, 17-hydroxyprogesterone and estradiol-17-beta levels at 4-hour interwals during the periowulatory phase of the menstrual cycle

J Clim Endocrinol Metab 39, 754; 1974

Trounson A O, Leeton J S, Wood C, Webh J, Wood J Pregnancies in humars by fertilization in vitro and embryo transfer in the controlled ovulatory cycle Science 212,$681 ; 1981$

Vandekerckhove D, Dhondt $M$ The relationship between serum $L H$ levels, as determined by radioimmunoassay, and the life span of the corpus luteum

Ann Endoc 33, 205; 1972

Wang C F, Gemzell C The use of human gonadotropins for the induction of ovulation in women with polycystic ovary disease

Fertil Steril 33, 479; 1980

Weick R F, Dierschke D J, Karsch F J, Butler W R, Hotchkiss J, Knobil E Periovulatory time course of circulating gonadotropic and ovarian hormones in the R/hesus Monkey Endocrinology 93,$1140 ; 1973$

Wells P N T The possibility of harmful biological effects in ultrasonic diagnosis

In: Cardiowascular Applications of Ultrasound

Ed: R S Reneman: North-Holland Publ. Company, Amsterdam; 1974

Wetzels $1, C$ G, Hoogland H J, Haan J de Basal body tenperature as at method of ovulation detection: comparison with ultrasonographical findings

Gynccol Obstet Invest 13, 235; 1982

WHO Scientific Report Biology of fertility control by periodic abstimence WHO Techn Rep Ser 360, 1967

WHO Task Force Temporall relationships between ovulation and defined changes in the concentration of plasma estradiol-17-beta, luteinizing hormone, follicle stimulating hormone, and progesterone Am J Obstet Gynecoll 138, 383;1980

Williams R F, Hodgen G D Disparate effects of human chorionic gonadotropin during the late follicular phase in monkeys: normal ovulation, follicular atresia, ovarian acyclicity and hypersecretion of folliclestimulating hormone

Fertil Steril 33, 64; 1980

Wu C H Monitoring of ovulation induction

Fertil Steril $30.617 ; 1978$

Yen S S C, Llerena O, Little B, Pearson O H Disappearance rates of endogenous Luteinizing Hormone and Chorionic Gonadotropin in man

$\rrbracket C$ lin Endocr 28, 1763; 1968 
Yen S S C, Tsai C C, Naftolin F, Vandenberg G, Ajaber L. Pullatile patterns of gonadotropin release in subjects with and without ovarian function

IClin Endocr 34,$671 ; 1972$

Yöstalo P, Rönnberg L, Jouppila P Measurement of the ovarian follicle by ultrasound in ovulation induction

Fertil Steril 31.651; 1979

Ylöstalo $\mathbf{P}$, Lindgren $\mathbf{P}$ G, Nillius $\mathbf{S} \mathbf{J}$ Uhrasonic measurement of ovarian follicles, ovarian and ulerine size during induction of ovulation with human gonadotrophins

Acta Endocrinol 98, 592; 1981

Younger J $\mathbf{B}$, Boots $\mathbf{L}, \mathbf{R}_{*}$ Coleman $\mathbf{C}$ The use of a one-day Luteinizing Hormone assay for timing of artificial insemination in infertility patients

Fertil Steril 30,$648 ; 1978$

Yussman M A , Taymor M L Serum levels of follicle stimulating hormone and luteinizing hormone and of plasma progesterone related to ovulation by corpus luteum biopsy

J Clin Endocr 30, 392; 1970

Yussman M A, Taymor M L., Miyata J, Pheteplace C Serum fevels of Follicle Stimulating Hormone, Luteinizing Hormone, and plasma progestins correlated with human ovulation

Fertil Steril 21, 119; 1970

Zerbe G O Randomization analysis of the completely randomized design extended to growth and response curves

J Am Statist Ass 215, 74; 1979 


\section{Curriculum vitae}

3-8-1948 Geboren te Limbricht

1967 Eindexamen gymmasium-beta aan het Bisschoppelijk College te Sittard

1975 Artsexamen aan de Katholieke Uniwersiteit Nijmegen

1975-1976 Militaire dienstplicht

1976 Aanvang opleiding obstetrie en gynaecologie (B-opleiding) in het Ziekenhuis St. Annadal Maastricht (opleider Dr. J.L.H.M. Specken)

1978 Voortzetting opleiding obstetrie engynaccologie (A-opleiding) in het Ziekenhuis St. Annadal Maastricht (opleider Prof. dr. J. de Haan)

1981 Inschrijving specialistenregister

1982 Als gynaecoloog verbonden an het Zuiderzee Ziekenhuis te Lelystad 